\title{
Global Perspectives on China's Belt and Road Initiative
}

\section{Asserting Agency through Regional Connectivity}

Edited by Florian Schneider

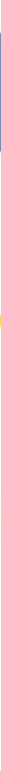


Global Perspectives on China's

Belt and Road Initiative 



\section{Global Perspectives on China's Belt and Road Initiative}

Asserting Agency through Regional Connectivity

Edited by

Florian Schneider 
Cover illustration designed by Nicoline McCarthy-Emmer - blauwzand.nl

Cover design: Coördesign, Leiden

Typesetting: Crius Group, Hulshout

ISBN $\quad 9789463727853$

e-ISBN $\quad 9789048553952$ (pdf)

DOI $\quad 10.5117 / 9789463727853$

NUR $\quad 754$

(c) Florian Schneider / Amsterdam University Press B.V., Amsterdam 2021

All rights reserved. Without limiting the rights under copyright reserved above, no part of this book may be reproduced, stored in or introduced into a retrieval system, or transmitted, in any form or by any means (electronic, mechanical, photocopying, recording or otherwise) without the written permission of both the copyright owner and the author of the book.

Every effort has been made to obtain permission to use all copyrighted illustrations reproduced in this book. Nonetheless, whosoever believes to have rights to this material is advised to contact the publisher. 


\section{Table of Contents}

Acknowledgements

1 Actors and Agency in China's Belt and Road Initiative

An Introduction

Florian Schneider

\section{Part I Global Connectivity}

2 China's BRI and International Cooperation in Higher Education and Research

A Symbiotic Relationship

Ingrid d'Hooghe

3 Trade, Tax, and Development Finance

Understanding China's Choice of BRI Agreements and Institutions

Michael Sampson, Jue Wang and Irma Mosquera Valderrama

\section{Part II Regional Dynamics}

4 The BRI in Latin America

New Wine in Old Bottle?

Matt Ferchen

5 Ascertaining Agency

Africa and the Belt and Road Initiative

Stacey Links

6 Parameters and Pathways

Agency in the Case of the Southern African Development

Community

Stacey Links

7 Over Hills and Valleys Too

China's Belt and Road Initiative in the Caribbean

Ruben Gonzalez-Vicente 


\section{Part III Local Actors}

8 The Geopolitical Relevance of the BRI 197

The Jakarta-Bandung High-Speed Railway in Indonesia

Frans-Paulvan der Putten and Mirela Petkova

9 Elite Legitimation and the Agency of the Host Country

Evidence from Laos, Malaysia, and Thailand's BRI Engagement

Cheng-Chwee Kuik

10 The Two Faces of the China Model

245

The BRI in Southeast Asia

Matt Ferchen

11 The Belt and Road Initiative in South Asia

Regional Impact and the Evolution of Perceptions and Policy Responses

Richard Ghiasy

12 Geographic Agency

291

Iran as a 'Civilizational Crossroads' in the Belt and Road Geography

Mohammadbagher Forough

13 Exploring the Political, Economic, and Social Implications of the Digital Silk Road into East Africa

The Case of Ethiopia

Sanne van der Lugt

Contributors

\section{List of Figures and Tables}

Figures

Figure 1.1 Extolling the virtues of the Belt and Road; screenshot of YouTube music video taken on 25 June 2020 Source: New China TV (2017)

Figure 3.1 Dominant drivers of China's institutional approach by issue area

Source: Author's compilation of data from UNCTAD 
Figure 5.1 Intra-regional Trade per Region (2015-2017)

Source: Author's compilation of data from UNCTAD

Figure 7.1 Interior of Trinidad's National Academy for the Performing Arts during an event in January 2020, with the Queen's Park Savannah and the hills of Port of Spain in the background

Source: Author

Figure 9.1 BRI-related projects in Laos, Malaysia, and Thailand 228 Source: Author's compilation

Figure 11.1 India's unique geographic centrality in South Asia 268 Source: Image in the public domain, via the United Nations

Figure 13.1 The causal mechanism 325

Figure 13.2 The resulting causal mechanism

Tables

Table 8.1 Infrastructure Projects in Indonesia with Chinese Financial Investment of at least US $\$ 1$ billion Initiated from 2013 to Early 2020

Source: Author's compilation

Table 9.1 Laos, Malaysia, and Thailand's BRI Engagement with China

Source: Author's compilation 



\section{Acknowledgements}

This book would not have been possible without the assistance and continuous efforts of numerous people. The LeidenAsiaCentre's manager, Lily Sprangers, has worked tirelessly to coordinate our editorial work, aided by our project manager, Jonas Lammertink, and they have the heartfelt gratitude of our entire team of researchers. Nicholas Olczak has done an excellent job copy-editing this book, with much of the work taking place at the eleventh hour, and we are deeply grateful for his assistance. Then there are our contributors, who have engaged in highly productive and collegial debate throughout the span of the project, and it has been a pleasure seeing them work together and create these insightful studies. Work on this project was made ever more difficult as the Coronavirus crisis unfolded, and I am very thankful to everyone involved for staying committed to the project during such unprecedented and difficult times.

Substantial parts of our debates about the Belt and Road Initiative (BRI), and about the relevance of actors and agency, took place outside of Leiden University. We would like to thank the EU Centre in Singapore, especially its director, Yeo Lay Hwee, for hosting a fruitful conference on BRI-related developments in January 2020. Our discussions at Nanyang Technological University very much shaped our thinking on this complex topic and now inform many aspects of this book.

Finally, our gratitude goes to our editors at Amsterdam University Press for all their help and assistance along the way, especially to Saskia Gieling, who has been instrumental in bringing this book to press.

The Leiden AsiaCentre is an academic institution. Its research is funded independently and is not subject to partisan influence.

\section{Florian Schneider}

Leiden, 31 August 2020 



\title{
$1 \quad$ Actors and Agency in China's Belt and Road Initiative
}

\author{
An Introduction \\ Florian Schneider
}

\begin{abstract}
This introduction provides the context and theoretical background that informs the studies in this volume. It introduces the volume's common theme: the question of how different actors give shape to BRI projects. It outlines how, rather than treating nation states as singular, monolithic actors, this volume teases apart the way different people and organizations insert themselves into BRI decision-making and implementation. The chapter discusses how we might conceptualize agency in such contexts, drawing together the volume's findings to arrive at four conclusions: 1) that in understanding the BRI, geographical context matters; 2) that the BRI is a pluralist endeavour rather than a single, unified agenda; 3 ) that BRI efforts often extend rather than challenge existing politics; and 4) that outcomes depend on the activities of local actors.
\end{abstract}

Keywords: Belt and Road Initiative, agency, China, local actors, introduction, pluralism

Two women are having a casual discussion about global affairs. One asks the other: 'Kimi, ever heard of the Belt and Road?' Kimi responds: 'Yeah, the big vision of economic exchange.' Her interlocutor swiftly follows up: 'Know exactly what they are?' To which Kimi responds: 'The Belt is along the old Silk Road and the Road is the Silk Road on the sea!'

'Oh, I see,' says the other woman, 'in Chinese: Yi Dai Yi Lu!' Music fades in, and a Chinese band of young men launches into a jazzy song, accompanied by funky percussion and a female background choir that hushes in husky

Schneider, Florian (ed.), Global Perspectives on China's Belt and Road Initiative: Asserting Agency through Regional Connectivity. Amsterdam, Amsterdam University Press 2021 DOI: 10.5117/9789463727853_CHO1 
Figure 1.1 Extolling the virtues of the Belt and Road; screenshot of YouTube music video taken on 25 June 2020

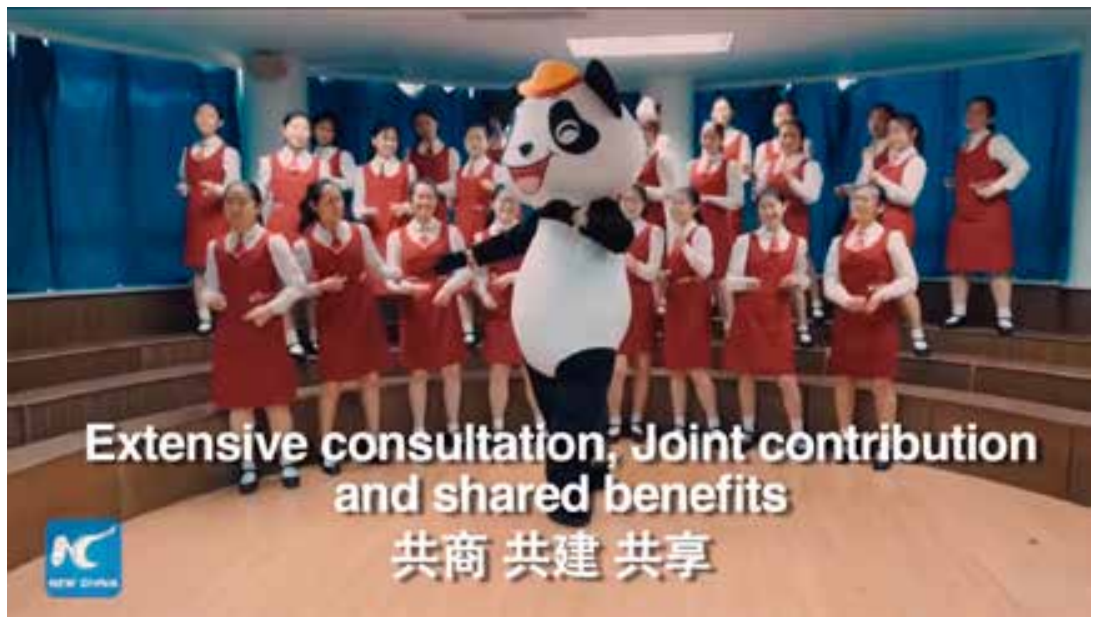

Source: New China TV (2017)

voices 'Whoo, Yi Dai Yi Lu, the Belt and Road!' Images show people around the world dancing and singing. Women in front of a Thai temple. A woman in front of Sydney's famous opera house. Several young people at iconic sites in Washington, DC.

The front singer raps about how Sri Lankans will no longer have to worry about electricity bills and how a Malaysian boy can finally scrape together the money to get married to his sweetheart. As images of harbour construction, highways, and railroads flicker across the screen, spliced with pictures of someone dancing in a panda costume, the rapper extols the virtues of infrastructure development: 'More trains, more ships, more airlines!' The choir sings 'Mutual benefits, joint responsibility, and shared destiny', then 'Silk Road Fund! BRICS bank! AIIB!' The music video culminates in a choreographed dance routine in an auditorium that features Chinese girls, the dancer in the panda suit, and, of course, the choir, which now sings 'Extensive consultation, joint contribution, and shared benefits', before finally concluding: 'Uh, Yi Dai Yi Lu!' (see figure 1.1).

This propaganda video was launched on 14 May 2017. China's central news agency Xinhua uploaded the clip to its official account, New China TV, on the video-sharing site YouTube and posted the link to its social media accounts on Facebook, Twitter, and Instagram - all services that are blocked in China. Xinhua claims that 'the sing-along was created by Chinese millennials. Young Generation around the world are singing and dancing with it [sic]' 
(New China TV 2017). Reception on YouTube seems more muted than Xinhua suggests, with only about 200 comments at the time of writing, most of which are derisive. 'These are some serious Nobel-prize-in-literature-level lyrics', writes one commentator; another remarks that this is like trying to garner support for textile mills through competitive break dancing' (ibid.).

YouTube commentators hardly seem convinced, and this may at first sight seem like a scathing indictment of Chinese soft-power efforts, but it may also be beside the point. Under the banner of its Belt and Road Initiative (BRI), the People's Republic of China (PRC) has rolled out a world-spanning economic, political, and social development strategy that is dizzying in scope. The Chinese state has flanked those efforts with propaganda videos like this one, which are probably meant less as a way to convince foreign audiences and more as a means to illustrate to relevant stakeholders the ambitions and motivations that fuel the BRI. Awkward and cringe-worthy as the propaganda may be, it offers useful insight into how China's leaders want the BRI to be understood: as a set of ostensibly benevolent infrastructure and development projects that mutually benefit Chinese investors and people around the world.

But how do these projects work out in practice? What are the implications of the BRI in different contexts, and how should we assess official PRC claims about the mutual benefits that these developmental interventions ostensibly entail? The aim of this book is to explore such dynamics in global, regional, and local contexts. The research presented here is the result of a large-scale collaborative project started in 2019, pre-COVID-19, at the LeidenAsiaCentre (LAC). The project examined the BRI in global perspective and was informed by subsequent discussions at workshops at Singapore's EU Centre and the LAC in the first half of 2020.

This chapter discusses the findings from that project. It first outlines some of the major concerns and debates in the existing scholarship on the BRI, focusing in particular on the internal and external aspects of the initiative as well as on the BRI's effects and the motivations that might drive its various projects. The chapter then introduces the core theme of this book: agency. It examines what 'agency' means in this volume, as well as why a focus on the actors that drive BRI-related processes is relevant. Following this brief conceptual discussion, the introduction provides an overview of the individual chapters and then concludes by presenting the core findings that emerge from the contributions. These findings are: that geography is an important factor in the BRI, that the initiative is shaped by diverse interests, that its projects often extend rather than challenge earlier initiatives (e.g. by international organizations), and that the BRI's practical implementation depends heavily on the actions of local actors. 


\section{Seven Years of the BRI: Hopes, Anxieties, and Controversies}

According to estimates (Hillman 2018), the Chinese authorities plan to spend somewhere between US $\$ 1$ to 8 trillion on BRI-related projects before the initiative runs its course on the eve of the PRC's hundred-year anniversary in 2049. Infrastructure has been at the heart of the initiative since its launch in 2013. Under the BRI banner, Chinese foreign direct investment has flown into electric power projects, mineral mining and processing plants, and the construction of bridges, highways, ports, and railways (Dai 2018; Kuik 2020: 82-83; Lai \& Lentner 2018; Negara \& Suryadinata 2018:12-23).

Trade has been another crucial dimension. The BRI has ushered in numerous 'economic corridors' and free trade agreements with partner countries (Lin 2015). As Li and Chaisse (2018: 465) put it, the BRI 'plays a key role in China's economic recovery agenda as its main purpose is to trigger various investment and trade demands to counteract the dwindling economic growth rate and excess production capacity'.

In this way, the BRI has much to do with China's domestic politics and economics. It is today shaped by concerns over a perceived lack of consumer-driven growth at home, overcapacities among state-owned enterprises, potential instabilities in China's financial system, and the wish to internationalize China's currency as reliance on the US dollar becomes more risky in the wake of the US-China trade war (Gordon et al. 2020:14-18; Tekdal 2018). But for elites in the PRC, the initiative also helps construct a community out of citizens who are at risk of becoming disillusioned by the waning of the Chinese Dream. Van Dinh (2020: 92) compares the BRI to the Great Wall and its ability to unite diverse peoples along China's borders, arguing that:

After 30 years of development at all costs, China seems to be losing the driving force of development, a worrying prospect for a Chinese Communist Party that has survived on the basis of continuous economic development for over 30 years. The BRI is the trump card that can supply a new glue for bonding the Chinese people against the temptations of separatism and disillusionment with progress.

Creating infrastructure networks to facilitate domestic cohesion and development is not at all a new strategy, and Ghiasy (Chapter 11 in this volume) reminds us that telegraph lines, railroads, and canals have been instrumental not just in facilitating trade but also in creating the standards and norms of how modernity now works. In many ways, the BRI is an 
attempt to shape such standards in the twenty-first century, to usher in an age of hyper-modernity defined by values popular in the PRC, whether it is in areas such as trade, taxation, and finance, as Sampson, Wang, and Mosquera Valderrama discuss in their contribution to this book (Chapter 3 ), or whether it is in education, science, and technology, as D'Hooghe shows in her chapter (Chapter 2).

It should then come as no surprise that the BRI is predated by, and in many ways marks the culmination of, earlier developmental and foreign policy strategies that also tried to give China a greater role in regional and global networks. Previous administrations already promoted the idea of developing Chinese border regions by 'going West' via Xinjiang (Moneyhon 2003) and by 'going out' to join international organizations like the WTO (Blanchard 2013; Lu 2015; and the contributions in Wang 2015). Indeed, while it may at times seem as though the BRI and its allied initiatives, such as the Asia Infrastructure Investment Bank (AIIB), challenge the institutions of the US-led Bretton Woods system, they frequently sit alongside existing institutions and they draw expertise and procedures from organizations like the International Monetary Fund (IMF) and the World Bank (see Wilson 2017). In some instances, as Gonzalez-Vicente illustrates in his chapter on China in the Caribbean (Chapter 7), BRI-related institutions reproduce rather than subvert the market-making and business-centric agendas and practices of the IMF, even if the different policy formats at times obscure such similarities. While this may not always be self-evident to practitioners in international organizations, the official motives that are meant to guide BRI investments are indeed not that different from those championed by earlier neoliberal capitalist institutions: to coordinate policy, improve connectivity, promote free trade, assure financial integration, and establish people-to-people bonds (State Council 2015).

As a vehicle for economic development, the BRI has been attractive in so-called developing countries, and it would be callous to dismiss the real-world transformative impact that BRI projects have had on people who can now often move more freely and live in more comfort due to the new infrastructure-led growth in their societies. However, the BRI's record has not been an unqualified success. It is important to ask who the beneficiaries of these transformations really are. Who stands to gain, and who is left out? Several analysts have contended that BRI-fuelled investments often pose dire environmental risks (Ewing 2019; Hughes 2019; Teo et al. 2019) and reveal a 'treacherous disconnect between China's commitment to fighting climate change at home versus abroad' (Friends of the Earth 2017: 61). Others have criticized the fact that BRI projects support states with poor governance 
records (Dollar 2018), raise questions about local employment effects and general labour standards (Zou 2019), lack transparency and privilege Chinese companies in potentially unfair ways (European Chamber 2020), and risk creating significant debt vulnerabilities in partner countries (Bandiera \& Tsiropoulos 2020; Dollar 2018).

In addition to these issues of BRI performance, the motivations behind the BRI have also been questioned, particularly the official Chinese narrative that the $\mathrm{BRI}$ is a benevolent development agenda with no strings attached. Recent studies have made the case that the BRI is part of the PRC's 'economic statecraft', and that Chinese leaders are using the substantial economic resources at their disposal to further their interests abroad (see the contributions in Li 2017). The BRI has consequently been compared to the 1948 Marshall Plan, which provided aid to Western Europe after the devastation of the Second World War (Economist 2018). This is a comparison that Chinese BRI proponents loathe due to its geopolitical implications (see Mitchell 2018).

Even though this analogy with the Marshall Plan is neither historically nor analy tically accurate (see Shen \& Chan 2018 for an insightful critique), it is telling that the BRI's political implications evoke such Cold War dichotomies, even if the two sides of that dichotomy are now effectively both capitalist. Perceptions about systemic and ostensibly irresolvable differences between China and 'the West' remain, and they continue to shape the debate. For instance, Chinese investments have raised concerns that the BRI might be accompanied by PRC attempts to strategically undermine liberal agendas, for instance by countering efforts to promote human rights, specifically by the European Union (Wong 2017). In some EU contexts, BRI-related funding has started to fuel anxieties that 'European member states are compromising on European principles to accommodate Chinese investment' (Hanemann \& Huotari 2017: 7; see also BusinessEurope 2020: 151). While in practice the record of the PRC's efforts to turn 'its economic heft into political influence' is likely 'far less worrisome than most popular writing suggests' (Reilly 2017: 182), Chinese officials have nevertheless remained mostly unsuccessful at 'reducing popular anxiety over China's rise' in target societies that are governed by long-standing threat perceptions of the PRC and its ruling Chinese Communist Party (ibid.; see also Pardo 2018).

Chinese leaders, diplomats, and planners continue to try and alleviate such threat perceptions (Goh \& Martina 2019) and address concerns about the BRI's sustainability and corporate social responsibility, with Xi Jinping announcing a recalibration of the BRI towards more 'high quality' cooperation that is 'open, green and clean' (Xi 2019). However, many of the 
complex problems that accompany the BRI are bound to persist. Preliminary observations about the effect that the COVID-19 crisis has had on the BRI suggest that some of these problems may even become further aggravated, for instance where BRI partners suffer crisis-related economic losses and find themselves hard-pressed to repay their debts (Kynge \& Yu 2020; Tower \& Staats 2020). All of this paints a picture of complex interactions that are extremely difficult to pin down and evaluate systematically. How, then, should we assess Chinese BRI projects seven years after the initiative's original inception?

\section{Actors and Agency in China's Globe-Spanning BRI Networks}

As the rapidly evolving discussions about the BRI show, scholars, analysts, and policymakers are arriving at nuanced assessments of the initiative that move beyond early depictions of the BRI as either a benevolent Chinese development project or a sinister geopolitical play for world dominance. Recent contributions to the debate emphasize the diversity of BRI-related projects and the need for careful empirical analysis (e.g. the contributions in Cerrai et al. 2020; Chong \& Pham 202ob; De Cremer et al. 2019). This present collection speaks to this growing field of inquiry that tries to tease apart how the BRI plays out in different contexts. It is informed by the realization that understanding the BRI requires both truly global perspectives and careful attention to the role that local actors play in giving shape to individual BRI projects.

The theme that runs through this book is agency. In much of the literature on global politics, and particularly in mainstream international relations theory, agency is located firmly with nation states. It can indeed be tempting to treat states like the PRC as monolithic, unified actors that push politics forward through their behaviour in a seemingly anarchic world. The metaphor of the state as a person has consequently become a commonplace shorthand that allows academics, journalists, and practitioners to home in on a core dynamic in international relations. For many, speaking of what 'China' does, how 'India' reacts, or what 'Indonesia' wants is not just convenient, it is an essential conceptual choice for cutting to the heart of global politics, and scholars like Alexander Wendt (2004) have staunchly defended this practice.

The contributions in this volume do not dismiss the relevance of nation state actors in international relations, certainly not in a context like the BRI, where a one-party state is powerfully inserting itself into regional and 
global networks of goods, people, finances, and information. At the same time, this book contends that viewing the BRI mainly as a coherent strategy by a growing monolithic Great Power is too much of a simplification, and that we should instead understand the BRI as a complicated set of political, economic, and social initiatives launched by a dizzying array of actors, all of whom are trying to understand (and profit from) the changing role of the PRC in world politics and economics. Importantly, our point is not just that there are many actors implementing the PRC government's vision, but that the central government is one of many actors trying to make sense of an important moment in the developmental trajectory of the country as a whole (see also Gonzalez-Vicente, Chapter 7 in this volume).

Such a perspective promises to bring nuance to the discussion, but, as Healy (2017: 119) has warned, nuance for nuance's sake is not necessarily helpful and can become a self-serving 'holding manoeuvre' that offers a convenient way not to have to make decisions 'when faced with a question for which one does not yet have a compelling or interesting answer'. So why do we need the additional nuance that an analysis of actors and agency promises to offer? What do we gain by looking at this dimension of the BRI?

As Michael Billig (2013) has argued, academic accounts too frequently reify the processes that shape our world, turning them into handy categories that are ultimately inaccurate representations of what is actually happing around us. To Billig, there is a real risk of 'describing how things happen in the social world without mentioning how people might make them happen, or, indeed who the people are who make them happen' (ibid.: 142). Limiting an argument or analysis to categories like 'China', 'Africa', 'Europe', 'the West', etc., means doing injustice to the people who inhabit those categories. It means not describing the world as it is, and this should be of major concern to practitioners who must make decisions in complex, rapidly evolving situations shaped by high degrees of uncertainty. This is evident from various empirical studies of actors in different contexts (see, for example, Latour \& Woolgar 1986; MacKenzie 2006; Miller \& Slater 2000; Schneider 2019).

Another benefit of following the actors is that it provides a reality check on where agency truly lies. Latour, providing one definition of agency, has argued that agency describes the ability to 'modify a state of affairs by making a difference' in ways that 'make others do things' (Latour 2005: 71, 107). We should then ask: Who has that ability in a specific context? Is it PRC government officials, private Chinese entrepreneurs, their counterparts elsewhere, or someone else entirely, for instance illegal actors (see Ferchen on China and Southeast Asia, Chapter 10 in this volume)? 
As Links demonstrates in her chapters (Chapters 5 and 6), and as is also evident from Van der Lugt's contribution (Chapter 13), relations between Chinese actors and their interlocutors in African countries may at times take on dynamics that the existing literature on Chinese activities in Africa tends to overlook. African actors attract Chinese investments, negotiate context-dependent outcomes, or exert their own influence in the process. As often as not, Links points out, such agency does not turn adversarial; it empowers local actors to make their own choices. Similarly, Kuik shows in his chapter (Chapter 9) how agency can be unevenly distributed across Southeast Asia, with actors carefully balancing their own interests against different domestic constraints. But agency does not have to be limited to making decisions and acting in the world; for some actors, it can mean shaping and remaking the world in which they then act. As Forough shows (in Chapter 12) in his discussion of such 'geographic agency', we should also explore how actors 'define, articulate, and (rep)present themselves and their place (their identities, fears, and aspirations) in the world geographically'.

In many ways, then, it is unhelpful to reduce nation states like 'China' to single actors. The PRC and the region-spanning networks that its BRI are currently recalibrating around the world are instead the backdrop before which different people and groups make their own politics happen, often in deeply idiosyncratic ways. That is what this book is about.

\section{Overview of This Book}

In this volume, our contributors offer a theoretically informed, interdisciplinary analysis of China's BRI in various global, regional, and local contexts. The overarching framework is grounded in critical area studies, emphasizing that local knowledge and perspectives matter in international affairs. The authors come from diverse disciplinary backgrounds, ranging from politics and international relations to law, geography, and economics. The chapters of this volume provide detail-oriented empirical studies, based on first-hand fieldwork and policy analysis. They offer both bird's-eye views of China's BRI at age seven, as well as important interventions into debates about how we might conceptualize agency at a time when Chinese actors seem to be at the heart of so many rapidly evolving regional and global networks. Following this general introductory chapter, the book proceeds in three parts. The first provides 'big picture' analyses of China's BRI in international institutions and global collaborations. The second part offers analyses of regional dynamics. The third part examines individual case studies in specific settings. 
Chapter 2, by Ingrid d'Hooghe, examines the connection between the BRI and Chinese policies for international cooperation in higher education as well as science and technology. It argues that Chinese stakeholders - e.g. various government organizations and education and research institutes - make the connection work in two directions: the BRI is used as an instrument to promote the country's higher agendas in education as well as science and technology and, vice versa, international cooperation in these areas is used to promote the BRI. By analysing the roles of state and non-state actors in education and science diplomacy, D'Hooghe finds that efforts to build the relationship are primarily state-driven. The chapter ends with a discussion of what this development means for China's position in higher education as well as science and technology. Who may benefit and who may lose out?

In Chapter 3, Sampson, Wang, and Mosquera Valderrama examine the decisions that inform the BRI's institution building. The chapter explores the tension between strategic and efficiency-oriented concerns, and it traces those tensions across three issue areas: tax, trade, and development finance. As the authors show, in dealing with the challenges, the Chinese government lacks an integral governance framework that systemically coordinates all the relevant institutions. Instead, it takes varied institutional approaches to oversee the operation of BRI projects and mediate disputes, ranging from bilateral trade agreements to multilateral financial institutions. Based on multiple case studies, the chapter illustrates the plurality among Chinese actors; it argues that China's development of tax initiatives for the BRI is mostly motivated by efficiency drivers, its trade agreements with a number of key BRI partners by strategic drivers, and its effort in establishing multilateral financial institutions by both drivers.

In the first contribution to Part II of this book (Chapter 4), Ferchen turns to regional dynamics, specifically to the role of the BRI in relations with Latin America and the Caribbean. Prior to 2017, Chinese officials and scholars clearly and directly rejected the idea that these regions were part of the BRI. Even though the BRI was geographically expansive, extending as far as Africa and Western Europe as parts of both the overland and maritime components of the plan, the Western Hemisphere appeared to simply be beyond the BRI's scope. However, in 2017, China started to sign a series of BRI Memoranda of Understanding (MoU) and BRI-related infrastructure and other 'connectivity' deals with governments in Central America, the Caribbean, and South America. This expansion of the BRI to Latin America and the Caribbean took place at precisely the same time that the United States was beginning a concerted pushback against Chinese dealmaking and influence in regions like Latin America and Africa. Chapter 4 thus 
offers an overview of the still-short history of the BRI in Latin America and the Caribbean, what it means in the broader context of China's developing country diplomacy in the region, and how it is playing out against the backdrop of widening US-China strategic rivalry.

In Chapter 5 , Links introduces the reader to the African region in relation to China and the BRI. She provides an overview of the current field of China-Africa studies and identifies common narratives that have enveloped these relations. As a cornerstone region, Links sketches Africa's centrality to the BRI while introducing one of the remaining lacunas in the field, namely the question of African agency. In particular, the chapter looks at reasons for the general neglect of the issue of agency in the literature, as well as how it is incorporated in the few instances where it is analysed. As a region, Links explores Africa's centrality to the BRI against the backdrop of intensifying China-Africa relations, making a case for Africa as a fundamental cornerstone of understanding the BRI in both its practical and more ideological facets.

Links continues her analysis of the BRI in Africa in Chapter 6, which provides an in-depth analysis of the Southern African Development Community (SADC) and its interaction with China through the BRI. In this chapter, Links explores the issue of agency on the part of African actors, specifically the agency exercised by SADC as a regional power that covers a vast geographical area. Often overlooked by scholars of China's BRI in Africa, Links's focus on SADC demonstrates the reach of the BRI as well as the relevance of this project for seemingly geographically 'distant' locales, as seen through the eyes of the 'users' themselves. Links employs a deductive approach to the issue of agency, whereby agents are placed at the centre of analysis and themselves demarcate the bounds of agency. This agent-oriented or user perspective circumvents the paternalism of imposed definitions in order to place onus and definitional power on the actors themselves. Such an approach, Links argues, promises to provide the foundations of an open and empowered conversation on matters of international relations more broadly.

Chapter 7 moves the emphasis to the Caribbean, specifically to Jamaica, and Trinidad and Tobago. Gonzalez-Vicente shows how the BRI's financial muscle and infrastructure building have transformed the Caribbean developmental landscape. Key to this transformation has been China's capacity to launch new projects in otherwise heavily indebted or cash-strapped economies. This has been achieved through complex financial arrangements that involve China's diplomacy, policy banks, and construction and natural resources-based enterprises. As a result, some of the region's traditional interlocutors, such as the IMF or the EU, have lost their undisputed capacity 
for influence and coercion. However, Sino-Caribbean relations have also contributed to entrenching long-established structural and postcolonial impediments to development. The chapter explores broader regional trends and illustrates them using the cases of China's relationship with Jamaica and Trinidad and Tobago. Gonzalez-Vicente argues that the BRI represents yet another iteration of neoliberal business-centric development, and as such it remains unable to foment qualitative socio-economic change in the Caribbean.

Chapter 8 by Van der Putten and Petkova constitutes the first analysis in Part III of this book. It explores the geopolitical significance of the BRI in the case of Indonesia, the largest country in Southeast Asia. Van der Putten and Petkova argue that this region constitutes the geographical centre of today's global great-power rivalry, in which the United States and China are the key players. It was in the Indonesian capital Jakarta that President Xi Jinping, in 2013, announced China's ambition to build a modern-day version of the maritime Silk Roads. Which economic and diplomatic activities constitute the BRI in the case of Indonesia, and what is their impact on political relations between Indonesia and China and Indonesia's position with regard to China-United States tensions? This chapter focuses in particular on Indonesia's efforts to maintain strategic autonomy and on manifestations of great-power influence on the country's foreign policy-making.

Kuik continues the discussion about Southeast Asian cases in Chapter 9, turning to Laos, Malaysia, and Thailand. He asks: Why do China's BRI projects progress relatively smoothly in communist Laos but slowly and selectively in military-ruled Thailand and substantially, albeit with volatility, in quasi-democratic Malaysia? Kuik argues that differences in political systems are only part of the answer. By focusing on the BRI engagement of these three nation states, his study highlights the agency of the host countries in shaping the patterns of foreign-funded infrastructure cooperation. China as a stronger partner will always 'push the envelope' in its partnerships. Nevertheless, it is the host country, specifically the ruling elites, who will engage China-backed projects based on their need to optimize their respective pathways of legitimation vis-à-vis the contending elites and masses domestically, leading to varying responses.

Chapter 10 also focuses on Southeast Asia. As Ferchen argues, analyses of the 'China model' of development have until recently focused almost exclusively on explanations for, and debates about, China's own domestic economic growth. Yet as China's global trade, investment, and financial role has expanded, especially under Xi Jinping and his signature BRI policy, 
there is growing interest in whether China seeks to export a version of the China model abroad. Ferchen shows how state-led forms of development, especially BRI-related infrastructure finance and construction, are only one aspect of the export of the China model abroad. Providing case studies from Cambodia, Myanmar, and Vietnam (with additional insights from the Philippines), the chapter explores how the much less discussed, but just as crucial, informal and often illicit aspects of the China model are creating complications for the BRI in host countries and for China itself.

In Chapter 11, Ghiasy examines how the BRI has impacted connectivity and integration in South Asia. More significantly and extensively, he investigates how academic perceptions and policies have evolved in India and Pakistan in response to the BRI since its inception in 2013. These two states provide a unique agency, which Ghiasy defines as the ability to influence or resist influence, in the BRI context. The region's dominant power, India, is a staunch critic that refuses to sit at the BRI table. India is exemplary of the degree to which a non-partaking actor can counter, or supplement, the BRI in its region. The region's other power, Pakistan, hosts the BRI's flagship project, the China-Pakistan Economic Corridor (CPEC), and is the single largest recipient of BRI investment. Pakistan provides insight into how a deep-seated partaker's perceptions and policies on the BRI have evolved. To permit tailored data collection, Ghiasy draws from a series of interviews he conducted with leading Indian and Pakistani academics. His work shows how these academics make sense of China in the region, and it grants an understanding of the BRI's interplay with South Asia's various geopolitical fissures.

In Chapter 12, which focuses on the Iranian situation, Forough tackles two issues: the first is to demarcate in a preliminary fashion the conceptual boundaries of what he calls 'geographic agency'. The second is to apply this concept to the case of Iran and its geoeconomic processes. Adopting a critical geography approach, Forough unpacks how Iran is reinventing itself geographically through certain 'space-making processes' and policies (such as port modernization, the 'railway revolution', or its 'geoeconomic connectivity drive') and certain 'space-framing assumptions' that underlie those processes. Forough argues that the country is showing agency at three geographical levels: 1) as a nation state, it is systematically representing the 'idea of Iran' as a 'civilizational crossroads'; it does so 2) in a region that the Iranian government chooses to call 'West Asia' (and not the Middle East), thereby reconnecting it to Asia, and 3) in an emergent world whose organizing trope is that of a 'New Silk Roads' imaginary and whose overriding logic is more geoeconomics than geopolitics. 
In the final chapter of this book, Chapter 13, Van der Lugt analyses various causal relations through which Ethiopian and Chinese actors interact in the context of the Digital Silk Road initiative. She contends that, from a Chinese perspective, the Digital Silk Road is explained as a serious attempt to narrow the gap between underdeveloped and developed countries by improving their own capacities. From a Western perspective (Freedom House, Human Rights Watch, etc.), Chinese investments in the Digital Silk Road are often depicted as unethical support to authoritarian leaders. What is playing out in Africa (and other parts of the world) is part of a larger contest between the West and China for dominance over the future of technology and global influence. Through detailed, formal process tracing, Van der Lugt moves beyond the simple dichotomy of good and bad Chinese investments in the digitalization of Africa. Instead, her chapter identifies the actors involved in the digitalization of Ethiopia and investigates their motives and levels of influence.

\section{Main Findings}

The contributions in this volume run the gamut from aerial views of the role that Chinese actors play in global institutions and regional networks to specific case studies that zoom in on BRI dynamics in local contexts. Four recurring observations stand out as the main findings of this book:

1 Geographical context matters: as several of the contributors show (e.g. Van der Putten and Petkova), geopolitical and geoeconomic understandings of the world shape how actors make decisions in BRI-related contexts. In some cases, physical geography functions as an almost 'static reality' that 'talks back' to actors as they go about their activities (as Ghiasy illustrates). In other cases, actors exert definitional agency to give meaning to geography and turn it into a resource for decision-making processes (see Links and Forough). In all of these instances, actors put their geographic context to work in the service of specific agendas, both conceptually and materially.

2 The BRI is a pluralist endeavour: there is no single, unified BRI agenda. This becomes clear from the various individual cases presented in this volume, especially Ferchen's and Kuik's comparative analyses, but it is also evident from the behaviour of Chinese actors in different institutional settings (as illustrated by both D'Hooghe and Sampson, Wang, and Mosquera Valderrama). Different contexts require their own understanding of the situation, and consequently their own policy responses. 
3 Old wine in new bottles: as Gonzalez-Vicente shows, and as the work of Sampson, Wang, and Mosquera Valderrama also suggests, BRI efforts often extend rather than challenge existing politics. The PRC's investment, aid, and connectivity projects frequently take their cues from institutions like the IMF and World Bank, reproducing both best practices and the problematic externalities that have characterized these predecessor activities.

4 BRI outcomes depend on local actors: the BRI is shaped by diverse local actors who exercise their agency by connecting with Chinese counterparts to achieve their own goals. This is particularly evident from the studies of BRI-related projects in Africa (Links, Van der Lugt) and Southeast Asia (Ferchen, Kuik). In these cases, local actors integrate the PRC leadership's ambitious plans for cooperation into their own developmental frameworks.

In short, the authors represented in this volume each examine contextspecific dynamics by following the actors to show how the BRI's outcomes take shape in practice. Practitioners and observers would be well advised to similarly approach these complexities on a case-by-case basis, so as not to fall into the trap of overlooking or misinterpreting how different people and organizations insert themselves into the highly complex decision-making and implementation processes that make the BRI a near-global reality today.

In the PRC's propaganda video on YouTube, Kimi exclaims: 'The Belt is along the old Silk Road and the Road is the Silk Road on the sea!' While the video itself remains campy and awkward, her statement illustrates how clever Chinese propagandists have been in at least one regard: their branding of the PRC's foreign development initiative as a direct extension of historical cultural and trade relations. Several of the BRI's core projects and institutions now contain the evocative label 'Silk Road'. The titular 'Belt' and 'Road' are officially called the 'Silk Road Economic Belt' and '21st-Century Maritime Silk Road', the BRI's alternative name is the 'New Silk Road' (see also Pairault 2020), and the authorities have dubbed their extension of the BRI into cyberspace with the 'Digital Silk Road' (Ghiasy \& Krishnamurthy 2020; see also Van der Lugt, Chapter 13 in this volume). The idea of ancient, far-flung networks emanating from China informs much of the imagination surrounding the BRI (Griffiths 2017: 21). Xinhua's Twitter accounts, for instance, are awash with images that are meant to illustrate this: dunes, camels, exotic markets, desert sunrises, peoples in colourful ethnic dresses, and so on (for examples and a discussion, see Nie 2019: 184). 
The contemporary, modern reinvention of the so-called Silk Roads arguably has little to do with the actual historical record of these routes (for discussions, see Chong \& Pham 2020a; Christian 2000; Hansen 2012). Be that as it may, branding the BRI as the 'New Silk Road' is ultimately an effective marketing strategy (SupChina 2016), designed to invite as many stakeholders as possible into projects that promise to jump-start past successes and glories, be they real or imagined. The results of these projects are often idiosyncratic, and they are at times fraught with risk or failures. These outcomes are of course important, but regardless of the BRI's efficacy, the actors involved in the BRI are recalibrating the world as we know it. As more and more actors take up, challenge, revamp, and rework these much-evoked 'Silk Roads' in diverse situations, we need critically minded research that does not shy away from leaning into the complexities and nuances of the BRI to unpack both its global ambitions and its local instantiations.

\section{References}

Bandiera, Luca \& Tsiropoulos, Vasileios (2020). 'A Framework to Assess Debt Sustainability under the Belt and Road Initiative'.Journal of Development Economics, 146, 1-20.

Billig, Michael (2013). Learn to Write Badly: How to Succeed in the Social Sciences. Cambridge: Cambridge University Press.

Blanchard, Jean-Marc F. (2013). 'The Dynamics of China's Accession to the WTO: Counting Sense, Coalitions and Constructs'. Asian Journal of Social Science, 41(3-4), 263-286.

BusinessEurope (2020, January). The EU and China:Addressing the Systemic Challenge. Brussels: BusinessEurope. Retrieved 25 June 2020 from https://www. businesseurope.eu/publications/eu-and-china-addressing-systemic-challenge.

Carrai, Maria Adele, Defraigne, Jean-Christophe \& Wouters, Jan (eds.) (2020). The Belt and Road Initiative and Global Governance. Cheltenham: Edward Elgar.

Chong, Alan \& Pham, Quang Minh (2020a). 'Critical Perspectives from Outside China on the Belt and Road Initiative: An Introduction'. In Alan Chong \& Quang Minh Pham (eds.), Critical Reflections on China's Belt \& Road Initiative (pp. 1-20). Singapore: Palgrave Macmillan.

Chong, Alan \& Pham, Quang Minh (eds.) (202ob). Critical Reflections on China's Belt \& Road Initiative. Singapore: Palgrave Macmillan.

Christian, David (200o). 'Silk Roads or Steppe Roads? The Silk Roads in World History'.Journal of World History, 11(1), 1-26. 
Dai, Anna Chuwen (2018). 'The International Investment Agreement Network under the "Belt and Road” Initiative'. In Julien Chaisse \& Jędrzej Górski (eds.), The Belt and Road Initiative: Law, Economics, and Politics (pp. 220-249). Leiden \& Boston, MA: Brill.

De Cremer, David, McKern, Bruce \& McGuire, Jack (eds.) (2019). The Belt and Road Initiative: Opportunities and Challenges of a Chinese Economic Ambition. Los Angeles, CA: Sage.

Dollar, David (2018). 'Is China's Development Finance a Challenge to International Order?' Asian Economic Policy Review, 13, 283-298.

Economist (2018, March 8). 'Will China's Belt and Road Initiative outdo the Marshall Plan?' The Economist. Retrieved 25 June 2020 from: https://www.economist. com/finance-and-economics/2018/03/08/will-chinas-belt-and-road-initiativeoutdo-the-marshall-plan.

European Chamber (2020). The Road Less Travelled:European Involvement in China's Belt and Road Initiative. Beijing et al.: European Union Chamber of Commerce in China. Retrieved 25June 2020 from https://www.europeanchamber.com.cn/ en/publications-archive/762/The_Road_Less_Travelled_European_Involvement_in_China_s_Belt_and_Road_Initiative.

Ewing, Jackson (2019, May 3). 'Making the Belt and Road Environmentally Sustainable'. The Diplomat. Retrieved 25 June 2020 from https://thediplomat. com/2019/05/making-the-belt-and-road-environmentally-sustainable/.

Friends of the Earth (2017). Investing in a Green Belt and Road? Assessing the Implementation of China's Green Credit Guidelines Abroad. Retrieved 25June 2020 from https://foe.org/resources/investing-green-belt-road-assessing-implementationchinas-green-credit-guidelines-abroad/.

Ghiasy, Richard \& Krishnamurthy, Rajeshwari (2020). 'The Digital Silk Road - Strategic Repercussions for the EU and India'. IPCS-LAC DSR Policy Paper. Retrieved 16 November 2020 from https://leidenasiacentre.nl/en/chinas-digital-silk-roadstrategic-implications-for-the-eu-and-india/.

Goh, Brenda \& Martina, Michael (2019, April 24). 'China to Recalibrate Belt and Road, Defend Scheme against Criticism'. Reuters. Retrieved 25 June 2020 from https://www.reuters.com/article/us-china-silkroad-forum/china-to-recalibratebelt-and-road-defend-scheme-against-criticism-idUSKCN1SooAZ.

Gordon, David F., Tong, Haoyu \& Anderson, Tabatha (2020). Beyond the Myths - Towards a Realistic Assessment of China's Belt and Road Initiative: The Development-Finance Dimension. London: International Institute for Strategic Studies. Retrieved 25June 2020 from https://www.iiss.org/blogs/research-paper/2020/03/ beyond-the-myths-of-the-bri.

Griffiths, Richard T. (2017). Revitalising the Silk Road:China's Belt and Road Initiative. Leiden: HIPE. 
Hanemann, Thilo \& Huotari, Mikko (2017). Record Flows and Growing Imbalances: Chinese Investment in Europe in 2016. Berlin: MERICS. Retrieved 25 June 2020 from https://rhg.com/research/record-flows-andgrowing-imbalances-chinese-investment-in-europe-in-2016/.

Hansen, Valerie (2012). The Silk Road: A New History. Oxford: Oxford University Press. Healy, Kieran (2017). 'Fuck Nuance'. Sociological Theory, 35(2), 118-127.

Hillman, Jonathan E. (2018, April 3). 'How Big Is China's Belt and Road?' Center for Strategic \& International Studies (CSIS). Retrieved 25 June 2020 from https:// www.csis.org/analysis/how-big-chinas-belt-and-road.

Hughes, Alice C. (2019). 'Understanding and Minimizing Environmental Impacts of the Belt and Road Initiative'. Conservation Biology, 33(4), 883-894.

Kuik, Cheng-Chwee (2020). 'Connectivity and Gaps: The Bridging Links and Missed Links of China's BRI in Southeast Asia'. In Maria Adele Carrai, Jean-Christophe Defraigne \& Jan Wouters (eds.), The Belt and Road Initiative and Global Governance (pp. 76-95). Cheltenham: Edward Elgar.

Kynge, James \& Yu, Sun (2020, April 30). 'China Faces Wave of Calls for Debt Relief on "Belt and Road" Projects'. Financial Times. Retrieved 25 June 2020 from https:// www.ft.com/content/5a3192be-27c6-4fe7-87e7-78d4158bd39b.

Lai, Huaxia \& Lentner, Gabriel M. (2018). 'Paving the Silk Road BIT by BIT: An Analysis of Investment Protection for Chinese Infrastructure / Projects under the Belt \& Road Initiative'. In Julien Chaisse \& Jędrzej Górski (eds.), The Belt and Road Initiative: Law, Economics, and Politics (pp. 250-283). Leiden \& Boston, MA: Brill.

Latour, Bruno (2005). Reassembling the Social: An Introduction to Actor Network Theory. Oxford: Oxford University Press.

Latour, Bruno \& Woolgar, Steve (1986). Laboratory Life: The Construction of Scientific Facts. 2nd ed. Princeton: Princeton University Press.

Li, Karlok Carlos \& Chaisse, Julien (2018). 'Infrastructure Investments: Ports, Rail, and International Economic Rules'. In Julien Chaisse \& Jędrzej Górski (eds.), The Belt and Road Initiative: Law, Economics, and Politics (pp. 465-504). Leiden \& Boston, MA: Brill.

Li, Mingjiang (ed.) (2017). China's Economic Statecraft: Co-optation, Cooperation and Coercion. Singapore: World Scientific.

Lin, Justin Yifu (2015). “'One Belt and One Road” and Free Trade Zones - China's New Opening-Up Initiative'. Frontiers of Economics in China, 10(4), 585-590.

Lu, Xiankun (2015). 'The 2001 WTO Accession of China: Negotiating Experience Challenges, Opportunities and Post-Accession Approaches'. In Uri Dadush \& Chiedu Osakwe (eds.), WTO Accessions and Trade Multilateralism: Case Studies and Lessons from the WTO at Twenty (pp. 439-447). Cambridge: Cambridge University Press. 
MacKenzie, Donald Alexander (2006). An Engine, Not a Camera: How Financial Models Shape Markets. Cambridge, MA: MIT Press.

Miller, Daniel \& Slater, Don (2000). The Internet - An Ethnographic Approach. Oxford \& New York: Berg.

Mitchell, Tom (2018, September 25). 'Beijing Insists BRI Is No Marshall Plan'. Financial Times. Retrieved 25 June 2020 from https://www.ft.com/content/48f21df89c9b-11e8-88de-49c9o8bif264.

Moneyhon, Matthew D. (2003). 'China's Great Western Development Project in Xinjiang: Economic Palliative, or Political Trojan Horse?' Denver Journal of International Law and Policy, 31(3), 491-519.

Negara, Siwage Dharma \& Suryadinata, Leo (2018). 'Indonesia and China's Belt and Road Initiatives: Perspectives, Issues and Prospects'. Trends in Southeast Asia, 11. Retrieved 25June 2020 from https://www-degruyter-com.ezproxy.leidenuniv. nl:2443/view/title/557996.

New China TV (2017, May 14). 'Music Video: The Belt and Road, Sing Along'.Xinhua. Retrieved 25June 2020 from https://www.youtube.com/watch?v=98RNh7rwyf8.

Nie, Yuxi (2019). Microblogging and Media Policy in China: Xinhua's Strategic Communication on the Belt and Road Initiative. PhD thesis, Leiden University. Retrieved 25June 2020 from https://openaccess.leidenuniv.nl/handle/1887/79516.

Pairault, Thierry (2020). 'Examining the Importance of the New Silk Roads for Africa and for Global Governance'. In Maria Adele Carrai, Jean-Christophe Defraigne \& Jan Wouters (eds.), The Belt and Road Initiative and Global Governance (pp. 155-180). Cheltenham: Edward Elgar.

Pardo, Ramon P. (2018). 'Europe's Financial Security and Chinese Economic Statecraft: The Case of the Belt and Road Initiative'. Asia Europe Journal, 16(3), 237-250.

Reilly, James (2017). 'China's Economic Statecraft in Europe'. Asia Europe Journal, $15(2), 173-185$.

Schneider, Florian (2019). Staging China: The Politics of Mass Spectacle. Leiden: Leiden University Press. Retrieved 25 June 2020 from https://openaccess.leidenuniv. nl/handle/1887/80359.

Shen, Simon \& Chan, Wilson (2018). 'A Comparative Study of the Belt and Road Initiative and the Marshall Plan'. Palgrave Communications, 4(1), 1-11.

State Council (2015, March 30). 'Action Plan on the Belt and Road Initiative'. State Council of the People's Republic of China. Retrieved 25June 2020 from http://english. www.gov.cn/archive/publications/2015/03/30/content_281475080249035.htm.

SupChina (2016, August 18). 'It's All Connected: Silk Roads Old and New'. Sinica Podcast. Retrieved 25 June 2020 from https://supchina.com/podcast/ connected-silk-roads-old-new/.

Tekdal, Veysel (2018). 'China's Belt and Road Initiative: At the Crossroads of Challenges and Ambitions'. Pacific Review, 31(3), 373-39o. 
Teo, Hoong Chen, Lechner, Alex Mark, Walton, Grant W., Chan, Faith Ka Shun \& Cheshmehzangi, Ali, et al. (2019). 'Environmental Impact of Infrastructure Development under the Belt and Road Initiative'. Environments, 6(6). Retrieved 25 June 2020 from https://www.mdpi.com/2076-3298/6/6/72.

Tower, Jason \& Staats, Jennifer (2020, April 29). 'China's Belt and Road: Progress on “Open, Green and Clean?”' United States Institute of Peace. Retrieved 25 June 2020 from https://www.usip.org/publications/2020/04/ chinas-belt-and-road-progress-open-green-and-clean.

Van Dinh, Trinh (2020). 'Infrastructure Construction as Empire Consolidation in Chinese History'. In Alan Chong \& Quang Minh Pham (eds.), Critical Reflections on China's Belt \& Road Initiative (pp. 81-93). Singapore: Palgrave Macmillan.

Wang, Luolin (ed.) (2015). China's WTO Accession Reassessed. New York \& London: Routledge.

Wendt, Alexander (2004). 'The State as Person in International Theory'. Review of International Studies, 30(2), 289-316.

Wilson, Jeffrey D. (2017). 'The Evolution of China's Asian Infrastructure Investment Bank: From a Revisionist to Status-Seeking Agenda'. International Relations of the Asia Pacific, 19, 147-176.

Wong, Reuben (2017). 'China's Use of Economic Tools in Its Human Rights Disputes with the EU'. In Mingjiang Li (ed.), China's Economic Statecraft: Co-optation, Cooperation and Coercion (pp. 36-63). Singapore: World Scientific.

Xi, Jinping (2019, April 26). 'Working Together to Deliver a Brighter Future for Belt and Road Cooperation: Keynote Speech by H.E. Xi Jinping President of the People's Republic of China at the Opening Ceremony of the Second Belt and Road Forum for International Cooperation'. Ministry of Foreign Affairs of the People's Republic of China. Retrieved 9 July 2020 from https://www.fmprc.gov. cn/mfa_eng/zxxx_662805/t1658424.shtml.

Zou, Mimi (2019), 'China and the Belt and Road Initiative: Transnational Labor Law under State Capitalism 4.o'. AJIL Unbound, 113, 418-423. 


\section{About the Author}

FLORIAN SCHNEIDER, PhD, Sheffield University, is Senior University Lecturer in the Politics of Modern China at the Leiden University Institute for Area Studies. He is managing editor of Asiascape: Digital Asia, director of the Leiden Asia Centre, and the author of three books: Staging China: the Politics of Mass Spectacle (Leiden University Press, 2019), China's Digital Nationalism (Oxford University Press, 2018), and Visual Political Communication in Popular Chinese Television Series (Brill, 2013, recipient of the 2014 EastAsiaNet book prize). In 2017, he was awarded the Leiden University teaching prize for his innovative work as an educator. His research interests include questions of governance, political communication, and digital media in China, as well as international relations in the East Asian region. 



\section{Part I}

Global Connectivity 



\title{
2 China's BRI and International Cooperation in Higher Education and Research
}

\author{
A Symbiotic Relationship
}

Ingrid d'Hooghe

\begin{abstract}
This chapter examines the connection between the BRI and Chinese policies for international cooperation in higher education (HE) and science \& technology (S\&T). It argues that Chinese stakeholders make the connection work in two directions: the BRI is used as an instrument to promote China's HE and S\&T agendas, and international cooperation in HE and S\&T is used to promote the BRI. The concepts of education and science diplomacy are used to analyse the roles of state and non-state actors. The chapter finds that efforts to build the relationship are primarily state driven. Finally, the chapter discusses what this development means for China's position in HE and S\&T, and for other parts of the world. Who may benefit and who may lose out?
\end{abstract}

Keywords: Belt and Road Initiative, China, science and technology, higher education, research, cooperation

The development of international cooperation in China's higher education (HE) and science and technology (S\&T) plays an important role in China's Belt and Road Initiative (BRI). According to Chinese President Xi Jinping, this cooperation has 'helped lay a solid popular and social foundation for pursuing the Belt and Road Initiative' (Xi 2017a). Indeed, in recent years, Chinese policies aimed at advancing China's HE and S\&T agendas have been developed in close connection with policies serving the broader economic

Schneider, Florian (ed.), Global Perspectives on China's Belt and Road Initiative: Asserting Agency through Regional Connectivity. Amsterdam, Amsterdam University Press 2021 DOI: $10.5117 / 9789463727853 \_$CHO2 
and political goals of the BRI, including China's aim to become world leading in HE and S\&T by $205^{\circ}$ (Xi 2017b). This nexus between HE and the BRI is sometimes referred to as the 'Educational Silk Road', but this term has not (yet) caught on in international educational circles.

This above aim for world leadership in these fields already appeared in Chinese policy documents before the BRI was launched. However, the BRI has given China's efforts in HE and S\&T an extra boost and the country is making steady progress in working towards this goal. China's substantial investments in education and research, made throughout the past decades, have yielded results. Chinese top universities are rapidly rising in the international university rankings and China has also become the largest producer of scientific articles (National Science Board 2019), the largest source of international patent applications (WIPO 2020), and one of the leading countries in fields of science such as artificial intelligence, bio science, and engineering (D'Hooghe et al. 2018). However, China's HE and S\&T still face many challenges with regard to capacity and overall quality. The country has a long way to go before it will become a global leader in these two areas.

This chapter examines the various dimensions of the connection between the BRI and HE and S\&T, with a focus on HE. It explores how the BRI-HE nexus impacts the development of China's HE, the global HE landscape, and the realization of BRI policy goals. It will argue that the connection is symbiotic: BRI policymakers have good reason to promote China's HE and S\&T internationalization agendas, while China's HE and S\&T policymakers benefit from serving the BRI and its goals of achieving China's overall rejuvenation and making China a leading country in the world. It will examine these issues through the lens of diplomacy and some of its subsets: the BRI is analysed as an instrument as well as a target of China's science and education diplomacy, and international cooperation in HE and S\&T is analysed as an instrument of BRI diplomacy.

\section{China's Diplomacy in All Shapes and Sizes}

Diplomacy is an instrument of foreign policy, aimed at serving state and/ or non-state actors' interests through communication, negotiation, and the provision of incentives. It is an open-ended process that includes economic, cultural, social, as well as political forms and functions and where diplomatic agency is not limited to the sovereign state. In today's diplomatic practice a wide range of non-state actors from domestic and international civil society, epistemic communities, and the private sector have become part 
of diplomatic networks. These non-state actors matter as they bring to the negotiation table in-depth knowledge on specific policy areas, such as the environment, cyber security, or global diseases. Within these networks, non-state actors seek to influence policy and to make global and regional governance processes more open and accountable (Lee \& Hocking 2011). In China, too, broader networks are involved in the country's diplomacy. However, as this chapter will show, the state still dominates when it comes to international communication and negotiation.

Diplomacy comes in many shapes, three of which are relevant for this study. They are the subsets of public diplomacy, science diplomacy, and education diplomacy. Public diplomacy is a form of diplomacy that seeks 'to influence foreign audiences' thoughts and mobilize actions to advance a state or non-state actor's interests and values abroad by building and managing relationships and developing a mutual understanding of cultures, attitudes, and behaviour' (D'Hooghe 2015: 6). China's major public diplomacy goals are to create understanding, respect, and ultimately support for China's political model and policies; to advance China's agenda; and to help China to win friends and allies.

Science diplomacy is a broad and somewhat fuzzy concept that is seen to comprise three elements: 1 ) using science cooperation to improve international relations between countries across various policy areas (science for diplomacy);2) facilitating international science cooperation (diplomacy for science); and 3) informing foreign policy objectives with scientific advice (science in diplomacy) (Royal Society 2010). In this study, only the first and second elements are relevant; the concept of science diplomacy is used to examine how science cooperation helps improve international relations in the policy areas of the BRI, HE, and S\&T. Advancing BRI policies includes making BRI better known and winning support for the realization of BRI projects. A similar role can be played by education diplomacy with both 'education for diplomacy', and 'diplomacy for education' processes being relevant. Through practices such as student and staff exchanges, scholarship programmes, joint projects and meetings, and language training, broader policy objectives can be promoted. Where science and education diplomacy seek to promote knowledge about and win support for the BRI, they can be regarded as instruments of public diplomacy.

Agency in these different subsets of diplomacy lies with various Chinese state and non-state actors. A primary role is played by the Chinese state: actors at the national and subnational level include government leaders and institutions like ministries, China's National Development and Reform Commission (NDRC, a macroeconomic planning agency under the State 
Council), provincial or municipal governments, and national scholarship organizations. The category of non-state actors includes HE institutions, their staff and students, and enterprises. Although policymakers and knowledge institutions in countries that joined the BRI (hereafter ' $\mathrm{BRI}$ countries') ${ }^{1}$ play a significant role in the processes discussed in this chapter, the focus of this research is on Chinese stakeholders.

\section{The Connection in Words}

The connection between the BRI on the one hand and HE and S\&T on the other hand is made in words and deeds. This section of the chapter will examine the words by first looking at BRI policy documents that discuss the role that $\mathrm{HE}$ and $\mathrm{S} \& \mathrm{~T}$ cooperation can play in promoting and realizing the BRI and then also looking at HE and S\&T policy documents that refer to the importance of serving the BRI.

\section{BRI Policies and the Promotion of International Cooperation in Higher Education}

Soon after the BRI was launched, its connection with international cooperation in HE and S\&T was established. The first elaborate BRI policy document, the 2015 'Vision and Actions on Jointly Building Silk Road Economic Belt and 21st-Century Maritime Silk Road' (hereafter '2015 Vision and Actions'), explicitly pointed to the importance of promoting academic exchanges as one of the 'Cooperation Priorities' (NDRC 2015). It stated that academic exchanges could help 'win public support for deepening bilateral and multilateral cooperation'. It also called for more student exchanges and for jointly running schools in BRI countries. The document mentioned providing 10,000 government scholarships for students of BRI countries and called for actions to improve China's S\&T innovation capability, including the promotion of S\&T personnel exchanges, the expansion of cooperation in joint laboratories, as well as the establishment of research centres and international technology transfer centres.

Two years later, in his speech at the 2017 Belt and Road Forum in Beijing, President Xi offered more details. He highlighted the need to integrate S\&T into industries and finance, and to build a Digital Silk Road through

1 The term 'BRI countries' refers to countries that have officially joined the BRI by signing a BRI MoU with China. 
intensifying cooperation in 'frontier areas' such as digital economy, artificial intelligence, nanotechnology, quantum computing, big data, cloud computing, and smart cities (Xi 2017a). He also announced the launch of a 'Belt and Road Science, Technology and Innovation Cooperation Action Plan', which is currently being implemented (Xi 2017a). This plan maps out a broad range of programmes and actions for the period 2017-2022, including a 'S\&T People-to-People Exchange Initiative', 'Joint Laboratory Initiative, Science Park Cooperation Initiative', and a 'Technology Transfer Initiative'. In concrete terms, under the plan, China will receive 2500 young foreign scientists for short-term research visits to China, will train 5000 foreign scientists, engineers, and managers, and will set up 50 joint laboratories (MOST 2017).

The documents highlighted here are just a few of the many BRI policy documents, speeches and plans that include references to international cooperation in HE and S\&T. ${ }^{2}$ However, they can be seen as representative of the Chinese government's views on how the BRI should aim to speed up and expand the internationalization of China's HE as well as its views on how this endeavour should advance the country's scientific and technological agendas.

\section{Higher Education and Science Policies and the Promotion of the BRI}

Just as HE and S\&T feature extensively in BRI policy documents, the BRI features extensively in China's HE and S\&T policy documents. The most explicit and elaborate connection is made in the 'Education Action Plan for the Belt and Road Initiative', which was issued by China's Ministry of Education in 2016 (hereafter '2016 Action Plan'). This document stated that increased cooperation in HE by the BRI countries will serve the goals of the BRI, and also that, in turn, the BRI will support the internationalization of HE as it 'affords immense opportunities for greater openness, further exchanges, and deeper integration in education in the regions and countries along the routes' (MoE 2016). The ‘2016 Action Plan' formulated major policy lines for strengthening educational connectivity between China and BRI countries and put forward three overall goals: 1) the promotion of people-to-people ties, which is explained as deepening the understanding between China and BRI countries, in particular where it concerns China's language and culture, and Chinese policies; 2) the cultivation of 'the much-needed talent

2 See, for example, the documents listed at the Belt and Road Portal of the Chinese government: https://eng.yidaiyilu.gov.cn/zchj/qwfb/12731.htm. 
for the Belt and Road Initiative'; and 3) achieving common development of education along the BRI route with the goal of building an 'integrated educational community'.

These views and goals, which are elaborated upon below, are repeated in most Chinese HE and S\&T policy documents. They appear, for example, in 'China Education Modernization 2035', the country's blueprint for the future of China's education that was issued in 2019, and in the Ministry of Education's 'Key Points of Work of the Ministry of Education's Opening up of Education in 2019' (CC and State Council 2019a; MoE 2019c). These repeated references in policy documents underline the continuity of these plans and the importance the Chinese government attaches to making the two policy domains strengthen each other.

\section{Deepening the Understanding of China and Chinese Policies}

A major theme in HE and S\&T policies supporting the BRI is deepening the understanding of China and Chinese policies, including the BRI, through 'fostering closer people-to-people ties' (MoE 2016). This is also one of the major goals of China's overall public diplomacy. While the instrument of 'people-to-people contacts' seeks to involve non-state actors, the contacts are in practice usually strongly guided by government officials, who define the format and content of the exchanges (D'Hooghe 2015, 156). In order to achieve the goal of a better understanding of China, the Ministry of Education encourages the organization of seminars and research on topics related to China. It also encourages education in the Chinese language, both in Chinese HE institutions and abroad.

The latter task is where the Confucius Institutes play a role. They are explicitly mentioned in the ' 2016 Action Plan' and are regularly lauded by Chinese leaders for their positive role in the BRI (Xinhua 2016). Of the more than 525 Confucius Institutes and more than 1113 Confucius Classrooms around the world, 154 Institutes and 149 Classrooms are located in 54 BRI countries (MoE 2019a). The Confucius Institutes not only teach Chinese but also organize lectures, forums, international conferences, and research groups on BRI-related themes. Furthermore, Confucius Institutes worldwide are called upon to implement the Confucius China Study Plan, which aims to recruit more than 250 students and scholars per year to do research or a $\mathrm{PhD}$ on the BRI. In Thailand a Maritime Silk Road Confucius Institute has been established that is devoted to supporting the BRI (Shuto 2018: 133). According to the Confucius Institute Headquarters (Hanban), it should become 'the driving force to all the Confucius Institutes of nations along "One Belt and One Road"' (Hanban 2015). 
In order to strengthen their role in the BRI, China aims to optimize the global layout of the Confucius Institutes, revise the Confucius Institute Charter, and accelerate the professionalization of Chinese deans and teachers (MoE 2016). While many universities in the US and Europe are reconsidering their cooperation with Confucius Institutes, BRI countries in Asia and Africa often welcome the opportunity the institutes offer in terms of free language training and scholarships to study in China.

\section{Cultivating and Training Talents}

The goal of cultivating and training talents and personnel in BRI countries is one of the major aims of connecting international cooperation in HE and S\&T with the BRI. In order to successfully implement the BRI, the Chinese government needs more people with knowledge and skills, not only domestically, but also abroad. Studies carried out by Chinese researchers have identified a lack of the kinds of skilled professionals that are needed by Chinese enterprises in BRI countries (MoE 2016). This is where the internationalization of China's HE, in particular in the area of S\&T, can help. The '2016 Action Plan' and '2015 Vision and Actions' address this issue by proposing two policy lines: increasing student and educational staff mobility, and expanding China's vocational training abroad.

The policy aim to increase mobility with BRI countries cannot be separated from China's overall HE goal to expand mobility. Both outgoing and incoming student mobility is encouraged, but the primary focus is on incoming mobility and realizing China's goal to receive 500,000 foreign students in 2020. To increase the country's attractiveness for international students, policymakers are urged to improve the quality of Chinese HE and to create more platforms that can facilitate and accelerate the training of high-level international talents. To support this effort the '2016 Action Plan' proposes various instruments to enhance two-way student exchanges, including BRI scholarship programmes, cooperation in running educational institutions and programmes overseas, teacher training, and education assistance in the framework of 'South-South Cooperation' (MoE 2016).

The second policy line concentrates on encouraging China's top vocational and technical institutions to establish colleges and training centres overseas and to jointly develop educational resources and programmes. In this process, the institutions should collaborate in particular with Chinese high-speed railroad and telecommunication companies (MoE 2016). This way the collaboration will contribute to realizing the BRI goals of meeting infrastructure needs and building a Digital Silk Road. A good example of how a measure proposed in the '2016 Action Plan' is translated into more 
detailed programmes is provided by the Luban workshop programme, which aims to contribute to the development in foreign countries of vocational and technical schools. Judging by the attention given to the Luban workshop in publications on the websites of the Ministry of Education and in academic articles, the programme is a showpiece of the BRI-HE nexus.

Named after the father of Chinese architecture Lu Ban (4th century BC), the programme was developed around 2010 under the auspices of Tianjin Municipality. It was then later included in and adapted to BRI plans. It is designed to provide technical and vocational training overseas to both students and teachers, and to enhance collaboration among vocational schools around the world with the final goal of 'serving the purpose of BRI' (Li \& Wang 2019). The first Luban Workshop was held in 2016 in Thailand and in the two years that followed over 2000 students received training in engineering practice in the school, enabling them to work at Chinese enterprises (Li \& Wang 2019). Luban Workshops have been established in India, Indonesia, Pakistan, Cambodia, Djibouti, and two European countries: the UK and Portugal. There are plans for more workshops in Africa and Asia (Li \& Wang 2019).

In addition to expanding vocational training abroad, the Chinese government also seeks to further S\&T and innovation. According to Minister of Science and Technology Wang Zhigang, S\&T cooperation with BRI countries should realize China's aims to transform the Belt and Road into 'a boulevard for innovation' (Xinhua 2019a). This should be achieved through the creation of technological innovation platforms, laboratories, industrial technology research institutes, and entrepreneurship incubation bases, and through the promotion of science exchanges and the sharing of resources (MoE 2018).

\section{Building an Integrated Educational Community}

The third aim concerns building 'an integrated educational community'. This should be achieved through the coordination of national education policies between China and BRI countries. Such coordination can be realized by providing advice and policy consultation to BRI countries, establishing framework agreements for educational cooperation and mutual recognition of dual and joint degrees, simplifying visa application procedures, and setting up platforms for cooperation and exchanges. These efforts are a part of a more ambitious policy goal of enhancing and increasing China's international influence on education through active participation in global education governance and the development of international education rules, standards, and evaluation systems (CC and State Council 2019a). 


\section{Actions and Agency in Creating the HE-BRI Nexus: A State- Driven Approach}

Who are the actors driving the development of a closer connection between BRI policies and policies with regard to HE and S\&T? Looking at the many policy documents and guidelines that are put forward by CCP organs and major government institutions, and the fact that the government is providing most of the funding for the implementation of the policies, it is clear that this endeavour is primarily state-driven. Chinese policymakers seek to steer and encourage the science and educational diplomacy in the BRI context primarily via top-down approaches, both at national and subnational levels. Reliance on Chinese public funding will likely continue as most BRI countries lack financial and other resources (Wu \& Chan 2019).

This is not to say that connecting the BRI with the agendas of HE and S\&T is solely a state affair; universities and enterprises are important stakeholders, too. However, it should be noted that in China, universities are closely tied to the government and are required to execute government and party policy directives. In implementing BRI policies, both universities and enterprises are pushed by government directives and/or pulled by financial and other government incentives.

\section{The Role of the Government at National and Local Level}

BRI policy documents emphasize the role of the Chinese government at national and local levels. Among the state actors involved are CCP organs such as the Central Committee (CC) and a plethora of government institutions. The State Council and the National Development and Reform Commission (NDRC) play a major role in the formulation of overall policies. The Ministry of Education and the Ministry of Science and Technology develop and disseminate more detailed policies and coordinate action plans. In addition, organizations such as the National Natural Science Foundation of China (NSFC) are also important with regards to financing and overseeing research programmes (Applebaum et al. 2018; NSFC n.d.).

What stands out in various policy documents is the prominence given to the role of provinces and cities, which are tasked with developing their own education action plans for the BRI. They should use the advantages of their geographical positions and local characteristics but ensure that they closely align their own plans with the 'national master plan' (MoE 2016). Many provinces and cities have jumped at this opportunity. Some have developed extensive programmes to further S\&T collaboration. One 
example is Tianjin Municipality's 'Belt and Road Science, Technology, and Innovation Cooperation Action Plan' (TMSTB 2017). Another example is Shanghai Municipality's 'Belt and Road International Cooperation Programme' (STCSM 2019). These programmes are extensive; the latter, for example, provides funding for six international joint laboratory projects, 60 young scientist exchanges, and five technology transfer projects, all of which will be aimed at countries participating in the BRI (STCSM 2019). Other provinces have developed more modest programmes (Zhang 2017; Fujian Provincial Department of Education 2017). By 2019, China's Ministry of Education had signed memoranda with eighteen provinces to co-build education activities in support of the BRI (MoE 2019a).

Policy documents also contain calls for high-level (government) consultations to promote education and science cooperation in support of the BRI through bilateral and multilateral cooperation mechanisms of organizations, such as the Shanghai Cooperation Organisation (SCO), the Asia-Pacific Economic Cooperation (APEC), the Asia-Europe Meeting, the various BRI economic corridors, the Forum on China-Africa Cooperation (FOCAC), UNESCO, and many more (MoE 2016). Research shows that policymakers do engage actively with these organizations in promoting HE and S\&T cooperation (King 2019; Cheng 2019).

\section{The Role of Non-State Actors: Knowledge Institutions and Organizations}

Universities and other knowledge institutions play a key role in translating the policy lines put forward by the government and the CCP into the concrete programmes and projects that they subsequently implement. They are also called upon to work together with Chinese enterprises in exploring opportunities for cooperation in talent cultivation, technology transfer, and linking training to employment. The initiatives developed by knowledge institutions are innumerable and diverse. In the paragraphs below the activities of only a few major stakeholders are discussed to highlight the enormous scope of science and education diplomacy and BRI public diplomacy activities that Chinese knowledge institutions currently undertake.

\section{Projects and Programmes}

A major role in BRI education and science diplomacy is played by the Chinese Academy of Sciences (CAS). The President of CAS, Bai Chunli, regards S\&T as 'the core driving force for the BRI development' (Bai 2018). He has led CAS to develop a comprehensive framework of scientific cooperation programmes 
and sectoral multilateral cooperation initiatives in support of the BRI. In the period 2013-2018, CAS has provided more than US\$268 million for the construction of BRI S\&T projects. These include the construction of nine overseas research and education centres in BRI countries, the implementation of over a hundred research and development projects, training and education of over 5000 individuals from BRI countries, and more than 20,000 exchanges a year with scientists from BRI countries (Bai 2018). CAS has also established the Alliance of International Science Organizations in the Belt and Road Region (ANSO) with 37 national scientific institutions and international organizations, including UNESCO (ANSO n.d.). In addition, CAS has launched a Belt and Road Industry Alliance, with more than a hundred high-tech enterprises and research institutes, aimed at cooperation to serve regional economic and social development.

While the BRI-related activities CAS has developed stand out because of their breadth, Chinese universities have also taken up the call to develop BRI-related programmes. They have established BRI study units and have organized international conferences and workshops on BRI-related themes. Some have also developed specific BRI study programmes. Tsinghua University, for example, offers an International Master of Public Administration in the Belt and Road Initiative (IMPA-BRI) programme. The programme, which is 'guided' by a state actor - the National Development and Reform Commission (NDRC) - is designed to train promising talents for BRI countries (Tsinghua SPPM n.d.). Also at Tsinghua University, the People's Bank of China School of Finance (PBCSF n.d.) offers a prestigious 'BRI Finance EMBA' programme, which targets international business leaders from China and Southeast Asia and focuses on the role of regional economies in the BRI (PBCSF n.d.).

\section{Building Networks}

Universities are also active in building networks to either strengthen BRIrelated cooperation or to simply promote the BRI. Some networks bring institutions together, whilst others aim to connect individual researchers or students. An example of the former is the University Alliance of the Silk Road (UASR), which was launched by Xi'an Jiaotong University in 2015. The UASR is an international educational platform that aims to build a Silk Road Academic Belt through institutional exchanges and partnerships. According to its website, the Alliance has been joined by approximately 150 universities from 38 countries and regions, including 41 Chinese universities (UASR n.d.). The UASR has established sub-alliances that focus on law, management, advanced manufacturing, and nanotechnologies. It has also established a 
Silk Road Economic Belt Collaborative Innovation Center and a BRI Free Trade Area Research Institute. A similar initiative has been developed by Lanzhou University, which has established the Belt and Road University Alliance (BRUA 2016). Meanwhile, Xiamen University has launched the University Consortium of the 21st Century Maritime Silk Road (UCMSR 2018). In addition, universities and other knowledge institutions have established smaller institutional networks that focus on one specific theme, such as engineering (MoE 2019b), nanotechnology, and forensic studies (Rolland 2019).

It might be asked to what extent these networks result in major new collaboration projects that would not have been realized without them. These networks' activities are often limited to a yearly, highly publicized meeting of university presidents and a few seminars. This suggests that the networks serve as instruments for BRI public diplomacy rather than for deepening S\&T cooperation. ${ }^{3}$ Furthermore, the internationalization strategies of the universities that are leading these networks are focused on developing collaboration with the best international partner universities in relevant science fields rather than with universities in BRI countries (Dinah Birch in Baker 2019). They do seek to strengthen their networks by urging partner universities to sign up for the BRI platforms regardless of whether they are located in BRI countries or not. However, when foreign universities decline, it does not affect the (initiation of) joint projects that are beneficial to the Chinese side.

Rather than these institutional networks, the building of networks of students and scholars may lead to more positive results, given that personal connections often play a significant role in the development of international projects. An example of such a network is the Belt and Road Studies Network (BRSN), which was initiated in Beijing in April 2019 with the aim of providing a mechanism to share ideas and research findings and facilitate academic exchange and cooperation between researchers (BRSN 2019). Another example is the Student Association for the Belt and Road Initiative (SABRI), which is hosted by Tsinghua University. SABRI provides a platform for youth globally 'to share ideas, hopes, and innovations about the BRI'. According to its LinkedIn profile, SABRI has more than 500 members from over 70 countries and has chapters already established in countries like Pakistan, Indonesia, Kazakhstan, and Nepal (SABRI 2020).

Many of the above initiatives involve the participation of foreign or international organizations and universities, but in some cases international 
partners take a more prominent role. One example is the UK-China-BRI Countries Education Partnership Initiative, set up by China's Ministry of Education and the British Council. The initiative aims to provide seed funding for UK universities to develop multi-country education collaboration with institutions from China, and ASEAN and African countries (British Council 2019). Another example is the Silk Road Research Grant project for international young researchers, which has been jointly set up by China's Ministry of Education and UNESCO (Cheng 2019).

\section{Results and Challenges}

This overview of just a few of the innumerable activities that are reported on university websites or mentioned in action plans or in the media illustrates the enormous scope and wide variety of projects and programmes that have been developed by Chinese universities and other knowledge organizations in answer to the Chinese government's call to strengthen the BRI-HE nexus. A number of these plans and programmes already existed before the BRI was launched but were later given a BRI label. This way universities and enterprises show the government and the party that they are aligning their plans with national policies. At the same time, it enables them to benefit from BRI-related funding. However, it is not always clear to what extent these plans are realized and have impact. Some projects seem to exist primarily on paper and may not result in much more than good intentions and one or two discussion meetings per year. Meanwhile, other activities do produce results. The large number of initiatives by stakeholders pose a challenge to the Chinese government in terms of coordination and efficient use of resources. This challenge was recognized early on and the government has worked to strengthen overall planning and coordination between different ministries, provinces, and cities across China (MoE 2016).

\section{The Impact of China's Investment in BRI Science and Education Diplomacy}

According to the Chinese government, steady progress is being made with regard to strengthening the connection between the BRI, HE and S\&T. Many tangible results contribute to one or more of the aims laid out in the various policy documents: building an integrated educational community, cultivating talents, furthering S\&T and innovation, and deepening understanding of China and Chinese policies. The impact is most clearly visible in student 
and staff mobility numbers, the export of China's educational institutions and programmes, and the training of foreign talents in BRI countries. In addition, the developments discussed have multiple indirect and sometimes far-reaching implications at the domestic and global level.

\section{Student and Staff Mobility}

The Ministry of Education reported in 2019 that the implementation of the '2016 Action Plan', had led to the following results: the signing of mutual recognition agreements for $\mathrm{HE}$ degrees with $24 \mathrm{BRI}$ countries, the launch of 60 overseas schools in 23 BRI countries, and the establishment of seventeen joint laboratories along the Belt and Road (MoE 2019a). The 24 mutual degree recognition agreements are out of a total of 46 agreements worldwide, illustrating that HE and S\&T plans focused on the BRI are aligned with the country's overall HE policies. Furthermore, by 2019, China had set up 70 research projects involving 46 different BRI countries (Peters 2019). Meanwhile, think tanks had produced research reports for 66 BRI countries. In the period 2017-2019 China jointly held 146 workshops with countries participating in the BRI, training more than 2100 science personnel and more than 1800 foreign doctoral and master's students (Xinhua 2019a). The export of Chinese vocational training to BRI countries has led to positive results, too: in the period 2016-2018, 351 international cooperation projects saw nearly 60oo students educated and over 100,00o trained (MoE 2019b). S\&T research involving BRI countries has also been stepped up. State-level joint science parks involving eight BRI countries are currently being developed (Xinhua 2019a).

The Chinese government has not disclosed a complete overview of the development of student numbers since the implementation of BRI policies and scholarships. Available figures show that in 2016, a total of 310,720 international students in China came from BRI countries, accounting for $65 \%$ of the total number of foreign students in China (British CoC 2019). In 2017, the absolute number had slightly increased to 317,200 , but in relative terms there was no increase, the number again accounting for $65 \%$ of the total number of incoming students (MoE 2019b). The numbers of scholarship-sponsored students from BRI countries accounted for $61 \%$ of all scholarship-sponsored students in 2016, which was an 8\% rise from 2012 (British $\mathrm{CoC} 2019$ ). With regard to outgoing mobility, figures show that in 2017 a total of 66,100 Chinese students studied in 37 BRI countries. This number indicated a growth rate of $15.7 \%$, which was considerably higher than the 
overall growth rate of Chinese students abroad (11.75\%). Of this group a small minority of 3679 students were government sponsored (MoE 2019b). ${ }^{4}$

Based on these figures, it is not possible to attribute developments in student mobility to China's BRI policies. Many BRI countries are rapidly developing and they could have benefitted from collaboration with China without their participation in the BRI. Conclusions about the success of BRIHE policies are also premature because most BRI scholarship programmes have only been being implemented since 2015-2016. However, it is unlikely that China's many BRI programmes, funding schemes, and scholarships will have had no results. Educational and research traffic has grown among China and Belt and Road countries and particularly those countries with less developed academic systems are benefitting from the programmes. Furthermore, anecdotal information about what is driving students from less developed BRI countries to go to China for study - scholarships and lack of places at domestic universities - suggests that we may see a more pronounced influx of students of BRI countries into China in the coming years (McCarthy 2018). So far, information about the total government budget for the BRI scholarships being offered to international students has not been published. It is therefore also unclear to what extent these BRI-HE plans are being financed by newly earmarked funds rather than funds that were already available but are now just labelled as part of the BRI.

\section{Domestic Impact}

At the domestic level the BRI-HE nexus leads to a strengthening of existing policies rather than adding something new. The impact is visible in three areas. Firstly, the call to serve the BRI has led to an acceleration of China's efforts to modernize its HE and has contributed to an expansion of China's international cooperation in HE and S\&T. The BRI promotion of HE has brought more investment and has led to rising demands for quality education in China (Linney n.d.). This underpins the Chinese government's longstanding aim of improving the quality of China's universities and vocational schools (CC and State Council 2019a). Furthermore, the BRI needs talents trained in areas such as green and smart technologies, engineering, and information technology. This has forced the government to address the fact that currently the majority of international students in China study social sciences and humanities and has urged it to develop more capacity as well as policies that explicitly attract 
students in these fields (Wu \& Chan 2019). The government has already implemented policies aimed at changing international students' study choices through scholarship regulations. In 2016, the largest group among Chinese government-sponsored international students were enrolled in engineering degrees (ibid.).

Secondly, through providing training and technology to BRI countries, China is positioning itself as a country that exports and shares knowledge, rather than a country that seeks knowledge. This is not to say that the Chinese government no longer seeks knowledge abroad, but the advanced S\&T and innovation it needs is generally found in well-developed countries that have not signed up to the BRI. This means that in the short term the BRI focus on HE cooperation will not contribute to the Chinese government's goal of becoming a knowledge economy.

The third area concerns the impact of China's science and educational diplomacy on the BRI. First and foremost, China's vocational and technology projects in and with BRI countries are resulting in a growing pool of welltrained talents. This helps to solve the problem of a lack of local personnel for Chinese enterprises working on projects in BRI countries. In this way HE cooperation helps China implement BRI infrastructural, digital, S\&T, and financial projects. Secondly many of the BRI-HE actions discussed in this chapter can be understood as BRI public diplomacy. They serve to positively shape perceptions of the BRI and co-opt academic, professional, and business groups into supporting BRI policies. In non-BRI countries, BRI public diplomacy in HE has been less successful, as policymakers and scholars are not interested in, and in some cases even reluctant to engage in, cooperation with China on HE and research under the framework of the BRI (D'Hooghe et al. 2018).

\section{Global Impact}

Research into BRI-HE actions for this chapter, as well as a scan of Chinese academic articles on the BRI in the China National Knowledge Infrastructure database $(\mathrm{CNKI})^{5}$, indicated that in the past years BRI-HE policies have been implemented first and foremost in the Asian region. BRI-related projects in Europe, the MENA region, and Africa are less numerous. This is not surprising. In the first years after its launch, the overall focus of the BRI

5 Of the 253 titles in the CNKI database containing the terms 'BRI' and 'higher education' (search executed for the period 2015-June 2020), 39 discussed specific cases on international collaboration; of these 39 cases, 25 dealt with Asian countries or ASEAN. 
was on Asia, and the majority of BRI economic corridors are located in Asia. Furthermore, China's HE ties with Asia were already relatively strong. An additional reason for this focus may have been the wish to reverse the trend of dropping numbers of Asian students in China. From 2003 to 2016, the percentage of Asian students in the total of international students in China dropped from $81.9 \%$ to $59.8 \%$ (Wu \& Chan 2019).

Both China and BRI countries benefit from the BRI-HE policies. However, as the aims of the policies are primarily fine-tuned to China's needs, it is to be expected that China will reap the most benefits, as may be a matter of course for the country that develops and finances the projects. In the long run BRI countries run the risk of becoming increasingly dependent on China's HE system and policies, which may reduce their room for making policy decisions that counter Chinese interests, not only in bilateral relationship but also in multilateral contexts. This would contribute to China's overall global influence in HE and S\&T.

Another impact that may be felt worldwide is China's increasing attractiveness as a study destination. The worldwide demand for students is growing, in particular in the hard sciences, and competition for talent and funding is becoming increasingly stiff. The growing quality and student capacity of Chinese universities, in combination with China's generous scholarship programmes, will likely lead to growing numbers of students opting to go to China for study. This means that China will increasingly train young foreign talents who, as a result, may develop strong ties to China and work in BRI projects in China or in their home countries instead of studying and working in other parts of the world. It could therefore potentially contribute to a growing shortage of skilled workers in other parts of the world. There is currently already a shortage of trained personnel in Europe and the US (McGrath 2019) and many universities expect a future decline in the number of students (Redden 2019). If China succeeds in its aim to link study in China to job opportunities in China or in Chinese projects in BRI home countries, China may become even more attractive as a study destination for young people in BRI countries.

China's plans to align the BRI with HE may, in the long term, also have an impact on international research collaboration. Collaborative research involving China has been growing rapidly over the past decade (Kirby and Van der Wende 2019). This is particularly true for research involving various BRI countries (Baker 2019). While this growth may be insignificant in view of global research output, it is relevant to note that China is succeeding in also developing BRI-HE cooperation with knowledge institutions in 
non-BRI countries. The fact that the UK has not signed up to the BRI has not stopped the British Council and individual British knowledge institutions from engaging in BRI-related programmes, as we have seen above. These developments will strengthen China's relative position in S\&T and will boost global acceptance of the BRI, even if this acceptance is only half-hearted and to benefit from the funding and cooperation it brings.

A final development with a potentially big impact is China's success in involving BRI countries in building an integrated educational community. Through engaging with HE policymakers in BRI countries and providing them with advice and funding, China creates opportunities to access and shape these countries' academic systems in ways that support China's needs and views on governance. Further research is needed to learn if China is also making use of such opportunities.

\section{Conclusion}

The connection between HE, S\&T, and the BRI is comprehensive, but it is still currently in its first phase of development. It is therefore too early to draw far-reaching conclusions. However, based on the research presented in this chapter, it has been possible to identify several trends and discuss preliminary conclusions with regard to the domestic and global impacts of the nexus.

This study shows that the Chinese government is building strong connections between the BRI and HE and S\&T, not only on paper, but also in practice. It also shows that this relationship is symbiotic: policies and actions in the two policy domains strengthen each other. These policy plans and actions are numerous, broad and diverse in scope, and are based on a long-term and strategic vision. Furthermore, and importantly, they are supported by funding. This funding is not only an important pull factor for BRI stakeholders, but also for Chinese knowledge institutions and enterprises.

At the domestic level, the building of the BRI-HE nexus results in an acceleration of the modernization and internationalization of China's $\mathrm{HE}$, a strengthening of China's positioning as a country that exports and shares knowledge, and an expansion of China's pool of well-trained talents. Furthermore, it supports the publicization and realization of the BRI. At the global level it leads to an expansion of China's HE and S\&T cooperation with BRI countries and to a strengthening of China's attractiveness as a study destination. It also leads to the advancement of the Chinese government's aim of building an education community led by China. 
Agency in building the nexus between the policy areas of the BRI, HE and S\&T is diverse. Multiple Chinese national-level CCP organs and government institutions develop the policies that aim to create and strengthen the nexus. Subnational government actors, such as provincial and municipal government policymakers, are urged to develop their own plans, but they are limited in this role by the requirement to stay aligned with the national 'master plan'. Non-state stakeholders such as Chinese universities and enterprises are first and foremost involved in the development and execution of practical policies and plans that closely follow policy guidelines. They are pushed by the requirement to respond to government calls for action and pulled by financial incentives and opportunities that may support their own policy goals. The focus in this chapter has been on Chinese agency and state and non-state policymakers, but it should be noted that Chinese and foreign students, as well as foreign $\mathrm{HE}$ and S\&T organizations, are important actors, too.

\section{Looking Ahead: Challenges and Uncertainties}

The impacts and potential consequences discussed above are based on the assumption that current trends will continue. However, the COVID-19 pandemic that erupted in early 2020 may have a profound impact on the international HE and S\&T landscape. Currently, the pandemic has significantly affected student mobility and the way HE is organized. It has also impacted the implementation of the BRI. Being in the middle of a still unfolding worldwide COVID-19 crisis, it is too early to discuss its broad and long-term consequences on the developments that are the focus of this chapter. It may strengthen the growing apprehension in Western countries of China's increasing global influence in general and the BRI in particular. Although scholars and policymakers emphasize the need to collaborate with China (LAC 2018), concerns about the lack of academic freedom in China and the infringement on research ethics are growing. For example, a recent decision by China to limit the free sharing of research findings with regard to the origins of the COVID-19 virus has seriously damaged trust in China's academic system (Cooper 2020). However, in many countries China's COVID-19 diplomacy, which consisted of offering medical supplies to help with fighting the virus and publicizing efforts to develop medicines and a vaccine against COVID-19, may strengthen positive perceptions of China's global leadership, paving the way for increased cooperation with China on BRI-HE projects. 


\section{References}

ANSO (n.d.). Alliance of International Science Organizations website. Retrieved 3 April 2020 from http://www.anso.org.cn/about/anso/.

Applebaum, Richard P., et al. (2018). Innovation in China: Challenging the Global Science and Technology System. Cambridge: Polity Press.

Bai, Chunli (2018). 'The Road to Innovation'. Bulletin of the Chinese Academy of Sciences, 32(3), 130-132.

Baker, Simon (2019, May 14). 'Is China's Belt and Road Initiative Boosting Academic Links?' Times Higher Education. Retrieved 4 January 2020 from https://www.timeshighereducation.com/news/chinas-belt-androad-initiative-boosting-academic-links.

BRIGC (n.d.). 'Belt and Road Initiative International Green Development Coalition (BRIGC)'. Green Belt and Road Initiative Center website. Retrieved 1 May 2020 from https://green-bri.org/belt-and-road-initiative-green-coalition-brigc.

British CoC (2019). 'Education on the Belt and Road'. British Chamber of Commerce in China website. Retrieved 4 January 2020 from https://www.britishchamber. cn/wp-content/uploads/2019/o2/Education-on-the-Belt-and-Road-Final-0219.pdf British Council (2019). 'UK-China programme to provide seed funding to grow partnership opportunities for British institutions in China, ASEAN and African countries'. British Council website. Retrieved 3 January 2020 from: https://www.britishcouncil.cn/en/programmes/education/seeding? ga $=2.62618858 .7737055^{23} \cdot 15^{88328732-1029684014.1588328732}$

BRSN (2019). Belt and Road Studies Network website. Retrieved 20 April 2020 from http://www.brsn.net/English/index.html.

BRTDP (2018). 'Belt and Road Talent Training Program'. Belt and Road Talent Development Program website, Tsinghua University. Retrieved 5 January 2020 from http://llm.law.tsinghua.edu.cn/beltroad/belt.html.

BRUA (2016). Belt and Road University Alliance website. Retrieved 8 April 2020 from https://en.lzu.edu.cn/static/Belt_Road/.

CC and State Council (2019a). 'Zhongguo jiaoyu xiandaihua 2035' [China education modernization 2035]. Xinhua Wang. Central Committee of the Chinese Communist Party and the State Council of the People's Republic of China. Retrieved 19 December 2019 from http://www.xinhuanet.com/politics/201902/23/c_1124154392.htm.

CC and State Council (2019b). 'Jiakuai tuijin jiaoyu xiandaihua shishi fang'an (20182022)' [Implementation plan for accelerating the modernization of education (2018-2022)]. Central Committee of the Chinese Communist Party and the State Council of the People's Republic of China. Retrieved 27 April 2020 from http:// www.gov.cn/zhengce/2019-02/23/content_5367988.htm. 
Cheng, Si (2019, May 15). 'Young scholars to receive aid for Silk Road research'. China Daily.

China Education News (2017, July 29). 'Yidai yilu rencai peiyang xiao qi lianmeng jiepai' [Belt and Road Talent Training School-Enterprise Alliance unveiled]. Zhongguo jiayu bao [China education news]. Ministry of Education. Retrieved 20 April 2020 from http://www.moe.gov.cn/jyb_xwfb/moe_2082/zl_2017n/2017_ zl38/201707/t20170731_310371.html.

Cooper, George (2020, April 24). 'Chinese State Censorship of COVID-19 Research Represents a Looming Crisis for Academic Publishers'. Retrieved 25 April 2020 from https://blogs.lse.ac.uk/impactofsocialsciences/2020/04/24/chinese-statecensorship-of-covid-19-research-represents-a-looming-crisis-for-academicpublishers/.

D’Hooghe, I. (2015). China's Public Diplomacy. Leiden \& Boston: Brill Nijhoff.

D'Hooghe, I., et al. (2018). Assessing Europe-China Collaboration in Higher Education and Research. Leiden: Leiden Asia Centre.

Fujian Provincial Department of Education (2017, May 16). 'Fujian sheng yu “yidai yilu" yanxian guojia jiaoyu jiaoliu qingkuang de jianyao huibao' [A brief report on the educational exchange between Fujian Province and the countries along the 'Belt and Road']. Ministry of Education, People's Republic of China. Retrieved 25 April 2020 from http://www.moe.gov.cn/jyb_xwfb/xw_zt/moe_357/ jyzt_2017nztzl/2017_zto3/2017_zto3_fj/17zto3_yw/201705/t20170523_305464.html.

Hanban (2015, July 27). 'The First "Confucius Institute of Maritime Silk Road" Established in Thailand'. China Top Universities Admissions Services (CTUAS) website. Retrieved 5 June 2020 from http://www.ctuas.com/Article/news/ id/1437965253.

King, Kenneth (2019). 'China-Africa Education Cooperation: From FOCAC to Belt and Road'. ECNU Review of Education, 1(14).

Kirby, William \& Van der Wende, Marijk (2019). 'The New Silk Road: Implications for Higher Education in China and the West?' Cambridge Journal of Regions, Economy and Society, 12(1), 127-144.

Lee, Donna \& Hocking, Brian (2011). 'Diplomacy'. In Bertrand Badie, Dirk BerkSchlosser \& Leonardo Morlino (eds.), The International Encyclopaedia of Political Science (pp. 659-669). Thousand Oaks, CA \& London: Sage.

Li Yunmei \& Wang Yan (2019). 'Zhongguo renwen jiaoliu pinpai - Luban gongfang jianshe. Tiyan guan xunli' [Sino-foreign cultural exchange brand - Luban workshop construction. Experience hall tour]. Tianjin zhiye yuanxiao lianhe xuebao [Journal of Tianjin vocational schools], 21(3), 122-128.

Linney, Sarah (n.d.). 'How China's Belt and Road Initiative Is Impacting Higher Education on a Global Scale'. QS. Retrieved 6 January 2020 from https://www. qs.com/chinas-belt-initiative-impacting-he-global-scale/. 
McCarthy, Simone (2018, September 27). 'Why Foreign Students along the Belt and Road Are Jostling to Enroll in China's Universities'. South China Morning Post. McGrath, John (2019). 'Analysis of Shortage and Surplus Occupations Based on National and Eurostat Labour Force Survey Data. Shortages and Surpluses 2019'. European Commission.

MoE (2016). Education Action Plan for the Belt and Road Initiative. Ministry of Education, People's Republic of China. Retrieved 5 October 2018 from https:// eng.yidaiyilu.gov.cn/zchj/qwfb/30277.htm.

MoE (2018). Gaoxiao keji chuangxin fuwuyidaiyilu changyixingdongjihua [University science and technology innovation serving the Belt and Road Initiative Action Plan]. Ministry of Education, People's Republic of China. Retrieved January 5 from http://www.moe.gov.cn/srcsite/A16/kjs_gjhz/201901/t20190102_365666.html.

MoE (2019a). Jiaoyubu sanxiang chengguo naru di erjie 'yidai yilu' guoji hezuo gaofeng luntan chengguo qingdan [The three achievements of the Ministry of Education are included in the list of achievements of the second 'Belt and Road' International Cooperation Summit Forum]. Ministry of Education, People's Republic of China. Retrieved 6 April 2020 from http://www.moe.gov.cn/jyb_xwfb/ gzdt_gzdt/moe_1485/201904/t20190428_379826.html.

MoE (2019b, April 25). 'Fuwu “yidai yilu” jiaoyu zai xingdong' [Serve the 'Belt and Road' education in action]. Ministry of Education, People's Republic of China. Retrieved 5January 2020 from http://www.moe.gov.cn/jyb_xwfb/s5147/201904/ t20190425_379436.html.

MoE (2019c, March 7).Jiaoyu bu 2019 nian jiaoyy duiwai kaifang gongzuo yaodian [Key points of the Ministry of Education's 2019 opening up of education]. Ministry of Education, People's Republic of China. Retrieved 6 April 2020 from: http:// www.jsj.edu.cn/n2/7001/12107/1258.shtml.

MOST (2017, July 13). 'Xi Jinping: China Launches Belt \& Road STI Cooperation Action Plan'. Ministry of Science and Technology, People's Republic of China, website. Retrieved 5 June 2020 from http://www.most.gov.cn/eng/pressroom/201707/ t20170713_134067.htm.

National Science Board (2019). 'Publications Output: US Trends and International Comparisons'. Science and Engineering Indicators. Washington, DC: National Center for Science and Engineering Statistics.

NDRC (2015, March). 'Vision and Actions on Jointly Building Silk Road Economic Belt and 21st-Century Maritime Silk Road'. National Development and Reform Commission, Ministry of Foreign Affairs and Ministry of Commerce, People's Republic of China. Retrieved 25 October 2020 from https://web.archive.org/web/20181127225143/ http://en.ndrc.gov.cn/newsrelease/201503/t20150330_669367.html.

NSFC (n.d.). National Natural Science Foundation of China website. Retrieved 1 May 2020 from http://www.nsfc.gov.cn/english/site_1/index.html. 
PBCSF (n.d.). 'BRI EMBA Program'. People’s Bank of China School of Finance, Tsinghua University. Retrieved 20 April 2020 from http://bri.emba.pbcsf.tsinghua. edu.cn/web/program.php.

Peters, Michael A. (2019, May). 'China's Belt and Road Initiative: Reshaping Global Higher Education'. Educational Philosophy and Theory, 52(6), 586-592.

Redden, Elisabeth (2019, November 18). 'Number of Enrolled International Students Drops'. Inside Higher Education.

Rolland, Nadège (2019). 'Mapping the Footprint of Belt and Road Influence Operations'. Retrieved 5 January 2020 from https://sinopsis.cz/en/ rolland-bri-influence-operations/.

Royal Society (2010). New Frontiers in Science Diplomacy: Navigating the Changing Balance of Power. RS Policy document 01/10. London: Science Policy Center.

SABRI (2020). Student Association for the Belt and Road Initiative LinkedIn profile. Retrieved 25 April 2020 from https://www.linkedin.com/company/ tsinghua-sabri/.

Shuto, Motoko (2018). 'Patterns and Views of China's Public Diplomacy in ASEAN Countries: Focusing on Confucius Institutes'. Journal of Contemporary East Asia Studies, 7(2), 124-148.

STCSM (2019). 'Shanghai "Belt and Road" International Cooperation Programme (2019 annual call)'. Science and Technology Commission of Shanghai Municipality. Retrieved 5 January 2020 from http://chinainnovationfunding.eu/project/ shanghai-belt-and-road-international-cooperation-programme-2019-annualcall/.

TMSTB (2017). 'Tianjin shi yidai yilu keji chuangxin hezuo zhuanxiang guanli banfa (shixing): jinke gui [2017] 6 hao' [Tianjin Municipal Science and Technology Commission on Special Management Measures for Tianjin's 'Belt and Road' Technology Innovation Cooperation (Trial)]. Tianjin Science Regulation no. 6. Tianjin Municipal Science and Technology Bureau. Retrieved 12 November 2019 from http://kxjs.tj.gov.cn/zhengwugongkai/zcfg/zcjd/201711/t20171106_133985.html

Tsinghua SPPM (n.d.). 'About IMPA-BRI'. School of Public Policy and Management, Tsinghua University. Retrieved 5 January 2020 from http://www.sppm.tsinghua. edu.cn/english/Admission/IMPAN/IMPABRI/AboutIMPABRI/.

UASR (n.d.). University Alliance of the Silk Road website. Retrieved 25 April 2020 from http://uasr.xjtu.edu.cn/index.htm.

UCMSR (2018). University Consortium of the 21st Century Maritime Silk Road website. Retrieved 18 April 2020 from http://www.ucmsr.com/.

WIPO (2020, April 7). 'China Becomes Top Filer of International Patents in 2019 Amid Robust Growth for WIPO's IP Services, Treaties and Finances'. Retrieved 8 April 2020 from https://www.wipo.int/pressroom/en/articles/2020/article_0005. html. 
Wu, Xuan \& Chan, Wing Kit (2019). 'Integrating International Student Mobility in the Belt and Road Unitiative: From State-Dominated to State-Steering?' Higher Education Evaluation and Development, 13(1), 33-47.

Xi, Jinping (2017a, May 15). 'Speech at Opening of Belt and Road Forum'. Global Times. Retrieved 4 January 2020 from http://www.globaltimes.cn/content/1046925. shtml.

Xi, Jinping (2017b, October 18). 'Secure a Decisive Victory in Building a Moderately Prosperous Society in All Respects and Strive for the Great Success of Socialism with Chinese Characteristics for a New Era'. Report to the 19th National Congress of the Communist Party of China.

Xinhua (2016, December 12). 'Confucius Institutes Lauded in Promoting "Belt and Road" Initiative'. China Daily. Retrieved 3 January 2020 from https://www. chinadaily.com.cn/china/2016-12/12/content_27640662.htm.

Xinhua (2019a, April 26). 'Initiative a "Boulevard” of Innovation for Globe'. Xinhua. Xinhua (2019b, December 12). 'CPEC Has Potential to Revamp Pakistani Education System through Promoting E-learning: Experts'. Xinhua.

Zhang Xiang (2017, December 21). 'Jiangsu Scholarships Lure BRI Students'. China Daily.

\section{About the Author}

Dr. INGRID D'HoogHE is sinologist and a researcher at the LeidenAsiaCentre, China lecturer at Leiden University, and senior associate fellow at the Clingendael Institute of International Relations. For the LeidenAsiaCentre she has studied cooperation in the field of research and higher education between China and the EU/Netherlands (LeidenAsiaCentre 2018, update September 2019, follow-up study to be published October 2020). Her fields of interest include China's foreign policy and diplomacy, China and global governance, and China's Belt and Road Initiative. Major publications include the monograph China's Public Diplomacy (Brill/Nijhoff, 2015) and the coauthored report 'Assessing China - EU Collaboration in HE and Research'. 


\title{
3 Trade, Tax, and Development Finance
}

\author{
Understanding China's Choice of BRI Agreements and \\ Institutions
}

Michael Sampson, Jue Wang and Irma Mosquera Valderrama

\begin{abstract}
Chapter 3 examines the decisions that inform the BRI's institution building. It explores the tension between strategic and efficiency-oriented concerns, tracing these tensions across three issue areas: tax, trade, and development finance. The chapter shows that, in dealing with challenges, the Chinese government lacks an integral governance framework that systemically coordinates all relevant institutions. Instead, it takes varied institutional approaches to overseeing BRI projects, ranging from bilateral trade agreements to multilateral financial institutions. This raises the question of what is driving China's development of agreements and institutions for the BRI. The chapter argues that China's development of BRI tax initiatives is mostly motivated by efficiency drivers, its trade agreements with key BRI partners by strategic drivers, and its efforts to establish multilateral financial institutions by both drivers.
\end{abstract}

Keywords: Belt and Road Initiative, agreements, institutions, trade, tax, development finance

\section{What Is Driving the Belt and Road Initiative?}

There has been much academic and policy debate around the factors driving the Belt and Road Initiative (BRI) in recent years: Is the BRI an attempt by China to dramatically improve its power position in Asia? Or is it simply a mechanism by which China can support its own economic growth by providing markets for exports and returns on its investments? (De Soyres et al. 2019; Rahman \& Shurong 2017; Wang 2016) This debate has tended to operate at a high level

Schneider, Florian (ed.), Global Perspectives on China's Belt and Road Initiative: Asserting Agency through Regional Connectivity. Amsterdam, Amsterdam University Press 2021 DOI: $10.5117 / 9789463727853$ CHO3 
of generality, with less attention paid to precise mechanisms of cooperation in specific issue areas. This is partly due to the amorphous nature of the BRI project itself and partly due to its relatively recent emergence, rendering it difficult to draw definitive conclusions. This chapter provides a framework for a more precise resolution of this debate. It shows that strategic factors have more relevance in particular issue areas that fall under the umbrella of BRI cooperation whilst in other areas economic factors are much more prominent.

In this chapter we provide an analysis of three specific issue areas of cooperation under the BRI: trade, taxation, and development finance. We develop a new framework to understand why China has adopted the particular institutional approaches that it has in each issue area. By doing so, we draw more precise conclusions about the future impact of the BRI more broadly. We show that Beijing's approach has often been driven by a concern to reduce transaction costs and maximize economic advantage in its economic cooperation with BRI partners. ${ }^{1}$ We refer to these factors as the efficiency drivers of China's approach to cooperation. However, broader geopolitical concerns have also played a significant role in Beijing's approach in some instances. We refer to these factors as the strategic drivers of China's behaviour. In the following analysis we show that the priority given to each of these types of factors varies across the three issue areas. In the area of trade, broader political and strategic concerns are relatively more prominent in shaping China's institutional design choices. In the area of taxation, both strategic desires and the need to reduce transaction costs are equally important considerations. In the area of development finance, we find it particularly interesting that China has recently engaged with some multilateral development finance institutions (MDFIs), despite the greater convenience of using existing domestic institutions to finance and coordinate BRI projects, suggesting a hybrid approach in this area. China's behaviour combines strategic considerations with a concern for avoiding loss and/or maximizing the return on China's investments. In the next section we introduce the theoretical framework and define both strategic and efficiency drivers of institutional design. We then turn to area-specific analyses, providing an overview of developments, along with some of the challenges presented by cooperation in each area. In every section we draw conclusions about the most important factors driving China's behaviour. We then conclude by drawing inferences about the future impact of the BRI across these issue areas and more broadly.

1 We use 'Beijing' throughout this chapter as shorthand to refer to the central government of the PRC. 


\section{Efficiency and Strategic Concerns}

In any cooperative endeavour, state behaviour is driven by a mix of strategic and efficiency concerns, which can be thought of as concerns for gains that are either relative (how one's position can be improved vis-à-vis others) or absolute (how one's present position can be improved vis-à-vis one's own past position) (Powell 1991). But whilst recognizing this complex reality, we can be more precise about when and where each consideration wins out over the other. In the following section we operationalize efficiency (absolute gains) concerns as a desire to reduce transaction costs resulting from economic exchange. Transaction costs can be thought of as the costs incurred in the process of economic transaction between two or more parties or the 'economic equivalent of friction in physical systems' (Williamson 1985: 19). These costs can be reduced by concluding an agreement, providing certainty about the future and removing the need for repeated bargaining. In general, the more comprehensive the initial institution or contract between the parties, the greater the certainty about the future relationship. This in turn tends to mean that the costs incurred from each iterated transaction are minimized.

Where efficiency (i.e. the reduction of transaction costs) is not the driving concern, the creation and design of cooperative institutions or contracts may instead be driven by broader political or strategic considerations. Therefore, where an agreement is inefficient and limited (compared to the available and feasible alternatives) we conclude that political or strategic drivers are the primary driving force. In practice this means that agreements that result in residual uncertainty about future behaviour are more likely to be driven by strategic concerns. We define these strategic concerns as the desire to maximize the relative power position of China vis-à-vis its BRI partners.

In terms of analysing China as an actor, we find that the most fruitful approach also differs across issue areas. In international trade China can often be treated 'as if' it is a unitary actor without loss of specificity or insight, given that policy is largely influenced by two central government departments; the Ministry of Commerce (MOFCOM) and the Ministry of Foreign Affairs (MOFA). ${ }^{2}$ In finance, because this is an area in which there are a much broader variety of actors and more arm's-length institutions

2 In this sense we adopt a unitary actor assumption for China in trade, an assumption which whilst not a precise description of reality, does allow the development of useful insights. On the relationship between assumptions and description, see Friedman 1953: 8. On the unitary actor assumption in international relations, see Wendt 2004. 
operating on behalf of the government, a reduction in theoretical parsimony is warranted in order to capture the relevant factors shaping China's behaviour in this area. In tax meanwhile China's international tax policy is centralized with the main actor being the State Administration of Taxation (SAT). SAT has participated actively in OECD-, G20-, and UN-level discussion of multilateral tax initiatives to deal with base erosion and profit shifting by multinationals. SAT is also responsible for introducing regulations to deal with transfer pricing and related tax disputes. China has also created its own Belt and Road Initiative Tax Administration Cooperation Mechanism (BRITACOM) with BRI countries. The council of the BRITACOM, which is the decision-making body, is chaired by the Commissioner of the SAT.

\section{Cooperation in Trade}

From the inception of the BRI, it was envisioned as a mechanism to stimulate cooperation in infrastructure, development, finance, social and cultural exchanges, and investment and trade (Johnston 2019: 42). Given the centrality of trade to the BRI, how should we understand the cooperation occurring in this area since the launch of the initiative in 2013 ? Has China's institutional approach been driven primarily by strategic or efficiency concerns?

It is important to note that even prior to the launch of the BRI, China was party to eleven trade agreements, including a major agreement with the Association of Southeast Asian Nations (ASEAN). It was also already in the process of negotiating a broader regional pact with fifteen states in the Asian Pacific, in the form of the Regional Comprehensive Partnership (RCEP). Participant countries in these negotiations were Australia, Brunei, Cambodia, China, India, Indonesia, Japan, Laos, Malaysia, Myanmar, New Zealand, the Philippines, Singapore, South Korea, Thailand, and Vietnam (Baltensperger and Dadush 2019:2). These agreements are the result of the great deal of energy that Beijing has devoted to concluding trade deals since China's entry into the World Trade Organization (WTO) in 2001, particularly with regional partners. Though it remains difficult to precisely delineate which states actively participate in the BRI at any particular time, one study suggests that of the 44 countries that either have, or are planning, trade agreements with China, 29 also participate in BRI. Of these, sixteen are party to completed trade deals or began negotiations before the BRI was launched in 2013 (Baltensperger and Dadush 2019: 4-5). In addition to the major trade agreement with ASEAN (encompassing ten countries), China is party to bilateral trade agreements with the BRI countries Georgia, 
Pakistan, and Singapore and has concluded agreements with the territories of Hong Kong and Macao.

Interestingly, unlike other major trading powers, such as the EU, the US, or Japan, which tend to conclude broad and deep trade agreements, China has engaged in an ongoing negotiating process to expand and deepen existing agreements. This is an approach that decreases the relative efficiency of the negotiating process by increasing the number of negotiations and therefore the negotiation costs incurred. This approach also increases uncertainty by leaving many details of the initial agreements to subsequent negotiations. Therefore, compared to agreements that are comprehensive from the start, it is unclear what the implications of the final versions of China's trade agreements will be for the economic sectors involved. Such an approach also maximizes the opportunity costs of concluding comprehensive agreements from the start whilst increasing China's bargaining leverage over time. ${ }^{3}$

Alongside the reductions in tariff and non-tariff barriers that result from these formal trade agreements, improving trade facilitation is also an important part of the BRI for China (Wei et al. 2018: 1233). Trade facilitation can be broadly defined as an effort to simplify and harmonize international trade procedures to increase the efficiency of cross-border trade. Trade facilitation was formalized as part of the WTO Trade Facilitation Agreement (TFA), which was negotiated in 2013 and entered into force in 2017. Prior to this, a 2015 BRI document titled 'Vision and Actions on Jointly Building Silk Road Economic Belt and 21st-Century Maritime Silk Road' stated:

Countries along the Belt and Road should enhance customs cooperation such as information exchange, mutual recognition of regulations, and mutual assistance in law enforcement; improve bilateral and multilateral cooperation in the fields of inspection and quarantine, certification and accreditation, standard measurement, and statistical information; and work to ensure that the WTO Trade Facilitation Agreement takes effect and is implemented. (NDRC 2015; Johns et al. 2018: 12)

However, not all BRI participant states are party to the TFA because some are not WTO members; of 71 BRI countries, 58 are WTO members. Of

3 As an illustration of this point: China's trade agreements often initially only entail liberalization of trade in goods, with subsequent services agreements concluded some years later. As such the benefits of trade cooperation in services during that intervening period are lost - this is the opportunity cost. This approach also has the effect of increasing China's bargaining power, given its comparatively higher levels of economic growth and growing dependence of its trade partners. See Sampson 2019 . 
these members, as of 2018 , four have not ratified the TFA. As such, there remains scope for improvement for BRI participants on this front (Johns et al. 2018: 22-24). Trade facilitation initiatives from BRI countries are meanwhile also taking place outside of formal trade agreements. Efforts to improve transport facilitation have taken place under the auspices of the Shanghai Cooperation Organisation (SCO) and as part of the Central Asia Regional Economic Cooperation (CAREC) initiative led by the Asian Development Bank, China, Pakistan, Georgia, Azerbaijan, and seven other Central Asian countries. A treaty on facilitation of cross-border paperless trade in Asia and the Pacific was also concluded in 2016 (Ramasamy et al. 2017:14-15).

In addition to multilateral cooperation in trade, there are six main economic corridors that constitute the broader BRI: the New Eurasian Land Bridge Corridor, the China-Central Asia-West Asia (CAWA) Corridor, the China-Pakistan Corridor, the China-Russia-Mongolia Corridor, the Bangladesh-China-Myanmar Corridor, and the China-Indochina-Peninsula Corridor (Brookings 2019). It would be incorrect to assume that the level of trade cooperation and integration in each of these corridors is uniform, and in fact there is wide variation. In particular, the China-Pakistan Corridor (the only bilateral corridor) and the China-Indochina Corridor are supported by pre-existing trade agreements with Pakistan and ASEAN, respectively. In the remaining corridors no formal trade agreements exist, and the CAWA Corridor is perhaps the least well integrated as a group of countries in terms of formal trade institutions (Ramasamy et al. 2017: 18).

With respect to Pakistan, there has been cooperation in trade in which China is a crucial export destination and import source for Pakistan. In addition to this, China has also made a large number of investments in crucial infrastructure projects in Pakistan in recent years. Pakistan's level of dependence is therefore high and continues to grow (Ramasamy et al. 2017: 30). This asymmetrical relationship is exacerbated by the sequential negotiation of elements of the trade agreement. The agreements on goods and services were negotiated separately and eight rounds of trade negotiations have occurred under Phase II of the initial agreement. These culminated in negotiations to upgrade the deal in late 2016, despite Pakistan's hesitancy regarding deepening the trade relationship further (Haider 2015). Under Phase I of the agreement, Pakistan introduced zero tariffs on $35 \%$ of China's products, while China has reduced duties to $0 \%$ on $40 \%$ of Pakistan's products. Pakistan has requested revision of existing elements of the treaty because it argues that the agreement brings few economic advantages (Sampson 2019). However, given the deepening strategic relationship between 
the two states and the importance of China's investments, it is difficult to see Pakistan genuinely resisting a deepening of trade integration with China or resisting the BRI more generally. Indeed, in 2018 Pakistan had an annual trade deficit with China of over US $\$ 12$ billion. This was before the second phase of the trade agreement came into effect at the end of 2019 (Sampson 2020).

\section{Challenges in Trade}

One of the driving forces of the BRI was arguably the strategic challenge presented by the American-led Trans-Pacific Partnership (TPP) (Vines 2018: 343; Wang 2016). Though this threat to Chinese influence appears to have receded, there remain other challenges to the success of the BRI as an initiative that serves to expand China's political influence alongside its exports and investments. These challenges can be placed into two categories: technical and political.

First, there are a number of technical challenges to the success of the BRI. BRI states are becoming increasingly important players in world trade. In 2015 , they accounted for around $37 \%$ of world exports, up from $21 \%$ in 1995. With respect to the global value chain, BRI states tend to be focused on exporting mainly intermediate, rather than finished, goods and they account for a $42 \%$ share of world intermediate exports (Boffa 2018: 5) Yet despite the growing importance and interconnectedness of the BRI economies, the majority remain developing countries and as such there are still numerous technical inefficiencies that need to be resolved if the BRI is to succeed. The customs procedures in many participant countries, for example, are still outdated. This is true in all six economic corridors to varying extents. In many cases extensive customs documentation is still required for crossborder trade. This documentation process is also not supported by modern ICT infrastructure in a number of locations. In addition, there is a continued lack of harmonization of standards both within, as well as between, BRI countries (Ramasamy et al. 2017: 42)

Alongside these non-tariff issues, trade barriers between China and many BRI participants remain significant, particularly in sensitive areas such as textiles and agriculture (Cui \& Song 2019: 41). The conclusion of further trade agreements and increased coordination on trade facilitation will help to ameliorate these problems. However, there is still a long way to go in this regard. These processes will take time and progress will likely remain inconsistent. As an illustration of this, whilst there is evidence that customs and border agencies within many BRI countries are improving in terms of 
efficiency, performance in some areas has actually declined, specifically on the China-Pakistan and Bangladesh-China-India-Myanmar Corridors (Johns et al. 2018: 31). In all of the main BRI corridors, apart from the New Eurasian Land Bridge Corridor, the time that it takes to export and import goods is still above the global average. In some corridors, the time taken is well above this average (Johns et al. 2018: 29). In terms of efficiency, trade cooperation between BRI countries looks set to lag far behind cooperation in North America and Europe for quite some time.

In addition to these tricky and ongoing technical challenges, there are also the perhaps more difficult political and strategic challenges of sustaining and deepening trade cooperation between countries with vastly different economies, cultures, political systems, and geopolitical interests. There is already evidence of pushback in key partner countries such as Pakistan. In 2018, for example, Pakistan's newly elected Prime Minister Imran Kahn pledged to renegotiate agreements reached as part of the China-Pakistan Economic Corridor (CPEC) because these 'unfairly benefit Chinese companies' (Economic Times 2018).

\section{Driving Factors in Trade}

In evaluating the forces driving Beijing's approach to trade, a distinction should be drawn between multilateral cooperation around trade facilitation, which seems to be driven primarily by concerns to minimize the transaction costs involved with cross-border trade with BRI partners, and China's bilateral trade cooperation. Particularly in terms of China's bilateral trade agreements, strategic concerns seem to be significant, given the way in which China's sequential and drawn out negotiating approach increases uncertainty and negotiating costs. China's agreements often do not cover 'substantially all trade' with partner countries, and they incorporate large lists of exemptions and relatively shallow liberalization (Sampson 2019). ${ }^{4}$ At the same time the negotiations are structured in a way that maximizes China's leverage over time and are often linked to security cooperation (the case of Pakistan is a particularly prominent illustration of this). If anything, then, China's trade agreements with BRI partners do not substantially reduce uncertainty and often leave much to future negotiations.

4 GATT Article XXIV requires that free trade agreements entail 'duties and other restrictive regulations of commerce [...] are eliminated on substantially all the trade between the constituent territories in products originating in such territories'. 


\section{Cooperation in Tax}

With the BRI, China is strengthening its position as a capital export country by facilitating Chinese investment in the countries along the BRI (Europe and outside Europe). In order to strengthen this position, China is participating in already existing bilateral and multilateral tax initiatives and creating new institutional frameworks for BRI countries.

In the past, China focused on attracting investment by multinational companies into China, acting as a capital import country. However, the benefits of these activities for China's tax revenue were limited. This was due to the excessive number of tax/investment incentives in China and also due to 'base erosion profit shifting' (BEPS), a term that describes a practice where multinationals move their profits to locations with low taxes through aggressive tax planning and transfer pricing.

The BRI provides investment opportunities for Chinese companies and foreign companies in capital export countries along the BRI. These opportunities are in different sectors such as infrastructure, energy and resources, industrial development, and the financial sector. These activities will be subject to taxation in China and abroad. This means, therefore, that China's network of tax treaties will become relevant to prevent double taxation.

China has concluded more than a hundred bilateral tax treaties to prevent double taxation and tax avoidance. Approximately 50 of these tax treaties are with BRI countries (Meyer-Nandi et al. 2018). Furthermore, to tackle the base erosion profit shifting (BEPS) practices discussed above, China has participated as a member of the G2o in the OECD-G2o BEPS Project. ${ }^{5}$ In 2015, the BEPS Project introduced fifteen Actions to tackle aggressive tax planning. These included a 'Multilateral Convention to Implement Tax Treaty Related Measures to Prevent Base Erosion and Profit Shifting' ('Multilateral Instrument'), which has been in force since July 2018. China has signed this Multilateral Instrument and has expressed its intention to make this instrument applicable to almost all of the bilateral tax treaties that it has concluded (102 of 106 of its tax treaties) (OECD 2018a). This Multilateral Instrument is still pending ratification by China and therefore it has not yet entered into force there. ${ }^{6}$

5 The G2o is a political forum of governments with countries from Asia, North America, the Middle East and Europe. Following the 2008 economic crisis, the G2o has set an agenda for a higher level of international tax cooperation, e.g. G2o Summits in Los Cabos (Mexico), Washington (the United States), London (the United Kingdom) and Pittsburgh (the United States).

6 Status signatories and parties to the BEPS MLI as of 22 July 2020 retrieved 3 August 2020 from http://www.oecd.org/tax/treaties/beps-mli-signatories-and-parties.pdf. 
China is also actively taking part in the UN Committee of Experts on International Cooperation in Tax Matters. This committee aims to provide solutions to the problems faced by developing countries, including the practices of base erosion profit shifting. In some of the meetings of the UN Committee of Experts on International Cooperation in Tax Matters, for example, China has indicated that currently it does not have a system which quantitatively analyses its base erosion. However, it has also stated that: 'We do find, and it is obvious, that the major threat China faces is that many [multinational enterprises] have shifted their profits by means of tax planning and transfer pricing' (United Nations 2014: 1).

To address these initiatives in a coordinated way, in 2017 China signed a Memorandum of Cooperation (2017) alongside the other member countries of the BRICS groups of nations. ${ }^{7}$ The aim of this memorandum is to coordinate these nations' responses in international forums (such as the OECD, the United Nations) and to enhance knowledge sharing regarding BEPS implementation through the exchange of experiences on best practices.

\section{Challenges in Taxation}

The following paragraphs will address the challenges faced by China, BRI countries, and supranational organizations (such as the EU) in the implementation of international tax initiatives and BRI. These challenges are 1) increasing capacity building of tax administrations to deal with transfer pricing and related tax disputes and 2) enhancing transparency and a level playing field between China and BRI countries.

Despite China's participation in bilateral and multilateral initiatives, China's tax administration faces challenges implementing measures to deal with base erosion profit shifting because of its lack of administrative capacities. One challenge is the lack of comparable companies (i.e. a company carrying out similar economic/business activities) to make transfer pricing analysis (Avi Yonah \& Xu 2017). ${ }^{8}$ Another challenge is the number of tax/investment disputes, leading to uncertainty and unpredictability for

7 BRICS is an acronym for a group of five countries: Brazil, Russia, India, China and South Africa. The main objective is to cooperate to address common problems. Retrieved 3 August 2020 from https://infobrics.org/.

8 Avi-Yonah and $\mathrm{Xu}(2017)$ have stated that 'Chinese tax authorities makes their judgment by auditing MNE groups' annual filing and reviewing their contemporaneous documentation, considering the profit levels of the industry and comparable companies, and performing functional analysis. They then make adjustments as necessary when their judgment is made.' 
investment in China (Xu 2018a). In order to address these challenges, the State Administration of Taxation (SAT) has introduced new transfer pricing regulations and it has created additional resources for dispute settlement disputes (MAP and APAs ${ }^{9}$ ).

The SAT has introduced a transfer pricing regime that 'is now a more rigorous and comprehensive framework for regulating transfer pricing arrangements of multinational enterprises (MNEs) in China, both for inbound and outbound activity' (Cheng et al. 2019; Beng Teoh \& Wang 2019). In addition to this, a third division has been created within the SAT to assist in the handling of transfer pricing disputes. ${ }^{10}$ In this regard, Cheng et al. (2019) stated that:

$[\mathrm{P}]$ reviously, SAT resources for these matters were stretched, due to the commitment of relevant personnel to BEPS meetings from 2013 to 2015. With the new organizational structure and resources, the SAT has begun to deal with a large number of MAP cases as a matter of priority. Market intelligence indicates that a number of pending MAP cases have been reactivated with the aim of reaching an expedited solution. On the APA front, it is expected that the enhanced process introduced by the 2016 legislation (i.e. Announcement 64) will contribute to more rapid programme outcomes; this is important as the number of applications continues to increase.

Alongside these changes made by the SAT, to deal with these challenges and address the implementation of the BRI, China has launched the Belt and Road Initiative Tax Administration Cooperation Mechanism (BRITACOM). BRITACOM consists of 34 member countries, eleven countries that are observers from different regions (e.g. Asia, Africa, Europe), and one non-profit (academic) organization.

However, companies do not disclose the information, and therefore, according to these authors, 'it is unrealistic to find comparables from the over 2000 listed companies in China'.

9 A mutual agreement procedure (MAP) is a 'means through which tax administrations consult to resolve disputes regarding the application of double tax conventions'. An Advance Pricing Agreement (APA) is an 'arrangement that determines, in advance of controlled transactions, an appropriate set of criteria (e.g. method, comparables and appropriate adjustments thereto, critical assumptions as to future events) for the determination of the transfer pricing for those transactions over a fixed period of time'. Glossary (OECD 2017: 23, 28).

10 According to Cheng et al. (2019): 'There had previously been much concern that the backlog of MAP cases was affecting the processing of APA applications (MAPs and APAs are dealt with by a common team at the SAT level).' 
One of the aims of BRITACOM is to build capacity and to facilitate cooperation between the participating countries' tax administrations. In addition, BRITACOM aims to facilitate trade and investment, foster the economic growth of the BRI jurisdictions, and contribute to the fulfilment of inclusive and sustainable development as set out in the United Nations' 2030 Agenda for Sustainable Development.

In April 2019, BRITACOM countries agreed on an Action Plan for 2019-2021. According to this Plan, BRITACOM will commit 1) to the dissemination of good practices, 2) to identifying emerging issues that require joint actions, and 3 ) to seeking innovative solutions through tax administration cooperation. Furthermore, BRITACOM will contribute 4) to establishing a dialogue with business and 5) to providing more certainty by building a knowledge-sharing platform that informs investors of the interpretation and application of tax laws. BRITACOM will also 6) conduct research 'on tax certainty to identify problems, seek for solutions, increase predictability and consistency in the application of tax laws and tax treaties, as well as in tax administration practices.' ${ }^{11}$

Under the framework of BRITACOM, two new networks have been created. The first of these is the BRITACOF, which is

a non-profit official event, [which] aims to provide a platform for facilitating dialogue, strengthening cooperation in tax administration, and improving capacity building for jurisdictions, international organizations, academic institutions, businesses and other stakeholders who are willing to be involved in tax administration cooperation along the Belt and Road. ${ }^{12}$

The first BRITACOF conference took place in April 2019 and the second will take place in May 2021. ${ }^{13}$

The second network is BRITACEG, which consists of 'willing Member [tax administrations] TAs and Observers of the Council which, making full use of their existing training institutions or expertise, are dedicated to conducting tax-related training, research and technical assistance programs.' ${ }^{14}$ Through

11 Retrieved 3 August 2020 from http://www.chinatax.gov.cn/eng/n426o859/c5112272/5112272/ files/coae127d146f47aab6199320e37aee1d.pdf.

12 Retrieved 3 August 2020 from http://www.chinatax.gov.cn/eng/n4154446/common_article. html.

13 Postponed due to COVID-19. Retrieved 3 August 2020 from http://www.chinatax.gov.cn/ eng/n426o854/c5149476/content.html.

14 Retrieved 3 August 2020 from http://www.chinatax.gov.cn/eng/n4154453/common_article. html. 
this network, training courses, technical assistance, and academic research and exchange will be carried out to facilitate tax administration cooperation amongst the BRI jurisdictions.

This cooperation established in the Action Plan agreed upon by BRITACOM member countries only started recently (in 2019). It is therefore too early to evaluate this framework of cooperation. However, important elements addressed in the Action Plan, such as providing certainty for investors and facilitating cooperation between tax administrations, also need to be reinforced with initiatives to enhance transparency in the BRI process for investors outside of China. It is important to consider the concerns that have been expressed by the business sector regarding bilateral approaches to BRI that can undermine the EU as a business partner.

The EU sees the BRI as an opportunity for business in Europe. However, there are important changes that need to be made to the BRI in order to level the playing field between EU and Chinese companies. In an EU-China strategic outlook, the EU labelled China

as a cooperation partner with whom the EU has closely aligned objectives, a negotiating partner with whom the EU needs to find a balance of interests, an economic competitor in the pursuit of technological leadership, and a systemic rival promoting alternative models of governance. (EU Commission 2019:1)

One of the concerns of the EU is with the way in which some EU countries have endorsed the BRI. Some EU countries have endorsed the BRI, for instance, under the $17+1$ cooperation format signed by twelve EU member states and five western Balkan states. Others, such as Italy, Poland, and Hungary, have endorsed it through the use of a MoU with China. ${ }^{15}$ The Memorandum of Understanding $(\mathrm{MoU})$ signed between Italy and China, for example, aims to advance cooperation in transport, logistic, and infrastructure projects in the BRI, to expand trade and investment, and to strengthen bilateral communication and coordination on fiscal, financial, and structural reform policies in order to create a favourable environment for economic and financial cooperation (Memorandum of Understanding 2019b). However, adopting a bilateral position in this way reduces the role that the EU can play as a partner when dealing with China in the framework of the BRI (Van der Eijk \& Pandita Gunavardana 2019). 
Furthermore, for the EU and business associations there is a general lack of transparency in BRI investments that also affects taxation. This was highlighted in a recent BusinessEurope report (BusinessEurope 2020). The report refers to a 2018 study (Hanemann et al. 2019) that shows how, despite the $17+1$ cooperation format, 'Chinese investments in Central and Eastern EU Member States have remained low. In 2018, only $2 \%$ of all Chinese FDI into the EU was invested in Eastern European Member States' (BusinessEurope 2020: 151). This report also states that:

A 2018 survey amongst European businesses active in China demonstrated that $45 \%$ of the businesses do not see any opportunities in participating in the BRI. The survey furthermore demonstrated that many European companies are excluded from participating in the BRI because of preferential treatment of Chinese contractors, insufficient information available regarding potential projects and a lack of transparency in public procurement and tendering. (BusinessEurope 2020: 150)

Following this report, European Commissioner for Trade Phil Hogan emphasized the need to reinforce EU competitiveness and to ensure that competition is also fair in China and abroad (Hogan 2020). Thus, the benefits of the BRI for European business remain to be seen. Therefore, the actual commitment to the BRI of those countries that have either signed a MoU or endorsed it under a framework of cooperation $(17+1)$ should be closely examined.

Chinese companies carrying out BRI activities in the EU can also be susceptible to the state aid and (fair competition) tax procedures in the EU. ${ }^{16}$ According to the EU Commission, 'State aid is defined as an advantage in any form whatsoever conferred on a selective basis to undertakings by national public authorities. ${ }^{17}$ This advantage may distort fair competition and affect trade between EU countries. In 2017, China therefore concluded a MoU with the EU concerning dialogue about the state aid control regime and the Fair Competition Review System (Memorandum of Understanding 2019a).

In case that an EU country has provided an advantage to a selective group of (Chinese) companies, this advantage will be assessed in light of the EU state aid rules. This was the case in 2018, when the EU Commission

16 For the implications of EU tax rules in China, see Masseglia Miszczyszyn et al. 2020.

17 Retrieved 3 August 2020 from https:/ec.europa.eu/competition/state_aid/overview/ index_en.html. 
launched a state aid investigation into the Hungarian government's $€_{45}$ million investment aid given to the chemical company BorsodChem Zrt (a subsidiary of the Wanhua Industrial Group). In this case, the Commission assessed this investment aid based on the Guidelines on Regional State Aid for 2014-2020. These guidelines 'enable member states to support economic development and employment in EU's less developed regions and to foster regional cohesion in the Single Market' (EU Commission 2018). The Commission found that:

Without the public funding, the project would not have been carried out in Hungary or any another EU Member State, as it would have been cheaper for the beneficiary to continue importing aniline from the group's existing production plants in China. The Commission also found that the aid is limited to the minimum necessary to make the project sufficiently profitable for the company to decide to make the investment. (EU Commission 2018)

Blockmans and Hu suggested that with the approval of this investment 'the legal obstacles that the Belt and Road Initiative (BRI) had encountered in the single market of the EU were removed to serve the "community interest"' (Blockmans \& Hu 2019). They go on to state that:

While the Commission concluded that the investment in BorsodChem was not economically sound, it found that the aid would not unduly distort competition in the single market but rather help job creation, regional development and the attainment of environmental objectives. (Blockmans \& Hu 2019: 3)

\section{Driving Factors in Tax}

China has engaged actively with the OECD and the UN in implementing bilateral and multilateral tax initiatives to address international tax cooperation. This engagement has included exchanging information, preventing double taxation, and tackling aggressive tax planning. These initiatives are also of importance in the BRI since investors in the BRI will also have to deal with international taxation. Furthermore, in the framework of the BRI, China has set up an institutional framework for cooperation between BRI tax administrations, namely the BRITACOM and the two additional networks BRITACOF and BRITACEG. By contributing to these international initiatives and setting up its own institutional cooperation 
framework, China aims to foster economic growth, facilitate international tax cooperation, and assist BRI partners as they build capacities in their tax administrations.

Following these developments, it may be argued that China has engaged in these multilateral tax initiatives because of efficiency concerns - to reduce transactions costs by increasing cooperation between tax administrations participating in BRITACOM, and to increase the administrative capacity of the Chinese State Administration of Taxation (SAT) in dealing with transfer pricing disputes.

For some researchers and government officials (Blockmans \& Hu 2019), the BRI also appears to be a grand geopolitical strategy from China. This view holds that China seeks to achieve strategic aims by introducing its own mechanisms of cooperation with some EU countries. A number of problematic elements of the BRI are highlighted by countries and businesses. One is that it is neither clear nor transparent what benefits the BRI provides for participating countries. For instance, one concern from the EU regards China's use of MoUs, as well as certain other mechanisms of cooperation (such as the 17+1) with some EU countries. This diminishes the role of the EU as a partner in the BRI and increases the perception that EU businesses participating in the BRI lack an equal playing field when it comes to its benefits. Therefore, the challenge for China is to demonstrate that the BRI does not just bring economic benefits and increased investment for Chinese companies but also for foreign companies based in participating countries.

\section{Cooperation in Development Finance}

A wide range of development finance institutions are involved in BRI projects. They perform two main functions: financing and project management. These two functions are not exclusive from each other, because good project management ensures financial returns, and the two together form a sustainable mechanism of development finance. Several domestic Chinese institutions play a key role in financing and managing BRI projects. These institutions include policy banks and state-owned commercial banks, sovereign wealth funds and state-owned investment companies, as well as state-owned enterprises (SOEs). They are aligned with China's state strategy for the medium- and long-term development and they function as the state's financial tools for overseas development projects. Apart from the Silk Road Fund, most of these institutions were already active in overseas investment before the BRI was announced. 
Meanwhile, China has engaged in new MDFIs in order to strengthen BRI cooperation. In 2016, China led the establishment of the Asian Infrastructure Investment Bank (AIIB), which focuses on long-term infrastructure development in Asia. AIIB projects often share common geographical locations and development objectives with BRI projects. In addition, the Chinese Ministry of Finance is in the process of establishing the Multilateral Cooperation Center for Development Finance (MCDF). This is an institution that supports and coordinates BRI cooperation and in which the members (other than the ministry itself) are all MDFIs. This raises two questions: First, why does China engage with multilateral institutions despite the greater convenience of using domestic agencies for achieving BRI objectives through bilateral investment? Second, has China's multilateral institutional approach been driven primarily by strategic or efficiency concerns?

The Chinese policy banks and state-owned commercial banks are the most important financiers of the BRI. They provide finance for Chinese SOEs and foreign governments and corporations that are involved in BRI projects. The China Development Bank (CDB) is the world's largest development bank by total assets, and it is also one of the most active financial creditors of energy and infrastructure projects under the BRI (Carrai 2018; Sanderson \& Forsythe 2013). By March 2019, the CDB had directly provided financing of over US $\$ 190$ billion for more than 600 BRI projects (Reuters 2019). Meanwhile, the loans provided by the Export-Import Bank of China (Eximbank) for the BRI amounted to a combined value of US\$149 billion by April 2019 (Xinhua 2019a). Unlike the CDB, Eximbank also provides concessional loans and export buyer's credit for the countries that are involved in the BRI (Zhang 2018).

China's state-owned commercial banks, led by the 'Big Four' - the Industrial and Commercial Bank of China, the China Construction Bank, the Agricultural Bank of China, and the Bank of China - are also active financiers of BRI projects. This is especially the case for the Industrial and Commercial Bank of China and the Bank of China, which by April 2019 had respectively provided more than US $\$ 130$ billion and US $\$ 100$ billion for BRI projects (Xinhua 2019b). The Big Four have also initiated varied programmes in BRI countries based on their expertise. For example, the Bank of China has issued the largest amount of BRI-themed bonds to raise low-cost funding for medium- and long-term projects (Zhang 2019; Jiang 2019). The Agricultural Bank of China has particularly supported Chinese agricultural corporations to 'go out' and pursue overseas mergers and acquisitions as well as other forms of international cooperation (Trade Finance 2019). The China Construction Bank has developed various financial products to match 
the needs of infrastructural projects at different stages of construction. Meanwhile, the Industrial and Commercial Bank of China has initiated the Belt and Road Inter-bank Regular Cooperation Mechanism that brings together 94 financial institutions from $5^{1}$ countries for co-financing and other forms of collaboration (Hu at al. 2019).

Another source of financing for BRI projects is the Silk Road Fund. This is a medium- and long-term development and investment fund, established based on the investment from a number of state agencies. The fund carries out equity and debt investment for infrastructure, resources and energy development, industrial capacity cooperation and financial cooperation under the BRI and it also invests in other funds. Meanwhile, China Investment Corporation is a sovereign wealth fund responsible for managing part of China's enormous exchange reserves. It has increased its investment in the BRI regions, especially focusing on 'new infrastructure projects' such as telecommunication and digitalization (China News 2019). A further provider of funding for BRI projects is CITIC Group, a Chinese state-owned investment company. The company was actively engaged in overseas investment before the BRI was announced and it has developed further business interests in BRI countries since 2013 .

SOEs are technically not development finance institutions, but they channel finance and operate projects in a wide range of BRI countries. They are arguably the most important participants of the BRI. So far, 81 central SOEs have carried out more than 3400 BRI projects, including more than $60 \%$ of all the infrastructure projects under the BRI. They are the main project operators and investors in large infrastructure and energy projects (China Economic Net 2016; Xu 2020). The SOEs' BRI investments are mostly funded by Chinese policy banks and state-owned commercial banks. Although private companies are increasingly encouraged to participate in BRI projects, SOEs remain the dominant players in these projects thanks to their privilege in accessing state support.

The AIIB was proposed by the Chinese government in the same year as the BRI, namely 2013. It was initially aimed at mobilizing Asian savings and foreign exchange reserves to fill the gap in Asian countries' demand for infrastructure finance (ADB \& ADBI 2009). As more non-Asian members joined the bank, it became a truly global-scale multilateral development bank (MDB) that devotes itself to long-term infrastructure development. Nevertheless, China remains the dominant shareholder in the AIIB. As a multilateral institution, the AIIB does not directly finance China's BRI projects. These projects are typically sponsored by Chinese agencies, either solely or jointly with other government or private investors, and are operated 
by Chinese companies as primary contractors. However, the projects funded by the AIIB have geographical overlaps with the BRI projects and also share the common objective of improving infrastructure foundations and cross-border connectivity. It is fair to say that the AIIB and the BRI both reflect China's ambition for overseas expansion through infrastructure financing. China's participation in the AIIB shows its demand for a larger voice in the Asian regional governance of development finance, especially in terms of allocating financial resources and setting up rules for infrastructure development. The AIIB is also expected to stimulate a vibrant market and active government administrations for development finance in Asia, which would largely benefit the BRI. Other institutions, such as the BRICS New Development Bank as well as a potential development bank and fund that may be formed under the Shanghai Cooperation Organisation, are also seen as possible supporting multilateral institutions for the BRI (Xinhua 2018; Carrai 2018).

The MCDF was announced by China's Ministry of Finance in 2017. It is intended to provide a multilateral effort to support and coordinate BRI cooperation. So far, eight MDFIs have answered the Ministry's call and signed the MoU for establishing the Cooperation Centre. These include the Asian Development Bank (ADB), the AIIB, the Corporación Andina de Fomento, the European Bank for Reconstruction and Development, the European Investment Bank, the Inter-American Development Bank, the International Fund for Agricultural Development, and the World Bank..$^{18} \mathrm{At}$ the Second Belt and Road Forum for International Cooperation, President $\mathrm{Xi}$ Jinping endorsed the MCDF as a potentially key supporting institution for the BRI (You 2019). It has been confirmed that the AIIB will be the secretariat of the MCDF. According to the MoU, the MCDF will have three main functions:

1 Information sharing: to facilitate the flow of information across the parties and other development partners in order to avoid duplication and enhance collaboration.

2 Capacity building: to enhance relevant know-how and institutional capacity of development countries and their development partners in [...] investment climate, transparent and sustainable debt management, open procurement, environmental and social frameworks, and anti-corruption.

18 Memorandum of Understanding on Collaboration on Matters to Establish the Multilateral Cooperation Center for Development Finance, https:/www.aiib.org/en/about-aiib/who-we-are/ partnership/_download/collaboration-on-matters.pdf. 
3 Project preparation: to finance upstream activities including [...] pre-feasibility and feasibility studies, and environmental and social assessment. $^{19}$

These functions reflect the Chinese government's desire for better information and knowledge about its BRI partners, higher host country institutional capacity, and multilateral assistance in project preparation. These things are currently inadequate in many of the BRI operations, something that reveals the problems and challenges that exist with the BRI's current development finance mechanisms.

\section{Challenges in Development Finance}

As the BRI has grown to become China's grand strategy for economic expansion, its projects have faced increasing challenges that erode their financial returns. Although the BRI could create significant long-term benefits for China and its partners, numerous projects are currently facing financial losses and several have been halted indefinitely (Greer 2018). ${ }^{20}$ An OECD report indicated that, between 2005 and 2018, Chinese investors were associated with US\$101.8 billion of troubled assets in BRI regions (OECD 2018b). ${ }^{21}$ Loans made to several countries could not be repaid and China was accused of aggravating these countries' debt burdens (Abi-Habib 2018; Masood 2019; Weinland 2017; Wharton Knowledge podcast 2019; Hurley et al. 2018). This has created mounting operational risks for Chinese SOEs and financial risks for the Chinese banks. ${ }^{22}$

The challenges faced by Chinese financiers are multifaceted. First, returns on investment are associated with host countries' political, economic, and security conditions. These conditions are known to be volatile in many BRI countries. The former head of Eximbank, Li Ruogu, warned that many BRI host countries were not creditworthy (Li \& Wang 2018). Chinese investors are often inadequately prepared for the complex political structures and problems of host countries. These can include such things as a central-local

19 Ibid.

20 Greer pointed out that ' $270 \mathrm{BRI}$ infrastructure projects in the region (or $32 \%$ of the total value of the whole) have been put on hold because of problems with practicality or financial viability'.

21 'Troubled' means: the collateral value of the investment is below its liabilities; loans are not performing; the deal has been cancelled for delays in reviews or political opposition, and so on. 22 CDB's non-performance loans have increased according to its 2018 annual report. (CDB 2018). 
division, fierce competition among local regions, inconsistency between different elected governments, and corruption (Arduino \& Cainey 2019). Many BRI countries also tend to have weak industrial foundations, for example, low labour productivity, energy inadequacy, and low efficiency. They also tend to have poorer investment environments when compared to developed economies, as well as large debt issues (Jamal 2017; Arduino \& Cainey 2019). In 2017, the sovereign debt of 27 of the countries participating in BRI was rated as 'junk' by the three main rating agencies - Standard and Poor's, Moody's, and Fitch Group. Another fourteen participating countries were either not rated or had withdrawn their requests for ratings (Deloitte Insights 2018). Several BRI projects have also been interrupted by security threats in the host countries. These features create extra risks. Chinese investors can rush into locking in deals, based on a benign diplomatic relationship with the host countries, without thorough due diligence or adequate pre-project viability analysis. In addition, since the Chinese investors tend to adopt a 'non-interference' approach and distance themselves from host countries' local politics, they may be less responsive to the problems that emerge during projects (Russel \& Berger 2019).

Second, some BRI projects face strong resistance from the local communities in host countries. Infrastructure projects often incur negative social and environmental impacts, especially regarding land acquisition, migrant compensation, and labour abuse (Reed \& Hille 2019). In some cases, financial compensation is inadequate for migrants, who are forced to move and lose their means of living and social facilities to infrastructure projects. In such cases, Chinese investors' capacity to carry out environmental and social management can be challenged and questioned. Some Chinese overseas infrastructure projects have been criticized for lacking environmental and social conflict research and management (Russel \& Berger 2019; Gransow \& Price 2018). They have also received criticism for dismissing communication with the media, non-governmental organizations, ethnical minorities, and the lower strata population in the host countries (Jiang 2014). A report by the environmental organization Friends of the Earth International has indicated that the 'mining, oil and gas, large-scale hydropower and large-scale agriculture sectors in which CDB invests carry tremendous environmental and social risk' (Friends of the Earth 2012). Some improvements have recently been made to how both Chinese banks and SOEs approach environmental and social management, but further measures are needed. ${ }^{23}$

23 For example, the CDB publishes its environmental policy and performance data, participates in international initiatives to improve its environmental and social performance and finances 
Third, China's ambitious BRI, as a grand strategy for the outward economic expansion, has caused anxiety in its regional competitors, such as India and Japan. India sees China's BRI projects in Pakistan, Sri Lanka, and Bangladesh as a threat to its leadership in the South Asian regional economic and security orders. It has been sceptical about the BRI from the early days and refused to sign a BRI MoU (Kamdar 2019; Economic Times 2019b). Japan was the sole Asian regional leader in development finance for a long time after the Second World War, as well as the largest regional aid provider. Unsurprisingly therefore, the possibility that China may take over regional development finance leadership through the BRI has not been well received in Japan and it has refused to join the China-led AIIB (Pesek 2019). Territorial disputes with China, such as the Diaoyu/Senkaku Islands dispute between China and Japan and the recent disputes between China and India near Tibet and on the disputed Doklam plateau, have further dissuaded both Asian powers from endorsing the BRI. The BRI has also caused uneasiness in the West (Economic Times 2019a; Balding 2018). US and European governments and companies have criticized the Chinese state's intervention in BRI projects and Chinese SOEs' dominance in these projects on the grounds that they cause unfair competition and erode the benefits of non-Chinese partners (Chance 2016). The US is wary about China's rise, especially when this rise is achieved through economic links with some of the US-dominated regions, such as the Middle East and Latin America. The US has therefore refused to hail the Chinese leadership in development finance and rejected the AIIB. As discussed above, the EU sees some potential benefits of the BRI but has been cautious about China's engagement with Central and Eastern European countries and its impact on European integration (Kynge \& Peel 2017). Overall, tensions between China and other great powers have created large obstacles for the BRI.

Last but not least, the growth of the Chinese economy has slowed since 2008. This slowdown has also been accompanied by mounting corporate and local government debts, decreasing foreign exchange reserves, and worsening financial instability (Bloomberg 2017). The Chinese government tightened controls on overseas investment in 2016 as capital flight increased and the

renewable energy projects (Friends of the Earth 2012). The Chinese State Council now holds SOE managers responsible for their bad investment decisions, and disciplinary actions could be taken against them even after they retire (Thomas \& Price 2017). In November 2017, the China Banking Regulatory Commission issued its first regulations for China's policy banks, emphasizing greater risk controls for their overseas activities (Wu \& Jia 2017). In August 2018, Beijing issued policy papers to its SOEs involved in BRI projects regarding issues such as due diligence, project feasibility and ongoing operations (Deloitte Insights 2018). 
domestic economic slowdown continued (Reuters 2017). Since most of the BRI projects are financed by Chinese capital, a further economic slowdown in China may weaken the state's capacity to support the BRI. On the other hand, this makes good investment decisions and project management urgently important for Chinese financiers and projects operators (SOEs).

\section{Driving Factors in Development Finance}

Based on the examples of the AIIB and the MCDF, China's engagement with multilateral development finance institutions to smooth BRI cooperation is motivated by both efficiency and strategic concerns.

The MCDF's institutional design and its functions reveal China's concerns with the efficiency issues of existing BRI projects. Other than the Chinese Ministry of Finance itself, all the other MCDF members are MDFIs. China has had satisfactory collaboration with all these institutions. Among others, China has significantly benefited from the financial and technical assistance of the World Bank and the Asian Development Bank in the past four decades. These multilateral institutions have rich experience and substantial institutional capacity in dealing with the issues of development projects. They hire a large number of development experts to work on project preparation and post-investment management. The staff members in these institutions move internally between different regional and thematical departments, creating a vibrant internal knowledge and expertise mobility. Most of the MDFIs also have an in-house research department that focuses on in-depth studies of a wide range of development issues and provides intellectual support for their policy decisions. Therefore, they have developed a rather comprehensive understanding of developing regions, including many BRI countries.

The MDFIs have developed advanced practices to ensure the efficiency of development projects. For example, the public procurement guidelines of the World Bank and other MDBs encourage the use of competition in the allocation of contracts through open tendering, indicate clear evaluation criteria for determining the winning bid, and prevent collusion between bidders. Compared to the MDB guidelines, China's domestic Government Procurement Law and Bidding Law tend to support the award of BRI contracts to preferred Chinese suppliers (Ghossein et al. 2018), which constrains the allocative efficiency of BRI projects in the long run. Moreover, MDFIs often play a leading role in the area of environmental and social management. For example, both the World Bank and the International Finance Corporation have developed industry-specific social and environmental 
guidelines. The Equator Principles, prominent risk management guidelines for financial institutions, were based on the International Finance Corporation's environmental and social policy frameworks. However, the Chinese policy banks lag behind their international peers: the CDB and Eximbank did not join the Equator Principles and they have not adopted widely accepted guidelines for a grievance mechanism either (Suzuki 2007; Gallagher 2016). The MDFIs also work more closely with the media and non-governmental organizations, whose voices are crucial for a successful development project. All in all, the MCDF, through information sharing, capacity building, and project preparation, is expected to bring together experienced and capable MDFIs to help China fight the challenges it faces in BRI projects so that it can avoid loss and/or maximize the return on investments. Hence, the MCDF answers to China's efficiency concerns.

In addition, by establishing and participating in multilateral institutions like the AIIB and MCDF, China can strengthen its influence in rule setting and decision making in the area of development finance in general and in BRI countries in particular. The AIIB's institutional innovations, such as the sole focus on infrastructure development, the non-resident board of directors, and the simplified project preparation procedures (compared to the World Bank), reflect China's preferred alternative approach to multilateral development finance compared to the traditionally Western-led MDBs. The MCDF's institutional set-up, where there are MDFIs instead of sovereign states as members, also allows China to avoid direct confrontations with its regional and global great-power rivals in discussion of the BRI. The US has been vigilant about the World Bank joining China's multilateral initiative for supporting the BRI, but it cannot directly intervene in the interactions between the bank and China under the MCDF set-up. Therefore, China's multilateral approach to BRI cooperation, through the AIIB and MCDF, is also driven by strategic concerns.

\section{Conclusion}

In dealing with the varied challenges of the BRI, the Chinese government lacks an integral governance framework that systemically coordinates all the relevant institutions. Instead, it has developed different institutional approaches in various issue areas. Our analysis shows that Beijing's institutional approaches in the issue areas of trade, tax, and development finance are driven by two main concerns: 1) an 'efficiency concern' to reduce transaction costs and maximize economic advantages in BRI 
Figure 3.1 Dominant drivers of China's institutional approach by issue area
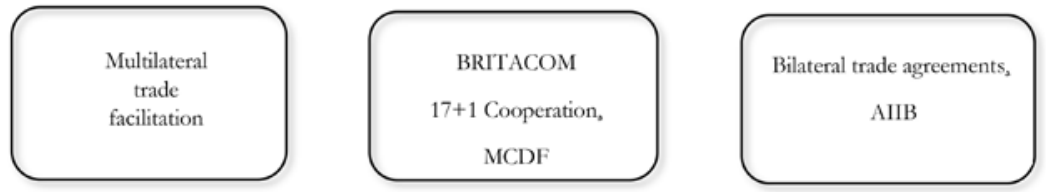

Source: Author's compilation of data from UNCTAD. ${ }^{24}$

cooperation; and 2) a 'strategic concern' to strengthen China's strategic position in the governance of BRI affairs. By taking a closer look at each issue area, we find that efficiency and strategic concerns drive Beijing to make different institutional choices even within the same issue area (see figure 3.1).

On the spectrum of factors driving China's institutional approach, we conclude that the design of its various bilateral and regional trade agreements is driven primarily by strategic considerations. We reach this conclusion for two reasons. First, the BRI itself was at least partially devised as a response to the challenge of the Trans-Pacific Partnership (TPP), which, given its exclusion of China, Beijing perceived as a threat to its regional influence. Second, China's approach to trade deals with BRI partner countries, beginning with shallow and limited agreements that are subsequently expanded in numerous rounds of negotiations over many years, has a number of consequences. It maximizes the opportunity costs resulting from the lack of an initially comprehensive deal, it increases uncertainty, and it raises negotiation costs. At the same time this approach maximizes China's bargaining power as the dependence of its trade partners grows. In contrast, the multilateral cooperation around trade facilitation seems to be driven primarily by efficiency concerns, namely a concern to minimize the costs of cross-border trade with BRI partners. The efforts on this front, however, are piecemeal and slow, with limited results, largely due to capacity constraints in partner countries.

The tax institutions of the BRI meanwhile are driven by the need for reduction of transaction costs accompanied by a desire to create a competing 
regulatory model that can challenge dominant Western approaches. The use of MoUs and cooperation mechanisms (the BRITACOM, and the $17^{+1}$ cooperation in the EU) has shown China's interest in dealing with the BRI in accordance with the needs of China's businesses. This is mainly due to efficiency concerns. However, there are also some strategic reasons behind these choices, since China has chosen to deal directly with EU countries rather than with the EU as a whole. This has created uncertainty in the EU and among EU businesses about whether the benefits of the BRI are only for Chinese investors or also for EU investors. China will need to address these concerns and ensure that the BRI provides clear benefits for all countries involved.

In the governance of development finance, China's engagement with the MCDF and the AIIB is motivated by both efficiency and strategic concerns. By establishing the MCDF, Beijing hopes to bring together experienced and capable MDFIs. These can help China fight the challenges it faces in BRI projects so that it can avoid financial loss and/or maximize return on investments. Hence, the MCDF answers to China's efficiency concerns. Meanwhile, through participating in China-dominated multilateral institutions like the AIIB and MCDF, Beijing aims to strengthen its influence in rule setting and decision making in the area of development finance. This reflects China's strategic concerns in BRI cooperation. That being said, since the AIIB has only been operational since 2016, and the MCDF has not yet started operating, their long-term impacts on BRI remain to be seen.

Attempts to answer questions about what factors drive China's approach to the BRI have often been too imprecise to be useful. By focusing on specific sub-areas within the broader BRI project in this chapter, it is clear that the factors driving China's policy differ in important ways across issue areas. We conclude that analyses that fail to recognize this complex reality are likely to draw flawed inferences regarding the complex motivations driving China's behaviour when it comes to the BRI.

\section{Acknowledgements}

The writing and research carried out for this chapter are the result of research in the framework of the GLOBTAXGOV Project. This project has received funding from the European Research Council (ERC) under the European Union's Seventh Framework Programme (FP/2007-2013) (ERC Grant agreement no. 758671). 


\section{References}

Abi-Habib, Maria (2018, June 25). 'How China Got Sri Lanka to Cough up a Port'. New York Times. Retrieved 4 August 2020 from https://www.nytimes.com/2018/06/25/ world/asia/china-sri-lanka-port.html.

ADB \& ADBI (2009). Infrastructure for a Seamless Asia. Manila: Asian Development Bank and Asian Development Bank Institute.

Arduino, Alessandro \& Cainey, Andrew (2019). 'Risk Assessment and Mitigation in Central Asia: Implications for Foreign Direct Investment and the Belt and Road Initiative'. European Bank for Reconstruction and Development (EBRD). Avi-Yonah, Reuven \& Xu, Haiyan (2017). 'China and the Future of the International Tax Regime'. Law \& Economics Working Paper. Retrieved 3 August 2020 from https://repository.law.umich.edu/cgi/viewcontent.cgi?article $=1249 \&$ context=law_ econ_current.

Balding, Christopher (2018). 'Why Democracies Are Turning against Belt and Road: Corruption, Debt and Backlash'. Foreign Affairs. Retrieved 4 August 2020 from https://www.foreignaffairs.com/articles/china/2018-10-24/why-democraciesare-turning-against-belt-and-road.

Baltensperger, M. \& Dadush, U. (2019). 'The Belt and Road Turns Five'. Russian Journal of Economics, 5(2), 136-153.

Beng Teoh, Choon \& Wang, Xiaoyue (2019, December 3). 'China Transfer Pricing Enforcement: Modernised Approach Matures'. International Tax Review. Retrieved 3 August 2020 from https://www.internationaltaxreview.com/article/bij8xvh3y7f3pb/ china-transfer-pricing-enforcement-modernised-approach-matures.

Boffa, Mauro (2018, May). 'Trade Linkages between the Belt and Road Economies'. World Bank Policy Research Working Paper.

Blockmans, Steven \& Hu, Weinian (2019). 'Systemic Rivalry and Balancing Interests: Chinese Investment Meets EU Law on the Belt and Road'. CEPS Policy Insights no. 4. Retrieved 3 August 2020 from https://www.ceps.eu/wp-content/ uploads/2019/03/PI_2019_04_SB-WH_EU-China_o.pdf.

Bloomberg (2017, November 4). 'China's Central Bank Chief Warns of "Sudden, Contagious and Hazardous" Financial Risks'. Bloomberg. Retrieved 4 August 2020 from https://www.bloomberg.com/news/articles/2017-11-04/ china-s-zhou-warns-on-mounting-financial-risk-in-rare-commentary.

BRITACOM (n.d.). 'The Belt and Road Initiative Tax Administration Cooperation Mechanism'. Retrieved 3 August 2020 from http://www.chinatax.gov.cn/eng/ n4260869/c5112279/content.html.

Brookings (2019). 'Winners and Losers along China's Belt and Road'. Retrieved 6 March 2020 from https://www.brookings.edu/blog/future-development/ 2019/o6/21/winners-and-losers-along-chinas-belt-and-road/. 
BusinessEurope (2020, January). The EU and China:Addressing the Systemic Challenge. Brussels: BusinessEurope. Retrieved 25 June 2020 from https://www. businesseurope.eu/publications/eu-and-china-addressing-systemic-challenge. Carrai, Maria Adele (2018). 'It Is Not the End of History: The Financing Institutions of the Belt and Road Initiative and the Bretton Woods System'. In Julien Chaisse \& Jędrzej Górski (eds.), The Belt and Road Initiative: Law Economics and Politics (pp. 107-145). Leiden: Brill.

CDB (2018). Annual Report. China Development Bank. Retrieved 4 August 2020 from http://www.cdb.com.cn/English/bgxz/ndbg/ndbg2018/.

Chance, Alek (2016). 'American Perspectives on the Belt and Road Initiative: Sources of Concern and Possibilities for Cooperation'. Washington, DC: Institute for ChinaAmerica Studies. Retrieved 4 August 2020 from https://chinaus-icas.org/wp-content/ uploads/2017/02/American-Perspectives-on-the-Belt-and-Road-Initiative.pdf.

Cheng, Chi, et al. (2019, January 29). 'Now That China Has Data, What Is It Going to Do with It?' International Tax Review. Retrieved 3 August 2020 from https://www.internationaltaxreview.com/article/b1fydc6pd5rw7c/ now-that-china-has-data-what-is-it-going-do-with-it.

China Economic Net [中国经济网] (2016, December 6). “首届“一带一路”企业贡献 排行榜评选公示' [Announcement of the first 'Belt and Road Initiative' ranking of corporation contributions]. Retrieved 4 August 2020 from http://intl.ce.cn/ specials/zxgjzh/201612/o6/t20161206_18418097.shtml.

China News (2019, March 29). “屠光绍: 中投在“一带一路”眼线国家已投资241亿美 元' [Tu Guangshao: China Investment Corporation has invested US\$24.1 billion in 'Belt and Road Initiative' countries]. China News. Retrieved 4 August 2020 from https://www.chinanews.com/cj/2019/03-29/8794847.shtml.

Cui, Lianbiao \& Song, Malin (2019). 'Economic Evaluation of the Belt and Road Initiative from an Unimpeded Trade Perspective'. International Journal of Logistics Research and Applications, 22(1), 25-46.

Deloitte Insights (2018). Embracing the BRI Ecosystem in 2018: Navigating Pitfalls and Seizing Opportunities. Deloitte China. Retrieved 26 October 2020 from https://www2.deloitte.com/content/dam/insights/us/articles/4406_Belt-androad-initiative/4406_Embracing-the-BRI-ecosystem.pdf.

De Soyres, François, Mulabdic, Alen, Murray, Siobhan, Rocha, Nadia \& Ruta, Michele (2019). 'How Much Will the Belt and Road Initiative Reduce Trade Costs?' International Economics, 159(July), 151-164.

Economic Times (2018). 'Pakistan Government Plans to Renegotiate Agreements Reached under China's BRI: Report'. Economic Times. Retrieved 6 March 2020 from https://economictimes.indiatimes.com/news/international/world-news/ pakistan-government-plans-to-renegotiate-agreements-reached-under-chinasbri-report/articleshow/65755576.cms?from=mdr. 
Economic Times (2019a, May 9). “Fed Up” of US Criticism of BRI, Says China'. Economic Times. Retrieved 4 August 2020 from https://economictimes.indiatimes. com/news/international/business/fed-up-of-us-criticism-of-bri-says-china/ articleshow/69253669.cms.

Economic Times (2019b, October 4). 'India Won't Join BRI, Its Concept Won't Apply to Us: Jaishankar'. Economic Times. Retrieved 4 August 2020 from https://economictimes.indiatimes.com/news/politics-and-nation/indiawont-join-bri-its-concept-wont-apply-to-us-jaishankar/articleshow/71441347. $\mathrm{cms}$ ?from $=\mathrm{mdr}$.

EU Commission (2018, September 28). ‘Commission Approves Hungary’s €45 Million Investment Aid to BorsodChem'. Press release. Retrieved 3 August 2020 from https://ec.europa.eu/commission/presscorner/detail/en/IP_18_5941.

EU Commission (2019, March 12). 'Joint Communication to the European Parliament, the European Council and the Council: EU-China - A Strategic Outlook'. JOIN(2019) 5 final. Retrieved 3 August 2020 from https://ec.europa.eu/commission/sites/beta-political/files/communication-eu-china-a-strategic-outlook.pdf.

Friedman, Milton (1953). 'Essays in Positive Economics Part I - The Methodology of Positive Economics'. Press II, 3-43.

Friends of the Earth (2012). China Development Bank's Overseas Investments: An Assessment of Environmental and Social Policies and Practices. Berkeley, CA: Friends of the Earth.

Gallagher, Kevin (2016). The China Triangle: Latin America's China Boom and the Fate of the Washington Consensus. Oxford: Oxford University Press.

Ghossein, Tania, Hoekman, Bernard M. \& Shinhal, Anirudh (2018). 'Public Procurement in the Belt and Road Initiative'. MTI Discussion Paper no. 10. Washington, DC: World Bank.

Gransow, Bettina \& Price, Susanna (2018). 'Social Risk Management at AIIB Chinese or International Characteristics?' Journal of Chinese Political Science, 24, 289-311.

Greer, Tanner (2018, December 6). 'One Belt, One Road, One Big Mistake: China's Signature Foreign-Policy Project Is a Failure That the US Should Copy'. Foreign Policy. Retrieved 4 August 2020 from https://foreignpolicy.com/2018/12/o6/ bri-china-belt-road-initiative-blunder/.

Haider, Irfan (2015, April 20). 'Details of Agreements Signed during Xi's Visit to Pakistan'. Dawn. Retrieved 1 September 2020 from https://www.dawn.com/ news/1177129.

Hanemann, Thilo, Huotari, Mikko \& Kratz, Agatha (2019). 'Chinese FDI in Europe: 2018 Trends and Impact of New Screening Policies'. Meric Papers on China. Retrieved 3 August 2020 from https://rhg.com/wp-content/uploads/2019/03/ RHG-MERICS-COFDI-Update-2019.pdf. 
Hogan, Phil (2020, January 20). 'Speech by Commissioner Phil Hogan at the Publication of BusinessEurope's Strategy Paper on the EU-China Economic Relations'. European Commission. Retrieved 3 August 2020 from https://ec.europa.eu/commission/commissioners/2019-2024/hogan/announcements/speech-commissionerphil-hogan-publication-business-europes-strategy-paper-eu-china-economic_en. Hu, Pingchao, Yu, Rui \& Zhang, Aifang (2019, April 24). 'Belt and Road Inter-bank Regular Co-op Promotes Financial Integration'. Xinhua Silk Road Information Service.

Hurley, John, Morris, Scott \& Portelance, Gailyn (2018, March). 'Examining the Debt Implications of the Belt and Road Initiative from a Policy Perspective'. CGD Policy Paper 121. Washington, DC: Center for Global Development.

Jamal, Nasir (2017, March 12). 'The Cost of CPEC'. Dawn. Retrieved 4 August 2020 from https://www.dawn.com/news/1320028.

Jiang, Heng (2014). 'Blind Spots and Erroneous Understanding of Environmental and Social Risks Overseas'. In Daojiong Zha, Fusheng Li \& Heng Jiang (eds.), Chinese Overseas Investment: Case Studies on Environmental and Social Risk (pp. 35-56). Beijing: Peking University Press.

Jiang, Xueqing (2019, April 12). 'Bank of China Issues BRI-Related Bonds'. China Daily. Retrieved 4 August 2020 from https://www.chinadaily.com.cn/a/201904/12/ WS5cafdo67a310484226ob5bfa.html.

Johns, Marcus Bartley, Clarke, Julian Latimer, Kerswell, Clay \& McLinden, Gerard (2018). 'Trade Facilitation Challenges and Reform Priorities for Maximizing the Impact of the Belt and Road Initiative'. Discussion Paper, MTI Global Practice no. 4. World Bank, September. Retrieved 1 September 2020 from http://documents1.worldbank.org/curated/pt/219761536948259167/pdf/Trade-Facilitation-Challenges-andReform-Priorities-for-Maximizing-the-Impact-of-the-Belt-and-Road-Initiative.pdf. Johnston, Lauren A. (2019). 'The Belt and Road Initiative: What Is in It for China?' Asia and the Pacific Policy Studies, 6(1), 40-58. Retrieved 1 September 2020 from https://doi.org/10.1002/app5.265.

Kamdar, Bandari. (2019, May 9). 'What to Make of India's Absence from the Second Belt and Road Forum?' The Diplomat. Retrieved 4 August 2020 from https://thediplomat.com/2019/05/what-to-make-of-indias-absencefrom-the-second-belt-and-road-forum/.

Kynge, James \& Peel, Michael (2017, November 27). 'Brussels Rattled as China Reaches out to Eastern Europe'. Financial Times. Retrieved 4 August 2020 from https://carnegieendowment.org/2018/10/19/europe-s-emerging-approachto-china-s-belt-and-road-initiative-pub-77536.

Li, Jinyan (2012). 'The Great Fiscal Wall of China: Tax Treaties and Their Role in Defining and Defending China's Tax Base'. Bulletin International Taxation, 66(9), 452-479. 
Li, Liuxi \& Wang, Fran (2018, April 18). 'Ex-China EximBank Chief Warns that Many BRI Host Countries Are Not Credit Worthy'. NewsIn Asia. Retrieved 4 August 2020 from https://newsin.asia/ex-china-eximbank-chief-warns-that-many-bri-hostcountries-are-not-credit-worthy/.

Masood, Salman (2019, May 12). 'Pakistan to Accept \$6 Billion Bailout from IMF'. New York Times. Retrieved 4 August 2020 from https://www.nytimes.com/2019/05/12/ world/asia/pakistan-imf-bailout.html.

Masseglia Miszczyszyn, Elena, Lamensch, Marie, Traversa, Edoardo \& Villar Ezcurra, Marta (2020). 'The EU-China Trade Partnership from a European Tax Perspective'. CEU Working Paper no. 6o. Retrieved 3 August 2020 from https:// www.ceuediciones.es/catalogo/libros/economia/the-eu-china-trade-partnershipfrom-a-european-tax-perspective/.

Memorandum of Cooperation (2017, July). 'Between China, Brazil, Russia, India and South Africa'. Retrieved 3 August 2020 from http://receita.economia.gov.br/ noticias/ascom/2017/julho/receita-federal-participa-de-reuniao-dos-paises-brics/ moc-signing-version.pdf.

Memorandum of Understanding (2019a, April). 'On a Dialogue in the Area of the State Aid Control Regime and the Fair Competition Review System between the State Administration for Market Regulation of the People's Republic of China and the Directorate-General for Competition of the European Commission'. Retrieved 3 August 2020 from https://ec.europa.eu/competition/international/ bilateral/mou_china_2019.pdf.

Memorandum of Understanding (2019b, March). 'Between the Government of the Italian Republic and the Government of the People's Republic of China on Cooperation within the Framework of the Silk Road Economic Belt and the 21st Century Maritime Silk Road Initiative'. Retrieved 1 September 2020 from http://www.governo.it/sites/governo.it/files/Memorandum_Italia-Cina_EN.pdf.

Meyer-Nandi, Sathi, et al. (2018). 'Tax Treaties Between Belt and Road Countries'. In Michael Lang \& Joeffrey Owens (eds.), Removing Tax Barriers to China's Belt and Road Initiative (pp. 197-258). Amsterdam: Wolters Kluwer.

NDRC (2015, March). 'Vision and Actions on Jointly Building Silk Road Economic Belt and 21st-Century Maritime Silk Road'. National Development and Reform Commission, Ministry of Foreign Affairs and Ministry of Commerce, People's Republic of China. Retrieved 25 October 2020 from https://web.archive.org/web/20181127225143/ http://en.ndrc.gov.cn/newsrelease/201503/t20150330_669367.html.

$\operatorname{OECD}(2017)$. 'Transfer Pricing Guidelines for Multinational Enterprises and Tax Administrations'. Organisation for Economic Co-operation and Development. Retrieved 1 September 2020 from https://www.oecd-ilibrary.org/taxation/oecd-transferpricing-guidelines-for-multinational-enterprises-and-tax-administrations-2017/ glossary_tpg-2017-4-en. 
OECD (2018a). 'BEPS MLI Position China'. Organisation for Economic Co-operation and Development. Retrieved 3 August 2020 from http://www.oecd.org/tax/ treaties/beps-mli-position-china.pdf.

OECD (2018b). 'China's Belt and Road Initiative in the Global Trade, Investment and Finance Landscape'. OECD Business and Finance Outlook 2018. Paris: Organisation for Economic Co-operation and Development.

Okano-Heijmans, Maaike \& Kamo, Tomoki (2019, May). 'Engaging but Not Endorsing China's Belt and Road Initiative'. Policy Brief. Clingendael Netherlands Institute of International Relations. Retrieved 3 August 2020 from https://www.clingendael. org/sites/default/files/2019-05/PB_China_Belt_and_Road_Initiative_May_2019.pdf.

Pesek, William (2019, October 9). 'EU-Japan Axis Emerges to Counter China's BRI'. Asia Times. Retrieved 4 August 2020 from https://asiatimes.com/2019/10/ eu-japan-axis-emerges-to-counter-chinas-bri/.

Powell, R. (1991). 'Absolute and Relative Gains in International Relations Theory'. American Political Science Review, 85(4), 1303-1320.

Rachman, Gideon (2019, March 11). 'The US, China and the Return of a Two-Bloc World'. Financial Times.

Rahman, S.U. \& Shurong, Z. (2017). 'Analysis of Chinese Economic and National Security Interests in China-Pakistan Economic Corridor (CPEC) under the Framework of One Belt One Road (OBOR) Initiative'. Arts and Social Sciences Journal, 8(4). Retrieved 1 September 2020 from https://doi.org/10.4172/2151-6200.1000284.

Ramasamy, Bala, Yeung, Matthew, Utoktham, Chorthip \& Duval, Y. (2017). 'Trade and Trade Facilitation along the Belt and Road Initiative Corridors'. ARTNeT Working Paper Series 172. Retrieved 1 September 2020 from http://artnet.unescap.org.

Reed, John \& Hille, Kathrin (2019, October 30). 'Laos's Belt and Road Project Sparks Questions over China Ambitions'. Financial Times. Retrieved 4 August 2020 from https://www.ft.com/content/a8dobdae-e5bc-11e9-9743-db5a370481bc.

Reuters (2017, January 18). 'China Steps up Capital Controls, Tightens Investment Rules for State Firms'. Reuters. Retrieved 4 August 2020 from https://www. reuters.com/article/us-china-economy-foreigninvestment-state/china-stepsup-capital-controls-tightens-investment-rules-for-state-firms-idUSKBN152oU1.

Reuters (2019, March 27). 'China Development Provides over \$19o Billion for Belt and Road Projects'. Reuters. Retrieved 4 August 2020 from https://www.reuters. com/article/us-china-finance-cdb-bri/china-development-bank-provides-over190-billion-for-belt-and-road-projects-idUSKCN1R8o95.

Russel, Daniel R. \& Berger, Blake (2019). 'Navigating the Belt and Road Initiative'. Report. Asia Society Policy Institute.

Sampson, Michael (2019). 'The Evolution of China's Regional Trade Agreements: Power Dynamics and the Future of the Asia-Pacific'. Pacific Review. Retrieved 1 September 2020 from https://doi.org/10.1080/09512748.2019.1660397. 
Sampson, Michael (2020, February 5). 'Expanding Influence: China's Evolving Trade Agreements in the Asia-Pacific'. The Diplomat. Retrieved $3 \mathrm{Au}-$ gust 2020 from https://thediplomat.com/2020/02/expanding-influencechinas-evolving-trade-agreements-in-the-asia-pacific/.

Sanderson, Henry \& Forsythe, Michael (2013). China's Superbank:Debt, Oil and Influence - How China Development Bank Is Rewriting the Rules of Finance. Singapore: Wiley. Suzuki, Eisuke (2007). 'Bilateral Policy Orientation in the Multilateral Development Policy: A Challenge for the China Exim Bank and Its Accountability'. Chinese Journal of International Law, 6(1), 127-133.

Thomas, Denny \& Price, Michelle (2017, September 27). 'When Deals Go Bad: China State Firm Managers Spooked by New Liability Rules'. Reuters. Retrieved $4 \mathrm{Au}-$ gust 2020 from https://www.reuters.com/article/us-china-soe-m-a/when-deals-gobad-china-state-firm-managers-spooked-by-new-liability-rules-idUSKCNıW2LW. Trade Finance [贸易金融] (2019, May 9). “农业银行: 推进“一带一路”及国际金 融服务体系建设' [Agricultural Bank of China: Pushing forward the 'Belt and Road Initiative' and the construction of the international financial service system]. Trade Finance. Retrieved 4 August 2020 from http://www.sinotf.com/ GB/yuanchuang/1110/2019-05-09/4OMDAwMDMzMzM4OQ.html.

United Nations (2014). 'China's Response' [The United Nations questionnaire on BEPS]. Retrieved 3 August 2020 from https://www.un.org/esa/ffd/wp-content/ uploads/2014/10/ta-BEPS-CommentsChina.pdf.

Van der Eijk, Femke \& Pandita Gunavardana, Angela (2019). 'The Road That Divided the EU: Italy Joins China's Belt and Road Initiative'. European Law Blog. Retrieved 3 August 2020 from https://europeanlawblog.eu/2019/06/25/ the-road-that-divided-the-eu-italy-joins-chinas-belt-and-road-initiative/.

Vines, D. (2018). The BRI and RCEP: ensuring cooperation in the liberalisation of trade in Asia. Economic and Political Studies, 6(3), 338-348. https://doi.org/10.1 o8o/20954816.2018.1498992

Wang, Y. (2016). Offensive for defensive: the belt and road initiative and China's new grand strategy. Pacific Review, 29(3), 455-463. https://doi.org/10.1080/0951 2748.2016.115469o

Wei, C., Zhigao, L., Tao, W., \& Won SONN, J. (2018). The structure and evolution of trade relations between countries along the Belt and Road. 28(9), 1233-1248. https://doi.org/10.1007/s11442-018-1522-9

Weinland, Don (2017, January 25). 'China Warned of Risk to Banks from One Belt, One Road Initiative'. Financial Times. Online: https://www.ft.com/ content/6o76cf9a-e38e-11e6-8405-9e558od6e 5fb

Wharton Knowledge podcase (2019, April 30) ‘China's Belt and Road Initiative: Why the Prices is Too High'. https://knowledge.wharton.upenn.edu/article/ chinas-belt-and-road-initiative-why-the-price-is-too-high/ 
Williamson, O. E. (1985). The economic institutions of capitalism. New York: Free Press.

Wu, Xiaomeng \& Jia, Denise (2017, November 15). 'New Rules Released on Policy Banks to Enhance Risk Control'. Caixin. Retrieved 4 August 2020 from https:/ www.caixinglobal.com/2017-11-16/new-rules-released-on-policy-banks-toenhance-risk-control-10117139o.html.

Xinhua (2018, June 10). 'China to Set up 20-bln-yuan Lending Facility Under SCO Framework:Xi'. Xinhua. Retrieved 4 August 2020 from http://www.xinhuanet. com/english/2018-06/10/c_137243965.htm.

Xinhua (2019a, April 22). 'China Exim Bank’s B\&R Loans Surpasses it Yuan'. Xinhua. Retrieved 4 August 2020 from http://www.chinadaily.com.cn/a/201904/22/ $\mathrm{WS}_{5}$ cbd71eoa310484226ob7919.html.

Xinhua (2019b, April 24)، ‘四大行各展身手, 多元化服务一带一路'建设” [The Big Four show their expertise, multiple services for the 'Belt and Road Initiative' construction]. Xinhua. Retrieved 4 August 2020 from http://www.xinhuanet. com/money/2019-04/24/c_1124409185.htm.

Xu, Beibei (2020, January 15). '81家央企在”一带一路”沿线承担超3400 个项目' [Eighty-one central state-owned enterprises operate more than 3400 projects along the Belt and Road]. Financial News. Retrieved 4 August 2020 from http:// www.financialnews.com.cn/cj/hyfx/202001/t20200115_175279.html.

$\mathrm{Xu}$, Diheng (2018a). 'China versus the BEPS Project'. Retrieved 3 August 2020 from https:/globtaxgov.weblog.leidenuniv.nl/2018/og/o3/ china-versus-the-beps-project/.

$\mathrm{Xu}$, Diheng (2018b). 'The Convergence and Divergence between China's Implementation and OECD/G2o BEPS Minimum Standards'. World Tax Journal, 10(3). IBFD Publications. 471-496.

You, Runtian (2019, April 26). ‘习近平: ‘一带一路’一切合作将在阳光下运作, 以 零容忍态度打击腐败’ [Xi Jinping: All ‘Belt and Road Initiative’ cooperation will operate under the sunshine, striking on corruption with zero tolerance]. Belt and Road. Retrieved 4 August 2020 from https://beltandroad.zaobao.com/ beltandroad/news/story20190426-951782.

Zhang, Kangle (2018). 'A Tale of Ending Poverty: The New Financial Institutions and China's Global Strategy'. In Wenhua Shan, Kimmo Nuotio \& Kangle Zhang (eds.), Normative Readings of the Belt and Road Initiative (pp. 105-127). Cham: Springer International Publishing.

Zhang, Mo (2019, April 16). ‘中行”一带一路’主题债券规模近 150 亿美元”. 经济参 考报' ['Belt and Road Initiative'-themed bonds issued by Bank of China have reached US $\$ 15$ billion]. Chinabond.com. Retrieved 4 August 2020 from https:// www.chinabond.com.cn/cb/cn/xwgg/zsxw/zqsc/jrz/20190416/151335892. shtml. 


\section{About the Authors}

Michael SAmpson is Assistant Professor of International Relations at Leiden University's Institute of Political Science. His research focuses on international political economy and the strategic and distributional consequences of trade institutions.

JUE WANG is a Lecturer at the Leiden University Institute for Area Studies. She is a scholar of international political economy, with a focus on China, its external economic relationships, and its role in regional and global economic governance. She also has a wide range of research interests in international economic organizations, international cooperation, and the development of emerging economies. Her academic work has been published in, amongst others, International Affairs and the Chinese Political Science Review. She is also an Associate Fellow in the Asia-Pacific Programme at Chatham House. She regularly comments on Chinese and international affairs for media outlets, including the BBC, CGTN, Al Jazeera, the New York Times, and The Times.

Irma Mosquera VAlderrama is Associate Professor of Tax Law at Leiden University, the Netherlands. She obtained her PhD (cum laude) in 2007 at the University of Groningen, the Netherlands. Her areas of expertise are international tax law and comparative tax law in developed and developing countries and, more recently, exchange of information, including taxpayers' rights and safeguards in exchange of information and BEPS-related issues in developing countries. She has published several articles in peer-reviewed journals and non-peer-reviewed journals. She has been awarded an ERC Starting Grant by the European Research Council to carry out research from 2018 to 2022 on a New Model of Global Governance in International Tax Law Making (GLOBTAXGOV). 



\section{Part II}

\section{Regional Dynamics}





\title{
4 The BRI in Latin America
}

\author{
New Wine in Old Bottle?
}

Matt Ferchen ${ }^{\prime}$

\begin{abstract}
Chapter 4 examines the role of the BRI in relations with Latin America and the Caribbean. Prior to 2017, Chinese officials rejected the idea that these regions were part of the BRI. While the BRI was geographically expansive, the Western Hemisphere appeared beyond its scope. However, in 2017, China started to sign BRI memoranda of understanding (MoUs) and BRI-related deals with governments in Central America, the Caribbean, and South America. This expansion of the BRI to the region occurred as the US began a concerted pushback against Chinese dealmaking and influence. This chapter offers an overview of the BRI's still-short history in Latin America and the Caribbean. It analyses what the BRI means in the context of China's developing country diplomacy in the region, and how it is playing out against widening US-China strategic rivalry.
\end{abstract}

Keywords: Belt and Road Initiative, China, South America, Caribbean, Central America, agency

Latin America has been, and continues to be, an outlier in terms of its relationship to China's Belt and Road Initiative (BRI). Geographically, Latin America has rarely appeared on the wide array of BRI maps produced inside

1 Unlike some of the other chapters in this study, the author did not conduct field work for this chapter. He has, however, worked extensively on the Latin America-China relationship since 2008. In addition to publishing academic and policy research on a range of China-Latin America issues, he also taught courses on China-Latin America relations and Latin American political economy in the Department of International Relations at Tsinghua University from 2008 to 2017. The author wishes to thank Lily Sprangers and Florian Schneider for their thoughtful feedback on earlier drafts of this chapter and chapter 10 and for support throughout the project.

Schneider, Florian (ed.), Global Perspectives on China's Belt and Road Initiative: Asserting Agency through Regional Connectivity. Amsterdam, Amsterdam University Press 2021 DOI: 10.5117/9789463727853_CHO4 
or outside of China. Latin America also did not feature in the original rollout of the New Silk Road concept or subsequent formulations explaining the combination of maritime and land-based corridors. The BRI has become known for its geographic expansiveness and overall programmatic ambiguity, inclusive not just of wide swaths of Asia but also Africa and Europe and even the Arctic (see the Polar Silk Road). However, the exclusion of the entire Western Hemisphere, including Latin America and the Caribbean, had long been a clear exception. Since around 2017, however, this has all changed. Almost 20 countries in Latin America and the Caribbean (LAC) are now at least signatories to BRI memoranda of understanding (MoUs) and/or are actively exploring BRI-branded projects. ${ }^{2}$

Yet to understand where the Latin America and the Caribbean region fits in the context of the BRI requires taking a step back to the decade prior to the introduction of the BRI itself. The diplomatic and commercial relationship between China and Latin America and the Caribbean really took off in the period around 2003-2004, based in no small part on a China-led commodity boom that saw the rapid expansion of Chinese demand for South American raw materials (Ferchen 2011). The contours of the relationship between China and Latin America and the Caribbean that were established during that time - the potential, the challenges, the disappointments - all set the tone for discussions today of the BRI in the region. In particular, concerns about commodity dependence and the unsustainable environmental and social impacts of ties between China and Latin America and the Caribbean, all of which were already clear well before the rollout of the BRI, have only been accentuated by the extension of the BRI to the region. At the same time, hopes that China would become a stable, long-term development partner for the region have also received a boost from the BRI's arrival.

Therefore, familiarity with the history of Latin America and the Caribbean's relations with China is key to any understanding of how the BRI is being rolled out and responded to inside and outside the region. In addition, because this history is so foundational to any understanding of where the BRI fits into the broader relationship between China and Latin America and the Caribbean, it is also important to ask how the extension of the BRI to Latin

2 As will become apparent in the body of this chapter, the LAC region's diversity has important implications for trade and investment relations with China. While South America was the focal point for most commodity-based trade and investment relations in the period before the extension of the BRI to the region, it is largely the Caribbean and Central America where most BRI-related activity has been focused in the years since 2017 . 
America and the Caribbean does or does not change the broader economic and political patterns that had already come to define the relationship.

Against this backdrop a key question is: What, if anything, is significant and new in the relationship between China and Latin America and the Caribbean as a result of the introduction of the BRI? The answer is that in many ways the introduction of the BRI to Latin America and the Caribbean has not fundamentally altered structural patterns already at play since the early 1990s. However, the BRI's introduction to the region has accentuated some of these patterns, including a growing wariness of China's presence in the region by the United States.

In a way significant to the broader comparative study of the BRI, the combination of hope and disappointment about the potential of China's developmental role in Latin America and the Caribbean is mirrored in other BRI regions like Africa and South and Southeast Asia. This is no coincidence. Prior to the introduction of the BRI, Latin America and the Caribbean had already become an important part of China's broader developing-country diplomacy and commercial outreach (Eisenman \& Heginbotham 2018). Africa, in particular, has been the other core element of China's twenty-first-century developing country diplomacy, a region that has long been at the heart of China's longer standing efforts to be seen as a leader and representative of the 'Third World' (Strauss 2009). ${ }^{3}$ In this regard, key features and challenges of the developmental relationship between China and Latin America and the Caribbean, including trade dependency, debt sustainability, and environmental and social impact issues, have also appeared prominently in the analytical and policy debates surrounding the impact of the BRI in regions covered in other chapters of this study. One question that emerges from this chapter, then, is: What lessons are or are not being learned in a comparative context across BRI countries and regions that share similar developmental challenges and aspirations in their ties to China?

\section{Relations between China and Latin America and the Caribbean: The BRI's Pre-history}

At least a decade before the BRI was introduced by Xi Jinping in 2013, resource-rich countries in South America had already begun to experience

3 For an excellent overview of the Mao-era roots of China's efforts to vie for symbolic and revolutionary leadership of the 'Third World', see Friedman (2015). 
a boom in exports to China. Even within South America, this trade-based take-off in relations with China was concentrated in a relatively small number of countries and commodity types. Countries rich in minerals such as copper (Chile) and iron ore (Brazil), agricultural resources such as soy (Argentina, Brazil and Uruguay), and fossil fuels such as oil and gas (Argentina, Brazil and Venezuela) all quickly saw China become a number one or number two export partner in the years after 2003 (Gallagher 2016). Booming, commodity-based trade relations were also accompanied by a flurry of high-level diplomatic exchanges, highlighted by then-President of China Hu Jintao's signature visit to Brazil in 2004. These diplomatic exchanges were part of a renewed Chinese effort to reinvigorate ties to developing countries, including those in Africa and Asia (Eisenman \& Heginbotham 2018).

Geopolitically, the take-off in China's commodity-based trade relations with South America also coincided with the rise of the 'New Left' in some of China's newly rediscovered trade partners. This included, most notably, the coming to power of Luiz Inácio Lula da Silva in Brazil and of Hugo Chavez in Venezuela (Schamis 2006). In the decade after 2003, China's rapidly expanding trade and investment ties throughout South America were not primarily determined by political considerations. However, China did establish especially close bilateral political ties with some New Left leaders in the region (for example, Chavez in Venezuela and Rafael Correa in Ecuador) and also played up a kind of emerging market solidarity with others (for example, with Brazil and the other countries of the BRICS grouping, Russia, India, and South Africa).

Yet this boom in China-South America trade and diplomatic relations did not play out in the same way in other parts of Latin America and the Caribbean. Notably, Mexico and countries in Central America and the Caribbean, which did not possess the same kinds of commodity endowments as their South America neighbours, did not experience the same kind of export-driven trade boom with China. Mexico, the second-largest economy in Latin America and the Caribbean, has experienced relations with China that have been distinctly more competitive, and less 'complementary', than those of most of its South American counterparts (Dussel Peters 2015). Even though Mexico has significant oil resources, its trade relationship with China has not been characterized by buoyant commodity exports to China, but instead by competition with China for assembly and export to third markets, including the United States. Moreover, Mexico's competitive trade relationship with China, including Mexican concerns about a large and sustained trade deficit with China, has also limited the kind of diplomatic 
amity that accompanied the trade-based boom in China-South America relations.

Although not as competitive as the Mexico-China relationship, the Spanish-speaking countries of Central America, as well as the relatively small, diverse countries of the Caribbean, also generally found themselves searching for viable sources of goods or services exports to China. This was even as they saw both the commercial and diplomatic potential of the expanded ties between their South American neighbours and China. In part because of the smaller size and relatively lower levels of economic development in Central America and the Caribbean, as well as the fact that many countries in the region recognized Taiwan rather than the People's Republic of China (PRC), China's stadium and road building, as well as generally more 'aid'-based activities, were a distinctive and prominent feature of its approach to the region prior to the introduction of the BRI (DeHart 2018). Overall, then, it is clear that in the years prior to the introduction of the BRI, South America was the region of Latin America and the Caribbean with the most dynamic economic and diplomatic relations with China.

If much of the dynamism and optimism of the boom years in relations between China and Latin America and the Caribbean was based in commodity-exporting South America, then many of the challenges and concerns were also concentrated there. China insisted on the 'win-win' benefits of commercial 'complementarity' (i.e. South America had the natural resources China needed). However, at least some South American governments and multilateral institutions worried, even during the height of the commodity boom, that the trade relationship with China looked uncomfortably similar to 'dependent' trade relations between Latin America and the Caribbean and North America or Europe in the nineteenth and twentieth centuries (Ferchen 2011; Stallings 2020). Dilma Rousseff, newly inaugurated as Brazil's president in 2011, thus felt compelled to insist that Brazil-China relations move 'beyond complementarity' (Ministry of Foreign Affairs 2011).

Whereas China's ability to maintain strong demand for South American commodities in the wake of the 2008/2009 financial crisis helped the region weather the crisis relatively well, the subsequent end of the China-led 'commodity super cycle', beginning around 2013, has meant that at least some fears of a boom-bust trade cycle have been borne out (Ferchen 2015). Countries such as Venezuela demonstrate this dynamic most clearly: ChinaVenezuela trade and diplomatic relations blossomed at the height of the commodity boom, but have run into extreme difficulties in the wake of Venezuela's ongoing post-commodity boom economic and political crisis. 
Venezuela also highlights how patterns of official Chinese state lending to some resource-rich Latin American countries at the height of the boom presaged some of the broader BRI-related concerns about the sustainability of Chinese 'development' lending in other regions as well (Ferchen 2018).

Thus, even if the boom years in the South America-China relationship were not altogether smooth, then the post-boom period has caused a good deal of reflection about what can and should sustain the economic and political relationship in a more stable and equitable way. Moreover, if there were challenges in the commodity-based, South America-China relationship, the countries of the Caribbean (see Gonzalez-Vicente, Chapter 7 in this volume) and Central America, as well as Mexico, were still left wondering how they could better link their own development and even diplomatic options to China. For some, the BRI has emerged as a symbol of a possible path forward. However, given the slow and tentative pace of China's willingness to extend the BRI to Latin America and the Caribbean, at least initially, and given the already clear and entrenched relationships between China and the region in the years directly before the launch of the BRI, the transformational potential of the BRI has so far remained limited at best. Yet surprisingly, it is in the Caribbean and Central America where the BRI has so far gained momentum.

\section{The BRI Finally Arrives: 2017 and New, Tentative Rollout of the BRI in the Americas}

For more than three years after the BRI was first introduced in 2013, there was much speculation among observers of relations between China and Latin America and the Caribbean about whether, and when, the initiative would be extended to the Americas. ${ }^{4}$ In September 2013, Xi Jinping introduced what would become known as the BRI in Kazakhstan, where it was formulated as the 'Silk Road Economic Belt'. Shortly afterward, in Indonesia, Xi announced plans for the '21st-Century Maritime Silk Road'. These introductions of the BRI highlighted that both the maritime and continental components of the BRI would be, at least initially, focused on China's Southeast and Central Asian neighbourhoods. Subsequent formulations of the BRI extended its

4 Based in Beijing from 2004 to 2017, the author participated in scores of academic, think tank, government and business community discussions among Chinese and LAC region participants about the China-Latin America relationship. Beginning around 2014, as the BRI concept picked up momentum, a common theme at such discussions was whether and when the BRI would be extended to Latin America and the Caribbean. 
geographic scope to Africa and then on to Europe, as a final destination for the convergence of both maritime and continental components. A muchcited official statement, published in 2015 by the National Development and Reform Commission and describing the aims of the BRI, stated: 'The Belt and Road Initiative aims to promote the connectivity of Asian, European and African continents and their adjacent seas' (NDRC 2015). The document therefore clearly omits the entire Western Hemisphere. Furthermore, the most recent 2016 official Chinese foreign policy document, or 'white paper', on relations between China and Latin America and the Caribbean, makes no mention of the BRI (State Council 2016). Clearly, as expansive, ambiguous, and often open-ended as the BRI has been, the Latin American and Caribbean region appears to at least initially have been seen by Chinese officials as simply beyond the project's core scope.

Yet in 2017 this all began to change. One important symbolic precursor to the rollout of the BRI in the region took place at the inaugural BRI forum in Beijing. There, Xi Jinping, speaking with then Argentine President Mauricio Macri, noted that the Latin America and Caribbean region was a 'natural extension' of the Maritime Silk Road (Barrios 2017). Similar official Chinese statements began to note that some countries in Latin America and the Caribbean could be important 'nodes' in the BRI network. Such comments were further bolstered by a 'Special Declaration on the Belt and Road', which was signed by officials from China and Latin America and the Caribbean at the first China-Community of Latin American and Caribbean States (CELAC) Ministerial Summit in January 2018.5

These symbolic, yet often still vague, statements indicated that both China and some countries in Latin America and the Caribbean were beginning to consider forms of participation under the rubric of the BRI. However, the truly catalytic BRI activities in the region began with a series of BRIthemed diplomatic and commercial agreements in Central America and the Caribbean. What is taken as inclusion in the BRI, or whether a country is considered as being 'in' or not, is still a largely nebulous and disputed category. However, one measure that has come to serve as a proxy is the signing of MoUs or other forms of BRI-themed 'cooperation agreements'. 6

5 The China-CELAC forum is similar in conception to the Forum on China-Africa Cooperation (FOCAC) but is newer and less institutionalized.

6 For instance, the Chinese government's official English language 'Belt and Road Portal' (https://eng.yidaiyilu.gov.cn/index.htm) lists 'partnership' countries defined as 'countries along the Belt and Road and countries that have signed cooperation agreements with China on Belt and Road Initiative'. This categorization is so expansive, though, that over 140 countries appear on the list. 
Panama was a bellwether: in June 2017, it switched its diplomatic recognition from Taiwan to the People's Republic of China and in November of the same year it also signed the first Latin American and Caribbean BRI MoU with China (Zhang 2018). In 2018, the Dominican Republic and El Salvador both followed suit by changing their diplomatic recognition and the Dominican Republic also signed a BRI MoU (Ellis 2018). Altogether, between 2017 and 2019, at least nineteen countries, the majority in Central America and the Caribbean, signed BRI MoUs or joint statements promoting BRI cooperation. ${ }^{7}$ In many of these cases, not only did Latin American and Caribbean countries make generally supportive statements about the BRI, but they also announced new infrastructure and commercial cooperation deals. Regardless of whether any of these deals are 'officially' designated as BRI projects by either the host government or by China (many of them are still on the drawing board or only partially completed), the symbolic connection between the MoUs and the announcement of projects such as ports, highways, and industrial parks is clear.

As such, 2017 was a turning point at least in terms of a series of BRI-themed MoU signings and associated infrastructure deals between China and Latin America and the Caribbean. But what are we to make of the relevance of this trend, especially in light of the history of relations between China and Latin America and the Caribbean that has been outlined above? One element that stands out is the concentration of Caribbean and Central American countries in the BRI-themed MoUs and related commercial deal announcements. As noted above, the real weight and momentum of the relationship between China and Latin America and the Caribbean has largely been with the commodity-rich countries of South America. One explanation for the relative concentration of BRI-themed announcements and dealmaking in Central America and the Caribbean is simply that those regions had untapped potential, especially in the area of highway and port infrastructure (see Gonzalez-Vicente, Chapter 7 in this volume). At the same time, because the BRI has a firmly established reputation as Xi Jinping's signature foreign policy project, governments in Latin America and the Caribbean have likely been willing to sign MoUs and brand certain projects as part of the BRI out of political as much as economic calculation. For the countries of Central America and the Caribbean that had long sought more commercial opportunities with China, signing on to the BRI may appear a low-cost gesture to facilitate Chinese lending and investment that had hitherto been in short supply.

7 See the following website for an unofficial listing of BRI MoUs to date: https://www.beltroadinitiative.com/memorundum-of-understanding-belt-and-road-initiative/. 
Regarding those countries in South America such as Venezuela, Ecuador, and Bolivia that have also signed BRI MoUs, such signings fit with these countries' close, and often politicized, diplomatic ties to China (Liévano 2019). ${ }^{8}$ They too are likely to have calculated that the signing of BRI agreements would, on balance, offer more dealmaking opportunities. Venezuela President Nicolas Maduro may also have hoped that signing BRI agreements would be of help in his efforts to retain China's diplomatic recognition and forbearance given Venezuela's limited ability to meet its debt and oil-export obligations to China. Of course, as notable as which countries have chosen to sign BRI-themed MoUs or deals is which ones have not. Neither Brazil nor Mexico, the two biggest countries in Latin America and the Caribbean, nor many of the South American countries at the core of commodity-based ties to China (with the exceptions of Chile and Peru), have signed such statements. For such countries, it may not be obvious what the benefits of signing BRI MoUs or BRI-themed infrastructure deals are, especially compared to similar previous efforts. In fact, doing more infrastructure deals has long been on the table in relations between China and Latin America and the Caribbean. While some of that cooperation has indeed come to fruition (even if attended by controversy), many other deals have been left on the table or scuttled altogether (Myers 2018).

Whatever the motives that lead Latin American and Caribbean countries to engage in, or refrain from, BRI-themed dealmaking with China, one clear element of what is new about the relationship between China and the region since 2017 is the attitude taken by the United States towards dealmaking between China and Latin American and Caribbean countries. The entrance, or extension, of the BRI into Latin America and the Caribbean since 2017 has coincided with a much more critical US government attitude towards China's role and influence in the Americas. It may be pure coincidence that the Trump administration came into office in 2017 at the same time as the Latin American and Caribbean BRI-themed MoUs and deals in that year were announced. However, what is clear is that the United States has taken a dim view of at least some of this BRI-themed dealmaking, especially in places like Panama. In Panama, the BRI MoU and related Panama Canal upgrade deals with China were also accompanied by Panama's change from diplomatic recognition of Taiwan to recognition of the PRC. US Secretary of State Mike Pompeo, in a visit to Panama in October 2018, made clear US concerns about China's role in the country (Wong 2018). Just a month

8 Peru also signed a MoU in 2019, although its ties to China have not been part of the 'New Left' foreign policy that has characterized some of its Andean neighbours. 
before that visit, the US temporarily recalled its top diplomats from Panama, as well as the Dominican Republic and El Salvador, over their decisions to withdraw diplomatic recognition from Taiwan (Webber 2018). While Venezuela's troubled ties to China were in place well before the BRI was born or Venezuela signed any BRI MoUs, the United States has in recent years highlighted Venezuela as one of the Latin American countries where Chinese financial deals have led to insalubrious results (Gunia 2019). While the BRI per se is not the reason for, or primary focus of, heightened US-China strategic competition in Latin America and the Caribbean, it is a potent symbol of China's presence and a lightning rod in the increasingly heated US-China great power competition.

Beyond the renewed diplomatic and dealmaking activity with China in Central America and the Caribbean, and a growing US pushback against China's presence in the region, there are a few other answers to what is 'new' in the relationship since the BRI's at least partial expansion to the region. Chinese-backed infrastructure development, while on the table for many years, has seen an uptick in recent years. Port developments in the Caribbean are one example, while electricity infrastructure deals, including in Brazil's electricity grid, are another (Myers 2018). Again, some of those transport infrastructure deals in the Caribbean and Central America are tied to BRI MoUs or otherwise branded as BRI projects by host governments and China, while energy grid deals in Brazil do not bear any obvious BRI stamp (Andreoni 2019).

In addition to transport and energy infrastructure deals, two additional elements of BRI 'connectivity'-themed developments merit mention in any assessment of what is 'new' in relations between China and Latin America and the Caribbean in recent years. The first component is activities branded as part of China's 'Digital Silk Road'. In addition to transport infrastructure like roads, railways, and ports, as well as energy infrastructure like dams, coal-fired power plants, and energy grids, Chinese officials have been keen to include digital infrastructure and digital connectivity as part of the BRI (Eder et al. 2019). In the case of South America, a fibre-optic cable across the Atlantic from Africa to Brazil has been at least partially financed, built, and operated by Chinese firms. A similar cable across the Pacific from China to Chile was under discussion until the contract was given to a Japanese firm (Huawei Marine 2018; Hirose \& Toyama 2020).

A second and more recent development is renewed discussion about the role of a 'Health Silk Road'. First proposed in 2015, China's National Health and Family Planning Commission formulated a plan to build health cooperation (Bing 2020), including 'infectious disease prevention and control', into 
the overall BRI framework. While largely focused on neighbouring countries in Southeast Asia, the Health Silk Road concept has gained new life, and attracted new controversy in light of the 2020 COVID-19 pandemic. The relevance for relations between China and Latin America and the Caribbean of cooperation under the rubric of the New Health Silk Road, as a kind of supplement to the BRI, has yet to be seen beyond an initial public diplomacy push and potential donations or sales of personal protective equipment, testing kits, and medical machines (Escobar 2020).

\section{Conclusion}

This overview of the BRI in Latin America and the Caribbean underscores how relatively new and partial the extension of the BRI, per se, is in the region. It also underscores how, even with the arrival of the BRI, much remains unchanged about the nature and dynamics of relations between China and Latin America and the Caribbean. Questions remain about the sustainability and equality of trade relations, especially commoditydependent exports from South America and concerns about trade deficits in Mexico. In other words, structurally, the relationship contains many elements of Latin American commodity dependency on Chinese demand (Stallings 2020). This is especially a concern in the wake of the COVID-19 crisis given that it is unlikely that China will be able to play the role of demand-side saviour for South American commodity exports during the global economic downturn that has already begun. ${ }^{9}$ As the chapter on the China-Caribbean relationship by Gonzalez-Vicente (Chapter 7 in this volume) highlights, China's role in the region has complicated many of the longstanding and unresolved questions about sustainable foreign investment and financial relations. Overall, China's role in Latin America and the Caribbean, including through the recent introduction of the BRI, has had contradictory impacts on the region's development prospects.

How the BRI underscores such longstanding contradictions is also borne out in other aspects of the relationship between China and Latin America and the Caribbean. For instance, academic and civil society discussions about whether the BRI will or will not change corporate social responsibilitytype (CSR) concerns about environmental and local community impacts

9 Media commentary that China is gaining geopolitical ground in Latin America and the Caribbean through its 'mask diplomacy' in the wake of the Corona crisis miss these bigger structural challenges. For example, see Stott (2020). 
of Chinese investments in the Amazon or the Andes are little different today from the era when the BRI had not yet reached the Americas (Ray et al. 2017). Even the US pushback against China's role in Latin America and the Caribbean seems less about the BRI per se and more about longer-term structural shifts in US-China relations.

Yet pondering the role and relevance of the BRI in Latin America and the Caribbean does offer an opportunity to place questions of learning and lesson-sharing in a comparative regional and historical perspective. In many ways, discussions about the role of the BRI in Latin America and the Caribbean demonstrate the combination of enthusiasm and anxiety that has characterized views from countries across the region since the early 2000s. In the early days of the relationship, there was both Chinese and Latin American and Caribbean regional enthusiasm (not to mention politicized boosterism) about the arrival of China in the region as a new commercial and diplomatic partner. As noted above, though, questions soon emerged about the quality and sustainability of those partnerships, questions that were tested and answered in different and sometimes contradictory ways after the 2008/2009 financial crisis and in the wake of the end of the commodity boom after 2013. In some ways, the entry of the BRI into the region has stoked similar questions about what new dimensions the BRI could bring to a relationship with well-entrenched patterns, challenges, and problems.

One theme that was always present throughout these pre-BRI years was the extent to which Latin American and Caribbean countries were passive or active players in relationships in which it almost always seemed to be the Chinese side that had proactive commercial or diplomatic strategies for regional or bilateral ties. As a Chinese initiative, the BRI has prompted similar questions with similar answers; as a region, Latin America and the Caribbean has not presented itself as a coherent actor. The consequence has been that the region is almost always a passive or divided player compared to China. Yet the reality has almost always been more complex. On the Chinese side, different Chinese government banks or firms, not to mention private firms, have adopted tailored approaches depending on the country or economic sector in which they are lending or investing. On the Latin American and Caribbean side, different countries have long adopted different approaches to diplomatic and commercial ties to China. On the ground, Latin American and Caribbean businesses, civil society actors, and researchers have been keen to learn and adapt to the opportunities or challenges they have seen with China's rising presence in the region. The BRI offers a new framework in which these long-established patterns will continue to play out. 
One last note on the linkage between agency and learning regards the question of whether or not, and how, different Latin American and Caribbean actors have learned from one another or from counterparts in other regions about China-specific challenges and opportunities. It is often striking how many government, business, civil society, or researcher discussions about relations between China and Latin America and the Caribbean countries sound like echoes of similar conversations, either in neighbouring countries or in other regions, such as Africa or Southeast Asia (Ferchen 2020). Who are the Chinese banks or companies involved in a package loan-for-infrastructure deal? Are Chinese businesses and government bureaus learning from past experience on CSR environmental or local community impact issues? Do the experiences gained from regional groupings such as ASEAN, 17+1, and FOCAC offer lessons for the relatively new China-CELAC regional forum (see Jakóbowski 2018)? The potential for academic and policy 'learning' would be greatly enhanced through ever more comparative research addressing these and similar questions.

\section{References}

Andreoni, Manuela (2019, August 9). 'China Bets on Wind and Solar Power in Brazil'. Diálogo Chino. Retrieved 19 November 2019 from https://dialogochino. net/en/climate-energy/29559-china-bets-on-wind-and-solar-power-in-brazil/.

Barrios, Ricardo (2017, July 18). 'China's Belt and Road Lands in Latin America'. InterAmerican Dialogue. Retrieved 17 September 2017 from https://www.thedialogue. org/analysis/chinas-belt-and-road-lands-in-latin-america/.

Bing, Ngeow Chow (2020, May 26). 'COVID-19 Speeds up China's "Health Silk Road”. East Asia Forum. Retrieved 29 May 2020 from https://www.eastasiaforum. org/2020/05/26/covid-19-speeds-up-chinas-health-silk-road/.

DeHart, Monica (2018). 'China-Costa Rica Infrastructure Projects: Laying the Groundwork for Development?' In Enrique Dussel Peters, Ariel Armony \& Cui Shoujun (eds.), Building Development for a New Era: China's Infrastructure Projects in Latin America and the Caribbean (pp.3-23). Mexico City: Asian Studies Center, Center for International Studies, University of Pittsburgh, and Red Académica de América Latina y el Caribe sobre China.

Dussel Peters, Enrique (2015, September 16). China's Evolving Role in Latin America: Can It Be a Win-Win? Atlantic Council. Retrieved 14 November 2015 from https:// www.atlanticcouncil.org/in-depth-research-reports/report/china-s-evolvingrole-in-latin-america-can-it-be-a-win-win/. 
Eder, Thomas; Arcesati, Rebecca \& Jacob Mardell (2019, August 28). 'Networking the "Belt and Road" - The Future is Digital'. Mercator Institute for China Studies. Retrieved 3 December 2019 from https://merics.org/en/analysis/networkingbelt-and-road-future-digital.

Eisenman, Joshua \& Heginbotham, Eric (eds.) (2018). China Steps Out: Beijing's Major Power Engagement with the Developing World. New York: Routledge.

Ellis, Evan (2018, August 21). 'El Salvador Recognizes the PRC: Confrontation on the FMLN's Way out the Door'. Global Americans. Retrieved 27 August 2018 from https://theglobalamericans.org/2018/o8/el-salvador-recognizes-the-prcconfrontation-on-the-fmlns-way-out-the-door/.

Escobar, Pepe (2020, April 2). 'China Rolls out the Health Silk Road'. Asia Times. Retrieved 8 April 2020 from https://asiatimes.com/2020/04/china-rolls-outthe-health-silk-road/.

Ferchen, Matt (2011). 'China-Latin America Relations: Long-term Boon or Short-term Boom?' Chinese Journal of International Politics, 4(1), 55-86.

Ferchen, Matt (2015, January 9). 'China, Latinoamérica y el fin del auge de las materias primas' [China, Latin America, and the end of the commodity boom]. El País. Retrieved 9January 2015 from https:/elpais.com/internacional/2015/01/07/ actualidad/1420651906_278565.html.

Ferchen, Matt (2018, August 16). 'China, Venezuela, and the Illusion of Debt-Trap Diplomacy’. AsiaGlobal Online. Retrieved 16 August 2018 from https://www. asiaglobalonline.hku.hk/china-venezuela-debt-trap-diplomacy.

Ferchen, Matt (2020, January 8). 'How China Is Reshaping International Development'. Carnegie Endowment for International Peace. Retrieved 8 January 2020 from https://carnegieendowment.org/2020/01/08/how-china-isreshaping-international-development-pub-80703.

Friedman, Jeremy (2015). Shadow Cold War: The Sino-Soviet Competition for the Third World. Chapel Hill: University of North Carolina Press.

Gallagher, Kevin (2016). The China Triangle: Latin America's China Boom and the Fate of the Washington Consensus. Oxford: Oxford University Press.

Gunia, Amy (2019, April 16). “Mr. Pompeo, You Can Stop”: China Refutes “Despicable” US Criticism of Its Involvement in Venezuela'. Time. Retrieved 28 September 2019 from https://time.com/5571403/china-us-latin-america-venezuela/.

Hirose, Yohei \& Toyama, Naoyuki (2020, July 29). 'Chile Picks Japan’s TransPacifıc Cable Route in Snub to China'. Nikkei Asian Review. Retrieved 30 July 2020 from https://asia.nikkei.com/Business/Telecommunication/ Chile-picks-Japan-s-trans-Pacific-cable-route-in-snub-to-China.

Huawei Marine (2018, September 5). 'South Atlantic Inter Link Connecting Cameroon to Brazil Fully Connected'. Press release. Retrieved 23 January 2020 from http://www.huaweimarine.com/en/News/2018/press-releases/pr20180905. 
Jakóbowski, Jakub (2018). 'Chinese-Led Regional Multilateralism in Central and Eastern Europe, Africa and Latin America: $16+1$, FOCAC, and CCF'.Journal of Contemporary China, 27(113), 659-673.

Liévano, Andrés Bermúdez (2019, June 18). 'China's Belt and Road Advances in Latin America's Andean Region'. Diálogo Chino. Retrieved 22 June 2019 from https:// dialogochino.net/en/infrastructure/27815-chinas-belt-and-road-advances-inlatin-americas-andean-region/.

Ministry of Foreign Affairs (2011, April 8). 'President Dilma Rousseff to Visit the People's Republic of China - Beijing, April 12-13, 2011'. Government of Brazil. Retrieved 9 June 2011 from http://www.itamaraty.gov.br/en/press-releases/1656o-presidentdilma-rousseff-to-visit-the-people-s-republic-of-china-beijing-april-12-and-13-2011.

Myers, Margaret (2018, November 13). 'China's Transport Infrastructure Investment in LAC: Five Things to Know'. Inter-American Dialogue. Retrieved 15 November 2018 from https://www.thedialogue.org/blogs/2018/11/ chinas-transport-infrastructure-investment-in-lac-five-things-to-know/.

NDRC (2015, March). 'Vision and Actions on Jointly Building Silk Road Economic Belt and 21st-Century Maritime Silk Road'. National Development and Reform Commission, Ministry of Foreign Affairs and Ministry of Commerce, People's Republic of China. Retrieved 25 October 2020 from https://web.archive.org/web/20181127225143/ http://en.ndrc.gov.cn/newsrelease/201503/t20150330_669367.html.

Ray, Rebecca, Gallagher, Kevin, López, Andres \& Sanborn, Cynthia (eds.) (2017). China and Sustainable Development in Latin America: The Social and Environmental Dimension. London: Anthem Press.

Schamis, Hector E. (2006). 'A "Left Turn" in Latin America? Populism, Socialism, and Democratic Institutions'. Journal of Democracy, 17(4), 20-34.

Stallings, Barbara (2020). Dependency in the Twenty-First Century? The Political Economy of China-Latin America Relations. Cambridge: Cambridge University Press.

State Council (2016, November 24). 'Full Text of China's Policy Paper on Latin America and the Caribbean'. State Council of the People's Republic of China. Retrieved 6 December 2016 from http://english.www.gov.cn/archive/white_paper/2016/11/24/content_281475499069158.htm.

Stott, Michael (2020, August 8). 'China Cleans up in Latin America as US Flounders over Coronavirus'. Financial Times. Retrieved 13 August 2020 from https://www. ft.com/content/741e72ed-e1db-46og-b389-969318f17oe8.

Strauss, Julia (2009). 'The Past in the Present: Historical and Rhetorical Lineages in China's Relations with Africa'. China Quarterly, 199, 777-795.

Webber, Jude (2018, September 8). 'US Recalls Ambassadors over Recognition of China'. Financial Times. Retrieved 9 November 2018 from https://www.ft.com/ content/1bf84e7c-b301-11e8-8d14-6fo49do6439c. 
Wong, Edward (2018, October 19). 'Mike Pompeo Warns Panama against Doing Business with China'. New York Times. Retrieved 25 October 2018 from https://www. nytimes.com/2018/10/19/world/americas/mike-pompeo-panama-china.html.

Zhang, Hui (2018, December 3). 'BRI Projects to Highlight Ties after Xi Visits Panama'. Global Times. Retrieved 5 April 2019 from http://www.globaltimes. cn/content/1130177.shtml.

\section{About the Author}

MATt FERCHEN's research focuses on the connections between China's foreign and domestic political economy. He has written extensively about China's economic statecraft, China's developing country diplomacy, and debates about the 'China model' of development. He is particularly interested in lessons researchers and policymakers can learn from comparisons of China's economic and political relations with different regions, from Southeast Asia to Latin America, Europe, and the United States. From 2008 to 2017 Ferchen was a faculty member in the Department of International Relations at Tsinghua University and from 2011 to 2019 he was a scholar with the Carnegie-Tsinghua Center for Global Policy. In 2020 he was appointed Head of Global China Research with the Mercator Institute for China Studies (MERICS). He has been engaged with LeidenAsiaCentre research since 2017. Ferchen holds an MA from Johns Hopkins School of Advanced International Studies and a PhD from Cornell. 


\title{
$5 \quad$ Ascertaining Agency
}

\author{
Africa and the Belt and Road Initiative
}

Stacey Links

\begin{abstract}
Chapter 5 introduces the African region in relation to China and the BRI. It provides an overview of the current field of China-Africa studies and identifies common narratives that have enveloped these relations. The chapter highlights one of the field's remaining lacunas, namely the question of African agency, looking at reasons why the issue of agency has been neglected in the literature and how it is treated in the few instances where it is analysed. The chapter also explores Africa's centrality to the BRI against the backdrop of intensifying China-Africa relations. It makes a case for Africa as a fundamental cornerstone of understanding the BRI in both its practical and more ideological facets.
\end{abstract}

Keywords: Belt and Road Initiative, agency, China, Africa, China-Africa relations

[T] he African Express Rail now connects all the capitals of our former states, and indeed they will be able to crisscross and see the beauty, culture and diversity of this cradle of humankind. The marvel of the African Express Rail is that it is not only a high-speed train, with adjacent highways, but also contains pipelines for gas, oil and water, as well as ICT broadband cables: African ownership, integrated planning and execution at its best! - African Union Commission Chairperson Nkosazani Dlamini Zuma, 'AU Email from the Future' (2014)

The quote above is an excerpt from the African Union (AU) Commission Chairperson's 'Email from the Future'. This is an email envisioning what

Schneider, Florian (ed.), Global Perspectives on China's Belt and Road Initiative: Asserting Agency through Regional Connectivity. Amsterdam, Amsterdam University Press 2021 DOI: 10.5117/9789463727853_CHO5 
Africa will look like in the year 2063. This hypothetical email, dated 24 January 2063, has been produced by the African Union Commission to reflect the goals that are set to be achieved through its agenda 'Africa 2063: The Africa We Want' (Zuma 2014). A palatable theme in the hypothetical email is the promise of an integrated and interconnected Africa, underpinned by 'state of the art' infrastructure that serves the people.

The centrality of development is a logical goal for the African continent given the twin and interrelated challenges of persistent poverty and chronic underdevelopment. This is not only a goal held by the continent's leaders but is also supported at an international level through the United Nations' Sustainable Development Goals, for example. Beyond this email from the Commission, the idea of African development as a way through the impasse of widespread poverty is reflected as a core objective of the African Union more broadly (African Union Commission 2015). It is also reflected in international law, included in documents such as the Declaration on the Right to Development (UN General Assembly 1986). The continued economic dependence of the African continent on so-called 'core' states is most famously reflected in Immanuel Wallerstein's world systems theory as well as dependency theories that emphasize the international division of labour as the source of Africa's persistent underdevelopment (Wallerstein 1974; Wallerstein 2004; Rodney 1972). Thus while the continent has formally become independent from the clutches of political colonial rule, economic independence remains an unfulfilled continental goal. Equally, the promises of following a neoliberal paradigm to escape from the poverty trap have remained problematic when considering the difficulties developing economies face in structurally upgrading and climbing up the global value chain (see, for example, Noman and Stiglitz 2012; Taylor 2016). Africa's economic activity continues to be dominated by the supply of natural resources, and there are few industrial strategies to escape this commodity dependency. Economically speaking the continent remains trapped in the perennial 'resource curse' despite efforts to break this cycle.

Understanding the relations between China and Africa from this point of departure is essential if we are to grasp the internal logic and contours of this engagement. China-Africa relations have increasingly become the focus of policy, international politics, and academic scholarship, over the past decade in particular. Despite the long timespan in which there have been relations between Africa and China, the deepening engagement between China and the continent, particularly economic engagement, has become a topic of international interest (and, some would argue, 'concern'). These deepening relations present the world with an arguably 'new' and seemingly 
unwavering form of cooperation. Emblematic of what scholars term SouthSouth cooperation, China-Africa relations have also become a focal point for understanding a 'rising China'. Despite areas for concern, China-Africa relations seemingly enjoy considerable support across the African continent (Gadzala \& Hanusch 2010; Hanush 2012; Lekorwe et al. 2016; Maru 2019). To shed light on why this is the case, it is paramount to understand how the relationship works and specifically how a project such as the Belt and Road Initiative (BRI) is 'received' on the continent.

The BRI has emerged as a key interest area and presents an active dimension of China-Africa relations that is worthy of exploration. In a world where China's impact is increasingly tangible and consequential, ascertaining the BRI's functioning across a range of regions is all the more important. The BRI's official goal of fostering development through global interconnectivity is particularly relevant given the African development agenda that has been outlined above (Xi 2019). If any one aspect of Chinese engagement on the continent is of particular interest, then the BRI is an obvious contender. However, Africa was given a relatively marginal role in the initial conceptualization of the BRI when it was launched by China in 2013. This means that ascertaining the current importance of the BRI in the African context requires insight into both the BRI and China-Africa relations more broadly. This chapter therefore aims to shed light on the BRI in Africa by taking into account the broader China-Africa engagement.

Analysing relations between Chinese and African actors raises the question of agency. Agency matters in that it provides insight into how actors behave. From an international relations perspective, it gives nuance to ideas about the drivers of, as well as constraints on, the behaviour of different actors. Naturally then, discussion of China-Africa relations, and the BRI in particular, is enriched if we are able to uncover the ways that actors navigate challenges, opportunities, and relations with each other. In this way, agency is also often relational and inter-subjective. An actor's agency does not stand alone but interacts with the (in)actions and intentions of others. Moreover, agency is closely related to power. Who has power, and in what ways, has become a central point of contention in debates about relations between China and Africa, particularly given the power differentials between China and individual African states. One assumption made about 'agency' and 'power' is that the actor with more power also has relatively more agency. However, within the context of this chapter, agency is defined as both the act of holding specific interests and goals as well as the capacity that actors possess to set agendas, negotiate, and act in accordance with their specific interests and goals. Power then, is not a focal or defining characteristic of 
agency but is closely related to structure. This is a point that will be further explored.

This leads to the crux of this chapter, namely the intersection between African agency and the BRI. Importantly, commentary on the BRI in Africa, as well as China-Africa relations more broadly, often presumes little to no room for African perspectives in dealings with China (French 2014; Mourdoukoutas 2018; Risberg 2019). Common narratives of 'neo-imperialism', 'neocolonialism', as well as tropes of the 'dragon in the bush' or the 'bear and the honeypot', reflect a widely held assumption that Africa remains a mere object in these relations (Marton \& Matura 2011). Questions around power and agency in this context are therefore frequently centred on China and its relative power/dominance vis-à-vis African actors. This chapter seeks to move away from reductive assumptions and instead outlines the need and ways in which the BRI can be understood through the lens of African agency.

The chapter proceeds as follows: It starts with an introductory overview of China-Africa relations and the BRI in Africa in particular. It does so with the question of African agency in mind and sets out issues for consideration in this often-overlooked area of research. It also raises the question of why understanding African agency in the context of the BRI is important. In doing so, it provides a foundational outline, which is then build upon in the subsequent chapters that examine the cases of the Digital Silk Road in Ethiopia and agency in the Southern African Development Community (SADC).

\section{Emergence of China-Africa Relations on the International Agenda}

Engagement between Africa and China has garnered significant attention in recent years. Despite a long history of engagement, recent relations were shaped by the first ever Forum on China-Africa Cooperation (FOCAC), a ministerial conference that took place in 200o. Broader relations between Africa and Asia date much further back to cooperation at the Bandung Conference of 1955. The historical relationship also includes China's political support for independence movements across the African continent during decolonization. However, the 2000 forum provided the first coherent framework within which China-Africa cooperation could operate in a 'new' era. This new era has coincided with China's period of unprecedented economic growth and visibility on the international stage. The growth of China has therefore led to the deepening of China-Africa cooperation and engagement formally and informally. 
In 2006, the third ministerial conference and the first Forum on ChinaAfrica Cooperation (FOCAC) summit were held in Beijing. These events garnered significant scholarly attention, in part due to the sheer number of African representatives in attendance as well as Hu Jintao's pledge of US $\$ 5$ billion of concessionary loans to the continent (King 2007; Naidu 2007). ${ }^{1}$ However, it was the fifth ministerial meeting, which was held in Beijing in 2012, combined with China's swift economic rise, that really placed China's engagement in Africa on the international agenda. This was exemplified by then US Secretary of State Hillary Clinton, who launched what has been termed a 'veiled attacked' on China's engagement on the continent (Ghosh 2012; Smith 2012). It was at this point that China-Africa relations entered into the public's international political discourse and were no longer confined to scholarly inquiry.

However, China-Africa relations are far more multifaceted and complex than is often assumed. Their engagement includes official diplomatic relations, concessional loans, gift giving, business relations and investment, and people-to-people exchange (Brautigam 2009). In 2018, two-way trade between China and the African continent totalled US $\$ 185$ billion. Meanwhile Chinese foreign direct investment (FDI) to the continent has been steadily increasing since 2003. In 2014, Chinese FDI exceeded that of the US, which has been declining since 2010 (CARI 2020). Similarly, Chinese foreign aid to the continent has increased from US $\$ 631$ million in 2003 to US $\$ 3.3$ billion in 2018. With the exception of rebounds in most sectors between 2016 and 2018, it would seem Chinese economic involvement on the continent has steadily expanded. While traditional partners remain important to countries in Africa, the Chinese presence has been notable and visible. This has led 'third-party' states to ask what this presence means for their own engagement. While economics are important, geopolitical implications and influence are undoubtedly also a consideration. The current situation has been described by some as a 'new' Cold War, or a 'new' scramble for Africa (Marton \& Matura 2011). In this way, the 'Western' and 'Chinese' activities on the African continent have frequently been presented in competitive terms.

Despite increased knowledge about China-Africa relations, because of the amount of largely speculative reports about their nature, scholarly investigation has concerned itself primarily with the task of 'myth-busting' incorrect ideas about them (see Hirono \& Suzuki 2014). The vast circulation

1 Several research and interest groups were created around this time, such as the Chinese in Africa /Africans in China Research Network (CA/AC), Sino-Africa Joint Research Centre (SAJOREC), China-Africa Research Initiative (CARI), and the China Africa Project (CAP). 
of such speculative reports has highlighted the need for rigorous research in what continues to be a highly politicized area of inquiry. The ever-increasing number of China-Africa institutes and research agendas reflects continued interest in the relations between China and the continent. The topic of China-Africa cooperation has also become of interest to policymakers who have focused on the implications of these relations for the international economic, political, and normative order(s) (see, for example, Chin \& Thakur 2010; Du Plessis 2016; European Parliament 2008).

While a large part of the challenge of disentangling myth from reality in China-Africa relations is empirical, there exists an equally pressing conceptual challenge. In many respects China-Africa relations challenge the very way in which international relations are traditionally theorized and thought about. Questions about whether self-interest primarily drives relations with African states, about the neocolonialist nature of these relations, and about whether some of these relations constitute forms of foreign aid all speak to popular assumptions about these relations. Similarly, the concept of agency that this chapter discusses, requires careful and critical analysis if we are to move away from simply reproducing reductive accounts of China-Africa relations. This chapter seeks to move beyond a baseline or universal definition of agency, as the capacity to hold specific interests or goals, in order to highlight the specific considerations of African agency (vis-à-vis the BRI). In its consideration of these specificities, the chapter broadly fits with the approach taken by constructivist international relations theory. However, it also adopts innovative and critical perspectives that seek to reconcile the structure-agent debate (see Klotz 2006). The objective is therefore not to give a detailed account of all things China-Africa, but rather to give an overview of China's BRI in Africa and reflect on the challenges and considerations of African agency within this context.

\section{China's BRI in Africa}

Since its inception, China's BRI has grabbed international attention for its scope, ambition, and novelty. ${ }^{2}$ In part due to its sheer magnitude, this global project is under considerable scrutiny from onlookers. Some have touted it as China's tool for global domination and hegemony (Cavanna 2018; Ellis 2018; Sharma 2019). Others have noted its mixed effects, both positive and 
negative (China Power Team 2017; De Cremer et al. 2020). Meanwhile others have gone further to provide detailed and nuanced accounts (Zhang 2018).

Described as the twenty-first-century Silk Road, the BRI has been envisioned to connect landmasses from China through to the Middle East, Africa, and Europe, largely mimicking the original silk trade routes (see Sarwar 2017; Chan 2018; Ling 2020). Nevertheless, over time it has become an umbrella term under which a variety of Chinese developmental projects focused on regional connectivity and infrastructure have been placed. Geographically, then, the project has become global in scale and is not bound to a single uninterrupted route as was initially envisioned when the initiative was launched with the name 'One Belt One Road' or OBOR. While the initial route remains the core of the initiative, the 'opening up' of the BRI has enabled the inclusion of disparate parts of the world that were previously not directly linked in the core trajectory.

\section{Extending the Silk Roads 'into Africa'}

An area that has been subsumed under the BRI is Africa, most notably East Africa. As a result, the BRI has become an additional 'facet' of broader China-Africa engagement. The inclusion of Africa into the core trajectory of the BRI has been straightforward and has resulted in a range of projects. To this end the BRI has provided a way forward for greater connectivity and integration, for example, that in the East African region. It has thus been largely welcomed across the continent (EAC 2020). Examples of BRI projects in Africa include the construction of a port in the East African state of Djibouti, which has developed into a BRI hotspot. Another BRI project is the Kenyan Standard Gauge Railway, connecting the cities of Mombasa and Nairobi. However, of significant value has been the way in which the BRI has tapped into the intra-regional 'connectivity' market in Africa. This involves cross-border infrastructure projects such as the Lamu Port South Sudan-Ethiopia Transport corridor (LAPPSET) and the Standard Gauge Railway that connects Addis Ababa to the Port of Djibouti (Eom et al. 2018: 2). These projects have inadvertently kick-started much-needed intra-African trade that advances the goal of pan-African development. In a similar way, the Digital Silk Road, which is a part of the BRI focused on information technology, has seemingly fit the needs of regional digital networks and telecommunication development. As is noted by the China-Africa Research Initiative (CARI), while it is increasingly known that China-Africa cooperation is diverse, the BRI is set to accelerate existing infrastructure and industrial cooperation, expanding cooperation even further (Chan 2018). 
From a financing perspective, the China Development Bank and the Export-Import Bank of China (Eximbank) are the key lending sources of BRI projects, alongside the Silk Road Fund. While the Eximbank provides $67 \%$ of loans to Africa (Chan 2018:1), it is specifically mandated to provide BRI firms, or Chinese firms and state-owned enterprises, with low-interest credit, tax incentives, and customs-free exports of Chinese goods and machinery that may be necessary for projects (ibid.: 2). It is important to note, however, that the BRI has not been established as an altruistic aid project, but as an economic project that acts in part as a conduit for China's domestic industrial overcapacity (Van Staden et al. 2018). In addition, though concerns related to the economic viability and sustainability of BRI projects remain, it is noteworthy that China is not a major contributor to debt distress on the continent despite trends of heavy borrowing (Eom et al. 2018).

The BRI's focus on infrastructure that supports cross-border trade and integration is seen as a panacea for African development and thus attractive to African states and regional organizations, such as the African Union. It should therefore not come as a surprise that the lack of viable alternatives to addressing these developmental challenges is often presented as a driver for continued cooperation (see Dahir 2018; Phiri \& Mungoma 2019).

Due to the vast scope of the projects included under the BRI, as well as the common practice of retroactively labelling projects BRI projects, the BRI has come to include a wide and diverse range of different kinds of projects (ibid.). Thus, while Africa was marginal within the BRI's initial geographic scope, the expansion of the initiative to an all-encompassing global project of connectivity and development has made Africa as relevant as any other region to discussions about the global impacts of the BRI.

One aim of this chapter is to examine African agency in relation to the BRI. Related to this topic, Van Staden et al. (2018) have highlighted the various complexities and diverse levels of African agency vis-à-vis the BRI. An important distinction that is directly related to agency is that while 'the BRI is Beijing-directed' it is 'not necessarily Beijing-controlled' (ibid.: 23). This will be further demonstrated in the chapter that follows after this, which looks at the case of Ethiopia. In this case, BRI projects have enabled direct connectivity between East Africa and Europe, despite the characterization of the BRI as an exclusively 'Chinese initiative'. This kind of outcome from the BRI is often attributed to the responsive nature of China-Africa relations. However, such examples also point to the agency exercised by African actors to instrumentalize the BRI to their benefit - a point that I will return to below (Demissie 2018; Jian 2018; Wissenbach 2020). 
Geographically speaking, North and East Africa have by far been the central focus of the maritime and overland 'Silk Roads' of the BRI. However, the initiative has far wider reach on the African continent (see Eom et al. 2018; Dollar 2019). Other parts of the continent, not directly linked to the BRI's core trajectory, have mostly been subsumed under memoranda of understanding (MoUs) that place them within the BRI or BRI-funded projects. One such region is Southern Africa, which arguably is of little direct appeal or consequence to the BRI's core route. For this reason, it has remained largely on the outskirts of analysis of the BRI. Nevertheless, due to the BRI's expansion as a broader global project, Southern Africa, like other regions, has been included, albeit from a distance (Breuer 2017). To this end, the BRI has become, or is at least on its way to becoming, an all-encompassing (geographic) project, transcending the boundaries of the 'original' silk routes.

\section{Regional Synergies: China's BRI and the Continental Goals}

Not only does China's BRI include Africa in a geographic sense, but it equally includes it in a discursive sense. The BRI fits into the broader regional agenda exemplified by the African Union's Agenda 2063. The synergies between these two projects were already noted in 2015, during gatherings such as the One Belt One Road and a Prosperous Africa Conference, convened by the Human Sciences Research Council (HSRC) in South Africa. In particular, the BRI and Agenda 2063 are seen as complementing each other in their goals of infrastructure development, industrialization, and peace and security (Ndzendze \& Monyae 2019). Scholars such as Ndzendze and Monyae (2019) note the synergies, convergences, and linkages between the African Union's agenda and the BRI. They also underscore the BRI's ability to strengthen the African Union's agenda (ibid.: 1). From this perspective, the overall tone of discourse is one where the BRI presents an opportunity for the continent in a number of key issue areas. According to the African Union, it is the 'prospect for development of many poor countries' that appeals to the continent as well as the idea that 'aspirations are [...] intertwined and mutually achievable' (African Union Commission 2015: 1). Addressing Africa's infrastructure deficit through the BRI is seen as having a 'multiplier effect' for Africa's growth plans (Ehizuelen \& Abdi 2017: 299). In this vein, 'the OBOR initiative is anticipated to stimulate African growth by snowballing infrastructure development' (ibid.: 300) - an issue that has long been on the African agenda.

As Dollar (2019) concludes, this position seems to trump the projections about the negative impact that the BRI might have on the continent. 
Curiously, despite the known risks and social impacts of specific projects, as well as questions about environmental and economic sustainability, Africa is reportedly the region of the world with the most positive perception of the BRI (García-Herrero \& Jianwei 2019:4). This warm reception of the BRI undoubtedly plays a role in its success on the continent (and the desire to see it succeed). Thus, although many unknowns remain and a cautious approach is increasingly visible on the part of African actors, the initiative continues to enjoy overall (official) support. Flexibility in Chinese engagement on the continent could be indicative of why, despite challenges and in some cases failures, the initiative maintains momentum (Brautigam 2009).

Two broadly dominant and opposing accounts have emerged regarding the BRI in Africa. They are both connected to the question of African agency. These categories are not normative categories by any means but instead merely denote their respective views of agency. On the one hand, there are those that hold that the BRI's success will 'depend on how recipient developing economies, in particular Africa, utilize China's investor interest for their own sustainable development' (Johnston 2016:1). In this scenario, the onus is placed on African actors and governments to utilize Chinese investment (whether BRI or otherwise) to further their domestic/regional goals. This implicitly assumes a degree of agency on the part of African actors and can be seen as affirming agency. On the other hand, there are those who view China-Africa relations as constituting a zero-sum game. This view can be categorized as denying agency. For those who hold this view, while agency may be gleaned from synergistic agendas, at its core the BRI lulls African actors into a false sense of complacency that in essence hides serious long-term sustainability challenges of these projects - particularly as far as debt is concerned. Placed at two opposite poles, these positions demonstrate the range of ideas related to agency in China-Africa relations and the BRI specifically.

The focus of the BRI on infrastructure is not only necessary for broadbased development and poverty eradication in Africa but also complements the recent establishment of the African Continental Free Trade Area (AfCFTA). At its core the AfCFTA is regarded as 'a critical response to Africa's developmental challenges' (Mene 2020) and has provided increased impetus to make the BRI 'work' for Africa (Phiri \& Mungoma 2019). The infrastructure deficit that the continent faces not only challenges the free movement of people and goods but also hinders the possibility of intra-regional trade. When compared to other world regions for example, Africa lags a long way behind in its portion of intra-regional exports, which in 2018 stood at a mere $18 \%$ of total exports as opposed to intra-Asian exports and intra-European exports, which stood at $59 \%$ and $69 \%$, respectively (Sow 2018). 
Figure 5.1 Intra-regional Trade per Region (2015-2017)

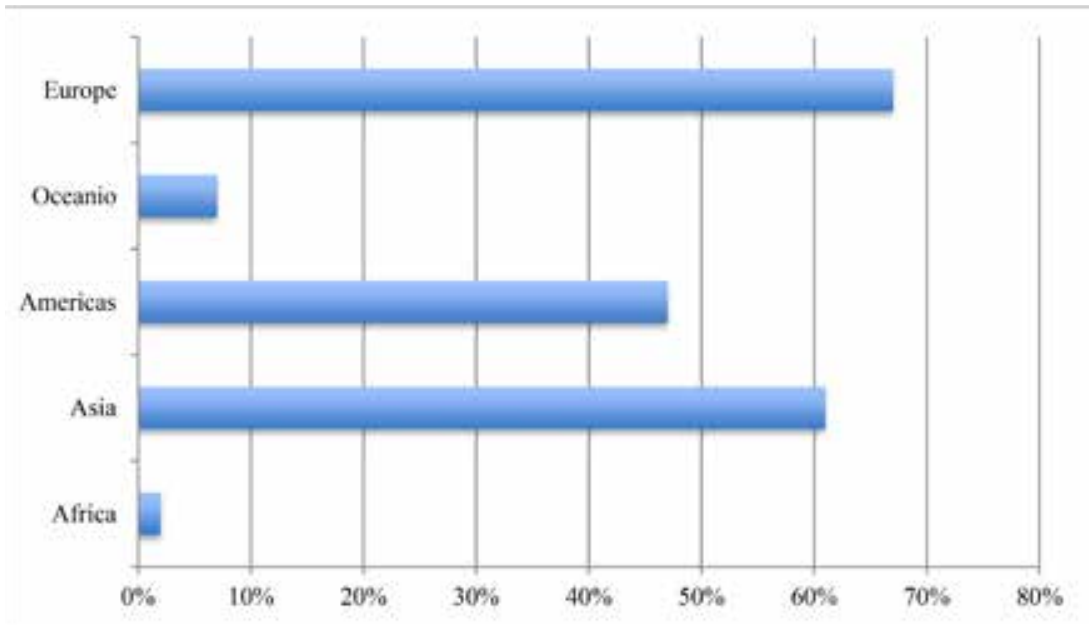

Source: Author's compilation of data from UNCTAD. ${ }^{3}$

In the broader China-Africa context, while Africa may not be of primary economic significance for an international heavyweight such as China (Pairault 2020), the BRI in particular presents Africa with the opportunity to build some of the pieces that are critical for solving the intra-African trade and pan-African development puzzle. The way that the BRI can contribute this to African development, coupled with the way it fits with Africa's broad industrial goals, are both features of President Xi Jinping's characterization of China-Africa relations as a 'win-win' (see ADB 2019).

These synergies, along with various bilateral projects, are evidence of the BRI's increasing traction on the African continent. More recently, in July 2019, the Belt and Road Fund for Africa was created. This fund is chaired by Dr. Iqbal Surve, who is the former chair of the South African chapter of the BRICS Business Council. While the fund remains in its infancy, its creation speaks to the deepening of cooperation under the BRI banner beyond a mere MoU. All of these instances, taken together, demonstrate the various areas of compatibility between African developmental agendas and the BRI as a global project.

This convergence of agendas has led to the characterization of the relations between Africa and China as being 'win-win'. This would denote a situation where agency is evenly distributed amongst the actors. If, however,

3 Intra-African trade (defined as average of intra-African exports and imports) around $2 \%$ (2015-2017) vs. America (47\%), Asia (61\%), Europe (67\%) and Oceania (7\%) - UNCTAD. 
the relationship is characterized otherwise, agency is attributed differently. For example, those that are sceptical about the degree to which Africa 'wins' in its relations with China implicitly or explicitly locate agency with China as a unitary actor and define agency largely in terms of material power. Relative gains potentially won by African counterparts seem minimal, and critics cite Africa's dependence on China as indicative of an imbalanced relationship (Tillerson 2018; Al Jazeera 2020). This imbalance, or 'win-lose' scenario, inadvertently characterizes these relations as zero-sum. Any 'wins' on the part of Africa are seen as relatively insignificant vis-à-vis potential future losses - especially loss of independence. The threat of an overly dependent relationship on the part of Africa looms visibly behind much of the commentary concerning the 'value' of Chinese engagement (investment) for the continent. Thus, while some may recognize the opportunities presented by the BRI, many question the ability of African states, institutions, and organizations to fully harness these to the benefit of the continent, and/or to mitigate/offset potential negative effects. It is this apparent (in)ability to 'steer' relations that is often tied to the notion of agency. This is related to the issue of structural constraints that, while real, can be overcome through creative uses of agency. I will explore this issue more below.

Far too often, however, zero-sum accounts are premised on a simplistic understanding of agency. In order to move beyond this a contextual approach is required; one that considers the contours and specificities of African agency. The following section unpacks the issue of agency and particularly African agency to uncover some of the specific challenges for consideration. ${ }^{4}$

\section{China in the Driver's Seat? Power and Agency}

For the most part, analyses of China-Africa relations have problematized the obvious power imbalances between a global 'heavyweight' like China and the African continent, which is made up of diverse states, communities, and interests. A common perception is that the power differentials seen

4 While the focus of these chapters are on BRI 'recipient states', it should also be noted that - as much as China's BRI is presented as an outright 'win' for China - the lack of conditionalities presents risks (albeit calculated) for China itself (Ehizuelen \& Abdi 2017: 303). Challenges such as governance, corruption, social and political tensions, as well as the effects of climate change across a large continent with often few resources to absorb such shocks render BRI projects not always an outright win. As Chinese engagement in the continent has already demonstrated, challenges exist and will persist despite idealized visions. 
between China and most African states inevitably place the former in the driver's seat and give the latter little to no negotiating power (Gomes 2007; Castillejo 2013; French 2014). These accounts have a direct effect on where agency is located and how it is seen to operate. These assumptions run rife through both public and scholarly reports about China in Africa. They in essence strip African actors from having any kind of agency. These accounts equate agency with material power and thus place agency solely with China as a unitary actor.

Dominant discourses on China-Africa relations have often relied on binary understandings of these relations that reduce representations to Africa as victim and China as perpetrator. These narratives have also fed into the idea that African actors are somehow without agency in China-Africa engagement. As highlighted by Fisher (2020), agency is often interchangeably used with 'influence', 'power', or 'ownership'. This has led, problematically, to an analytical imprecision about the concept of 'agency' itself. These narrow understandings of agency have routinely overlooked the existence of agency outside of hard or material power. They have not looked at how actors deal with or creatively bypass structural constraints. This has limited the depth of analysis on China-Africa relations. Similarly, while material structural constraints evidently impede agency to a certain degree, structural constraints do not begin and/or end with material power but likewise relate to structures of knowledge, ways of doing, and ways of being in international relations. Instead of these narrow understandings of the concept, questions concerning agency should be addressed by drawing on scholarship about China-Africa relations that has underscored the multidimensional, complex, and mutually constitutive nature of these relations.

The characterizations of relations between China and Africa that have been discussed above reflect an understanding of agency that is often discursively linked not only to power but also to the idea of a 'China threat' (i.e. the idea that China's agency, as equated with power, results in debt trap diplomacy, poor infrastructure, human rights abuses, negative effects on local markets and the displacement of local labour) (see Brautigam 2009; Sun et al. 2017). This also results in the assumption that China's relative power (and thus agency) necessarily negates any semblance of African agency. This assumption is in part normative in that it often equates African agency with vocal or explicit condemnation of China's engagement (i.e. agency as resistance). Importantly, however, agency need not preclude that engagement be beneficial to other actors (i.e. China). A central aspect of these 'China threat' narratives of China-African relations is the idea that China necessarily strong-arms African actors into cooperation. Along 
with this, these narratives also often express the idea that cooperation is characterized by self-interested, power-hungry elites who exercise agency only for themselves. While these kinds of normative accounts of agency may hold some degree of truth, they often cloud the ability to 'uncover' agency as a value-neutral concept that can be exercised independent of material power and/or nefarious gain.

Evidently, the issue of African agency in China-African relations cannot be understood in isolation but is deeply connected with a range of assumptions on the nature of China-Africa engagement as well as with actors' identities. While some of these assumptions may hold various degrees of empirical truth, others reflect politicized accounts of these relations.

Others have pointed to instances of African actors driving agendas for cooperation, engagement, or exchange with China. This evidence is contrary to the idea that engagement is solely driven by China. Research has shown that requests at the behest of African actors characterize relations to a greater degree than assumed (Van Staden et al. 2018). This drive does not preclude China's interest in Africa - nor do China's interests in Africa preclude agency on the part of African actors, once again reaffirming the idea that agency is both multidimensional and mutually constitutive. So while China may hold relatively more structural power, African actors have in fact exercised agency in so far as shaping and steering engagement are concerned.

Some researchers have argued that the agency of African actors is compromised in China-Africa relations because of the (long-term) 'hidden' costs of engaging with China, which include such things as debt and the long-term sustainability of projects (MinBuza 2019; Gavas \& Timmis 2019; Lorenz \& Thielke 2007; Harris 2018). However, these long-term effects are arguably not so much an indicator of agency as a simple projection of the consequences of choices. Embedded in these arguments is a set of assumptions about rationality as objective. The actors are assumed to necessarily act in their own best interest, which is assumed to correlate with a universal objective rationality. It is overlooked however that rationality is subjective.

These kinds of conceptualizations of agency are common in commentary on China-Africa relations. They have come at the cost of acknowledging and exploring the contours of African agency. They have overlooked the range of examples of African agency that can be seen over time. These include the continent's anti-colonial struggles, the African Union's prominent criticism of NATO intervention in Libya and its continued impact in intervention discourses, as well as the continent's near-jeopardization of the International 
Criminal Court. 5 These cases alone should give us pause to reflect on agency as a concept as well as how it is understood in China-Africa relations. However, there have been some works that have sought to address the multifaceted nature of African agency in China-Africa relations from a largely value-neutral perspective. These include studies by Mohan and Lampert (2013), Gadzala (2015), and Soulé-Kohndou (2016). These works have demonstrated the existence of multiple agencies (plural) that operate on and across multiple levels. They challenge the misperception that China-Africa relations are chiefly driven by Chinese interests and/or nefarious African leaders.

The aim of the rest of this chapter is not to devise an overarching universal concept of agency. Instead, it seeks to highlight the contours of agency within the African context as it relates to engagement with China and the BRI. This will provide a glimpse into the complex dynamics and interactions of agency.

\section{African Agency}

Africa has long occupied a unique place in international relations. Because it is considered a concentrated site of colonial ambitions both past and present, it has often been treated as an object upon which 'high' international relations has an impact or effect. As such, it has all too frequently been acted upon, spoken for, and talked about. This treatment has left no room for discussions of African agency. Its position as object has therefore rendered it a conundrum for international relations or as a continent 'non grata'. Imagery of African victims has been juxtaposed with leaders as 'perpetrators'. The narrative of African populations as voiceless victims has contributed to the idea of a continent without agency.

While the ability of 'Africa' to exert agency in the international system is limited by structural constraints, the idea of an agent-less Africa undoubtedly served political purposes during the colonial era and the Cold War. This idea now arguably continues to serve political purposes in the 'China threat' era. Placing African states and actors 'as serious objects of study [...] stands in sharp contrast to the standard approach to analysing Africa's international relations' (Brown 2012: 1890).

Scholars such as William Brown have tackled the idea of African agency and noted that multiple agencies exist, requiring a multidimensional

5 This is not to say that African agency alone resulted in these events but rather that they played a significantly important role in combination with other factors, such as the declining economic viability of colonialism. 
approach to understanding the concept. As well as the existence of multiple agencies, Brown emphasizes the different dimensions of agency in its various forms. In the case of Africa both state and non-state actors are important sites for agency. Moreover, the role and place of state leaders has been key in defining and articulating state preferences in the African context.

For Brown, the importance of spotlighting African agency is related to the continent's role and position 'as actor not just acted upon, historical agent not just history's recipient' (2012: 1889). The focus on African agency has become synonymous with a move to 'decolonize' traditional international relations frameworks so as to better reflect the range of actors and their realities in the international landscape. This is of importance not only at a conceptual level, but also because of international relations' inextricable link to policy. Expanding, reassessing, and reformulating concepts such as agency can have tangible implications for foreign policy. Stimulating the need to act with others, and not upon them, is a goal towards which the African foreign policies of different states should strive. These are particularly important considerations for third-party states, such the countries of Europe, in light of growing China-Africa relations and broader South-South cooperation.

An integral and perhaps obvious component of agency is an agent - or actor. According to Professor Ryo Osiba, actors in international relations are defined

as the entities which have the following three features: (a) They should have the autonomous capacity to determine their own purposes and interests; (b) They should also have the capability to mobilize human and material resources to achieve these purposes and interests; (c) Their actions should be significant enough to influence the state-to-state relations or the behaviour of other non-state actors in the global system. (Kan 2010: 234-235)

At this very basic level, Africa, like all world regions, is made up of a host of actors that have specific interests. Key considerations, however, are that agency is not necessarily or only defined by whether or not interests are successfully achieved and that attempts to pursue these interests are often hindered by (structural) constraints. As Brown notes in relation to Africa, 'a flexible conceptualization of agency is needed to locate agencies in the complex dialectical interplay with the structural contexts from which they arise and in relation to which they operate' (Brown 2012: 1890). For African actors, interests are often both linked to, and shaped by, the goal of dismantling structures that constrain agency in the first place. Put 
differently, if necessity is the mother of invention, then structural challenges to Africa's agency necessitate innovative solutions.

By taking these considerations into account, we are able to avoid equating agency directly with material power. Thus, while scholars such as Colin Wight view agency as 'the faculty or state of acting or exerting power', it is important to note that power can be defined outside of material hard power. By broadening the idea of power, we are able to extend the idea of agency to a wider range of actors that are not dependent on hard material power to enact agency. Power in this context therefore denotes a range of actions or expressions that are related inter alia to intentionality, agenda setting, and influence (Chabal \& Daloz 1999: 7; Fisher 2020: 4; Wight 2006: 187).

Nevertheless, one cannot speak of African agency without noting the existence of 'seemingly immovable structures of international inequality' (Brown 2012: 1889). This inequality exists firstly in the realms of poverty and underdevelopment. However, it also exists in the realms of politics and knowledge, which position Africa on the 'outskirts' of international relations as an object to be acted upon. Agency is inevitably impacted by structural constraints of this nature. This leads to African actors' focus on overcoming structural injustices not only through international representation but arguably more importantly through continental development. The pursuit of economic development is therefore seen not only as a means of combating the ills of chronic poverty and underdevelopment that the continent faces, but also as the key to unlocking the continent's potential and, most importantly, power. Here again, power is tied to agency in which 'full' agency is not limited by structural constraints but can be exercised freely.

A wide range of approaches exist for tackling questions of African agency. Instrumentalist frameworks, for example, position African agency as the ability of actors to secure their own interests by leveraging support from key states or partners in the international arena. Other approaches have instead located agency in African actors challenging the premise of Western engagement. Moreover, agency is equally visible in non-state actors and their ability to steer agendas, cooperate, collaborate, or block initiatives. In this sense agency is also often tied to activism. Here, agency is seen to be the challenging of authority or power and is seen as an answer to the question of how this is done.

Other approaches recognize the way in which agency operates at all levels, allowing states and business communities to leverage opportunities to their advantage and for their interests. A key facet of almost all these approaches to agency - and often seen in the idea of circumventing structural constraints - is the idea of a connection between agency and intentionality. 
Here, intentionally means pursuing courses of action (which can include inaction) in order to further one's interests. Fisher (2020:1), for example, notes the multilevel nature of African agency and the way in which these agencies have their own interests/rationales and processes/mechanisms. He maps the overlapping, diverging, and diverse nature of African agency, pointing to the need for expanding what is meant by 'Africa' beyond the state. He proposes that when analysing what is meant by 'agency' we must also consider the 'structural constraints imposed on Africa by global economic and political inequalities'.

Being open to a multiplicity of 'agencies' is evidently crucial to understanding agency in the African context. This means that, as will be demonstrated, histories, internal logics, aims, and discourses are important contextual factors to consider when interrogating African agency vis-à-vis the BRI and China, more broadly speaking.

\section{African Agency and the BRI: Points for Consideration}

As outlined above, African agency and the BRI bring together a vast range of issues and considerations. Exploring the nexus of the two therefore requires regard for both the unique attributes of African agency - and thus a contextual approach - as well as a holistic understanding of the BRI in the African regional context.

Important considerations are:

- the multifaceted nature of African agency (disaggregation);

- a value-free approach to understanding agency (what I term 'de-centring' normative frameworks);

- the interplay of structure and agency, most notably the structural confines within which African agency is performed or finds itself;

- agency beyond hard power (creative agency);

- BRI synergies with African (developmental) agendas;

- Chinese engagement (BRI) as responsive and flexible (short term, long term to be seen);

- 'structural focus' of the BRI;

- pressures (domestic) and sustainability (debt);

- the BRI as Beijing-directed and not Beijing-controlled;

- African demands.

Notably, part of the 'problem' is discussing both 'Africa' and 'China' as unitary actors. This research recognizes these limitations and like other scholarship 
sees analytical value in the 'concept' of Africa. Nevertheless, from an IR perspective, the state - as the primary unit of analysis as well as a set of intergovernmental institutions - is an important 'agent' to explore. This is not to discount other actors, but rather to narrow the scope of study. Equally, however, it is important to note that in the context of the BRI a range of actors are inevitably involved, from the Chinese state to private Chinese transnational corporations and independent Chinese entrepreneurs (Mohan \& Lampert 2013). It is important, then, for any study of agency to clearly define the units of analysis in order to contextually shed light on how agency operates in various cases by various actors.

A noteworthy general point to consider relates to the position of third parties in interaction between Africa and the BRI. Because of misperceptions about Africa's relatively 'weak' position vis-à-vis China, third parties have intervened on behalf of Africa and sought to 'warn' Africa about 'doing business with China'. While these warnings are in many instances warranted, the underpinning rationale that drives these prescriptions often comes from a paternalistic narrative that, for Africa, is far too well known. African actors have (in most part) recognized the risks that they run and the consequences that they may face. Negating African agency in relations between China and Africa, and in African engagement with the BRI in particular, places Africa in a voiceless position where the continent very quickly becomes 'spoken for'. Similarly, assuming a lack of agency on the part of African actors has led to an 'interventionist' approach to China-Africa relations from third-party states that position themselves as neutral arbiters. It is important to caution against this paternalistic approach. This is especially so considering the historical position that Africa has occupied in the international system, which has rendered many an African actor particularly sensitive to unsolicited 'advice' or attempts to 'save' them from threats. The way third-party states understand how Africa conducts its international relations and the various actors, agents, and structural constraints involved, necessarily impacts the way these states then relate to Africa. It is important that we also understand what makes China-Africa relations 'tick'. These relations can be seen as a form of South-South cooperation that is increasingly taking centre stage in international politics. These relations are becoming the 'new' grounds upon which the international system is being built. Understanding such cooperation therefore helps to understand and forecast the future trends of international relations and the central issues, challenges, and areas for cooperation and synergy that may come into play.

As a final consideration: In a world where global challenges such as the recent COVID-19 pandemic have demonstrated the need for coordinated 
regional responses, it has become all the more important to grasp the interaction of regional actors with initiatives such as the BRI. Actors across diverse regions exercise agency in various ways, while often facing structural constraints. These are important considerations when formulating constructive policy. Considering the goals of increased connectivity presented by the BRI, the current pandemic presents a new reality from which to assess these goals, their desirability, and their viability. In order to assess these things, the nuances of regional actors should be closely examined. Recent events will undoubtedly have an impact on the direction of the BRI (particularly the challenges and opportunities of increased connectivity), making it all the more important to understand regional agency in its multiple forms.

\section{Conclusion}

This introductory chapter has endeavoured to move away from conventional analyses of China-Africa relations and Africa's engagement with the BRI. In doing so, it has sought to highlight some of the key considerations and challenges of studying African agency. Understanding agency at its most basic level as the act of holding specific interests and goals by a range of actors allows for a non-normative approach to investigating a wide range of actors, interests, and processes. Considering these avenues for exploring African agency, this chapter has aimed to interrogate African agency from a value-free position. It does so by not assuming that agency is necessarily a form of resistance.

Importantly, when exploring African agency vis-à-vis the BRI, the interests of actors are key. This requires dismantling assumptions about the desirability of the BRI as a project. It also requires challenging assumptions about the 'power' or 'hold' that China may have over Africa and assumptions that there is a lack of agency on the part of African actors. This ought to be explored as part of the frequent neglect of Africa as an active player in the geopolitical power struggles between the 'West' and 'China'. Africa is often caught in the middle of this 'new Cold War'. Instead, taking seriously Africa's role, position, and contribution towards the BRI may help us illuminate what African agencies look like, how they are enacted, and their potential consequences. Therefore, drawing conclusions about whether engagement in the BRI or relations with China are 'good' for Africa should not be the main concern.

The following chapters will look at two cases of relations between Africa and the BRI. The first will look at the Southern African Development 
Community (SADC) as a regional organization. It will provide an overview of how this community conceives of agency and whether or not it is seen to exercise agency. The second chapter takes the case of Ethiopia and examines specific actors within this case and their projects that are connected to the BRI. As these chapters show, African agency exists and is exercised albeit in ways that may not always reflect the assumed responses to 'China in Africa'. These multiple agencies demonstrate the need to contextually understand agency while having equal regard for the structural barriers with which agents often grapple. Locating agency in the African context is therefore an exercise in uncovering the multiple and creative ways in which agency exists.

\section{References}

ADB (2019, November 13). 'African Has Grasped the Fourth Industrial Revolution, According to African Development Bank Report, but Its Role Globally Could Be Even Bigger'. African Development Bank. Retrieved 9July 2020 from https:// www.afdb.org/en/news-and-events/press-releases/african-has-grasped-fourthindustrial-revolution-according-african-development-bank-report-its-roleglobally-could-be-even-bigger-32644.

African Union (n.d.). 'AU in a Nutshell'. Retrieved 10 July 2020 from https://au.int/ en/au-nutshell.

African Union Commission (2015, September). 'Africa We Want: Agenda 2063'. Retrieved 16 April 2020 from https://au.int/sites/default/files/documents/36204doc-agenda2063_popular_version_en.pdf.

Al Jazeera (2020, February 19). 'Pompeo Caps Three-Nation Africa Tour with Veiled Swipe at China'. AlJazeera. Retrieved 9 July 2020 from https://www. aljazeera.com/news/2020/o2/pompeo-caps-nation-africa-tour-veiled-swipechina-200219142439604.html.

Brautigam, Deborah (2009). The Dragon's Gift: The Real Story of China in Africa. Oxford: Oxford University Press.

Breuer, Julia (2017, July). ‘Two Belts, One Road? The Role of Africa in China's Belt \& Road Initiative'. Blichwechsel. Retrieved 26 March 2020 from https://www. asienhaus.de/uploads/tx_news/Blickwechsel_OBOR-Afrika_o1.pdf.

Brown, William (2012). 'A Question of Agency: Africa in International Politics'. Third World Quarterly, 33(10), 1889-1908.

CARI (2020). 'Data: Chinese Investment in Africa'. China-Africa Research Initiative, School of Advanced International Studies, Johns Hopkins University. Retrieved 16 April 2020 from http://www.sais-cari.org/chinese-investment-in-africa. 
Castillejo, Clare (2013, March). 'Engaging China on Development'. FRIDE Policy Brief, no. 151.

Cavanna, Thomas P. (2018, June 5). 'What Does China's Belt and Road Initiative Mean for US Grand Strategy?' The Diplomat. Retrieved 9 July 2020 from https:// thediplomat.com/2018/o6/what-does-chinas-belt-and-road-initiative-meanfor-us-grand-strategy/.

Chabal, Patrick \& Daloz, Jean-Pascal (1999). Africa Works: The Political Instrumentalization of Disorder. Bloomington: Indiana University Press.

Chan, Man Hung Thomas (2018). 'The Belt and Road Initiative - The New Silk Road: A Research Agenda'. Journal of Contemporary East Asia Studies, 7(2), 104-123. https://doi.org/10.1080/24761028.2019.1580407

Chin, Gregory \& Thakur, Ramesh (2010). 'Will China Change the Rules of Global Order?' Washington Quarterly, 33(4), 119-138.

China Power Team (2017, May 8). 'How Will the Belt and Road Initiative Advance China's Interests?' China Power. Retrieved 4 May 2020 from https://chinapower. csis.org/china-belt-and-road-initiative/.

Dahir, Abdi Latif (2018, September 30). 'These Are the African Countries Not Signed to China's Belt and Road Plan'. Quartz. Retrieved 9July 2020 from https://qz.com/ africa/1718826/the-african-countries-not-signed-to-chinas-belt-and-road-plan/.

De Cremer, David, et al. (eds.) (2020). The Belt and Road Initiative: Opportunities and Challenges of a Chinese Economic Ambition. London: Sage.

Demissie, Alexander (2018). 'Special Economic Zones: Integrating African Countries in China's Belt and Road Initiative'. In Maximilian Mayer (ed.), Rethinking the Silk Road: China's Belt and Road Initiative and Emerging Eurasian Relations (pp. 69-84). Singapore: Palgrave Macmillan.

Dollar, David (2019, September). 'Understanding China's Belt and Road Infrastructure Projects in Africa'. Brookings Institution. Retrieved 26 October 2020 from https://www.brookings.edu/wp-content/uploads/2019/og/FP_20190930_china_bri_dollar.pdf.

Du Plessis, Rudolf (2016, September). 'China's African Infrastructure Projects: A Tool in Reshaping Global Norms'. SAIIA Policy Insights 35. South African Institute of International Affairs. Retrieved 9July 2020 from https://saiia.org.za/research/ chinas-african-infrastructure-projects-a-tool-in-reshaping-global-norms/.

EAC (2019). 'China Accredits Envoy to EAC Bloc'. East African Community. Retrieved 9 July 2020 from https://www.eac.int/press-releases/151-internationalrelations/899-china-accredits-envoy-to-eac-bloc.

Ehizuelen, Michael Mitchell Omoruyi \& Abdi, Hodan Osman (2017). 'Sustaining China-Africa Relations: Slotting Africa into China's One Belt, One Road Initiative Makes Economic Sense'. Journal of Comparative Politics, 3(4), 285-310. 
Ellis, Sam (2018, April 6). 'China's Trillion-Dollar Plan to Dominate Global Trade'. Vox. Retrieved 9 July 2020 from https://www.vox.com/2018/4/6/17206230/ china-trade-belt-road-economy.

Eom, Janet, et al. (2018). 'The Path Ahead: The 7 th Forum on China-Africa Cooperation'. Briefing Paper no. 1. China Africa Research Initiative.

European Parliament (2008, March 28). 'Report on China's Policy and Its Effects on Africa'. Retrieved 9 July 2020 from https://www.europarl.europa. eu/sides/getDoc.do?reference $=$ A6-2008-0080\&type=REPORT\&language $=$ EN\&redirect.

Fisher, Jonathan (2020). 'African Agency in International Politics'. In Nic Cheeseman (ed), Oxford Research Encyclopedia of African Politics. Oxford: Oxford University Press

French, Howard (2014). China's Second Continent: How a Million Migrants Are Building a New Empire in Africa. New York: Alfred A. Knopf.

Gadzala, Aleksandra W. (ed.) (2015). Africa and China: How Africans and Their Governments Are Shaping Relations with China. London: Rowman and Littlefield Gadzala, Aleksandra \& Hanusch, Marek (2010, January). 'African Perspectives on China-Africa: Gauging Popular Perceptions and their Economic and Political Determinants'. Working Paper no. 117. Afrobarometer. Retrieved 16 April 2020 from https://afrobarometer.org/sites/default/files/publications/Working\%2o paper/AfropaperNo117.pdf.

García-Herrero, Alicia \& Xu, Jianwei (2019, February 6). 'Countries' Perceptions of China's Belt and Road Initiative: A Big Data Analysis'. Breugel. Retrieved 28 September 2020 from: https://www.bruegel.org/2019/02/countries-perceptions-ofchinas-belt-and-road-initiative-a-big-data-analysis/

Gavas, Mikaela \& Timmis, Hannah (2019, November 14). 'What Does China's Investment in Africa Mean for Europe?' Friends of Europe. Retrieved 9 July 2020 from https://www.friendsofeurope.org/insights/what-does-chinasinvestment-in-africa-mean-for-europe/.

Ghosh, Jayati (2012, August 7). 'Hillary Clinton's Morally Superior Speech in Africa Was Deluded'. The Guardian. Retrieved 9 July 2020 from https:// www.theguardian.com/global-development/poverty-matters/2012/aug/o7/ hillary-clinton-speechZ-africa-deluded.

Gomes, Ana M. (2007). Draft Report on China's Policy and Its Effects on Africa. European Parliament Committee on Development. 72.11 PR|697015EN.doc (Motion for Resolution).

Hanusch, Marek (2012) "African Perspectives on China-Africa: Modelling Popular Perceptions and their Economic and Political Determinants" Oxford Development Studies, 40(4), 492-516. 
Harris, Grant T. (2018, August 30). 'China Is Loaning Billions of Dollars to African Countries. Here's Why the US Should Be Worried'. Time. Retrieved 9 July 2020 from https://time.com/5381467/china-africa-debt-us-security/.

Hirono, Miwa \& Suzuki, Shogo (2014). 'Why Do We Need "Myth-Busting" in the Study of Sino-African Relations?' Journal of Contemporary China, 23(87), 443-461. Jian, Junbo (2018). 'Africa in the Maritime Silk Road: Challenges and Prospects'. In Maximilian Mayer (ed.), Rethinking the Silk Road: China's Belt and Road Initiative and Emerging Eurasian Relations (pp. 99-114). Singapore: Palgrave Macmillan. Johnston, Lauren, A. (2016, September 15). “Africa, and China's One Belt, one Road initiative: Why now and what next?" International Centre for Trade and Sustainable Development. Retrieved 11 November 2020 from https://ictsd.iisd. org/bridges-news/bridges-africa/news/africa-and-china\%E2\%80\%99s-onebelt-one-road-initiative-why-now-and-what.

Kan, Hideki (2010). 'Actors in Global Politics'. In Masashi Sekiguchi (ed.), Government and Politics (pp. 242-259). Oxford: Eolss Publishers.

King, Kenneth (2007). 'The Beijing China-Africa Summit of 2006: The New Pledges of Aid to Education in Africa'. China Report, 43(3), 337-347.

Klotz, Audie (2006). 'Moving beyond the Agent-Structure Debate'. International Studies Review, 8, 355-381.

Lekorwe, Mogopody, Chingwete Anyway, Okuru, Mina \& Samson, Romaric (2016, October 24). Afrobarometer, Round 6, Dispatch no. 122. Retrieved 11 November 2020 from https://afrobarometer.org/sites/default/files/publications/ Dispatches/ab_r6_dispatchno122_perceptions_of_china_in_africa1.pdf.

Ling, Lily L.H.M. (2020). 'Squaring the Circle: China's “Belt and Road Initiative” (BRI) and the Ancient Silk Roads'. In Alan Chong \& Quang Minh Pham (eds.), Critical Reflections on China's Belt \& Road Initiative (pp. 23-40). Singapore: Palgrave Macmillan.

Lorenz, Andreas \& Thielke, Thilo (2007, May 30). 'China's Conquest of Africa'. Der Spiegel International. Retrieved 9July 2020 from https://www.spiegel.de/international/world/the-age-of-the-dragon-china-s-conquest-of-africa-a-484603.html.

Maasho, Aaron (2018, March 8). 'Africa Should Avoid Forfeiting Sovereignty to China over Loans: Tillerson'. Reuters. Retrieved 9 July 2020 from https://www. reuters.com/article/us-usa-africa/africa-should-avoid-forfeiting-sovereigntyto-china-over-loans-tillerson-idUSKCNiGK114.

Marton, Péter \& Matura, Tamás (2011). 'The "Voracious Dragon", the "Scramble", and the "Honey Pot": Conceptions of Conflict of Africa's Natural Resources'. Journal of Contemporary African Studies, 29(2), 155-167.

Maru, Mehari, T. (2019, January 6). "Why Africa Loves China". Aljazeera. Retrieved 11 November 2020 from https://www.aljazeera.com/opinions/2019/1/6/ why-africa-loves-china/. 
Mene, Wamkele (2020, March 19). 'Statement of H.E. Mr. Wamkele Mene on the Occasion of Swearing-in as the Secretary General of the AfCFTA Secretariat'. African Union. Retrieved 9 July 2020 from https://au.int/en/speeches/20200319/ statement-he-mr-wamkele-mene-occasion-swearing-secretary-general-afcfta.

MinBuza (2019) The Netherlands and China: A New Balance. Government of the Netherlands. https://www.government.nl/documents/policy-notes/2019/05/15/ china-strategy-the-netherlands--china-a-new-balance.

Mohan, Giles \& Lampert, Ben (2013). 'Negotiating China: Reinserting African Agency into China-Africa Relations'. African Affairs, 112(446), 92-110.

Mourdoukoutas, Panos (2018, August 4). 'What Is China Doing in Africa?' Forbes. Retrieved 16 April 2020 from https://www.forbes.com/sites/panosmourdoukoutas/2018/08/04/china-is-treating-africa-the-same-way-european-colonistsdid/\#2499f635298b.

Naidu, Sanusha (2007). 'The Forum on China-Africa Cooperation (FOCAC): What Does the Future Hold?' China Report, 43(3), 283-296.

Ndzendze, Bhaso \& David Monyae (2019). 'China's Belt and Road Initiative: Linkages with the African Union's Agenda 2063 in Historical Perspective'. Transnational Corporations Review, 11(1), 38-49.

Noman, Akbar \& Stiglitz, Joseph E. (2012). 'Strategies for Africa Development'. In Akbar Noma, Kwesi Botchwey, Howard Stein \& Joseph E. Stiglitz (eds.), Good Growth and Governance in Africa: Rethinking Development Strategies (pp. 3-51). Oxford: Oxford University Press.

Pairault, Thierry (2020). 'Examining the Importance of the New Silk Roads for Africa and for Global Governance'. In Maria Adele Carrai, Jean-Christophe Defraigne \& Jan Wouters (eds.), The Belt and Road Initiative and Global Governance (pp. 155-180). Cheltenham: Edward Elgar.

Phiri, Mwanda \& Mungoma, Nakubyana (2019, December). 'Leveraging the BRI for Africa's Industrialisation and Intra-Trade (Opportunities for the AfCFTA)'. Working Paper no. 38, Zambia Institute for Policy Analysis \& Research.

Risberg, Pearl (2019). 'The Give-and-Take of BRI in Africa'. New Perspectives in Foreign Policy, 17, 43-47. Retrieved 16 April 2020 from https://csis-prod.s3.amazonaws. com/s3fs-public/NewPerspectives_APRIL2019_Risberg.pdf.

Rodney, Walter (1972). 'How Europe Underdeveloped Africa'. In Paula S. Rothenberg (ed.), Beyond Borders: Thinking Critically about Global Issues (pp. 107-125). New York: Worth Publishers.

Sarwar, Lubina (2017). 'The Old Silk Road and the New Silk Road: An Analysis of the Changed Discourse'. Journal of Central Asian Studies, 24, 13-22.

Sharma, Subham (2019, June 4). 'Is China a New Alternative to US Hegemony?' Asia Times. Retrieved 9 July 2020 from https://asiatimes.com/2019/o6/ is-china-a-new-alternative-to-us-hegemony/. 
Smith, David (2012, August 1). 'Hillary Clinton Launches African Tour with Veiled Attack on China'. The Guardian. Retrieved 9 July 2020 from https://www. theguardian.com/world/2012/aug/o1/hillary-clinton-africa-china.

Soulé-Kohndou, Folashadé (2016). 'Passive Agents? Bureaucratic Agency in AfricaChina Negotiations: A Case study of Benin'. Working Paper no. 3/2016, LSE Global South Unit.

Sow, Mariama (2018, March 29). 'Figures of the Week: Africa's Intra- and ExtraRegional Trade'. Brookings: Africa in Focus. Retrieved 30 August 2020 from https://www.brookings.edu/blog/africa-in-focus/2018/03/29/figures-of-theweek-africas-intra-and-extra-regional-trade/.

Sun, Irene Yuan, Jayaram, Kartik \& Kassiri, Omid (2017, June). 'Dance of the Lions and Dragons: How Are Africa and China Engaging, and How Will the Partnership Evolve?' McKinsey \& Company. Retrieved 9 July 2020 from https://www.mckinsey.com/ /media/McKinsey/Featured\%2oInsights/Middle\%2oEast\%2oand\%2o Africa/The\%2oclosest\%2olook\%2oyet\%2oat\%2oChinese\%2oeconomic\%2o engagement\%2oin\%2oAfrica/Dance-of-the-lions-and-dragons.pdf.

Taylor, Ian (2016). 'Dependency Redux: Why Africa Is Not Rising'. Review of African Political Economy, 43(147), 8-25

Tillerson, Rex (2018, March 6). 'Remarks - Secretary of State Rex Tillerson on US-Africa Relations: A New Framework'. US Department of State. Retrieved 9 July 2020 from https://translations.state.gov/2018/03/o6/remarks-secretaryof-state-rex-tillerson-on-u-s-africa-relations-a-new-framework/

UN General Assembly (1986, December 4). Declaration on the Right to Development: Resolution / Adopted by the General Assembly, A/RES/41/128. Retrieved 10 July 2020 from https://www.refworld.org/docid/3boof22544.html.

Van Staden, Cobus, Alden, Chris \& Wu, Yu-shan. (2018, September). 'In the Driver's Seat? African Agency and Chinese Power at FOCAC, the AU and the BRI'. Occasional Paper 286. South African Institute of International Affairs (SAIIA).

Wallerstein, Immanuel (1974). The Modern World-System I: Capitalist Agriculture and the Origins of the European World-Economy in the Sixteenth Century. New York: Academic Press.

Wallerstein, Immanuel (2004). World-Systems Analysis: An Introduction. Durham, NC: Duke University Press.

Wight, Colin (2006). Agents, Structures and International Relations: Politics as Ontology. Cambridge: Cambridge University Press.

Wissenbach, Uwe (2020). 'African Agency in the Belt and Road Initiative: Kenya's Rail Investment as China's Flagship BRI Project in Africa'. In Maria Adele Carrai, Jean-Christophe Defraigne \& Jan Wouters (eds.), The Belt and Road Initiative and Global Governance (pp. 204-221). Cheltenham: Edward Elgar. 
Xi, Jinping (2019, April 26). 'Working Together to Deliver a Brighter Future for Belt and Road Cooperation: Keynote Speech by H.E. Xi Jinping President of the People's Republic of China at the Opening Ceremony of the Second Belt and Road Forum for International Cooperation'. Ministry of Foreign Affairs of the People's Republic of China. Retrieved 9 July 2020 from https://www.fmprc.gov. cn/mfa_eng/zxxx_662805/t1658424.shtml.

Zhang, Kangle (2018). 'A Tale of Ending Poverty: The New Financial Institutions and China's Global Strategy'. In Wenhua Shan, Kimmo Nuotio \& Kangle Zhang (eds.), Normative Readings of the Belt and Road Initiative Road to New Paradigms (pp. 147-181). Springer.

Zuma, Nkosazana Dlamini (2014, January 26). 'Email from the Future'. African Union. Retrieved 16 April 2020 from https://au.int/en/documents/20140126/ email-future.

\section{About the Author}

Dr. StACEY Links is a South African national based in the Netherlands as a Research Fellow at the LeidenAsiaCentre. Having obtained her PhD from Utrecht University's Department of Law, Governance and Economics, she now holds the position of Lecturer at Leiden University's Institute of Area Studies (LIAS), where her teaching focuses on China-Africa relations, postcolonial and critical international relations theory, as well as regional integration in Sub-Saharan Africa. Her research interests are human rights in China-Africa relations and specifically the right to development. Her research is set against the backdrop of critical IR theory as well as critical approaches to development. 



\title{
6 Parameters and Pathways
}

\author{
Agency in the Case of the Southern African Development \\ Community
}

Stacey Links

\begin{abstract}
Chapter 6 provides an in-depth analysis of the Southern African Development Community (SADC) and its interaction with China through the BRI. The chapter explores the agency of African actors, specifically the agency of SADC as a regional power. The chapter's focus on the often-overlooked SADC demonstrates the reach of the BRI as well as the relevance of this project for seemingly 'distant' locales. The chapter takes a deductive approach to agency where agents are placed at the centre of the analysis and themselves demarcate agency. This agent-oriented perspective circumvents the paternalism of imposed definitions, placing definitional power with the actors themselves. The chapter argues this can provide the foundations of an open and empowered conversation on international relations.
\end{abstract}

Keywords: Belt and Road Initiative, China, agency, Africa, Southern African Development Community, SADC

At this stage, the main focus should be on just maybe speaking up about opportunities in terms of what is it that we as SADC can benefit from strong ties [sic] with the Chinese and what is it that the Chinese can benefit if they get into formal ties with SADC in terms of cooperation. - SADC interview respondent (2019)

Much of the research into China and Africa relations to date has focused on the characteristic bilateral relations between individual African states and

Schneider, Florian (ed.), Global Perspectives on China's Belt and Road Initiative: Asserting Agency through Regional Connectivity. Amsterdam, Amsterdam University Press 2021 DOI: $10.5117 / 9789463727853 \_$CHO6 
China. Though this constitutes a large part of China-Africa engagement, this focus has overshadowed the study of the relations between collective bodies and China as well as the multilateral engagements of African actors with China. Exceptions are studies looking at the African Union (AU) and the Forum on China-Africa Cooperation (FOCAC) (Delgado 2015; Eom et al. 2018; Ukeje \& Tariku 2018). This bilateral focus in part reflects the most dominant and visible form of China-Africa engagement. However, it also relates to the scholarly goal of disaggregating China-Africa engagement. While generalizable claims about China-Africa relations from a macro perspective have their merits, particularly from the perspective of broader continental commonalities, scholars have underscored the importance of looking at a wider range of actors in order to more holistically ascertain the range of agendas, relations, and interactions that exist beyond the state level (Brautigam 2009; Mohan \& Lampert 2013). This has led to an expansion of research agendas to include the analysis of the relations that African cities, local communities, civil society, the media, and business have with China and Chinese actors (Rebol 2010; Samy 2010; Mohan and Tan-Mullins 2009). These inquiries often present a lens through which either support or opposition, and most usually opposition, to increasing Chinese presence on the continent is gauged (Lee 2009; HRW 2011). Though far from complete, this expansion of the types of unit being analysed has contributed to demystifying (or myth-busting) public discourses on these relations.

Despite this incremental inclusion of actors across the political, economic, and social landscape, less attention has been paid to engagement at the supra-national level - with the notable exception of studies looking at the African Union. Supra-national structures such as regional bodies have been noticeably absent from discussions on China-Africa relations, despite their important role as coordinating bodies for regional integration and development on the continent. This absence might be attributed to the relative lack of power and success that these actors enjoy vis-à-vis the state in the African context. It might also be attributed to a dearth of knowledge about these bodies outside of specialized scholarship and expertise on regional bodies and/or Africa's political economy (for overviews of regionalism in Africa, see Söderbaum 2009: 487-489; Postel-Vinay 2007).

A further focus of this chapter is agency. As discussed in the previous overview chapter, the specific question of African agency is frequently neglected or wholly absent in policy and scholarly fields of international relations (Fisher 2018; Brown 2012; Shaw 2015). This is in part attributable to the Eurocentric nature of IR scholarship, which has treated African actors as mere objects of inquiry as opposed to agents in their own right (ibid.; 
Seth 2011; Jones 2006). This trend is also visible in prominent perceptions of China-Africa engagement, where the emphasis has been placed on China as the all-powerful actor (singular) that acts upon an agent-less Africa (Quinn 2011; Van Mead 2018; US Senate Committee on Foreign Relations 2011). Equally, the idea of Africa as victim to the 'China threat' is embedded in similar assumptions. Taking seriously critical IR scholarship, this chapter seeks to remedy the partial and Eurocentric nature of IR (and subsequent understanding of China-Africa relations) by reinserting African actors and their agency(ies) in scholarly analyses.

This chapter sets out to first establish the relationship of the Southern African Development Community (SADC) with China and the BRI more specifically, and then, secondly, to assess from the agent's perspective what agency entails. This study does not seek to present an imposed definition of agency that is traced through various processes. Instead, the chapter is focused on exploring agency from the perspective of the agent. This means that while it adopts a base definition of agency as the ability of actors to take decisions in the interest of goals, this definition is engaged loosely in order to leave room for alternative iterations of the concept.

Thus, while states remain indispensable players in China-Africa relations their dominance in analyses has overshadowed the range of actors that are noteworthy of attention. Equally, though African agency is undoubtedly challenged by structural constraints, as has been discussed in the overview chapter, the range of agencies at work has also been neglected, which has simplified analyses. This chapter seeks to tackle these superficial and simplistic characterizations of both actors beyond the state and the role of agenc(ies) in discourses on China-Africa relations. It does this by investigating the engagement of SADC as a principal Regional Economic Community, with China and the BRI.

There is a lack of knowledge about the Southern African Development Community's relations with China and the BRI when compared, for example, with the East African Community (EAC). This lack of knowledge renders it a specifically interesting case from which to investigate the issue of agency. Given the synergies of the BRI's aims and the Southern African Development Community's regional integration goals, it is hoped that this case can provide insight into how agency is conceptualized and exercised at the African regional level. It specifically seeks to ascertain the Southern African Development Community's agency since the release of the BRI white paper in March 2015. The chapter's analysis is based on field research interviews conducted at the Southern African Development Community's headquarters in Gaborone, Botswana, as well as complementary expert interviews with 
individuals from the South African Institute of International Affairs (SAIIA) in Johannesburg, South Africa, which were conducted in October 2019.

\section{China, the BRI, and Africa's Regions}

As has been covered in the preceding overview chapter, Africa was incorporated relatively late into China's BRI. A notable development, however, has been the change in the wider continent's previously relatively marginal role to the BRI since the release of China's 2015 white paper. This white paper broadened the BRI project to encompass regions beyond the initially outlined geographical 'confines' (NDRC 2015). Given the common practice of retroactively including projects, the scope for the BRI in Africa widened (Breuer 2017). The result has been the signing of MoUs across the continent under the auspices of the BRI. South Africa - arguably the furthest away from the 'traditional' map - signed a MoU in 2015. Egypt signed one in 2016. Then both Kenya and Ethiopia signed MoUs in 2017 (Alden et al. 2017).

Relations between China and Africa's regional organizations were previously evident (for example, the relations China has with the African Union, Southern African Development Community, the Economic Community of West African States, and the Common Market for Eastern and Southern Africa). However, the BRI has brought the regional dimension of China-Africa engagement into greater relief and contributed to what Davies has termed 'China's commercial positivism towards African economies' (Davies 2008: 152). Within the context of the BRI, East Africa stands out as a regional focal point, most notably because of its inclusion as an indispensable geographical node of the 'original' One Belt One Road map. Demissie (2018) describes the East African region as the foremost beneficiary of the BRI in Africa, where projects have focused on transregionalism and include ports, naval bases, Special Economic Zones (SEZs), and rail connectivity (ibid.: 74). In this area, for example, it is noted that economic integration has already increased between Ethiopia and Djibouti because of cooperation (ibid.: 75). Despite these successes, the broader experiences of African states with new SEZs on the continent have highlighted that 'African governments have failed to think ahead to how SEZs can improve either their contribution to global trade or create links with global supply-chains' (Okere 2019). These mixed results display the continued challenge of productive regionalism on the continent and raise questions about avenues for African development.

Along with other challenges of China-Africa cooperation, much of the onus to harness the opportunities presented by Chinese investment and the 
BRI has been placed on African states and actors. Implicit in these perspectives is the idea that China's investments do in fact provide opportunities for the continent (Lin and Wang 2014; Kaplinsky 2013; Samy 2010). These observers suggest that while challenges persist regarding Chinese-African cooperation, the opportunities have not been effectively or adequately harnessed by all actors (Chen 2016; Ndzendze \& Zumbika-Van Hoeymissen 2018; Okere 2019). It is this assumption regarding the failure of African actors to harness opportunities that leads to the central question of this chapter. Specifically, this question is: Why have actors such as the Southern African Development Community not harnessed the apparent opportunities provided by China despite China's continued reiteration of the need for African ownership of relations? ${ }^{1}$ Undoubtedly a host of factors contribute to the success of China-Africa engagement and hinge upon how actors themselves define 'success' in relation to their diverse goals. This chapter takes the assumption that all actors hold agency (as has been elaborated on in the overview chapter) and takes the base definition of agency as the capacity to hold specific interests or goals. Based on this, the chapter seeks to understand the Southern African Development Community's agency by exploring its specific interests and goals as well as how the achievement of these is navigated through its engagement, or lack of engagement, with China. The chapter will also pay attention to how both structural and agent-related variables are seen by the agent to play a role in their exercising of agency.

\section{Regional Economic Communities (RECs)}

Within the African context regional economic communities (RECs) present vehicles through which regional integration is pursued. It is hoped that such integration will 'enable the continent to negotiate more effectively with other economic actors in the global economy' for the goals of poverty alleviation and broad-based development (Uzodike 2009: 28). Regional configurations in Africa such as the Economic Community of West African States (ECOWAS), the East African Community (EAC), and the Southern African Development Community (SADC) have featured in African political, social, and economic

1 See, for example, Sun et al. (2017:53), who cite a Chinese diplomat underscoring that 'we have been clear on how we'd like to see our relationships in Africa evolve. What would be tremendously helpful for us is if we could get that same level of clarity from our African counterparts.' Ownership in this context therefore refers to the extent to which African actors drive the terms and conditions of relations. 
research, policy, and debate. However, many outside of Africa, or outside of specialized fields of African political economy and African development, are not necessarily aware of their existence or prominence. These RECs share common goals, all seeking to deepen regional cooperation and development. However, they are trying to achieve these goals in different ways (for example, through either free trade, common markets, or customs unions) and have had varied levels of success as well as equally varied challenges (language, political systems, conflict, level of development) (Uzodike 2009; De Melo 2013; Anyanwu et al. 2014; Bronauer \& Yoon 2018).

Despite the dominance of bilateral relations within China-Africa engagement, BRI initiatives and close relations with China have also been harnessed at a multilateral regional level. This has been carried out most notably by the East African Community (EAC), which has geographical proximity to the 'new Silk Road'. At the time of research, however, markedly absent from discussions about China's engagement at the regional level (and from discussion about the BRI) was any discussion of the Southern African region and the Southern African Development Community in particular. At least, this was the case in public discourse. Despite countries in the region having strong bilateral relations with China (with the exception of Swaziland), anecdotal discussions revealed that not much was or would be happening between the regional body of the Southern African Development Community and China or the BRI. This fit the general assumption that China's engagement on the continent (and the BRI more specifically) is focused on areas with direct interest to China, despite evidence to the contrary (see Brautigam 2009). The lack of visible or notable engagement between the Southern African Development Community and China or the BRI has therefore been assumed to be the result of the region's relative lack of direct interest to the BRI, when compared with the East African region. This is despite the fact that the Southern African Development Community is one of the largest regional economic communities with fifteen member states. In light of the significant cooperation between China and regional economic communities such as the East African Community, this chapter was prompted to explore the reasons why there is a seeming lack of engagement between the Southern African Development Community and China, despite China's strong bilateral ties with states in this region. More specifically it was driven by the impetus to understand the role of agency (defined as the ability of actors to hold interests/goals) in this apparent lack of engagement and in turn to question how the Southern African Development Community's interests and goals are supported or not supported by its relations with China and/or the BRI. 


\section{Contested Agency}

In the context of China-Africa relations, agency has frequently been equated with a normative 'good'. This has meant much of the focus has been on an approach that is a form of activism and equates agency with grassroots movements and local communities (thus sub-state actors). This approach seeks to counter large-scale Chinese projects and Chinese influence on the African continent more broadly (whether this be with regard to nonconsultative projects that impact livelihoods of communities and drive communities out, or with regard to uprisings against unfair labour practices). The result has been that agency has become synonymous with activism that is against Chinese presence in Africa and broader anti-Chinese sentiment (HRW 2011; HRW 2006). Conversely, if and when agency is seen to be successfully harnessed by African actors in popular discourse, it is often directly related to the exercise of absolute or hard power. For this reason, agency is characterized as almost only ever being successfully exercised by corrupt and power-hungry elites. This take has become commonplace in analyses of China-Africa relations (French 2014; Heydarian 2015; Taylor 2008).

At the same time, there have been normative evaluations of agency that have interpreted all cases of African agency as a moral 'win' against the powers that be. Van Staden et al. (2018) note this, writing that

there is a belief that any act of agency by weaker actors within a system dominated by global powers is a normative good, because that necessarily challenges the lopsided power hierarchy. This outlook complicates the analysis of African agency because it ascribes moral purpose to the conduct of African actors because they occupy a weaker position compared to major powers. $(7-8)$

In the same vein, Murray-Evans (2015: 1847) has stated that:

Much of the recent African agency literature conceptualizes agency as the ability of African actors to have a significant impact on international political processes. This literature also often equates African agency with resistance to externally imposed policies and ideas and perhaps even with the ability to bring about progressive or emancipatory structural change.

All these cases demonstrate the couching of agency in normative frameworks, further complicating precise and conceptually clear research on agency. This reductive and often normative or political understanding of 
agency is eschewed in this chapter, which looks at agency in as neutral a light as possible. It does so inductively, by using an agent-oriented approach, which views agency from the position of the agent. In so doing it does not presume a fixed definition or normative stance on how, and to what end, agency is exercised. Instead, by taking an open-ended approach, the agent is placed at the centre of understanding how agency operates, underscoring agency as a context-bound variable that resides largely in the 'eye of the beholder'.

This chapter considers the complexities, as well as the specificities, of African agency(ies). These complexities, which include structural constraints, the centrality of identity, and history, have also been discussed in the overview chapter of this volume about the BRI and the African continent as a whole. For the examination of agency, regional economic communities (RECs) provide an interesting case of how actors with limited power (relative to the state) exercise agency in potentially creative and/or strategic ways. The question as to how the Southern African Development Community holds agency and what its constraints are is asked in an open-ended manner to allow for as wide as possible an understanding of agency. An agent-focused approach complements this inductive framework. In this way, it is hoped that the chapter can shed new light on how agency is perceived and exercised.

\section{The Southern African Development Community's Interests, Goals, and Challenges}

This chapter defines agency as the ability of an actor to hold interests and goals. It is therefore necessary to briefly discuss these interests and goals as they relate to the Southern African Development Community. Moreover, by adopting an agent-oriented perspective these interests and goals are limited to how the Southern African Development Community as an organization presents these itself. Equally it is necessary to caveat the discussion of the Southern African Development Community by pointing out some of the foremost challenges faced by the body that impact its autonomy.

Founded in 1992, the Southern African Development Community represents one of the largest regional economic communities (RECs) on the African continent (after the Common Market for Eastern and Southern Africa, the Economic Community of West African States, and the Community of Sahel-Saharan States). The Southern African Development Community is comprised of sixteen member states. Its primary objectives are stated to be achieving development and economic growth, poverty alleviation, improvement of life standards, as well as supporting socially disadvantaged groups all 
through a process of regional integration (SADC 2012). The Southern African Development Community secretariat is thus the region's coordinating body with a mission to 'provide strategic expertise and co-ordinate the harmonization of policies and strategies to accelerate Regional Integration and sustainable development' (ibid.: Vision, Mission \& Mandate).

A key agenda is the Southern African Development Community's Regional Indicative Strategic Development Plan (RISDP), which represents the operational framework for achieving specific goals set out in the Common Agenda. Importantly, the RISDP has a fifteen-year span (2005-2020), concluding in 2020. It sets out milestones and targets across a number of listed priority areas such as poverty eradication, infrastructure support, and environmental/ sustainable development (amongst others). Aside from the specifics laid out in the RISDP, the Southern African Development Community's focus on regional integration is best captured in its five directorates or themes, which are 1) Industrial Development and Trade; 2) Finance, Investment, and Customs; 3) Infrastructure \& Services; 4) Food Agriculture \& Natural Resources; and 5) Social \& Human Development; all are supported by the Southern African Development Community's specific policies and strategies (see ibid.: Overview, Common Agenda). Beyond regional integration, one of the goals of the Southern African Development Community is to develop the region to the degree that it can be competitive in international relations and the world economy. Regional integration, the establishment of a vision of a shared future, and the creation of a regional community are cited as necessary components to achieve this broader goal (SADC 2012: Vision, Mission \& Mandate).

Specifically, the Southern African Development Community has identified infrastructure as one of the major contributing factors for economic growth and poverty reduction in the region. The present state of infrastructure as well as the infrastructure gap between the Southern African Development Community region and the more developed countries constitutes a serious handicap to the region's production and competitiveness' (ibid.: Project Preparation Financing). This is captured in the Regional Infrastructure Development Master Plan (RIDMP) of 2012. This plan underscores the importance placed on infrastructure development as a fundamental cornerstone of regional integration (ibid.: RIDMP Executive Summary).

\section{Interviews}

In the following section, the chapter provides a thematic discussion of the key concepts that emerged in the range of open-ended interviews conducted 
with officials from the Southern African Development Community as well as experts at the South African Institute of International Affairs in October 2019. The interviews were open-ended to give interviewees the broadest possible scope to address issues related to relations between China and the Southern African Development Community, to discuss challenges faced by the Southern African Development Community, as well to speak about the question of agency. The four main themes focus on the Southern African Development Community's interests, the nature, and modes of engagement between the Southern African Development Community and its partners, and structural considerations.

\section{Interests}

As a point of departure, the Southern African Development Community officials that were interviewed felt it necessary to extensively outline the organization's structure and priority areas. They underscored that industrialization, infrastructure, peace and security, social and human development were the main focal points. They mentioned that the organization was in the process of developing strategies for after the Regional Indicative Strategic Development Plan ends in 2020 that would maintain the same priorities for the region. The interviewees stated that infrastructure was unique in its nature, being particularly capital intensive and thus requiring significant financing. However, they suggested that this capital-intensive nature of the sector was not particular to the Southern African Development Community region, but was an industry-wide reality. One of the respondents noted that 'we give a lot of importance to infrastructure development' and the idea of 'infrastructure in support of regional integration' (SADC interview 2019). They further indicated the centrality of this area to the Southern African Development Community's interests. The overlapping interest in infrastructure of Chinese investments in Africa and the Southern African Development Community was mentioned, underscoring the importance attributed to common interests. Despite this overlap, the respondents mentioned that for any project to qualify for financing, it 'must link with the priorities of the region [...] in a way that benefits the region' (ibid.). The fact that this was reiterated on several occasions shows the importance that SADC places on seeing that its interests are fulfilled.

The importance of quality support was also emphasized by several of the interviewees. This perhaps relates to the commonly held belief about the poor-quality projects deriving from China (Farrell 2016). The kind of quality control that is carried out on new projects includes resource mobilization 
checklists and involves a technical review of support and legal units, as well as a review of the resource mobilization allocation framework. The interviewees noted that at the Southern African Development Community: 'we have a very structured engagement mechanism' (ibid.). They reiterated that not just any project would be taken on but that strict guidelines had to be followed. They stated that the Southern African Development Community would not sign off on engagements that did not meet their very stringent needs. These decision-making capacities and forms of accountability arguably allow for agency to be asserted vis-à-vis powers like China and provide the organization with a framework within which to pursue their interests. The weight given to this issue by the respondents emphasized that China is unable to 'buy' or 'intercept' the priorities of the Southern African Development Community. This was captured in a statement made by one of the interviewees, who said: 'If it's not aligned to [the Southern African Development Community's] priorities, the cooperation would be aborted' (ibid.). These regulatory frameworks guide the Southern African Development Community's projects and should in theory allow for the pursuit of specific goals and interests. However, the reality of how this pans out in the context of cooperation between the Southern African Development Community and China remains to be seen. Nevertheless, these statements give insight into how the agent (in this case the Southern African Development Community) emphasizes the importance of both interest and mutual interest. As will be discussed later, despite this initial optimistic and arguably simplistic understanding, the interviewees also noted the way that effective collaboration depends on the interests of funders themselves.

In demonstrating their drive for cooperation, respondents tended to express their position in terms similar to the following: 'What is it that we as [the Southern African Development Community] can benefit from [through] strong ties with the Chinese? And what is it that the Chinese can benefit [from] if they get into formal ties with [the Southern African Development Community] in terms of cooperation?' (ibid.). These kinds of statements display an approach that focuses on what each party can get out of cooperation. This 'win-win' focus - though never explicitly mentioned as such - was evident throughout the discussions. Statements relating to this revolved around the importance of ensuring that both parties see their interests met. This indicates that the Southern African Development Community sees their relations with China as being mutual cooperation, as opposed to being zero-sum. The interviewees therefore challenged the idea that African actors are worse off in their cooperation with China. Instead, these interviewees reiterated the importance of seeing the benefits 
of cooperation for African actors: 'At this stage, really, it would be more useful to focus more on the opportunities' (ibid.).

In relation to the issue of interests, the interviewees also remarked that it was no longer feasible to simply bring funds into Africa. They said that foreign direct investment (FDI) now also needed to contribute to socioeconomic development. It might do this, for example, by linking African small- and medium-sized enterprises into investors' value chains. While it remains too early to tell whether or not China-Africa cooperation will contribute to socio-economic development in this way, the fact that the interviewees raised this point relates to the idea of agenda setting through the articulation of interests. This agenda-setting role was mentioned by the interviewees as central to agency. One of the experts interviewed remarked that the African continent and the Southern African region are at a critical juncture, where structural factors such as 'rapidly expanding markets, maturing middle classes [and the new] continental free trade agreement' (expert interview 2019b) are being leveraged. This allows for greater agency. The fact that Africa is going through a critical period, combined with the fact that the markets of Europe, North America, and increasingly Asia are highly saturated, has placed the region in a better negotiating position, creating increased room for African actors to exercise agency. In this way, it might be argued that global structural shifts are demonstrating the impact of structural change on agency.

\section{Modes of Engagement}

The Southern African Development Community respondents placed a strong emphasis on the priorities, resource mobilization strategies, and processes of the organization. However, they also mentioned that 'China is more open in terms of modalities, unlike the other partners [where] you have a lot of rules to follow, and processes' (ibid.). They therefore suggested that they saw relations with China as offering a degree of flexibility, or at least a range of options that would seemingly give the Southern African Development Community room to manoeuvre. What precisely these modalities would entail and look like in the context of engagement with China (given the Southern African Development Community's own regulatory frameworks) was, however, not clear, in part due to the fact that relations are still in a relatively early stage.

The interviewees mentioned that coordination between the Southern African Development Community and China 'is still young in terms of achievements [...] [but we have] strong ties with the Chinese partners, with 
Chinese stakeholders, and the Chinese government' (ibid.). The relative newness of these relations means that, while more combative assertions of agency grounded in competing or incompatible interests could characterize future engagement, this early stage of engagement has thus far only dealt with seemingly superficial compatible interests. When probed for possible points of incompatibility, the interviewees made clear that it was not productive to focus on the challenges as they had not experienced any to date. Instead, they were far more optimistic and focused on the opportunities that China and the BRI could bring to the project of regional integration.

Despite the recent nature of engagement, and in contrast to the assumption that the Southern African Development Community and China have no firm relations to speak of, the interviewees noted that a memorandum of understanding $(\mathrm{MoU})$ between the two parties had been in the making since 2016. More importantly, the establishment of relations and this MoU has been a process largely driven by the Southern African Development Community and not by China. The interviewees suggested that the apparent lack of commitment, and the fact that a MoU had not yet been signed, was a consequence of logistics rather than the existence of conflicting views, troubled negotiations, or a lack of interest on the part of the Southern African Development Community. This contrasts with the perception that the Southern African Development Community has been lacklustre in harnessing the potential opportunities that Chinese investment and cooperation provides. One interviewee, underscoring the drive to cooperate on the part of the Southern African Development Community, remarked that 'once the MoU is signed officially, then we will start aggressive engagement with China' (ibid.). While a MoU is meaningful to signal cooperative intent, how engagement concretely plays out will also be significant.

One of the experts interviewed noted differences in how the BRI was conceptualized, as either predominantly commercial or strictly political, suggesting that these differences necessarily reflected the interwoven nature of business and politics in China (expert interview 2019a.). This way that the BRI combines business and politics was seen by some interviewees as having a bearing on agency. In this view, China-Africa relations (under the BRI and beyond) have come to represent a unique form of engagement, different to Africa's engagement with traditional platforms or partners such as the European Union. Though international relations will always consist of a mixture of politics and business, China is seen as qualitatively distinct from traditional partners, particularly because of its avoidance of political reform in the form of political conditionality. This different 
political approach by China arguably affords a greater degree of agency for actors such as the Southern African Development Community in Africa. However, whether or not the Southern African Development Community is able to leverage this greater potential for agency, considering the structural impediments (as will be covered in the following section), is another question altogether. It is a question that the interviewees largely felt was too early to answer, given the relative silence on the issue of the Southern African Development Community and China at the time of the interviews. Thus far it would seem the biggest assertion of agency has been the initiating of relations by the Southern African Development Community in order to pursue their own agenda and goals. This is contrary to the widely held assumption that China-Africa relations are initiated and driven by Chinese actors and interests (Mohan and Lampert 2013).

Interestingly, after field research interviews were conducted, there was a new development in the relationship. The Chinese government pledged the continuation of development cooperation with the Southern African Development Community after finalizing the Southern African Development Community and China Framework Agreement, which was signed in October 2019 (SADC 2019). Beyond the Framework Agreement, which serves as a MoU, the Chinese delegation notably 'extended an annual grant amounting to US $\$ 100,000$ to the Southern African Development Community Secretariat to support its operational needs and implement activities that are in line with [Southern African Development Community] priorities' (ibid.). While this contribution is towards the operational needs, it will be interesting to see what, if any, Southern African Development Community projects are financed by China in the future. It will be also interesting to watch how these arrangements differ, if at all, from those with traditional partners. How these are negotiated will reveal more about the Southern African Development Community's agency vis-à-vis China and the BRI.

Although limited, these initial engagements have an important bearing on the question of the Southern African Development Community's agency. They speak to a degree of 'action' on the regional body's part. Despite the recent nature of relations, the initiation and pursuit of cooperation from the Southern African Development Community reflects the way in which the body has taken initiative in asserting its interests and agenda vis-à-vis China. Moreover, the Southern African Development Community's apparent unified position in approaching China (which would require consent from its diverse and wide-ranging member states) speaks to a degree of active agency on the part of the regional body. 


\section{Structural Considerations}

The interviews also sought to explore the range of challenges faced by the Southern African Development Community as an organization. It was hoped to reveal ideas around constraints to agency. What emerged was a range of challenges mostly related to structural constraints - the limitations inherent to regional bodies, regionalism, and the process of coordinating regional integration. These limitations include such things as the need for a consensus between member states, as well as the often-cumbersome pipelines with regards to project preparation - from identification to bankable stages (ibid.). The interviewees mentioned the challenges presented by the scope of cooperation: 'There will always be too much ground that needs to be covered' (SADC interview 2019). These challenges are evidently more related to the intrinsic challenges of coordinating regional projects for integration and development. Projects that would fall under the category of cooperation with 'China' or the BRI appear to be no different in this regard. However, the interviewees did mention that China was 'more open' to different modalities. What precisely these different modalities were and how they would either complicate or ease processes was not clear, partially because of the young nature of these relations.

The biggest challenge that the officials noted was the sustainability of programmes in relation to financing:

[The Southern African Development Community] is a member-statedriven organization. We receive contributions from our member states to run the organization. But those contributions are mostly for the [the Southern African Development Community] secretariat coordination, not to implement our programmes. [...] [M] ost of our programmes are still supported through donor support, which is not sustainable. (Ibid.)

From the discussions it was made clear that although the Southern African Development Community has its own set of priorities (not set by external partners), the sources of financing (i.e. financiers) in part dictate what money is spent. In terms of funding the main partner of support remained the EU, which is followed by German cooperation, and then there is the rest, which includes China (ibid.). The interviewees also mentioned that adequate interest from both sides was needed to set up a given project, again reiterating the centrality of compatible interests. The idea that China and the Southern African Development Community's goals were complimentary was presented by the interviewees as an opportunity where both parties' 
interests could be met. A more in-depth comparison of EU and Chinese funding would be needed to assess if there is a difference in amount of room these two sources of funding provide for African agency. At first glance, however, it would seem that cooperation between China and the Southern African Development Community may provide more room for manoeuvrability than cooperation between the EU and the organization, or a different kind of agency. The cooperation between the EU and the Southern African Development Community is often constrained by the dictates of donor approaches (Buzdugan 2013; Hurt 2012).

The experts interviewed noted numerous structural challenges relating to the Southern African Development Community's agency. These can be divided into three broad areas, namely historical legacies that the continent (and an organization like the Southern African Development Community) face, resource constraints, as well as the very nature of regional integration as a project itself (which was also mentioned by the interviewees from the Southern African Development Community). The issues presented by historical legacies were noted by the interviewees as being a continent-wide challenge. This is particularly with regards to the legacies of colonialism that have continued to have tangible effects on the pursuit of regional integration and continental development. It was mentioned that, particularly in infrastructure, different systems inherited from different colonial powers persist in countries across Africa. This presents structural and logistical challenges such as differing railway gauges, different legal systems, and different regulators (expert interview 2019b). As one interviewee noted, 'the whole concept of regional infrastructure is a massive challenge [in Africa]' (ibid.). Agency on the part of a body such as the Southern African Development Community is thus inherently limited by the configuration of the African political and historical landscape. Historical factors were also highlighted as a key difference in the levels of success of the East African Community and the Southern African Development Community. The East African Community's emergence was largely economically driven, in contrast with the Southern African Development Community, which emerged from very specific political rationales that initially sought to relieve the region of its dependence on apartheid South Africa. Corroborating this, another interviewee noted that the Southern African Development Community still has to 'deal with the legacy of its creation' (expert interview 2019d). This legacy presents a further structural impediment to the effective exercise of agency.

This ties into other distinct structural constraints of the region, when compared to the East African Community for example. The Southern African 
Development Community constitutes a much larger geographic region with a wider mix of disparate economies and countries. The countries in the region range from states that are small and landlocked (such as Lesotho, Malawi, Swaziland), to states that are large but arguably unconsolidated (such as the Democratic Republic of Congo), to states that are large but with low population density (such as Namibia and Botswana), and finally to a series of small island states (expert interview 2019c, 2019d). The dominance of the regional hegemon South Africa also presents a structural challenge, especially given the challenges that South Africa itself faces. Thus, while South Africa may enjoy a relatively diversified economy, the socio-economic challenges of unemployment and poverty remain a more immediate priority for the country. A challenge to the Southern African Development Community's exercising of agency lies in the serious developmental and political challenges that each member state faces. Bilateral engagement with China and/or the BRI therefore remains valuable, whereas the broader continental [or regional] dividend' remains a structural challenge (expert interview 2019c). Given the relative underdevelopment of regionalism in SADC, it is no surprise that pressing national concerns are often prioritized over regional agendas.

Another interviewee noted that the Southern African Development Community's constrained resources were also a potential structural barrier to agency (expert interview 2019c). This relates largely to the lack of personnel. The result is a largely understaffed secretariat with an exorbitantly high workload (ibid.). This has made coordinating integration incentives between the middle- and low-income countries that make up the continent and the region even more cumbersome. Perhaps surprisingly, the interviewees did not see the Southern African Development Community's need to finance itself as a constraint. Instead, they pointed to the lack of human resources and appropriate expertise need to provide project preparation (expert interview 2019b). This undoubtedly hampers the organization's ability to pursue and achieve its goals.

Equally relevant, the interviewees also mentioned that regional blocs such as the Southern African Development Community were challenged by their limited mandate and the accompanying limitations on decisionmaking power (ibid.). The very nature of the Southern African Development Community secretariat, which is a purely coordinating body, therefore presents a structural challenge to its agency. Nevertheless, if maintaining cordial relations and respecting member states' wishes is in the organization's interests, then arguably the limited role of the secretariat does not necessarily impact the Southern African Development Community's agency 
to the degree assumed. This highlights the way that the competing interests of an actor may be an obstacle to effective agency.

One thing that was not mentioned by the officials, but which was reiterated by the experts interviewed, was that the agency of a body like the Southern African Development Community when engaging in the BRI should be considered in combination with the structure of the BRI or the lack of such structure. The BRI is a very 'loose idea' with 'loose framing' (i.e. not having a secretariat or headquarters) (expert interview 2019a, 2019d). This looseness means that the structure of the BRI does not act as either a major constraining or an enabling factor for the Southern African Development Community's agency. This will also be affected by any changes to the BRI and its functioning.

The specificities of the African context were also noted as relevant to the Southern African Development Community's agency. Interviewees noted that agency in Africa is often shaped by a lack of structural power and thus exclusion that can result in a 'Global South version of agency' (expert interview 2019a). An important takeaway was that:

[t] here will always be something with structural constraints. So one would need to define agency in relation to how it's exercised in the context of constraints. [...] one model that immediately comes to mind is a tactics and strategy kind of model. To a certain extent, this kind of global south agency always has a strong practical element. (Ibid.)

This form of agency also involves the idea of 'strategic non-compliance' or the ability to 'block' actions that are being taken. Here, agency has as much to do with 'action' as 'inaction'. The above quotation points to the wide array of ways in which agency may be exercised, particularly in the face of structural barriers (expert interview 2019c). The interviewees made a similar point about the assumption that a lack of coordination, unified governments, or lack of articulating what cooperation would look like necessarily means a lack of agency' (expert interview 2019a). Instead, they suggested that these things might not mean a lack of agency. They indicated that the strategic choice of when to use institutional architecture to further particular interests 'itself could be seen as an exercise of agency or decision making' (ibid.). From interviews with officials from the Southern African Development Community it appeared that official frameworks would be used to ensure engagement suited the organization's interests. However, as has already been mentioned, the type of arrangements made remain to be seen. These could very well be different from what traditional partners have pursued. 
Despite these constraints, all respondents reiterated that China and the BRI present a great opportunity for the region's development. The preeminent challenge to agency would be the very nature of the Southern African Development Community's secretariat with its limited mandate and authority:

[I]f we can agree on a very specific way that we want to trade with each other, and we as a region want to trade with the rest of the world, then I think we can start talking about real agency developing; agency in the sense of influencing the development dividends, the way we articulate our particular positions, the way we articulate our expectations, and the way we can insist that our expectations are met. The question for me is whether the SADC secretariat can play that role. (Expert interview 2019c)

In part, then, the call is for a 'much stronger regional integration body' that is able to move beyond the structural limitations of a coordinating body and this secretariat's lack of independence - something which was also highlighted as an obstacle (expert interview 2019d). However, a question is whether this is possible, given the structural challenges that exist in the individual member states and have been described above. This remains a fundamental question and one that is not specific to relations between China and the Southern African Development Community. The main issue is not the dominance of bilateral engagement between China and states in the region, but rather diverging priorities between member states themselves. If the BRI and Chinese cooperation with the Southern African Development Community, given its focus on infrastructure development and structural transformation, is able to successfully incentivize national governments to prioritize and coordinate regional projects, then the Southern African Development Community, as a regional body, could be inadvertently strengthened. This however remains highly speculative.

\section{Discussion}

The interviews conducted for this research provided numerous key insights with regards to the main tenets of agency as conceptualized by officials from the Southern African Development Community secretariat as well as experts in the field. Common concepts related to agency were leverage, influence, interests (and their articulation), as well as agenda-setting and decision-making power. The Southern African Development Community 
itself emphasizes its interests as central to any engagement, supporting the idea that agency at its very fundamental level is the ability of an actor to possesses goals and interests. In relation to its engagement with China, the interviews reflected an active pursuit of interests, related to the task of exercising agency.

What is clear from the interviews is that beyond the formulation, articulation, and pursuit of interests, there exists a strong relational component to understanding the Southern African Development Community's agency. Most notably, the different nature and modes of engagement between Africa and China, when compared to Africa and traditional powers, results in different types or expressions of agency, as either conflicting, complementary, or a mix of both. At this stage, China is presented by those participating in the cooperation as holding (mostly) complementary goals and interests, which has resulted in a more inconspicuous form of agency. This relational dimension of interests and their compatibility emerged from the interviews as a key consideration in understanding agency. The tendency within research to overlook how agency might still be being exercised when the interests of actors are synergistic, or overlap, has narrowed the understanding of agency. A preliminary hypothesis for future research would be that overlapping interests, such as the interests which lie behind Chinese BRI investments and the Southern African Development Community's goals, present greater scope for agency, particularly on the part of the more structurally constrained actor, which in this case is the Southern African Development Community. This arguably affects the effectiveness of agency positively. The inverse would be that more disparate and conflicting interests, such as the interests of the EU and the Southern African Development Community's goals, when in combination with structural constraints, act to limit the effectiveness of agency, particularly on the part of the structurally constrained actor.

Furthermore, the interviewees discussed at length numerous structural factors that impede scope for exercising effective agency. There are various kinds of structural constraints. However, what emerged as an interesting point is the way in which China's engagement (through the BRI) could potentially alleviate some of these constraints. While it remains too early to tell, future engagement will demonstrate how effectively the Southern African Development Community's agency has worked to secure its goals and interests. Here the BRI may contribute to achieving these goals through its focus on key priority areas such as infrastructure. Equally, because of the loose nature of the BRI itself, this platform may provide increased room for the Southern African Development Community to effectively achieve its goals. 
Important aspects, mentioned in both the interviews with the Southern African Development Community officials and the experts, were financing and agenda setting. While the EU remains the largest funder of the Southern African Development Community, how this funding differs from that provided by other funders, as well as the specifics of relations between the EU and the Southern African Development Community, are key considerations in understanding the Southern African Development Community's ability to exert effective agency. An equally important consideration is the nature of relations and the conditions of engagement/ funding between the Southern African Development Community and its funders. Part of this relates to the very nature of the Southern African Development Community's regionalism project. This project is one that is grounded in economic liberalization (Hurt 2012). In the interviews with officials, however, there was little reflection on the origins of the Southern African Development Community's interests as well as the influence of partners on its model of regionalism. An interesting question now is whether, and if so how, engagement with China and the BRI will steer the organization or certain projects in a different direction. A related question is whether the Southern African Development Community's goals and interests will be compromised in considering alternative pathways. Evidently, a degree of mutual interest is required in order for cooperation between the Southern African Development Community and its partners to be successful. However, to what degree this need for mutual interest differs amongst partners and how that affects the effective exercising of agency on the part of the Southern African Development Community remains to be seen.

A notable contribution that this research has made is to confirm the existence of formal relations and the intention for greater cooperation between the Southern African Development Community and China (as well as the BRI). During the research for this chapter, the experts interviewed were not aware of the impending MoU. However, the interviews with officials from the Southern African Development Community came at an opportune time, just as the MoU was being finalized. The fact that there is increasing cooperation between the Southern African Development Community and China contradicts the preliminary assumption that the Southern African Development Community has been apathetic towards such cooperation. It has been found that during this stage the Southern African Development Community has largely driven and instigated cooperation with China demonstrating an active pursuit of interests and thus agency. However, it remains to be seen to what extent the MoU is actionable, and, 
more importantly, whether a truly regional dividend can emerge from this kind of cooperation. This, in part, will reflect the effectiveness of the Southern African Development Community's agency. However, it needs to be assessed in the context of the many structural challenges the organization faces. This point was emphasized by one interviewee, who stressed the need for the Southern African Development Community to have a 'very clear [and] tangible agenda or even a very concrete implementation plan' with 'very clear benchmarks', considering the infrastructure deficit in the region (expert interview 2019c).

Beyond descriptions of how the Southern African Development Community works and what the main challenges to its interests are, the interviews were also insightful regarding how to best research agency. A noticeable challenge, however, was found with asking officials about agency directly. When asked there seemed to be a conflation of the idea of agency as 'the capacity for an actor to act in its interest' with agency as 'an organizational body or branch'. This reflects an evident gap between 'scholarship' on agency and how agency is understood in 'practice' by the agent themselves.

The biggest divergence in the interviews was on the issue of financing as an impediment to agency. The experts interviewed did not mention financing as a significant challenge, whereas the officials from the Southern African Development Community did. That being said, the latter qualified the challenge presented by financing, saying that this was the challenge of satisfying the interests of financiers. Meanwhile, the experts interviewed (in particular, expert interview 2019b) focused on the issue of project preparation and the limited resources in this phase. The interviews with officials from the Southern African Development Community relayed the various financing mechanisms and their respective challenges. Certain pathways for financing were highlighted as more restrictive with regards to agency, while others were seen to provide more leeway. Evidently, this has been recognized as a challenge by the secretariat and is a mechanism through which room for manoeuvre can be created.

One topic worth further exploration that emerged was the relationship between agency and effectiveness, or the question of how one might measure the effectiveness of agency. Important considerations and questions are 1) formulating points to achieve/interests, 2) a seat at the table, 3) to what extent can one shape the agenda, and 4) to what extent can one take this beyond just an agenda item (expert interview 2019d). The issue therefore is not whether agency exists, but rather to what degree it is functional and effective, given structural limitations. 
Despite structural challenges related to the 'form' of the regional body itself, the current setup did not appear to hamper the ability of the Southern African Development Community secretariat to articulate its interests and set agendas. It would seem that 'frequently there is an underestimation of who the African actors are, and particularly the fact that all these African actors are exercising agency in different ways and on different levels' (expert interview 2019a). This also seems to be consensus among experts with regards to the Southern African Development Community and its engagement with China and the BRI. If harnessed strategically, the BRI presents a vehicle through which structural challenges to the region's development can be addressed, thereby complementing the Southern African Development Community's interests.

\section{Conclusion}

This chapter has highlighted the importance of an agent-oriented approach to understanding agency in the African context. Considering the dearth of research into actors beyond the nation state and their relations with China, it has specifically focused on the supra-state level by looking at a regional body, the Southern African Development Community. By shifting the unit of analysis beyond the state, it has uncovered the range of considerations, opportunities, and obstacles that such regional bodies face in the realm of agency. Moreover, by using an inductive approach to agency, certain facets have emerged as central. These are the importance of interests and their articulation through agenda setting. A regional body such as SADC that pursues its interests by actively seeking collaboration with potential financiers such as China, demonstrates a degree of effective agency. Added to this, it emerged that, from the perspective of the agent, agency is shaped (constrained and enabled) by structural and relational factors that are context dependent.

Moreover, the particularities of agency within cooperative spaces and coinciding interests emerged as an often-overlooked area of agency. This is notable in the context of relations between China and Africa, and in the case of relations between the Southern African Development Community and China and the BRI that have been examined in this chapter. Relations between Africa and China provide alternative foci and thus alternative pathways to fostering collaboration when compared with relations between Africa and traditional donors. Highlighting the space for cooperation and complementarity, the Southern African Development Community's agency 
in terms of its relations with China and the BRI is at this early stage limited to cooperative engagement.

This chapter has also highlighted the importance of conflicting and complementary interests as central to understanding agency. These aspects underscore the need to obviate normative judgements on what agency ought to look like if one is to truly 'ascertain' or locate agency. It concludes that alongside the question of whether agency is exercised there is also an altogether separate question that must be asked. This is whether agency is effective, that is, whether agency achieves intended goals or secures interests (such as in the priority area of infrastructure development). This chapter has illuminated why agency has not been explicit or apparent (i.e. complementary interests). However, it has also noted that the effectiveness of this agency remains to be seen.

This chapter has also identified the centrality of structure to the discussion of agency in Africa and in the Southern African Development Community specifically. In this way, the chapter has provided a basis from which to further analyse the potential for China's engagement with the Southern African Development Community, within and outside of the BRI, to contribute to structural transformation in the region. More specifically, the ability of these new partnerships to contribute to the achievement of the Southern African Development Community's goals and interests, which are regional integration through development, specifically in the area of infrastructure, are areas worth exploring more. This will further advance our discussion of how effective the Southern African Development Community's agency is. Equally interesting is the question of whether the efficacy of agency in the case of the Southern African Development Community is dependent on shared interests.

This chapter has served as an introductory and exploratory investigation into the possible dynamics of agency within the Southern African Development Community and between the Southern African Development Community and China and the BRI. Shedding light on the parameters and pathways of agency is becoming increasingly relevant for how actors in Africa, in China, and in third-party states engage one another. Misconstruing agency not only obfuscates the complexities of how regional actors engage the powerhouse that is China and its BRI, but it also runs the risk of oversimplification. This chapter has hopefully managed to underscore the value of an agent-oriented, contextual, and relational approach to agency. 


\section{References}

Alden, Chris, Sidiropoulos, Elizabeth \& Wu, Yu-Shan (2017, May 29). 'China's Belt and Road Initiative: Where Does Africa Fit?' South African Institute of International Affairs (SAIIA). Retrieved 26 March 2020 from http://www.saiia. org.za/opinion-analysis/china-s-belt-and-road-initiative-where-does-africa-fit.

Anyanwu, John C., Conceição, Pedro \& Kayizzi-Mugerwa, Steve (2014). 'Regional Integration in Africa: An Introduction' African Development Review, 26(s1), 1-6. Brautigam, Deborah (2009). The Dragon's Gift: The Real Story of China in Africa. Oxford: Oxford University Press.

Breuer, Julia (2017, July). 'Two Belts, One Road? The Role of Africa in China's Belt \& Road Initiative'. Blichwechsel. Retrieved 26 March 2020 from https://www. asienhaus.de/uploads/tx_news/Blickwechsel_OBOR-Afrika_o1.pdf.

Bronauer, Jan \& Yoon, Ji (2018, August). 'Regional Economic Development in SADC: Taking Stock and Looking Ahead'. Report 25. South African Institute of International Affairs (SAIIA). Retrieved 26 October 2020 from https://saiia.org.za/research/ regional-economic-development-in-sadc-taking-stock-and-looking-ahead/.

Brown, William (2012). 'A Question of Agency: Africa in International Politics'. Third World Quarterly, 33(10), 1889-1908.

Buzdugan, Stephen Robert (2013). 'Regionalism from Without: External Involvement of the EU in Regionalism in Southern Africa'. Review of International Political Economy, 20(4), 917-946.

Chaponnière, Jean-Raphaël (2009). In Meine Pieter van Dijk (ed.), The New Presence of China in Africa (pp.55-82). Amsterdam: Amsterdam University Press.

Chen, Huiping (2016). 'China's One Belt, One Road Initiative and Its Implications for Sino-African Investment Relations'. Transnational Corporations Review, 8(3), 178-182.

Davies, Martyn J. (2008). 'Special Economic Zones: China's Developmental Model Comes to Africa'. In Robert I. Rotberg (ed.), China into Africa: Trade, Aid, and influence (pp. 137-154). Washington, DC: Brookings Institution Press.

Delgado, Daniel Lemus (2015). 'Discourse, Identity and International Development Cooperation: China, Africa and FOCAC'. Asia-Pacific Social Sciences Review, 15(2), 1-18.

De Melo, Jaime (2013, December 3). 'Regional Trade Agreements in Africa: Success or Failure'. International Growth Centre (IGC) blog.

Demissie, Alexander (2018). 'Special Economic Zones: Integrating African Countries in China's Belt and Road Initiative'. In Maximilian Mayer (ed.), Rethinking the Silk Road: China's Belt and Road Initiative and Emerging Eurasian Relations (pp. 69-84). Singapore: Palgrave Macmillan. 
Eom, Janet, et al. (2018). 'The Path Ahead: The 7 th Forum on China-Africa Cooperation'. Briefing Paper no. 1. China Africa Research Initiative.

European Parliament (2008, March 28). 'Report on China's Policy and Its Effects on Africa'. Retrieved 9 July 2020 from https://www.europarl.europa.eu/sides/ getDoc.do?reference=A6-2008-008o\&type=REPORT\&language=EN\&redirect. Farrell, Jamie (2016, August 14). 'China's Undeserved Reputation for Building Bad Infrastructure in Africa'. China Africa Project. Retrieved 21 August 2020 from https://chinaafricaproject.com/podcasts/podcast-infrastructure-china-africajamie-fuller/.

Fidler, Mailyn (2018, March 7). 'African Union Bugged by China: Cyber Espionage as Evidence of Strategic Shifts'. Council on Foreign Relations. March 7. Retrieved 26 May 2020 from http://cfr.org.

Fisher, Jonathan (2020). 'African Agency in International Politics'. In Nic Cheeseman (ed), Oxford Research Encyclopedia of African Politics. Oxford: Oxford University Press

French, Howard (2014). China's Second Continent: How a Million Migrants are Building a New Empire in Africa. New York: Alfred A. Knopf.

Heydarian, Richard Javad (2015, January 20). 'China's Scramble for Africa'. AlJazeera. Retrieved 16 July 2020 from https://www.aljazeera.com/indepth/opinion/2015/01/ china-troops-africa-economic-201511810569508263.html.

HRW (2006, November 2). 'China-Africa Summit: Focus on Human Rights, Not Just Trade'. Human Rights Watch. Retrieved 16 July 2020 from https://www.hrw. org/news/2006/11/o2/china-africa-summit-focus-human-rights-not-just-trade. HRW (2011, November 3). 'You'll Be Fired If You Refuse - Labor Abuses in Zambia's State-Owned Copper Mines'. Human Rights Watch. Retrieved 26 February 2020 from https://www.hrw.org/sites/default/files/reports/zambian11ForWebUpload.pdf.

Hurt, Stephen R. (2012). 'The EU-SADC Economic Partnership Agreement Negotiations: “Locking in” the Neoliberal Development Model in Southern Africa?' Third World Quarterly, 33(3), 495-510.

Jones, Branwen Gruffydd (ed.) (2006). Decolonizing International Relations. New York: Rowman \& Littlefield.

Kaplinsky, Raphael (2013). "What Contribution can China make to Inclusive Growth in Sub-Saharan Africa?” Development and Change, 44(6), 1295-1316.

Kayizzi-Mugerwa, Steve, Anyanwu, John C. \& Conceicao, Pedro (2014). 'Regional Integration in Africa: An Introduction'. African Development Review, 26 (s1), 1-6.

Lee, Ching Kwan (2009). 'Raw Encounters: Chinese Managers, African Workers and the Politics of Casualization in Africa's Chinese Enclaves'. China Quarterly, 199, 647-666.

Lin, Justin Yifu, and Yan Wang (2014). "China-Africa co-operation in structural transformation: Ideas, opportunities, and finances”, WIDER Working Paper, No. 2014/046. 
Marsh, Jenni (2018, March 30). 'Free Gift? China Extends Influence in Africa with \$32M Grant for Regional HQ'. CNN. Retrieved 27 September 2020 from https:// cnnphilippines.com/news/2018/o3/28/china-32M-grant-ECOWAS-regional-HQ. html.

Ministry of Foreign Affairs (2019). The Netherlands and China: A New Balance. Government of the Netherlands. https://www.government.nl/documents/ policy-notes/2019/05/15/china-strategy-the-netherlands--china-a-new-balance.

Mohan, Giles \& Lampert, Ben (2013). 'Negotiating China: Reinserting African Agency into China-Africa Relations'. African Affairs, 112(446), 92-110.

Mohan, Giles \& Tan-Mullins, May (2009). 'Chinese Migrants in Africa as New Agents of Development? An Analytical Framework'. European Journal of Development Research, 21, 588-605.

Murray-Evans, Peg (2015). 'Regionalism and African Agency: Negotiating an Economic Partnership Agreement between the European Union and SADC-Minus'. Third World Quarterly, 10, 1845-1865.

NDRC (2015, March). 'Vision and Actions on Jointly Building Silk Road Economic Belt and 21st-Century Maritime Silk Road'. National Development and Reform Commission, Ministry of Foreign Affairs and Ministry of Commerce, People's Republic of China. Retrieved 25 October 2020 from https://web.archive.org/web/20181127225143/ http://en.ndrc.gov.cn/newsrelease/201503/t20150330_669367.html.

Ndzendze, Bhaso \& Zumbika-Van Hoeymissen, Sara (2018, September 27). 'China and Africa's Integration Agenda: The Role of FOCAC'. Italian Institute for International Political Studies. Retrieved 16 July 2020 from https://www.ispionline. it/it/pubblicazione/china-and-africas-integration-agenda-role-focac-21280.

Okere, Austine (2019, August 16). 'Specialized Economic Zones (SEZs) in Africa: Exporting Production, Performance, and Perils'. Impakter. Retrieved 16 July 2020 from https://impakter.com/specialized-economic-zones-in-africa/.

Postel-Vinay, Karoline (2007). 'The Historicity of the International Region: Revisiting the Europe and the Rest' Divide'. Geopolitics 12(4), 555-569.

Quinn, Andrew (2011, June 11). 'Clinton Warns against "New Colonialism” in Africa'. Reuters. Retrieved 27 September 2020 from https:/www.reuters.com/article/ us-clinton-africa-idUSTRE75AoRI20110611.

Rebol, Max (2010). 'Public Perceptions and Reactions: Gauging African Views of China in Africa'. African Journal of Agricultural Research, 5(25), 3524-3535.

Taylor, Ian (2008). 'Sino-African Relations and the Problem of Human Rights'. African Affairs, 107(426), 63-87.

SADC (2012, August). 'Regional Infrastructure Master Plan: Executive Summary'. Southern African Development Community. Retrieved 25 October 2019 from https://www.sadc.int/files/7513/5293/3530/Regional_Infrastructure_Development_Master_Plan_Executive_Summary.pdf. 
SADC (2019, November 28). 'Chinese Government Pledges Continued Development Cooperation with SADC'. Southern African Development Community. Retrieved 16 July 2020 from https://www.sadc.int/news-events/news/ chinese-government-pledges-continued-development-cooperation-sadc/.

Samy, Yiagadeesen (2010). 'China's Aid Policies in Africa: Opportunities and Challenges'. Round Table 99(406), 75-9o.

Seth, Sanjay (2011). 'Postcolonial Theory and the Critique of International Relations'. Millennium:Journal of International Studies, 40(1), 167-183.

Shaw, Timothy (2015). 'African Agency? Africa, South Africa and the BRICS'. International Politics, 52(2), 255-268.

Söderbaum, Fredrik (2009). 'Comparative Regional Integration and Regionalism'. In Todd Landman \& Neil Robinson (eds.), The SAGE Handbook of Comparative Politics (pp. 477-496). London: SAGE.

Sun, Irene Yuan, Jayaram, Kartik \& Kassiri, Omid (2017, June). 'Dance of the Lions and Dragons: How Are Africa and China Engaging, and How Will the Partnership Evolve?' McKinsey \& Company. Retrieved 9 July 2020 from https://www.mckinsey.com/ /media/McKinsey/Featured\%2oInsights/Middle\%2oEast\%2oand\%20 Africa/The\%2oclosest\%2olook\%2oyet\%20at\%2oChinese\%2oeconomic\%2o engagement\%2oin\%2oAfrica/Dance-of-the-lions-and-dragons.pdf.

Ujeke, Charles \& Tariku, Yonas (2018). 'Beyond Symbolism: China and the African Union in African Peace and Security'. In Chris Alden, Abiodun Alao, Zhang Chun \& Lara Barber (eds.), China and Africa (pp. 289-309). Cham, Palgrave Macmillan.

US China Economic and Security Review Commission (2020, May 8). 'Hearing on “China's Strategic Aims in Africa”. Retrieved 16 July 2020 from https://www. uscc.gov/hearings/chinas-strategic-aims-africa.

US Senate Committee on Foreign Relations (2011, November 1). Subcommittee Hearing: China's Role in Africa: Implications. Subcommittee on African Affairs. Retrieved 16 July 2020 from https://www.foreign.senate.gov/hearings/ chinas-role-in-africa-implications.

Uzodike, Nwabufo Okeke (2009). 'The Role of Regional Economic Communities in Africa's Economic Integration: Prospects and Constraints'. Africa Insight, 39(2), 26-42.

Van Mead, Nick (2018, July 31). 'China in Africa: Win-Win Development, or a New Colonialism?' The Guardian. Retrieved 27 September 2020 from https://www. theguardian.com/cities/2018/jul/31/china-in-africa-win-win-development-ora-new-colonialism.

Van Staden, Cobus, Alden, Chris \& Wu, Yu-shan. (2018, September). 'In the Driver's Seat? African Agency and Chinese Power at FOCAC, the AU and the BRI'. Occasional Paper 286. South African Institute of International Affairs (SAIIA). 
Wang, Jianwei \& Zou, Jing (2014). 'China Goes to Africa: A Strategic Move?' Journal of Contemporary China, 23 (90), 1113-1132.

Zhang, Zhexin (2018). 'The Belt and Road Initiative: China's New Geopolitical Strategy?' China Quarterly of International Strategic Studies, 4(3), 327-343.

\section{About the Author}

Dr. StAcey Links is a South African national based in the Netherlands as a Research Fellow at the LeidenAsiaCentre. Having obtained her PhD from Utrecht University's Department of Law, Governance and Economics, she now holds the position of Lecturer at Leiden University's Institute of Area Studies (LIAS), where her teaching focuses on China-Africa relations, postcolonial and critical international relations theory, as well as regional integration in Sub-Saharan Africa. Her research interests are human rights in China-Africa relations and specifically the right to development. Her research is set against the backdrop of critical IR theory as well as critical approaches to development. 



\title{
7 Over Hills and Valleys Too
}

\author{
China's Belt and Road Initiative in the Caribbean
}

Ruben Gonzalez-Vicente

\begin{abstract}
Chapter 7 focuses on the Caribbean, specifically on Jamaica and Trinidad and Tobago. Taking these two states as cases, it shows how the BRI's financial muscle and infrastructural building capacity have transformed the Caribbean developmental landscape. Key to this transformation has been China's capacity to launch new projects in heavily indebted or cash-strapped economies. It has resulted in some of the region's traditional 'partners', such as the IMF or the European Union, losing their undisputed capacity for influence and coercion. However, Sino-Caribbean relations have also helped entrench long-established structural and postcolonial impediments for development. The chapter argues the BRI represents another iteration of neoliberal business-centric development in the region and so does not produce qualitative socio-economic change.
\end{abstract}

Keywords: Belt and Road Initiative, China, agency, Caribbean, Jamaica, Trinidad and Tobago

Few regions in the world can claim relations with China that are as multifaceted and complex as those currently held by the Caribbean. Despite its small population of just about 46 million inhabitants, scattered around sixteen sovereign states and seventeen dependent territories, the Caribbean contains not only exporters of natural resources, economies with a manufacturing base, and world-class tourism destinations, but also a mix of high-, mid- and low-income economies. It is also home to five states that do not officially recognize the People's Republic of China (PRC); one of the few remaining communist regimes in the world; and the two major destinations for Chinese investment in the world, if we exclude Hong Kong,

Schneider, Florian (ed.), Global Perspectives on China's Belt and Road Initiative: Asserting Agency through Regional Connectivity. Amsterdam, Amsterdam University Press 2021 DOI: 10.5117/9789463727853_CHO7 
the British Virgin Islands and the Cayman Islands. ${ }^{1}$ Consequently, the region occupies a curious position in relation to China's Belt and Road Initiative $(\mathrm{BRI})^{2}$ : commercially, it is an almost insignificant periphery, albeit one full of infrastructural investment opportunities following decades of economic impasse; financially, it is at the core of many crucial operations, channelling Chinese investments and guarding the fortunes of Chinese elites; geopolitically, it is an area of logistical importance due its proximity to the Panama Canal, and is also a potential minefield right at the centre of the unilaterally designated 'backyard' of the United States; diplomatically, it represents China's last frontier in the battle with Taiwan over international recognition.

In this chapter, I will focus on China's relations with the fourteen sovereign states that are members of the Caribbean Community (CARICOM). I choose this focus because the diversity of relations would make it too complex to cover all of the Caribbean within one cohesive in-depth analysis. From this vantage point, the chapter argues that the BRI has significantly shifted the hierarchies of development in the Caribbean, but it has done so without necessarily altering the region's broad developmental trajectory. In particular, the BRI has allowed regional economies to triangulate beyond a few traditional Western 'partners' (a generous word in this context) in search of better financing deals. However, despite broadening the developmental landscape, the BRI has also contributed to a narrow developmental horizon. The BRI's infrastructural focus has done little to reverse the region's structural dependence on the world market, the unequal postcolonial socio-economic order within Caribbean societies, or the prevalence of neoliberal business-centric understandings of development among local political elites. Whereas these are issues that can be attributed to the historical preconditions and contemporary political agency within the region, BRI projects have helped to perpetuate these trends by discouraging transparent, accountable, and participatory development approaches. This chapter also contends that the failure of the BRI projects to broadly improve socio-economic conditions in the Caribbean has resulted in an increased backlash from a wide range of social actors in precisely those countries where the BRI has been most successful in advancing Chinese business interests.

1 Forty per cent of all the assets managed in the British Virgin Islands are traceable to Chinese and Hong Kong capital, including rerouted investments of state-owned enterprises and offshore dealings by Chinese top officials and business elites (Donovan 2018; Robertson 2019).

2 Rather than studying the BRI as an institutional initiative that requires countries to become formal signatories, I refer to the BRI more flexibly as a political economic stage in China's developmental trajectory characterized by the internationalization of the country's construction sector in response to issues of domestic overaccumulation. 
This chapter draws on fieldwork conducted over a period of more than five years in nine Caribbean countries, Taiwan, and the PRC. During this time, I conducted 83 interviews on China-Caribbean relations, held meetings with a number of local stakeholders, participated in regional fora, and collaborated with colleagues at the University of the West Indies to track and analyse China's variegated engagements in the region. The chapter is organized as follows. The first section briefly reviews the history of (under) development in the Caribbean to contextualize contemporary Chinese activities in the region. The second section provides a panoramic view of the different Chinese economic activities in the Caribbean, giving particular attention to the different stages of engagement, the relevant actors, and the preponderant types of investment driving the relationship. After this, the next two sections explore BRI activities in two countries: Jamaica, and Trinidad and Tobago. A conclusion then summarizes the chapter's findings and core arguments.

\section{Antecedents: A Drama in Three Acts}

The developmental outcomes and geopolitical repercussions of BRI activities in the Caribbean cannot be properly assessed without considering the context in which they take place. A proper understanding of the Caribbean context needs to assess the repercussions of the colonial, neocolonial/ dependent, and neoliberal periods that are found within the region's contemporary social configuration and international links.

These processes can be traced back to the incorporation of the Caribbean into the European colonial system in the fifteenth century. They found particular salience in the eighteenth century, when European empires crafted a system of international production centred around Caribbean sugar. For Eric Williams, Caribbean plantation economies represented the first instance of globalization in the modern world, comprising slave labour brutally uprooted from Africa, European finance capital, trans-Atlantic trade routes, along with Caribbean production and European consumption (Williams 1984). Going far beyond the trade relations that different parts of the world had previously held, this complex commercial apparatus represented the world's first attempt at globalized production. For the Caribbean, this resulted in a process of 'passive incorporation' into the world economy as plantation societies. This 'passive incorporation' would have fundamental repercussions for the Caribbean both in terms of its outward relations with the rest of the world and its domestic social configurations (Girvan 2009). It 
would be impossible to review here all the different ways in which colonial history has shaped the postcolonial trajectory of Caribbean societies, but it would also be misguided to ignore the many living legacies from the colonial past. Amongst these legacies, three should at least be mentioned briefly. The first is how Caribbean sugar economies remained largely monocultural, dependent on external markets, and very vulnerable to external economic fluctuations following formal decolonization (Gumbs 1981). The second is how a sort of 'epistemic dependency' developed in relation to the imperial powers that had designed and managed the colonies from afar (Beckford 1972). The third is the way in which domestic societies were, and in some cases still are, stratified following racial patterns (Bissessar \& La Guerre 2013).

Many of these features survived in more or less similar forms into the post-independence period. Indeed, critical scholars from the region and post-independence leaders clearly identified many of the impediments to development that had prevailed during the colonial years (GonzalezVicente \& Montoute 2020). However, the various attempts to break away from structural and epistemic dependency encountered formidable opposition and were short-lived. The result was a perpetuation of said dependency into the post- or neocolonial period. In general, many newly independent states experimented with import-substitution strategies in the 1960 ond 1970s (ECLAC 2000). Some of these countries, such as Barbados, Jamaica, and Trinidad and Tobago, developed a manufacturing base but were overall unable to truly substitute imports. Perhaps more radically, other countries, such as Jamaica, Guyana, and Grenada, experimented with indigenous forms of socialism. These experiments either ended up becoming something different (as in the case of Guyana's economic nationalism under Forbes Burnham) or were crushed by the pressures of transnational investors or direct military invasion by the United States (as in Grenada in 1983) (Stone 1986). The oil crisis of 1973 also affected the finances of many oilimporting countries in the region. Meanwhile the debt crisis of the early 1980 s decimated the entire region, pushing many governments into the hands of the International Monetary Fund (IMF).

It was therefore in the late 1970 s and early 1980 s that the neoliberal era began in the Caribbean. Jamaica, for example, signed its first two agreements with the IMF in 1977 and 1978 . This initiated a profound restructuring of the Jamaican economy in the 1980 s, which included currency devaluation, reduced government expenditure, and liberalization of prices and imports (Lundy 1999). While the IMF was initially able to force the region into a market-oriented trajectory (Kirton \& Ferguson 1992), increasingly the 
unfolding of neoliberalism would also rely on compliant regional leaders who saw no 'viable alternatives' to the new market consensus (Levitt 2009: 192). This is curious, as the switch to neoliberal orthodoxy was not able to reduce the levels of indebtedness in most countries in the region, which instead soared and would soon top world rankings of debt relative to GDP despite the close attention these countries had paid to IMF guidance (ECLAC 2018). Jamaica, for example, had repaid more than it had ever lent by 2013 , but high interest rates kept the country among the most heavily indebted in the world. By 2009, interest costs consumed as much as $50 \%$ of Jamaican tax revenues, while this figure has remained at around $30 \%$ since then (Clarke 2019). As a result, Jamaica's budgets for education, healthcare and poverty eradication shrank (Dearden 2013). In general terms, discontent with IMF conditionalities and their impacts has continued to grow throughout the Caribbean (Black 2001). Yet the region has also been increasingly tied by debts and policy commitments that have effectively meant that the economic plans of many countries in the region have been actively drafted and supervised by international finance institutions (Girvan 2012). Today, the economies of the region stand out for their high degrees of openness, dependence on a few export-oriented natural resources sectors and tourism, and reliance on foreign markets. This, on the whole, renders the region particularly vulnerable to exogenous economic shocks. It has also reduced the region's international negotiating capacity as a block, despite the efforts of the Caribbean Community, which remains marred by a minimalist intergovernmental approach and a broad neoliberal allegiance (Payne \& Sutton 2007; Grenade 2011).

All of this means that the Caribbean that China encounters in the twentyfirst century is one that in terms of external links remains structurally vulnerable to external shocks and is dependent on foreign markets. It is one where epistemic dependency is still apparent in the way in which regional economic policies are devised by Washington, DC-based institutions. Many countries in the region have attained middle-income status or above, often on account of enclave sectors such as tourism and natural-resource extraction. However, this status actually runs counter to their possibilities of accessing bilateral and multilateral development grants. Internally, the inability to develop economically has resulted in high levels of inequality, poverty, and vulnerability, with high unemployment rates also leading to a worrying rise of violence throughout the region (Pantin 1996; CDB 2016). The Caribbean is therefore a region that after decades of neoliberal orthodoxy seems ready to engage new partners willing to entertain unorthodox economic alternatives. 


\section{The China Connection: A New Stage?}

The relationship between China and the English-speaking Caribbean can be traced to 1806, when a vessel of the East India Company arrived in Trinidad with 192 Chinese immigrants brought to complement the then waning influx of African slave labour (Look Lai 1998: 22). The arrival of indentured Chinese workers would intensify following the abolition of chattel slavery in the British West Indies in the 1830 s. As the Asian community grew, many of its members went on to play important roles in the development of the region throughout the twentieth century. Notable examples in high politics include Solomon Hochoy, the first Governor-General of Trinidad and Tobago; Arthur Chung, the first President of Guyana; and Eugene Chen, a Trinidadian lawyer who would befriend Sun Yat-sen to later become the foreign minister of the Republic of China. Beyond politics, Chinese descendants also left an imprint in Caribbean culture. Jamaican-Chinese producers like Vincent Chin and Leslie Kong helped to popularize reggae music, while artists like Edwin Ayoung succeeded as prominent calypsonians in Trinidad and Tobago. However, the links covered in this chapter are more recent and relate to the internationalization of Chinese capital since the start of the new millennium.

Just like many other regions in the developing world, the Caribbean started experiencing the rise of China in an indirect way. Through the $1990 \mathrm{~s}$ and the first decade of the twenty-first century, global value chains started to re-centre around China, attracted first by an almost unlimited pool of inexpensive labour, but also gradually by the country's logistical capacity and increasingly qualified workforce. This dealt a death blow to those Caribbean economies that still aspired to develop a manufacturing base with the possible exception of the Dominican Republic. Competition from China became insurmountable, particularly following its ascension to the World Trade Organization in 2001 (Bernal 2000; Padilla Pérez \& Hernández 2010). In parallel, China's industrialization and its relentless urbanization process, the largest in world history, would increase the demand for natural resources and subsequently raise their prices, which facilitated a decade of economic growth in countries that export natural resources during the resource boom of 2003-2013. These two trends combined and pushed the Caribbean region to further retrench to its comparative advantages in a number of natural resources sectors and the tourism industry - two of the only niches in which it could remain globally competitive in a world economy that increasingly tilted towards China.

However, it was the arrival of Chinese capital in the Caribbean that first signalled an epochal change in the eyes of many observers. Chronologically, 
we can distinguish three periods of Chinese investment and financial activity in the Caribbean. The first period, running up until 2007, involved limited activity, most of which was in relation to the PRC's battle for diplomatic recognition with Taiwan. As part of its 'dollar diplomacy', the Chinese government granted concessional loans and gifts to persuade countries that still held diplomatic relations with Taiwan, like Grenada and Saint Lucia, to switch their allegiance. Saint Lucia switched back its ties to Taiwan in 2007, much to the chagrin of Beijing. A number of Chinese construction firms landed in the region to build stadiums for the 2007 Cricket World Cup. These projects could still be considered part of China's 'dollar diplomacy', but they also marked the start of a second period in the relations. This period coincided with a general increase in Chinese outward investment throughout the world at the height of the 'Go Out' strategy, when a large number of Chinese companies internationalized in search of markets, technology, and resources (Gonzalez-Vicente 2011). In the case of the Caribbean, a region with small markets that are heavily dependent on foreign technology, commodities were the main pull factor. Attracted by the availability of natural resources, a number of Chinese companies came to the region. They invested, for example, in Trinidad and Tobago's oil sector in 2009, in Jamaica's sugar industry in 2010, and in Guyana's bauxite mining in 2012.

These trends continued in the third period of the relationship. However, this third period stands out for the way in which the BRI has financed a large number of infrastructural projects since 2013. Some of these projects are linked to traditional sectors such as tourism (e.g. resorts and hotels in the Bahamas and Barbados). Others have targeted the expansion of transportation infrastructure (e.g. Antigua, Bahamas, Guyana, Jamaica), the development of government buildings (e.g. Antigua, Trinidad and Tobago), the erection of convention centres (e.g. Antigua, Guyana, Jamaica, Trinidad), or more recently plans to develop industrial parks (e.g. Antigua, Jamaica, and Trinidad). Typically, infrastructure works are financed by Chinese policy banks such as the Export-Import Bank of China and the China Development Bank. These have given loans totalling over US $\$ 6.6$ billion in the broad Caribbean region, with Trinidad and Tobago (US $\$ 2.7$ billion) and Jamaica (US\$2.1 billion) standing out as the largest loan recipients (Gallagher \& Myers 2020). ${ }^{3}$

The investment strategies behind these various projects involve both geopolitical, developmentalist, and market rationales. To unpack these strategies, it is useful to first consider the different actors involved and then to consider the types of investment. Larger actors, such as the Chinese Ministry of Foreign 
Affairs and Ministry of Commerce, as well as China's policy banks and a few major state-owned enterprises, decide their investment strategies based on both economic and political considerations. As discussed above, a great geopolitical driver of China's relations with the Caribbean is the One-China policy. Through diplomatic manoeuvring and economic incentives, Beijing aims to ensure that those Caribbean countries that do not recognize the PRC (Belize, Haiti, Saint Kitts and Nevis, Saint Lucia, and Saint Vincent and the Grenadines) switch their allegiance. Two developmentalist considerations - intertwining political and economic goals - are also relevant. First, Chinese policy banks have actively subsidized the internationalization of Chinese companies since the deployment of the 'Go Out' strategy in order to increase the competitiveness of Chinese firms. With the launch of the BRI, these banks have also extended loans to regional governments in order to create new markets for Chinese construction firms that are currently facing a crisis of overaccumulation within the Chinese market (Jones \& Zeng 2019). Second, a number of major Chinese state-owned firms in commodity sectors understand resource procurement as both a market imperative and a state goal in relation to the use value of strategic resources such as bauxite in the Chinese economy ( $\mathrm{Lu} 2020)$. Finally, other Chinese state-owned and private firms in sectors such as construction see their role as eminently market-driven, and their 'logics of accumulation' are in this sense quite similar to those of global private capital (Lee 2017).

A second way of unpacking the transformative potential of Chinese investments in the region is by analysing their distinct impacts and the 'mechanisms of accumulation' required to set them in motion (Gonzalez-Vicente 2020). From this perspective, we can distinguish three types of investment (Gonzalez-Vicente \& Montoute 2020). First, we encounter investments that have a cumulative impact on regional development trends. These involve projects in sectors such as tourism or consolidated industries that export natural resources and so require little transformative activity and merely add to existing trends. Secondly, we have a number of Chinese companies that have ventured into sunset industries across the Caribbean, such as bauxite refining and sugar in Jamaica. The reasons why companies like the Jiuquan Iron and Steel Company (JISCO) in Jamaica can invest in sectors deemed unproductive by other transnational companies include their access to cheap credit from Chinese policy banks and the logics of accumulation described above that allow them to see some natural resources not just from the perspective of exchange value but from that of use value. Other reasons are that they have a different time logic as they are not tied by the immediate pressures to generate shareholder value, as well as their capacity to cut labour costs with the use of Chinese workers who are paid lower wages and work longer hours. 
Third, the quest for markets for Chinese construction firms that drives the BRI has introduced an innovative 'mechanism of accumulation' in the region (Gonzalez-Vicente 2020). China's 'state-coordinated investment partnerships' combine the various business and political rationales described above (Gonzalez-Vicente 2019). These arrangements involve the diplomatic branches of the Chinese government that negotiate with their local counterparts, policy banks that extend credits to host countries, a Chinese state-owned construction company that gets paid to complete the project, and sometimes a second company that will manage the project or circulate the resources used to pay for it. Crucially, these arrangements allow host governments to pay for the projects with a variety of arrangements. They might pay for a project, for example, with the future production of a resource or with concessions of land. Former Jamaican Prime Minister Bruce Golding explained how this has allowed heavily indebted economies to undertake necessary infrastructural works without increasing their debt burden or needing to agree to onerous macroeconomic conditionalities (Golding 2018). In this way, the arrival of Chinese investors in the Caribbean has created room for regional leaders to triangulate between economic partners, expanding investment despite the high debt burdens of many regional economies.

However, Chinese investments have also been the subject of critique. Scholars, the media, opposition politicians and a number of civil society actors have raised questions about the low levels of transparency in Chinese negotiations and the mounting debts that Caribbean economies now face after taking numerous Chinese loans. They have also raised concerns about poor labour standards, incomplete or low-quality projects, environmental impacts, and the prospects for broad socio-economic development on the back of an infrastructure-focused blueprint. The issue of low transparency has been a matter of concern throughout the Caribbean, as the type of government-to-government agreements promoted by Chinese policy banks entails high degrees of secrecy, sidelines debates on the need for BRI projects in the first place, prevents civil society scrutiny, and puts the procurement process under the control of a foreign entity (Raymond 2014). Piling debts are also a thorny issue in a region that has been held back by debt repayments for decades. A crucial question here is whether new investments in infrastructure can act as multipliers and generate enough economic activity to make up for their costs and interest rates.

When it comes to labour standards, two issues stand out. On the one hand, some Chinese companies in the region have ignored previous labour agreements and customs that, although not protected by law, had come to be expected. This has been the case in places like Jamaica, which I 
shall discuss in more detail below. On the other hand, the large numbers of Chinese workers that have been brought in to complete projects have limited the number of jobs available for locals, while also helping Chinese contractors to bypass local customs and regulations on wages and working conditions.

Delays and problems in the construction of projects are not unique to Chinese contractors, but those incurred by Chinese companies stand out due to the sheer size and relevance of some of these infrastructural endeavours. For example, in 2016 the project to build the Baha Mar resort in the Bahamas, the largest in the Caribbean, needed to file for bankruptcy after years of delays and problems with 'shoddy construction work' (Cohen 2016). The project had received a US\$2.5 billion loan from the Export-Import Bank of China, and had China State Construction Engineering as its main contractor. With a final cost of over US $\$ 3.5$ billion, the project would eventually be acquired and resurrected by Hong Kong's Chow Tai Fook Enterprises, but the case still features prominently in many debates about the reliability of Chinese projects in the region.

Questions have also been raised about the environmental impacts of Chinese projects. Despite a number of controversies, there is no data to indicate that the environmental standards of Chinese companies are lower than those of other local or transnational firms in the region. However, because they focus on the development of infrastructure and on the exploitation of natural resources, the environmental footprint of BRI activities in the Caribbean is inevitably a matter of contention. In the broader perspective of regional development, it is also not yet clear how much socio-economic progress can derive from large infrastructural works. In other words, it is not clear how much the lives of average Caribbean citizens can improve on the basis of the BRI's infrastructural blueprint for development.

In order to examine these issues further, the following two sections analyse the deployment of the BRI in Jamaica and Trinidad and Tobago, the two largest economies in CARICOM. The two cases contain a variety of projects and as such they cannot be seen as an ideal type of any singular trend. There are overlapping trends in both countries that can also be observed in other regional economies. However, the case of Jamaica offers the opportunity to study in some detail the prospects of Chinese investments in productive sectors and logistics. Meanwhile, the Trinidad and Tobago case contains more examples of infrastructural projects associated with the hospitality industry, as well as the culture and sports sectors. In both cases, I focus on the trajectories of Chinese investments and the ways in which these are shaped by different types of local agency. The question of agency 
has been extensively debated and documented in the literature on China's overseas investments (Levy 2015). Scholarship has typically focused on identifying the actors that mould China's global footprint, be these Chinese business and state actors or host governments and civil societies. Going beyond this, I contend that in analysing the forays of Chinese investments in the Caribbean it is also necessary to appraise the agency of other actors. We need to examine, for example, the role of actors such as the IMF and others that through decades have played a role in delineating the policy alternatives available to Caribbean states and crafting the political economic environment in which Chinese companies now operate. As such, agency is seen here as the capacity to shape developmental trajectories vis-à-vis contextual constraints, and in negotiation and conflict with the ideas and interests of other relevant actors.

\section{Jamaica: Not an Easy Road}

Perhaps more than any other in the Caribbean, the relationship between China and Jamaica has been shaped, and continues to be shaped, by the neoliberal era that preceded it. For decades, Jamaica has been crippled by one of the highest debts per capita relative to GDP and sluggish economic growth. The IMF's structural adjustment plans did little to lift the island out of its situation of underdevelopment. Instead, the privileging of debt repayment over other social priorities has been identified as a main cause of the low economic growth, high unemployment rates, inequality, and vulnerability that Jamaica has suffered (Johnston 2013). Therefore, when Chinese companies came to the island at the beginning of the twenty-first century, Jamaica was a country desperate for new sources of funding to address a number of socio-economic maladies. However, a decade after deepening the relationship with China, Jamaica has not overcome its developmental impasse. While Chinese finance and investments have reshaped the country's international outlook, many of the problems developed in Jamaica's recent history remain, and new challenges have emerged in the Sino-Jamaican link. To understand these trends, I will first assess BRI projects in Jamaica by the yardstick of their own business success, asking whether they have achieved what they originally intended to. After that, I will review the limitations and promises that such projects carry from a critical development perspective. Then I will reflect more broadly on the geopolitical and developmental trajectory of Jamaica under Chinese influence. 
From the perspective of business success, the BRI in Jamaica offers a mixed track record. First, there have been a number of projects that have not managed to lift off. An early investment of US\$26o million by China's Pan-Caribbean Sugar Company encountered a series of social and cultural barriers that hindered its bid to revitalize the sugar sector. Productivity remains low and company managers have floated the idea of closing down in the face of competition from countries like Thailand (Jamaica Gleaner 2017). Plans by the China Harbour Engineering Company (CHEC) to build a transshipment terminal in Goat Island were aborted on account of civil society pressures and concerns over environmental impacts (Jamaica Observer 2016). This remains one of the few cases of successful societal organization against a Chinese project in the Caribbean. As such, it should not be seen as a failure in itself, but an exemplary case of how civil society can mobilize to shape developmental trajectories.

Second, there have been a number of projects that have been completed but remain underutilized. One of these is the North-South Highway, which is a centrepiece of China's infrastructural campaign in Jamaica. The 'Beijing Highway', as the project is sometimes known, was successfully completed by CHEC in 2016 with a US $\$ 457$ million loan by the China Development Bank. However, the highway is operating at limited capacity, as the toll prices charged by CHEC are unaffordable for a majority of locals (Foxcroft 2019). The utility and economic viability of other projects has also been questioned. For example, the Montego Bay Convention Centre, which was built with a US $\$ 45$ million concessional loan from the Export-Import Bank of China (Eximbank), is said to remain underutilized and has incurred significant losses after its construction (Radio Jamaica News 2012). The case of JISCO's investment in the Alumina Partners of Jamaica |(Alpart), which operates a bauxite refinery, is more ambiguous. JISCO was able to reopen the plant, generate employment, and significantly revitalize economic activity in the Saint Elizabeth area of the island. However, the refinery operations have been suspended for a period of at least two years since September 2019, when the company presented the government with plans to expand and modernize the plant. This has also put on hold plans to develop an industrial park in the surrounding area. JISCO's business success will therefore depend on whether the modernization of the plant allows it to cope with the issues of low productivity encountered by previous investors, particularly against the backdrop of low aluminium prices (Aluminium Insider 2019). All in all, from a business perspective, Chinese firms have had relative success in the delivery of infrastructure. However, they have encountered problems when trying to put this infrastructure into use and when attempting to revitalize natural resources industries. 
If we go beyond measurement of the projects according to their stated goals, assessing them instead on their broad developmental impacts, a different type of question needs to be asked. Regarding labour, Chinese companies have generated a significant number of jobs, particularly in the construction sector. While this has helped to address problems of unemployment and exclusion, the quality of Chinese jobs has helped to perpetuate trends of exploitation. This is clear in JISCO's operations in Saint Elizabeth. The Nain area of Saint Elizabeth had lain semi-abandoned for almost a decade until operations restarted in the plant under Chinese ownership. JISCO rehired 700 local workers to operate the plant. However, the plan to make the refinery productive included significant cuts in labour costs. This involved the casualization of local workers, who unlike in the past are now hired with flexible short-term contracts and salaries that are lower than those received in 2009. A significant contingent of Chinese workers joined the operation. Chinese workers live in compounds next to the refinery, receive lower salaries, and are possibly the main targets of exploitative labour practices.

A similar case is found on Chinese construction sites. Chinese infrastructural projects often require the creation of 'spaces of exception' that allow the transfer of Chinese labour practices into Jamaica (Gonzalez-Vicente 2019). For example, Chinese workers are often paid Chinese salaries into Chinese accounts, bypassing local labour regulations. Meanwhile, Chinese companies benefit from levies on equipment duties and other taxes. Jamaican workers have also complained about wages that are lower than those provided by other local contractors. However, not all labour problems can be traced back to a uniquely Chinese way of running business. It is indeed the case that Chinese companies do not follow the salary scales negotiated between the Incorporated Masterbuilders Association of Jamaica and trade unions in the sector. Yet, in choosing to ignore these agreements, Chinese contractors are adhering to IMF-promoted flexible labour laws, which impose no sector-specific minimum wages but a cross-sectoral minimum wage of about US $\$ 5^{\circ}$ per week. As indicated above, the impacts of the BRI on labour issues in Jamaica have very much been shaped by preceding decades of neoliberal orthodoxy.

More broadly, Chinese investments have also generated debates about environmental sustainability, local agency and participation, transparency, and the ultimate developmental potential of infrastructural works. JISCO's activities have been a key concern for environmentalists in Jamaica. Local residents in the Nain area have been affected by dust blown from the refinery's disposal area, although long-term observers such as Richard 
Bernal have noted that 'the residue from bauxite plants [has] been here since they were established 50 years ago by Canadian and American firms' (Foxcroft 2019). From an environmental perspective, Chinese firms in Jamaica have mostly had a cumulative impact and do not stand out as the main drivers of environmental damage. However, when it comes to issues of local agency, participation, and transparency, Chinese investors do stand out for their poor performance. Despite allowing the Jamaican government to overcome its dependence on Western institutions and investors, the government-to-government, closed-door deals produced by the BRI have cemented a top-down, elite-driven approach to development. The agency and leverage devolved to the Jamaican central government has been used in ways that undermine participatory development. As a consequence, the adequacy of BRI infrastructural projects in Jamaica has not been properly debated (Gonzalez-Vicente \& Montoute 2020). Central government elites have rushed to sign agreements with China, pressed by the urgency to create jobs and generate economic activity. Few of these projects seem to have significantly improved the lives of targeted beneficiaries. Chinese infrastructure has also not acted as a multiplier that has been able to generate economic activity beyond the construction sector itself.

All in all, the BRI has not offered Jamaica an easy road out of its decades-long developmental impasse. Chinese finance and investment have boosted economic activity on the island and generated much-needed jobs in the construction and natural resources sectors. Yet these jobs are often precarious, and despite that fact that Jamaica's debt to China has increased significantly, the country has not significantly addressed any of its structural and socio-economic challenges. From a geopolitical perspective, there is little evidence to suggest that Chinese companies act as Beijing's political envoys. Instead, what we observe is substantial Chinese state support for the expansion of Chinese capital, in the form of soft loans and diplomatic efforts. This confirms the view that the BRI is driven by a crisis of over-accumulation in China and implemented by both state agencies that pursue a developmentalist goal and businesses that respond to a commercial mandate (Gonzalez-Vicente 2019; Jones \& Zeng 2019).

However, despite the concerns expressed by US diplomats, Jamaica's growing relationship with China has not drawn it away from its traditional allies. For example, Prime Minister Andrew Holness recently joined other Caribbean leaders at Donald Trump's private club in Palm Beach to discuss a potential change of regime in Venezuela - a move that the Chinese government would be unlikely to endorse. More recently, in the midst of the coronavirus crisis, Jamaica once again applied for IMF loans. Finally, a 
somewhat paradoxical result of the growing relations between Jamaica and China has been a relative decline in China's soft power. On the one hand, political elites within the country have been very open to the immediate economic gains - and subsequent political capital - granted by an increased engagement with Chinese banks and companies. On the other, however, the very visible growth of Chinese activity in Jamaica has triggered an anti-China discourse that unfortunately has also at times translated into xenophobic attitudes by the general public and some media. If China's growing economic might in Jamaica does not result in improved life standards for a majority of the country's population, it is possible that increased engagement will lead to resistance rather than the embrace of a new hegemony.

\section{Trinidad and Tobago: Ready for the Road?}

Unlike Jamaica, Trinidad and Tobago is a resource rich, high-income economy that ranks high in the UN's human development index (UNDP 2019). However, the country's dependence on its oil and gas sectors has been traditionally associated with high levels of inequality, unemployment, problems diversifying the economic basis, and recurring vulnerability and poverty (Auty 2017). In the case of Jamaica it could be said that the BRI has a mixed track record on a project-by-project basis and has proved overall unable to lift the country from its developmental impasse. Meanwhile, in Trinidad and Tobago what we observe is a mismatch between what the BRI has offered to date and what the country would need in order to tackle its various developmental shortcomings. BRI funding has been directed at the construction of a number of buildings scattered throughout Trinidad. These have great visual impact but have not truly had a clear developmental function, whether from an economic or a broader social perspective. The recent plans to use Chinese capital to develop the Phoenix Park Industrial Estate in southern Trinidad seek to address some of the shortcomings of earlier Chinese investments. However, these plans have not yet come to fruition and there are precedents that suggest a cautious appraisal of the Phoenix Park's developmental prospects. In order to further understand the relationship between China and Trinidad and Tobago, I will first evaluate the success of Chinese projects in delivering their intended outcomes. Then I will go on to reflect on whether these projects tackle the needs of the twin-island state.

The assessment of Chinese business success in Trinidad might begin by looking at a series of natural resources-focused investments that have 
contributed to perpetuating the role of the country as an exporter of natural resources. One of these was a US $\$ 850$ million investment by the China Investment Corporation to acquire a 10\% share in Atlantic LNG in 2011. Another was an agreement in 2018 to export asphalt from Trinidad's Pitch Lake to pave the runways of the Beijing Daxing International Airport (Ellis 2019). These are investments in sectors in which Trinidad has been traditionally competitive. As such they have run relatively smoothly. A second group of investments are those in the construction sector which successfully delivered what they had promised. Here we can include the construction of the National Cycling Velodrome, the National Aquatic Centre, the National Tennis Centre, the Prime Minister's Official Residence (built with an interestfree loan) (Stallings 2017: 81), the Port of Spain Waterfront, the Ministry of Education Tower, and the restoration of the Knowsley Building. All of these projects were completed by the Shanghai Construction Group (SCG), which is without a doubt the most active Chinese company in Trinidad.

SCG has, however, encountered challenges in some of its other projects. For example, the Couva Children's Hospital remains emblematic of the BRI's emphasis on physical infrastructure rather than content. The hospital needed to be repurposed as a 'multi-training facility' after encountering staffing problems and other shortcomings related to the project's design (Khan 2020). Some other announced projects have failed to come to fruition. These include, for example, a contract awarded to the China Gezhouba Group (CGG) to build 5000 'low-cost' apartments. Trinidad's cabinet revoked the contract after media and activists took issue with the costs of the project, with estimates putting the total cost at US\$80o million $-30 \%$ above the rates usually charged by local contractors (Raymond 2019). Commentators also lamented the lack of transparency in the negotiations and the fact the agreement privileged a foreign investor over local contractors, with tax exemptions, an agreement to grant 600 working permits for Chinese workers, and full financial guarantees on the payment to CGG (Wilson 2019). Another interesting case is the scrapping of plans to develop a five-star Sandals resort in Tobago. The project would have involved China's HNA Group, but was dropped by Sandals under allegations that the conflicts between Trinidad and Tobago's two main political parties contributed to a discouraging business environment (Bridglal 2019).

These last two cases shed light onto a pattern that has emerged around Chinese investments in Trinidad. The mechanisms of accumulation advanced by the BRI have allowed the two main parties to engage in a battle to surpass each other's infrastructural legacy. The NAPA-SAPA saga illustrates this trend quite well. The National Academy for the Performing 
Figure 7.1 Interior of Trinidad's National Academy for the Performing Arts during an event in January 2020, with the Queen's Park Savannah and the hills of Port of Spain in the background

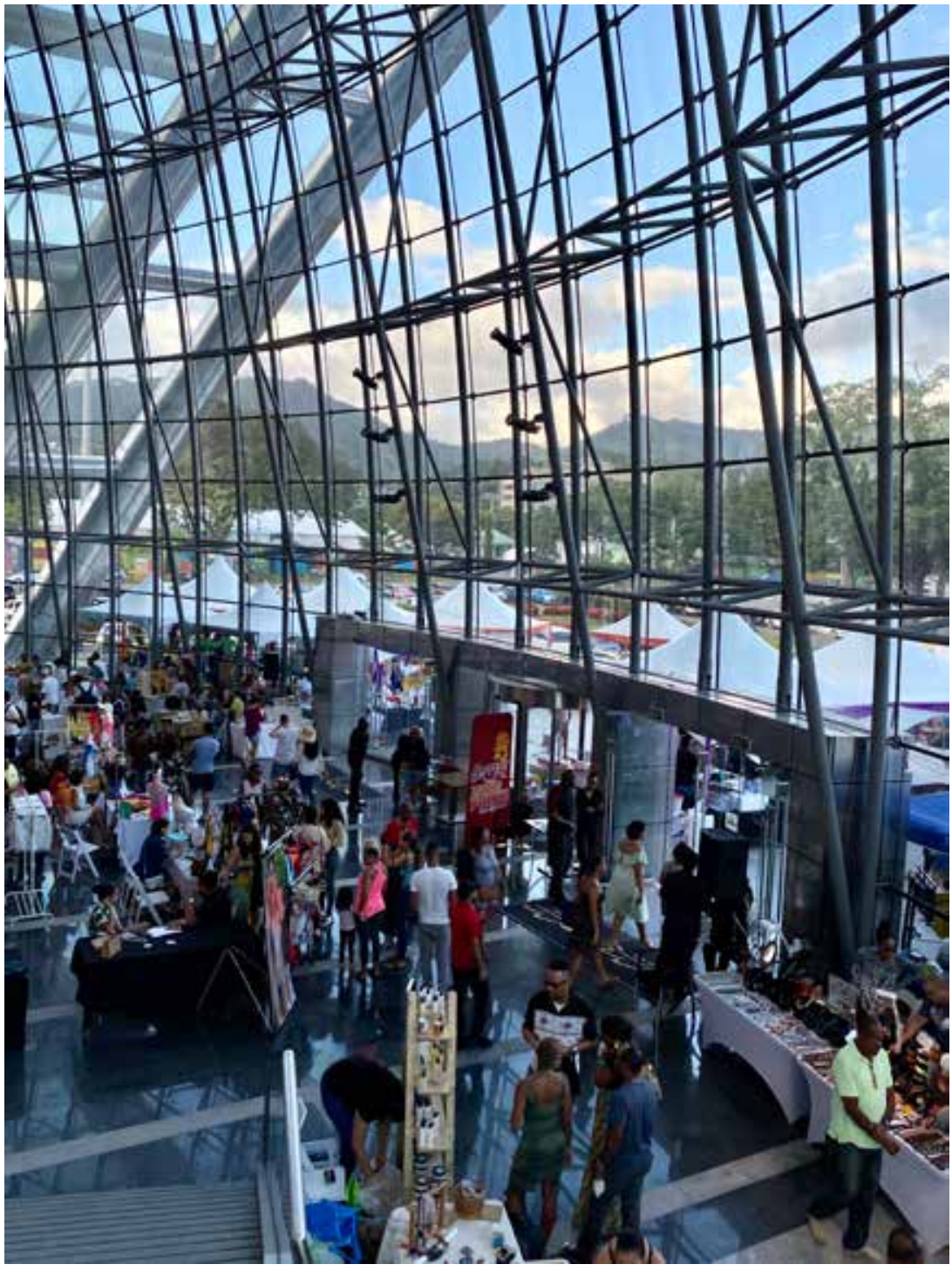

Source: Author

Arts (NAPA), an imposing structure adjacent to Port of Spain's Queen's Park Savannah, was commissioned by the Patrick Manning government (People's National Movement, PNM) and completed by the SCG in 2009. The 
United National Congress (UNC) had been a vocal critic of the project, which incurred costs overruns and involved a potential case of embezzlement by the former chairman of the Urban Development Corporation of Trinidad and Tobago (Oosterveld et al. 2018). Soon after reaching power in 2010, the Kamla Persad-Bissessar administration (UNC) closed down the NAPA, claiming problems with the original design. In the meantime, the UNC inaugurated the Southern Academy for the Performing Arts (SAPA), an equally imposing structure in the city of San Fernando. San Fernando lies close to the central plains of Trinidad, where UNC votes have been concentrated since the 1960 s (Premdas 2004). SAPA was also built by the SCG, and as had been the case with NAPA, it was a top-down project developed without properly consulting local artists (Newsday 2010). NAPA would reopen in 2015, once the PNM returned to power, although only after the building was repaired at a significant cost, with parts of the compound, such as a 53-room hotel, still underutilized.

Projects such as NAPA and SAPA indicate that Trinidad and Tobago has not made the best possible use of BRI financing, privileging legacy infrastructure over potentially meaningful projects. For example, Trinidad experiences serious traffic problems, with a deficient public transportation system and daily two-hour traffic jams to get in and out of Port of Spain. Yet the possibility of harnessing Chinese loans towards improvements in public transportation has not been discussed, despite Chinese companies' expertise in this area. The BRI has also done little to tackle perennial structural problems, such as lack of economic diversification and high unemployment rates. Following the shutdown of Petrotrin, one of the main employers in San Fernando, the government came to an agreement with the Beijing Construction and Engineering Group (BCEG) to develop the Phoenix Park Industrial Estate and a dry dock in La Brea for a cost of around US\$60o million (Ellis 2019). If these plans materialize, the park will host ten Chinese firms in sectors such as air conditioning, food processing, building materials, and communication equipment, and could generate up to 4,500 jobs (News.gov.tt 2018). However, despite a number of ceremonies to announce the project, construction work has been virtually halted. In interviews conducted for this chapter, local experts speculated that the government's urgency to announce the plan had more to do with the August 2020 general election than with actual progress in planning the project, particularly given the urge to appease the population in southern Trinidad following the shutdown of Petrotrin.

All in all, the BRI has not truly addressed Trinidad and Tobago's developmental bottlenecks, while the country's debt to China has risen after 
receiving loans for US\$2.7 billion. The responsibility for many of the missed opportunities lies with the local government and its inability to direct Chinese finance towards meaningful projects. This highlights the relevance of local agency. However, the BRI, as an infrastructure-focused campaign, also has limited potential to address Trinidad's needs for diversification and for the creation of long-term sources of well-paid qualified jobs. The plans to develop the Phoenix Park could signal that Trinidad and Tobago and China are moving along the learning curve in their relationship, if the project delivers the 4,500 jobs promised. However, the precedents are not encouraging. It also remains unclear how Trinidad and Tobago will boost its competitiveness in sectors not related to or subsidized by the country's energy sector.

\section{Conclusion}

The Belt and Road Initiative has generated a new wave of economic activity in the Caribbean, a region that had experienced an arduous cycle of debt and sluggish growth in the decades building up to its engagement with China. Some Chinese investments have gone into traditional sectors, and as such have had a cumulative impact. Others have helped to at least temporarily revitalize some sunset industries. However, the majority of Chinese investments have gone into the region's infrastructural sectors, and have been facilitated by loans provided by China's policy banks at a market rate. Overall, the projects that have seen the most success are those that have built into the region's already existing strengths in the tourism industry and some natural resources sectors. Other infrastructural projects have become white elephants, in part due to a tendency by some regional governments to endorse projects that generate immediate economic activity and short-term jobs without seriously considering their long-term prospects vis-à-vis rising debt.

Importantly, Chinese finance has allowed regional economies to seek sources of financing that do not impose the type of neoliberal conditionalities promoted by institutions such as the IMF or the World Bank. While this could in principle suggest a potentially unorthodox development partnership, this chapter's findings suggest that the BRI instead encourages an elitist and business-centric developmental rationale that dovetails with other predominant socio-economic trends in the region. The BRI eschews participatory approaches and relies on opaque government-to-government agreements, which has prevented Caribbean civil societies from playing 
an active role in deciding what are the regional priorities or in designing projects that take into consideration the needs of communities. Thereby, despite its distinct format, the BRI in the Caribbean remains a campaign to open markets for Chinese investors, and its goals are hence remarkably similar to those of other transnational investors and Western-based institutions. As such, the BRI has not been a panacea for the Caribbean and has instead helped to perpetuate the structural constraints that have historically characterized the region's developmental trajectory.

\section{References}

Aluminium Insider (2019, August 18). 'Falling Aluminium Prices May Make Life Difficult for Jamaican Bauxite Operations: PM Paulwell'. Retrieved 30 April 2020 from https://aluminiuminsider.com/falling-aluminium-prices-may-make-lifedifficult-for-jamaican-bauxite-operations-pm-paulwell/.

Auty, Richard M. (2017). 'Natural Resources and Small Island Economies: Mauritius and Trinidad and Tobago'.Journal of Development Studies, 53(2), 264-277.

Beckford, George L. (1972). Persistent Poverty: Underdevelopment in Plantation Economies of the Third World. New York: Oxford University.

Bernal, Richard (2000). 'Globalisation and Small Developing Countries: The Imperatives of Repositioning'. In Dennis Benn \& Kenneth Hall (eds.), Globalisation: A Calculus of Inequality Perspectives from the South (pp. 88-127). Kingston: Ian Randall Publishers.

Bissessar, Anne M. \& La Guerre, John G. (2013). Trinidad and Tobago and Guyana: Race and Politics in Two Plural Societies. Lanham: Lexington Books.

Black, Stephanie, dir. (2001). Life and Debt. New Yorker Films.

Bridglal, Carla (2019, January 17). 'PM: We Chased Sandals Away'. Newsday. Retrieved 30 April 2020 from https://newsday.co.tt/2019/01/17/pm-we-chased-sandals-away/. CDB (2016). The Changing Nature of Poverty and Inequality in the Caribbean: New Issues, New Solutions. Barbados: Caribbean Development Bank.

Clarke, Nigel (2019, February 19). 'Lessons from Jamaica for Small Countries with Big Debts'. Financial Times. Retrieved 9 May 2020 from https://www.ft.com/ content/0487ofa8-2e12-11e9-8od2-7b637agerba1.

Cohen, Muhammad (2016, December 14). 'How China Rescued - Then Ruined - The Caribbean's Largest Resort Project'. Forbes. Retrieved 9 May 2020 from https:// www.forbes.com/sites/muhammadcohen/2016/12/14/how-china-rescued-thenruined-the-caribbeans-largest-resort-project/\#4a66fded3edb.

Dearden, Nick (2013, April 16). 'Jamaica's Decades of Debt Are Damaging Its Future'. The Guardian. Retrieved 4 May 2020 from https://www.theguardian. 
com/global-development/poverty-matters/2013/apr/16/jamaica-decades-debtdamaging-future.

Donovan, Elise (2018, March 29). 'Going for Global Growth: Why China Chooses the BVI'. BVI House Asia. Retrieved 5 May 2020 from http://www.bvihouseasia. com.hk/news/going-for-global-growth-why-china-chooses-the-bvi.

ECLAC (2000, January 31). 'The Caribbean in the Decade of the gos: Summary'. LC/CAR/G.6oo. Port of Spain: UN Economic Commission for Latin America and the Caribbean.

ECLAC (2018, June). The Caribbean Outlook. Santiago: UN Economic Commission for Latin America and the Caribbean.

Ellis, Evan (2019, March 26). 'China's Engagement with Trinidad and Tobago'. Global Americans. Retrieved 5 May 2020 from https://theglobalamericans.org/2019/03/ chinas-engagement-with-trinidad-and-tobago/.

Foxcroft, Tiffany (2019, November 28). 'Jamaica Has China to Thank for Much-Needed Infrastructure - But Some Locals Say It Has Come at a Price'. CBC News. Retrieved 5 May 2020 from https://www.cbc.ca/news/world/ china-power-belt-and-road-caribbean-jamaica-1.5374967.

Gallagher, Kevin P. \& Myers, Margaret (2020). 'China-Latin America Finance Database'. Washington, DC: Inter-American Dialogue.

Girvan, Norman (2009). 'Plantation Economy in an Age of Globalization'. In Lloyd Best \& Kari Levitt Polanyi (eds.), Essays on the Theory ofPlantation Economy: A Historical and Institutional Approach to Caribbean Economic Development (pp. xvii-xxii). Jamaica, Barbados and Trinidad and Tobago: The University of the West Indies Press.

Girvan, Norman (2012, August 22). '50 Years of In-dependence in Jamaica: Reflections'. Lecture presented at the SALISES 50-50 Conference Critical Reflections in a Time of Uncertainty, Kingston, Jamaica.

Golding, Bruce (2018, April 1). 'North-South Highway Paternity'.Jamaica Observer. Retrieved 28 April 2020 from http://www.jamaicaobserver.com/parliament/ north-south-highway-paternity_129364\&template=MobileArticle.

Gonzalez-Vicente, Ruben (2011). 'The Internationalization of the Chinese State'. Political Geography, 30(7), 402-411.

Gonzalez-Vicente, Ruben (2019). 'Make Development Great Again? Accumulation Regimes, Spaces of Sovereign Exception and the Elite Development Paradigm of China's Belt and Road Initiative'. Business and Politics, 21(4), 487-513.

Gonzalez-Vicente, Ruben (2020). 'Varieties of Capital and Predistribution: The Foundations of Chinese Infrastructural Investment in the Caribbean'. Made in China Journal, 5(1), 164-168.

Gonzalez-Vicente, Ruben \& Montoute, Annita (2020). 'A Caribbean Perspective on China-Caribbean Relations: Global IR, Dependency and the Postcolonial Condition'. Third World Quarterly (Online First). 
Grenade, Wendy (2011, September). 'Regionalism and Sub-regionalism in the Caribbean: Challenges and Prospects - Any Insights from Europe?' Jean Monnet/ Robert Schuman Paper Series, vol. 11, no. 4.

Gumbs, Frank (1981). 'Agriculture in the Wider Caribbean'. Ambio, 10(6), 335-339. Jamaica Gleaner (2017, November 21). 'Chinese Hit Hard by Realities in Local Sugar Industry'. Retrieved 6 May 2020 from http://jamaica-gleaner.com/article/leadstories/20171121/chinese-hit-hard-realities-local-sugar-industry\#.XVxzYcbz2Hw. email.

Jamaica Observer (2016, September 28). 'Environmentalists Welcome Scrapping of Goat Island Project'. Jamaica Observer. Retrieved 6 May 2020 from http://www.jamaicaobserver.com/news/Environmentalists-welcome-scrapping-of--Goat-Island-project.

Johnston, Jake (2013, June). 'The Multilateral Debt Trap in Jamaica'. Issue Brief. Center for Economic and Policy Research (CEPR). Retrieved 6 May 2020 from http://cepr.net/documents/publications/jamaica-debt-2013-06.pdf.

Jones, Lee \& Zeng, Jinghan (2019). 'Understanding China's “Belt and Road Initiative": Beyond "Grand Strategy" to a State Transformation Analysis'. Third World Quarterly, 40(8), 1415-1439.

Khan, Rishard (2020, February 29). 'Lee Pleased with COVID-19 Plans for Couva Hospital'. Trinidad and Tobago Guardian. Retrieved 6 May 2020 from http:// www.guardian.co.tt/news/lee-pleased-with-covid19-plans-for-couva-hospital6.2.1067874.1e42e264fi.

Kirton, Claremont \& Ferguson, James (1992). Jamaica Debt and Poverty. Oxford: Oxfam.

Lee, Ching Kwan (2017). The Specter of Global China: Politics, Labor and Foreign Investment in Africa. Chicago: University of Chicago Press.

Levitt, Kari P. (2009). 'In Search of Model IV'. In Lloyd Best \& Kari P. Levitt (eds.), Essays on the Theory of Plantation Economy: A Historical and Institutional Approach to Caribbean Economic Development (pp. 189-196). Jamaica, Barbados and Trinidad and Tobago: The University of the West Indies Press.

Levy, Katja (2015). 'Introduction: China and Latin America - Bringing the Actor Back In'. Journal of Chinese Political Science, 20 (3), 221-225.

Look Lai, Walton (1998). The Chinese in the West Indies 1806-1995. Kingston: The Press University of the West Indies.

Lu, Juliet (2020). 'Strategic Resources and Chinese State Capital'. Made in China Journal, 5(1), 154-159.

Lundy, Patricia (1999). Debt and Adjustment: Social and Environmental Consequences in Jamaica. Aldershot: Ashgate.

Minto, Jevon (2019). 'Examining the Lending Practices of Chinese Policy Banks in the Caribbean (2000-2018)'. In Enrique Dussel Peters (ed.), China's Financing 
in Latin America and the Caribbean (pp. 153-176). México, D.F.: Universidad Nacional Autónoma de México.

Newsday (2010, March 21). 'Stop the South Academy'. Newsday. Retrieved 6 May 2020 from https://archives.newsday.co.tt/2010/03/26/stop-the-south-academy/.

News.gov.tt (2018). 'MOU between eTeck and BCEG for Development of Phoenix Park Industrial Estate'. News.gov.tt [Government of the Republic of Trinidad and Tobago]. Retrieved 6 May 2020 from http://news.gov.tt/content/moubetween-eteck-and-bceg-development-phoenix-park-industrial-estate\#. XqhdhxMzZhA.

Oosterveld, Willem, Wilms, Eric \& Kertysova, Katarina (2018). The Belt and Road Initiative Looks East: Political Implications of China's Economic Forays in the Caribbean and the South Pacific. The Hague: The Hague Centre for Strategic Studies.

Padilla-Pérez, Ramón \& Hernández, René A. (2010). 'Upgrading and Competitiveness within the Export Manufacturing Industry in Central America, Mexico, and the Dominican Republic'. Latin American Business Review, 11(1), 19-44.

Pantin, Dennis A. (1996). The Challenge of Youth Unemployment in the Caribbean. The Role of Youth Employment Training Programmes. Port of Spain:International Labour Organization Caribbean Office.

Payne, Anthony \& Sutton, Paul (2007). 'Repositioning the Caribbean within Globalisation'. Caribbean Paper no. 1. Centre for International Governance Innovation. Retrieved 26 October 2020 from https://www.cigionline.org/sites/ default/files/1._repositioning_the_caribbean_within_globalisation.pdf.

Premdas, Ralph R. (2004). 'Elections, Identity and Ethnic Conflict in the Caribbean: The Trinidad Case'. Pouvoirs dans la Caraïbe, 14, 17-61.

Radio Jamaica News (2012, October 10). 'UDC under the Gun, Suffers Loss of \$500 Million'. Radio Jamaica News. Retrieved 6 May 2020 from http://rjrnewsonline. com/local/udc-under-the-gun-suffers-loss-of-500-million.

Raymond, Afra (2014, April 30). 'G2G Policy'. Afraraymond.net. Retrieved 9 May 2020 from https://afraraymond.net/2014/04/30/g2g-policy/.

Raymond, Afra (2019, September 4). 'Property Matters - In-Dependence?' Afraraymond.net. Retrieved 6 May 2020 from https://afraraymond.net/2019/o9/04/ property-matters-in-dependence/.

Robertson, Justin (2019). 'Global Financial Networks Confront Headwinds: China's Shifting Offshore Relationship with the British Virgin Islands'. Pacific Review, DOI: 10.1080/09512748.2019.1671893.

Stallings, Barbara (2017). 'Chinese Foreign Aid to Latin America: Trying to Win Friends and Influence People'. In Margaret Myers \& Carol Wise (eds.), The Political Economy of China-Latin America Relations in the New Millennium: Brave New World (pp. 69-91). New York: Routledge. 
Stone, Carl (1986). 'Prospects for Socialist Transformation: Reflections on Jamaica, Guyana and Grenada'. In George Beckford (ed.), A Caribbean Reader on Development (pp. 20-48). Kingston: Friedrich Ebert Stiftung.

UNDP (2019). Human Development Report. United Nations Development Programme. Retrieved 6 May 2020 from http://hdr.undp.org/en/content/ 2019-human-development-index-ranking.

Williams, Eric (1984). From Colombus to Castro: The History of the Caribbean. New York: Vintage Books.

Wilson, Anthony (2019, September 6). 'HDC Project Halted'. Trinidad Express. Retrieved 6 May 2020 from http://trinidadexpress.tto.newsmemory.com/? publink=obc61b661.

\section{About the Author}

Ruben GonZalez-ViCEnte is a Lecturer at Leiden University. His research interests include 'South-South' development cooperation, China's international relations (with a specific interest on China's engagement in Latin America and the Caribbean), the role of natural resources in processes of development, and the transformation of politics and international relations under late capitalism. His work has been published in journals such as Review of International Political Economy, Political Geography, Globalizations, the China Quarterly, and Latin American Politics and Society. He received his PhD from Cambridge in 2012 and worked as an Assistant Professor in the City University of Hong Kong between 2012 and 2016 before moving to Leiden. 


\section{Part III}

Local Actors 



\title{
8 The Geopolitical Relevance of the BRI
}

\author{
The Jakarta-Bandung High-Speed Railway in Indonesia \\ Frans-Paulvan der Putten and Mirela Petkova
}

\begin{abstract}
Chapter 8 explores the geopolitical significance of the BRI in the case of Indonesia, Southeast Asia's largest country. It argues this region constitutes the geographical centre of today's global great-power rivalry, in which the US and China are the key players. It was in the Indonesian capital, in 2013, that China first announced its ambitions for the Maritime Silk Road. This chapter asks which economic and diplomatic activities constitute the BRI in the case of Indonesia. It then asks what impact these activities have on China and Indonesia's political relations as well as on Indonesia's position with regard to China-US tensions. The chapter particularly focuses on Indonesia's efforts to maintain strategic autonomy and on manifestations of great-power influence on the country's foreign policy-making.
\end{abstract}

Keywords: Belt and Road Initiative, China, Jakarta-Bandung High-Speed Railway, Indonesia, geopolitics, strategic autonomy

\section{Background $^{1}$}

The Chinese government envisions that the Belt and Road Initiative (BRI) will make a significant contribution to global development (NDRC 2015). The geographic scope of the BRI is correspondingly very broad and comprises most of the world's regions. A particular aim of the Chinese government is to employ the BRI as a framework for international cooperation in the field of

1 The authors are grateful to Nanto Sriyanto, Lidya Christin Sinaga, Hayati Nufus, Ardhitya Eduard Yeremia Lalisang, Evan A. Laksmana, Anita Prakash, Siswo Pramono, Shafiah F. Muhibat, Firman Noor, Cheng-Chwee Kuik, Simon Tan, Lily Sprangers, Florian Schneider, Richard Ghiasy, Nicholas Olczak, and Aljosja van Dorssen for their valuable support.

Schneider, Florian (ed.), Global Perspectives on China's Belt and Road Initiative: Asserting Agency through Regional Connectivity. Amsterdam, Amsterdam University Press 2021 DOI: $10.5117 / 9789463727853 \_$CHo8 
infrastructure improvement as a way to support the developmental policies of other countries. Given the high costs typical of many infrastructure projects and the fact that Chinese financial institutions are major funders of BRI-related activities, BRI infrastructure projects can potentially create long-term financial relations between China and developing countries. This, in turn, may have a geopolitical impact.

A major feature of the contemporary international order is the geopolitical rivalry between China and the United States. They are two very influential actors in international economic, diplomatic, and military affairs. For the purpose of this study the concept of geopolitics is defined as the balance of power between two or more states as measured by their influence relative to third actors or spatial domains. A key feature of the struggle between China and the US is that it also affects the two countries' relationships with third countries and their involvement in other territorial, maritime, cyber, or space domains. These relationships which China and the US have with third countries and other domains can also, in turn, affect their relations with each other. Given the relevance of the BRI for China's bilateral relations with a large number of developing countries, the question may be asked whether, and how, the BRI affects the dynamics of Sino-US geopolitics.

This chapter addresses this question through analysis of one case study. This case study concerns the role that Indonesia's largest BRI project, the construction of a high-speed railway between Jakarta and Bandung, plays in China-US-Indonesian geopolitical dynamics. The Jakarta-Bandung HighSpeed Railway (HSR) project is the main BRI-related project in Indonesia, both in financial terms (involving a US $\$ 4.5$ billion loan from the China Development Bank) and in terms of visibility (other relevant projects are either highways or power plants). Indonesia is just one of many countries where Chinese actors engage in large-scale infrastructure projects in ways that create new financial ties with China. However, from a geopolitical point of view Indonesia is more relevant than many other countries since it is by far the largest country in Southeast Asia, which is a region where Sino-US geopolitical rivalry is highly visible (especially in the South China Sea).

The region became a main stage for Sino-US geopolitical competition on 23July 2010. During a visit to Vietnam, the then US Secretary of State Hillary Clinton announced that the United States would henceforth play an active role in security matters in the South China Sea. She made this statement both behind closed doors, at a meeting of ministers of foreign affairs where China and all Southeast Asian countries were also represented, and publicly, during a press conference after the meeting (Asia Society 2012). In subsequent years, the US and China have stepped up both their military presence in the 
South China Sea itself and also their activities towards several Southeast Asian countries. A notable feature of the Chinese government's approach is its attempts to signal to Southeast Asian counterparts that they should not bring in the US as a party in security issues that play a role in relations between China and themselves, such as the maritime and territorial disputes in the South China Sea. Under the Obama and Trump administrations, the US government has been making strong efforts to convince Southeast Asian counterparts that they should do the opposite and help the US to play such a balancing role (Landler 2016).

The Indonesian government's response to these conflicting geopolitical pressures is relevant for the region as a whole. This is because Indonesia is the most influential actor within the Association of Southeast Asian Nations (ASEAN), of which nearly all regional states are members. While ASEAN is not a security alliance, the organization is an important mechanism for regional diplomatic cohesion in relation to external actors (Egberink \& Van der Putten 2010).

Indonesia is not a military ally of the US (unlike Thailand and the Philippines; meanwhile, China does not have any military allies in the region). Indonesia is also not as diplomatically close to China as some other Southeast Asian countries (notably Cambodia and Laos). According to Damian Wnukowski, Indonesia belongs to a category of ASEAN member states that support the BRI but do not do so unconditionally (PISM 2019). Other countries in this group are Malaysia, Myanmar, Singapore and Thailand. Together they constitute a middle position, between strong supporters of the BRI (namely Cambodia and Laos, and also Brunei) and those sceptical towards the BRI (namely Vietnam and the Philippines).

In order to assess the geopolitical significance of the BRI in the case of Indonesia and the Jakarta-Bandung HSR, this chapter focuses on two questions. The first question is: Does the Jakarta-Bandung HSR enhance China's leverage over Indonesian foreign policy-making? To answer this question, the analysis will explore whether the project makes the Indonesian government more dependent on Chinese actors (such as financial institutions) in ways that could enable the Chinese government to influence Indonesia's foreign policy. A key aspect of this is the conditions under which long-term financial relations between China and Indonesia have been evolving in relation to the railway-building project. Also key is the role played by governmental and private actors on both the Chinese and Indonesian sides.

The second question is: In foreign policy, has Indonesia's positioning in relation to the geopolitical rivalry between the US and China changed in recent years in ways that suggest a role either for the Jakarta-Bandung HSR 
or for the BRI in general? In addressing this second question, it is necessary to look at the attitude of the Indonesian Ministry of Foreign Affairs towards reliance on the US as a counterbalance to Chinese regional influence, as well as to look for potential signs that this attitude results from concerns over an increase of Chinese influence through the BRI.

The first and second parts of the chapter, respectively, discuss these two questions. The chapter's main argument is that, in the case of the Jakarta-Bandung HSR, the BRI has not had a significant geopolitical impact. However, as the concluding section will argue, the factors relevant to the lack of a geopolitical impact are particular to Indonesia and may not apply to other countries.

This study is based mainly on desk research through the use of publicly available policy documents and secondary sources. These sources were accessed in order to collect insights into BRI-related activities in Indonesia, their financial dimensions, the roles played by relevant Indonesian and Chinese actors, and policy-making within the Indonesian government in relation to US-China geopolitical rivalry. The desk research was complemented by interviews conducted during a visit to Jakarta in January $2020{ }^{2}$

\section{The BRI as a Potential Source for Political Chinese leverage}

There is no list of BRI activities in Indonesia that are formally acknowledged as such by both the Indonesian and the Chinese governments. In fact, the Indonesian government has been reluctant to classify even the largest projects as part of the BRI (Cheang 2019). For the purpose of this analysis we assume that the BRI comprises all activities that are aimed at operating

2 The interviews were conducted with six experts on Indonesian foreign policy and/or on Indonesian-Chinese relations (three at the Indonesian Institute of Sciences (LIPI), two at the Center for Strategic and International Studies (CSIS), and one at Universitas Indonesia), one expert on ASEAN and regional international relations (at the Economic Research Institute for ASEAN and East Asia (ERIA)), and one official at the policy-planning division of the Indonesian Ministry of Foreign Affairs. These experts were selected on the basis of their extensive knowledge of Indonesia's foreign policy with regard to China and/or of Indonesia's position towards US-China geopolitical rivalry. The interviewees were asked to provide their views on the relevance of the BRI for Indonesia, and the perceptions and policy responses by the Indonesian government. The interviews were conducted in English and were not recorded. Instead, notes were taken that were later incorporated in the research. The aim of these interviews was to acquire insights into local factors so as to help the authors to better understand and assess data derived from the desk research that formed the main basis for this study. No ethical considerations feature in the way the interviews are used in the present study. 
or improving transport, energy, or communication infrastructure and in which Chinese actors are involved. ${ }^{3}$ As can be seen in Table 8.1, the largest Sino-Indonesian infrastructure projects initiated between 2013 (when the BRI was first announced) and early 2020 include one transport project and two energy projects. ${ }^{4}$

Table 8.1 Infrastructure projects in Indonesia with Chinese financial investment of at least US\$1 billion initiated from 2013 to early 2020

\begin{tabular}{lll}
\hline Project & Sector & Value of Chinese Investment \\
\hline Java 7 Coal Plant (Java) & Energy & US\$1.8 billion \\
Batang Toru Hydroelectric Dam (Sumatra) & Energy & US\$1.7 billion \\
Jakarta-Bandung High-Speed Railway (Java) & Transport & US\$4.5 billion \\
\hline
\end{tabular}

Source: Author's compilation

These three projects, as well as some smaller projects in Indonesian energy and transport infrastructure, ${ }^{5}$ involve Chinese actors at three distinct levels. First, in most cases construction works are partly or entirely carried out by Chinese contractors. Second, ownership of the infrastructure assets itself (a coal plant, dam, road or railway) is usually in the hands of a consortium that involves both Chinese and Indonesian companies. Third, financing is provided either partly or entirely by Chinese banks, often the China Development Bank (CDB) or the Export-Import Bank of China (Eximbank).

Among the three projects in table 8.1, the Jakarta-Bandung HSR project stands out. Not only is the size larger, but the type of investment is different.

3 While activities aimed at supporting processes of urbanization or industrialization, as well as instances of medical, educational and cultural cooperation, are also often labelled as part of the BRI, these remain outside the scope of this study.

4 Chinese actors are also active in the Indonesian communication infrastructure. Two Chinese companies, ZTE and Huawei, have sold equipment to Indonesia's telecommunication providers. However, there is no indication that this has led to new long-term financial ties between China and Indonesia.

5 Four smaller infrastructure projects with Chinese involvement initiated since 2013 are the construction of three toll roads - the Manado-Bitung Toll Road (Sulawesi), the Cisumdawu Toll Road (Java), and the Balikpapan-Samarinda Toll Road (Kalimantan) - and the construction of one coal-fired power plant (Tenaga Listrik Bengkulu Coal Plant (Sumatra)). The size of Chinese funding for the toll roads ranges between US\$65 and US\$225 million. In all three instances, financing has been provided by Eximbank, but solely for the Chinese section. None of the projects has yet been completed, and projected dates point to either 2020 or 2021. The value of the Bengkulu power plant, which is majority-owned by a Chinese company, is US\$36o million (China.org.cn 2019; Eximbank 2018; Indonesia Investments 2017). 
The Batang Toru Dam and the Java 7 power plant are owned by consortia in which a Chinese entity has a majority stake. In the case of the Batang Toru Dam this is Zhefu Holding Company (also known as Zhejiang Fuchunjiang Hydropower Equipment Company). For the Java 7 power plant, the controlling shareholder is Shenhua Group. Because of this ownership structure, both the Batang Toru Dam and the Java 7 power plant qualify as subsidiaries of Chinese enterprises and are instances of direct Chinese investment. The loans provided by Chinese financial institutions are therefore loans to Chinese companies. The loan for the Batang Toru Dam is provided by Sinosecure and Bank of China, while that for the Java 7 power plant is provided by the China Development Bank - all of these financial institutions are state-owned (SCMP 2018; Benar News 2020; Sumatran Orangutan Society 2018). These loans do not constitute a transfer of Chinese money to Indonesian enterprises or to the Indonesian state.

This is different in the case of the Jakarta-Bandung HSR. The entity that owns and will operate the railway, PT Kereta Cepat Indonesia-China (KCIC), is $60 \%$ owned by a consortium of four Indonesian state-owned enterprises (Kereta Api Indonesia, WIKA, Perkebunan Nusantara VIII, and Jasa Marga) and 40\% owned by China Railway Construction Corp (CRCC), a Chinese state-owned enterprise. The Indonesian government appears to regard foreign involvement in the transport sector as more sensitive than in the energy sector. Domestic legislation sets out that foreign firms can control no more than $49 \%$ of transportation-related projects, which presupposes ownership through a joint venture. In contrast, foreign control in energy plants can be up to $100 \%$ (President of the Republic of Indonesia 2016).

As a result of the ownership characteristics of KCIC, the US\$4.5 billion loan made by the China Development Bank (CDB) to KCIC is a loan to an Indonesian entity. The Indonesian state, via the involvement of Indonesian state-owned enterprises, is ultimately responsible for this debt. The loan is to be repaid over a 40-year period, at an annual interest rate of $2 \%$, with a ten-year grace period (i.e. repayment does not start until ten years after the signing of the loan agreement) (Negara \& Suryadinata: 75). The loan agreement was signed in May 2017, during a visit by the Indonesian President Joko Widodo (Jokowi) to Beijing. As a result KCIC is to repay the sum of US\$4.5 billion plus interest to the China Development Bank by the year 2067. Since both KCIC and the China Development Bank are state-owned entities, this railway project means that the Indonesian and Chinese governments have indirectly entered into a long-term financial relationship.

The Jakarta-Bandung HSR will cover a distance of 142 kilometres and connect the Indonesian capital, Jakarta, with the city of Bandung. The train 
will travel at a speed of $35^{\circ}$ kilometres per hour and there will be several stations along the way. The railway's potential economic impact is therefore not just reduced travel times between Jakarta and Bandung, but also the development of urban areas along the track. However, this potential broader economic effect does not necessarily benefit KCIC itself. The Indonesian government expects KCIC to repay the debt to the China Development Bank out of the railway's operational revenues. In 2015 there was a heated debate within the Indonesian cabinet about the project as proposed by the Chinese actors involved. The Finance Minister strongly doubted whether the railway would attract sufficient travellers for the relatively expensive high-speed train service to be able to repay the debt. In spite of the opposition of several cabinet members, President Jokowi decided to support the project (Negara \& Suryadinata: 76-77).

This decision was made against a background of fierce lobbying that was carried out not only by Chinese entities, but also by a Japanese consortium. Both sides were eager to build the railway. The main difference between the Chinese and Japanese bids was that the Chinese one did not require any guarantee from the Indonesian government (Harding et al. 2015; Negara \& Suryadinata: 75). The Japanese bid included a demand for a guarantee for $50 \%$ of the loan, which was to be repaid in 40 years. Although the Japanese loan was cheaper, at an annual interest rate of only $0.1 \%$, it was less attractive because it involved a substantially higher risk. Based on the agreement with China Railway Construction Corp (CRCC) and CDB, the Indonesian government refers to the Jakarta-Bandung HSR as a business-to-business project since the government does not guarantee repayment of the debt.

As a result, the China Development Bank has provided KCIC with a substantial amount of money without obtaining any form of guarantee. The fact that China Railway Construction Corp (CRCC), a Chinese state-owned enterprise, owns $40 \%$ of KCIC does not eliminate the risk for the Chinese state since CRCC does not have a controlling stake. The decision made by the CDB and CRCC, and presumably the Chinese central government, to get involved in the Jakarta-Bandung rail project is all the more noteworthy because of the sense of uncertainty that existed in 2015, at least among several Indonesian ministers, regarding the ability of KCIC to repay its debt.

After several years of delay, caused mainly by the legal procedures that KCIC needed to go through to obtain the land needed for the construction activities, work on the tracks, stations, tunnels, and bridges is currently under way. Before the outbreak of the COVID-19 pandemic, construction work was expected to be completed in 2021. It is currently unclear how much pandemic-related travel restrictions for Chinese workers will delay 
the work. The construction work is being conducted jointly by Indonesian and Chinese contractors in order to facilitate the transfer of technology and know-how from the latter to the former (Marburn 2016).

The construction of the Jakarta-Bandung HSR is widely regarded as the BRI's flagship project in Indonesia (interviews with Indonesian experts, Jakarta, January 2020). There are only a few other significant BRI-related projects in Indonesia, amongst which the larger ones are instances of direct investment. Only in the case of the Jakarta-Bandung railway has the Indonesian state, indirectly through state-owned entities, entered into a long-term financial obligation with the Chinese government of a substantial size.

It seems unlikely that by itself this project will provide the Chinese government with political leverage over Indonesia's foreign policy-making. Indonesia had a GDP of US $\$ 1,119$ billion and government revenues of US\$140 billion in 2019 (Insider Stories 2020). This makes the US $\$ 4.5$ billion loan from the China Development Bank too small to be an instrument of influence. The absence of any collateral means that if KCIC, at some time in the future, proved unable to repay the loan, the Chinese government would still not have an instrument of influence.

This factual analysis of potential mechanisms of influence is only part of the story. It is not only because of Sino-Japanese competition over the Jakarta-Bandung rail project that the BRI has so far provided the Chinese government with limited means to exert influence on Indonesia's foreign policy. This also appears to be the result of a deliberate approach by both the Indonesian and Chinese governments. While no government welcomes foreign political interference, the Indonesian government has been very cautious to avoid even situations in which Chinese interference appears to exist (Storey 2000). This means that in the future the Indonesian government is likely to limit the number, size, and impact of BRI-related projects.

Understanding the perspectives of the Indonesian and Chinese governments regarding the issue of Chinese interference requires an insight into the history of Sino-Indonesian relations. In particular, it requires recognition of the relevance of Indonesia's ethnic Chinese population - numbering 2.8 million according to a 2010 census (SCMP 2019). Events that took place as long ago as the thirteenth century established a historical point of reference that continues to be relevant to Sino-Indonesian relations today. In 1293, a combined Mongol and Chinese army invaded and tried to conquer Java (Turnbull 2003). Despite the fact that the attack failed, and also that China was ruled by the Mongol Yuan dynasty at the time, the story lives on in Indonesian school textbooks and is seen as evidence of 'Chinese "expansionism"' (Laksmana 2011: 29). 
More recently, in the 1950 s and early 196os, shared anti-colonial sentiments fostered close diplomatic relations between the two countries. At the same time, conservative segments within Indonesian society were suspicious of China's communist government and its ties with Indonesia's sizeable ethnic Chinese population, as well as being suspicious of the Indonesian Communist Party (Zhou 2013). The Indonesian military's violent purge of the country's Communist Party in 1965 led to a rupture in diplomatic relations with China two years later. Indonesia abandoned its strategy of keeping distance from the great powers and established close security and economic ties with the United States (Wicaksana 2019; Roberts et al. 2015). This did not change even after the stabilization and normalization of Sino-US relations in the 1970s. During the 1980s, China and the US were strategic partners in their geopolitical struggle against the Soviet Union. China also tried to keep Vietnam from becoming dominant on the Southeast Asian mainland by briefly invading Vietnam in 1979 and providing military aid to Khmer Rouge guerrillas during the Vietnamese occupation of Cambodia. Although China and Indonesia's geopolitical interests had been converging since the 1970s, bilateral relations were only restored in 1990 when the Cold War came to an end (Sukma 2009). The 1998 eruption of mass violence against ethnic Chinese in Indonesia during the Asian Financial Crisis was a reminder that these sensitivities continued to exist even in the absence of Chinese interference (HRW 1998).

The image of China as a communist (i.e. atheist) expansionist power continues to exist in Indonesia (interview with experts, Jakarta, January 2020). There is widespread suspicion about the intentions of the Chinese government, as well as about its perceived ability to exert influence through Indonesia's ethnic Chinese population and through the use of military power (Sukma 2009). The current government, under President Jokowi, is vulnerable to accusations from opposition parties that it is too close to China (interview with experts, Jakarta, January 2020). This provides the government with an additional motivation to stay at some distance from BRI-related projects, or at least to be seen as doing so.

The Coordinating Minister for Maritime Affairs and Investment, Luhut Binsar Pandjaitan, has stated that the government prefers business-tobusiness cooperation with China over government-to-government cooperation (Saat \& Negara 2019). The model set by the Jakarta-Bandung railway is therefore also to be used for future projects. Moreover, not just Chinese financial influence but also the more visible presence of Chinese workers at construction sites is a sensitive issue in Indonesia's public opinion. The Indonesian government therefore encourages foreign labour only if there is 
no possibility to use the domestic labour force (Hardiyan 2018). It is relevant to note that the effects of the traumatic events of 1965 work both ways. The Chinese government has experienced setbacks in its relationship with Indonesia due to the domestic instability there. This means that the Chinese government is likely to avoid creating a situation where it is seen to be interfering in Indonesia's political affairs.

The political sensitivity of China's involvement in Indonesia may help explain why there is no major Sino-Indonesian project in the area of maritime infrastructure. This is remarkable because Indonesia is an archipelago. It is also remarkable because China's President Xi Jinping chose Jakarta as the location where, in October 2013, he launched the '21st-Century Maritime Silk Road' (the maritime component of the BRI). Since 2013, the Maritime Silk Road has hardly involved Indonesia. Instead it has emerged primarily through port constructions in South Asia and Africa, direct investment in European container terminals, and in China's growing influence in global maritime shipping.

Although both the Chinese and Indonesian governments are cautious due to the sensitivities relating to Indonesia's ethnic Chinese, economic relations between the two countries are flourishing. China is Indonesia's largest trade partner (Badan Pusat Statistik 2019). It entered the top ten direct investors in Indonesia in 2015 (Indonesia Investment Coordinating Board 2016). By 2019, China had become the source of $16 \%$ of the total investment in Indonesia, making it the third-largest investor after Singapore and Japan (Indonesia Investment Coordinating Board 2020). Against this background, BRI-related activities may have a considerable impact on Indonesia's economy. A report by Moody's estimated that without the BRI, in the 2018-2038 period, the Indonesian economy would grow by $4.6 \%$. However, with BRI, Indonesian growth could be between $5.8 \%$ and $6 \%$ (Kong et al. 2019).

The expectation of such long-term effects from BRI may be relevant to policymaking. This expectation could encourage the Indonesian government to remain open to increased BRI-related cooperation with China. In 2019 the Indonesian government announced 28 infrastructure and economic development projects worth around US\$91 billion. In relation to these plans the Indonesian government welcomes Chinese investment, on Indonesian terms, in four economic hub regions: 1) North Sumatra, as a logistical hub in the Malacca strait; 2) North Kalimantan, due to its hydro power resources; and the regions of 3 ) North Sulawesi and 4) Bali, due to their appeal to Chinese tourists (Yuniarni 2018).

Given the circumstances discussed above, the BRI is not suited to being a tool through which the Chinese government can exert influence over 
Indonesia's foreign policy. However, there is still a possibility that it could alter the geopolitical dynamics in China-US-Indonesia relations. This would be the case, for instance, if the Indonesian government responded to potential US concerns about Indonesian involvement in BRI. The following section will look into Indonesia's positioning towards Sino-US geopolitical rivalry.

\section{BRI and Indonesia's Position in Relation to Sino-US Rivalry}

Indonesia's capacity to conduct globally oriented foreign policy is limited. Recognizing this, the country has positioned itself as a regional power with selective foreign involvement that gives priority to issues directly related to Indonesia's national interests (Karim 2018). At the international level, China poses a security threat to Indonesia due to conflicting maritime claims in the South China Sea. Indonesia is not a claimant in the South China Sea and has no claim over the highly contested Spratly and Paracel Islands. Consequently, it was not directly involved as a territorial claimant in the arbitration case brought by the Philippines to the Permanent Court of Arbitration (Laksmana 2016a). Rather, Indonesia's strategic aims in the South China Sea and broader Indo-Pacific maritime space are twofold: 1) control over the Natuna Islands and the adjacent 200 nautical miles of exclusive economic zone; 2) preventing exclusionary or hegemonic tendencies. ASEAN has served as a platform for Indonesia to promote its view of the South China Sea. Indonesia played a leading role in preparing the 2019 'ASEAN Outlook on the Indo-Pacific'. This promotes an ASEAN-centred Indo-Pacific space that does not exclude China (ASEAN 2019).

Given these aims, Indonesia has an interest in the ability of the US to counterbalance China's growing geopolitical role. At the same time, however, the Indonesian government retains its longstanding tradition of non-alignment with great powers and its focus on the role of ASEAN. Indonesia's perception is that great power alignments foster liabilities rather than serving as assets, undermining policy independence and regime legitimacy domestically (Laksmana 2016b). In that regard Indonesia's management of great power relations resembles that of other developing economies. It carries out a balancing act between strategic autonomy and deeper engagement with either of the two external actors. Indonesia has had a strategic partnership with China since 2005, and a comprehensive strategic partnership since 2013. However, it also established a comprehensive partnership with the US in 2010, and a strategic partnership in 2015 (US Department of State 2020). Because the US is still seen as the main guarantor for regional stability, Indonesia 
has supported a stronger US regional military presence in Southeast Asia. It has conducted frequent bilateral military exercises and other engagements with the US, totalling approximately 240 a year (White House 2015; Cronin \& Burke 2019). US and Indonesian observers also largely share strategic concerns. The incursions of Chinese fishing boats, China's extensive island and base building, and the growing maritime capabilities of China are seen as an attempt to dominate the South China Sea. Nonetheless, the foreign ministry is not willing to support any moves or statements that would put Indonesia on a collision course with China or fuel US-China competition (Kurlantzick 2018).

There are also other issues that affect US-Indonesian relations, such as human rights concerns and trade imbalances. The US has openly criticized Indonesia's past military actions in East Timor on human rights grounds. For a considerable time, it halted cooperation with the Indonesian Army's Special Forces Command (Kopassus) (Jones 2003). Even more importantly, under President Trump the US has targeted Indonesia as one of the countries that it wants to address its trade imbalance (Hermansyah et al. 2017). This is at the same time as China is increasing the economic interdependence between itself and Indonesia. The US government has declared that it is studying whether to impose import tariffs on 124 Indonesian products. Currently, the goods are imported under the generalized system of preference, which aims to support developing countries by reducing import duties and taxes (Indonesia Investments 2018).

Overall, from an Indonesian perspective, China is more relevant to its economic and developmental considerations than the US. The US, however, offers strategic cooperation at the international level. In terms of trade and direct investment, the US cannot replace China (interview with an Indonesian expert, Jakarta, January 2020). Bilateral cooperation between Indonesia and the US has revolved around issues such as counterterrorism and trade deficits (Laksmana 2018). Indonesia has no military alliance with the US. It has tried to steer strategic engagement with China towards either ASEAN or the ASEAN Regional Forum, as they have been deemed more effective instruments (Sukma 2009).

Even though US-China geopolitical rivalry in Southeast Asia has intensified since 2010, there is no indication that the Indonesian government has taken steps to abandon its policy of non-alignment and ASEAN centrality or that it is preparing to do so (interviews with experts, Jakarta, January 2020). So far, Indonesia's government has been capable of resisting pressure to choose sides. It responds firmly to perceived illegal incursions by Chinese fishing boats in the economic zone of the Natuna Islands. However, at the 
same time, the Indonesian government separates this issue from its economic relations with China (interview with an expert, Jakarta, January 2020). BRI-related activities have not been a factor in a geopolitical repositioning of Indonesian foreign policy because such a change of direction has not occurred.

\section{Conclusion}

The Indonesian government's attitude towards the BRI has been open but cautious. The Jokowi administration is strongly focused on domestic economic development. BRI-related activities, such as the building of transport infrastructure or energy plants, fit very well into this agenda. As such, Chinese BRI-related investments are welcomed provided they are on Indonesian terms. The (informal) flagship project in Indonesia under the BRI is the Jakarta-Bandung HSR, which involves a loan for which the risk lies primarily with the Chinese side. The well-established position of Japanese financiers and contractors in Indonesia helped the bargaining position of the Indonesian government in this case, but the domestic political context is also relevant. The room to manoeuvre for both Indonesia and China is limited due to the presence of a large ethnic Chinese community in Indonesia. The country's public opinion is generally suspicious of China and potential Chinese influence through ethnic Chinese Indonesians. China therefore cannot be too forceful or too visible in its approach to the BRI, nor can the Indonesian government afford to appear to be trading away Indonesian sovereignty in return for economic benefits. One reason why there are no major port-related BRI projects in Indonesia seems to be that the country is careful not to allow too much Chinese influence in such strategically important assets. As Indonesia is an archipelago country, with a colonial past, seaports free from foreign interference are important symbols of national sovereignty. The potential for China to use the BRI as a source of leverage over Indonesia is very limited.

The military and diplomatic presence of the US in the region forms a welcome counterbalance to China's growing influence. Because of Indonesia's wariness about China's potential to become a regional hegemon and sensitivities resulting from its ethnic Chinese population, the Indonesian government will not side with China against the US. However, due to the benefits of economic relations with China, and its geographic proximity, Indonesia also does not want to take sides with the US against China. The leverage of the US is limited since it is unable to match China's importance 
in terms of trade and investment. Although US troops visit Indonesia on a rotational basis, the two countries are not military allies and Indonesia's national security does not depend on the presence of US troops in the way it does in Japan or South Korea. BRI-related activities do not constitute a major element in US-Indonesian relations, and there is no indication that they have had any notable effect on Indonesia's positioning on Sino-US rivalry.

In the case of Indonesia the BRI does not appear to constitute a major geopolitical factor. This may be seen as a success for Indonesia's strategy. It is generally not to the benefit of third-party countries to become entangled in great power competition. Indonesia's ability so far to steer clear of such entanglement may have been enabled by a very specific combination of factors. In the case of the Jakarta-Bandung HSR, the involvement of Japanese financial institutions and companies as a countervailing force in infrastructure construction played a role. For BRI-related projects in general, political sensitivities resulting from the presence of a large ethnic Chinese population are an important factor, as they limit the room for both the Indonesian and the Chinese government to allow displays, or even hints, of Chinese interference.

\section{References}

ASEAN (2019, June 23). 'ASEAN Outlook on the Indo-Pacific'. Association of Southeast Asian Nations. Retrieved 14 June 2020 from https://asean.org/ asean-outlook-indo-pacific/.

Asia Society (2012, July 12). 'Expert: Clinton Tries to Dampen Fears of China "Rivalry" in Southeast Asia Tour'. Retrieved 22 July 2020 from https://asiasociety.org/ blog/asia/expert-clinton-tries-dampen-fears-china-rivalry-southeast-asia-tour. Badan Pusat Statistik (2019, July 4). 'Statistics of Indonesia 2019'. Retrieved 14 June 2020 from https://www.bps.go.id/publication/2019/07/04/daaciba18cae1e90706ee58a/statistik-indonesia-2019.html.

Benar News (2020, January 24). 'In New China-Backed Power Plant, Activists Question Indonesia's Commitment to Clean Energy'. Benar News. Retrieved 22 July 2020 from https://www.benarnews.org/english/news/indonesian/powerplant-01242020165216.html.

Bijian, Zheng (2005, September). 'China's “Peaceful Rise” to Great-Power Status'. Foreign Affairs. Retrieved 14 June 2020 from https://www.foreignaffairs.com/ articles/asia/2005-09-01/chinas-peaceful-rise-great-power-status.

Cheang, Ko Lyn (2019, July 24). 'The Struggle to Define the Belt and Road Initiative in Indonesia'.Jakarta Post. Retrieved 13 June 2020 from https://www.thejakartapost. 
com/news/2019/07/24/the-struggle-to-define-the-belt-and-road-initiative-inindonesia.html.

China Daily (2016, October 26). 'China-Invested Power Plant Starts Construction in Indonesia to Resolve Electricity Shortage'. China Daily. Retrieved 14 June 2020 from https://www.chinadaily.com.cn/bizchina/2016-10/26/content_27179531. htm.

China.org.cn (2019, December 25). 'Section 2 of Indonesian Manado-Bitung Toll Road Completed'. China.org.cn. Retrieved 14June 2020 from http://www.china. org.cn/business/2019-12/25/content_75616150.htm.

Cronin, Patrick M. \& Burke, Isabelle M. (2019, July 30). 'Time to Take the USIndonesia Strategic Partnership Seriously'. The Diplomat. Retrieved 14June 2020 from https://thediplomat.com/2019/o7/time-to-take-the-us-indonesia-strategicpartnership-seriously/.

Egberink, Fenna \& Van der Putten, Frans-Paul (2010). 'ASEAN and Strategic Rivalry among the Great Powers in Asia'.Journal of Current Southeast Asian Affairs, 29(3), 131-141. Retrieved 22 July 2020 from https://www.clingendael.org/publication/ asean-and-strategic-rivalry-among-great-powers-asia.

Eximbank (2018, August 5). 'China Eximbank Signed Loan Agreement and Infrastructure Financing Cooperation Agreement with Indonesian Authorities'. Export-Import Bank of China. Retrieved 14 June 2020 from http://english. eximbank.gov.cn/News/NewsR/201810/t20181016_6943.html.

Harding, Robin, Chilkoti, Avantika \& Mitchell, Tom (2015, October 1). 'Japan Cries Foul after Indonesia Awards Rail Contract to China'. Financial Times. Retrieved 14 June 2020 from https:/www.ft.com/content/ eca4af84-67fa-11e5-97do-1456a776a4f5.

Hardiyan, Yodie (2018, August 8). 'Jokowi: 23.000 Pekerja China di Indonesia, Tapi 80.000 Pekerja Indonesia di China'. Ekonomi. Retrieved 14 June 2020 from https:// ekonomi.bisnis.com/read/20180808/12/825667/jokowi-23.00o-pekerja-china-diindonesia-tapi-80.ooo-pekerja-indonesia-di-china.

Hermansyah, Anton, Ribka, Stefani \& Salim, Tama (2017, April 3). 'Trump Puts Indonesia on Trade Hit List'. Jakarta Post. Retrieved 14 June 2020 from https:// www.thejakartapost.com/news/2017/04/o3/trump-puts-ri-on-trade-hit-list.html.

HRW (1998). 'Indonesia Alert. Economic Crisis Leads to Scapegoating of Ethnic Chinese, February 1998'. Human Rights Watch. Retrieved 14 June 2020 from https://www.hrw.org/report/1998/02/18/indonesia-alert/ economic-crisis-leads-scapegoating-ethnic-chinese-february-1998.

Indonesia Investment Coordinating Board (2016, January 21). 'Domestic and Foreign Direct Investment Realization in Quarter IV and January-December 2015'. Retrieved 14June 2020 from https://www3.bkpm.go.id/en/publication/press-release/ readmore $/ 10433 / 1387$. 
Indonesia Investment Coordinating Board (2020, January 29). 'Domestic and Foreign Direct Investment Realization in Quarter IV and January-December 2019'. Retrieved 14June 2020 from https://www.bkpm.go.id/images/uploads/file_siaran_pers/Paparan_Bahasa_Inggris_Press_Release_TW_IV_2019.pdf.

Indonesia Investments (2017, August 29). 'Infrastructure Update Indonesia: Balikpapan-Samarinda Toll Road'. Retrieved 14 June 2020 from https://www.indonesia-investments.com/business/business-columns/ infrastructure-update-indonesia-balikpapan-samarinda-toll-road/item8145.

Indonesia Investments (2018, July 6). 'Trade War Kicks off, Trump also Eyes Tariffs on Indonesian Goods'. Retrieved 14 June 2020 from https://www. indonesia-investments.com/news/news-columns/trade-war-kicks-offtrump-also-eyes-tariffs-on-indonesian-goods/item8881.

Insider Stories (2020, January 7). 'Budget Deficit of Indonesia Widens to $2.2 \%$ in 2019'. Insider Stories. Retrieved 22 July 2020 from https://theinsiderstories.com/ indonesia-posts-us25-21b-budget-deficit-in-2019/.

Jones, Sidney (2003, November 13). 'Why Indonesians Distrust the US'. Far Eastern Economic Review, 166(45), 27. Retrieved 14 June 2020 from https://www.crisisgroup.org/asia/south-east-asia/indonesia/why-indonesians-distrust-us.

Kang, David C. (2005). 'Why China's Rise Will Be Peaceful: Hierarchy and Stability in the East Asian Region'. Perspectives on Politics, 3(3), 551-554.

Karim, Moch Fasal (2018). 'Middle Power, Status-Seeking and Role Conceptions: The Cases of Indonesia and South Korea'. Australian Journal of International Affairs, 72(4), 343-363.

Kong, Veasna, Cochrane, Steven G., Meighan, Brendan \& Walsh, Matthew (2019, June). 'The Belt and Road Initiative - Six Years On'. Moody's Analytics. Retrieved 14 June 2020 from https:/www.moodysanalytics.com/-/media/article/2019/ belt-and-road-initiative.pdf.

Kurlantzick, Joshua (2018, January 26). 'Secretary of Defense Mattis's Trip to Southeast Asia: A Few Thoughts'. Council on Foreign Relations. Retrieved 14 June 2020 from https://www.cfr.org/blog/secretary-defensemattiss-trip-southeast-asia-few-thoughts.

Laksmana, Evan A. (2011). 'Variations on a Theme: Dimensions of Ambivalence in Indonesia-China Relations'. Harvard Asia Quarterly, 13(1), 24-31.

Laksmana, Evan A. (2016a). 'The Domestic Politics of Indonesia's Approach to the Tribunal Ruling and the South China Sea'. Contemporary Southeast Asia, 38(3), 382-388. Retrieved 14 June 2020 from https://www.jstor.org/ stable/24916763.

Laksmana, Evan A. (2016b). 'Pragmatic Equidistance: How Indonesia Manages Its Great Power Relations'. In David Denoon (ed.), China, the United States, and the Future of Southeast Asia (pp. 113-135). New York: New York University Press. 
Laksmana, Evan A. (2018, January 29). 'Indonesia-US Relations: Sweating the Small Stuff'. The Interpreter. Retrieved 14 June 2020 from https://www.lowyinstitute. org/the-interpreter/indonesia-us-relations-sweating-small-stuff.

Landler, Mark (2016, September 7). 'Obama Takes a Detour to Reconnect with Southeast Asia'. New York Times. Retrieved 22 July 2020 from https://www. nytimes.com/2016/og/o8/world/asia/obama-southeast-asia.html.

Marburn, Julkifli (2016, July 26). 'BPPT Studies Application of Jakarta-Bandung Speed Train Technology'. Republika. Retrieved 14 June 2020 from https://www. republika.co.id/berita/en/national-politics/16/o7/26/oawzdd317-bppt-studiesapplication-of-jakartabandung-speed-train-technology.

NDRC (2015, March). 'Vision and Actions on Jointly Building Silk Road Economic Belt and 21st-Century Maritime Silk Road'. National Development and Reform Commission, Ministry of Foreign Affairs and Ministry of Commerce, People's Republic of China. Retrieved 25 October 2020 from https://web.archive.org/ web/20181127225143/http://en.ndrc.gov.cn/newsrelease/201503/t20150330_669367. html.

Negara, Siwage Dharma \& Suryadinata, Leo (2019). ‘China's Maritime Silk Road Initiative and Indonesia'. In J.-M.F. Blanchard (ed.), China's Maritime Silk Road Initiative and Southeast Asia:Dilemmas, Doubts and Determination (pp.65-94). London: Palgrave Macmillan.

Parameswaran, Prashanth (2015, April 29). 'China Is Now One of Indonesia's Top Ten Investors'. The Diplomat. Retrieved 15 June 2020 from https://thediplomat. com/2015/04/china-is-now-one-of-indonesias-top-ten-investors/.

Perusahaan Listrik Negara (2015, November 25). 'PLN Tandatangani PPA Proyek IPP PLTU Bengkulu 2 x 100 MW'. Retrieved 14 June 2020 from https://web. pln.co.id/media/siaran-pers/2015/11/pln-tandatangani-ppa-proyek-ipp-pltubengkulu-2-x-100-mw.

Perusahaan Listrik Negara (2017, December 7). 'PLN Pastikan Agar China Bangun Pembangkit Listrik Efisien dan Rendah Emisi'. Retrieved 14 June 2020 from https://web.pln.co.id/media/siaran-pers/2017/12/pln-pastikan-agar-chinabangun-pembangkit-listrik-efisien-dan-rendah-emisi.

$\operatorname{PISM}$ (2019, December 10). 'ASEAN Countries' Approach to the Belt and Road Initiative'. Polish Institute of International Affairs. Retrieved 22 July 2020 from https://pism. pl/publications/ASEAN_Countries_Approach_to_the_Belt_and_Road_Initiative. President of the Republic of Indonesia (2016). 'Presidential Regulation of the Republic of Indonesia, Number 44, Year 2016, Concerning Lists of Business Fields That Are Closed to and Business Fields That Are Open with Conditions to Investment'. Indonesia Investments. Retrieved 14 June 2020 from https:// www.indonesia-investments.com/upload/documents/Negative-InvestmentList-May-2016-Indonesia-Investments.pdf. 
Roberts, Cristopher B., Habir, A. \& Sebastian, Leonard C. (eds.) (2015). Indonesia's Ascent Power, Leadership, and the Regional Order. London: Palgrave Macmillan. Saat, Norshahril \& Negara, Siwage Dharma (2019, October 21). 'Jokowi's Second-Term Priorities and Challenges: An Interview with Luhut B. Pandjaitan'. Perspective, 86. Retrieved 14 June 2020 from https://www.iseas.edu.sg/images/pdf/ ISEAS_Perspective_2019_86.pdf.

SCMP (2018, October 21). 'China-Backed Dam in Indonesia Rainforest to Cut through Home of World's Rarest Orangutan'. South China Morning Post. Retrieved 22 July 2020 from https:/www.scmp.com/news/asia/southeast-asia/ article/2169513/china-backed-dam-indonesia-rainforest-cut-through-home.

SCMP (2019, July 8). 'Can Indonesia's Chinese-Language Media Be Revived?' South China Morning Post. Retrieved 27 July 2020 from https://www. scmp.com/week-asia/lifestyle-culture/article/301749o/can-indonesiaschinese-language-media-be-revived.

Storey, Ian James (2000). 'Indonesia's China Policy in the New Order and Beyond: Problems and Prospects'. Contemporary Southeast Asia, 22(1), 145-174.

Sukma, Rizal (2009). 'Indonesia's Response to the Rise of China: Growing Comfort amid Uncertainties'. In Jun Tsunekawa (ed.), The Rise of China: Responses from Southeast Asia and Japan (pp. 139-154). Tokyo: National Institute for Defence Studies.

Sumatran Orangutan Society (2018, May). 'Damming Evidence: How the Batang Toru Megadam Threatens a New Orangutan Species with Extinction'. Retrieved 22 July 2020 from https://www.orangutans-sos.org/content/uploads/2018/05/ Damming-Evidence.pdf.

Turnbull, Stephen (2003). Genghis Khan \& the Mongol Conquests, 119o-140o. London: Osprey Publishing.

US Department of State (2020, January 21). 'US Relations with Indonesia'. Retrieved 14 June 2020 from https://www.state.gov/u-s-relations-with-indonesia/.

White House (2015, October 26). 'Joint Statement by the United States of America and the Republic of Indonesia'. Retrieved 14 June 2020 from https://obamawhitehouse.archives.gov/the-press-office/2015/10/26/ joint-statement-united-states-america-and-republic-indonesia.

Wicaksana, I Gede Wahyu (2019). 'The Family State: A Non-Realist Approach to Understanding Indonesia's Foreign Policy'. Asian Journal of Political Science, $27(3), 308-328$.

Xinhua (2017, November 3). 'Full Text of Xi Jinping's Report at 19th CPC National Congress'. Xinhua. Retrieved 14 June 2020 from http://www.xinhuanet.com/ english/special/2017-11/03/c_136725942.htm.

Yuniarni, Sarah (2018, July 5). 'Here's How Indonesia Can Benefit from China's Belt and Road Initiative'.Jakarta Globe. Retrieved 14 June 2020 from https:// 
jakartaglobe.id/business/heres-how-indonesia-can-benefit-from-chinas-beltand-road-initiative/.

Zhou, Taomo (2013, August). 'Ambivalent Alliance: Chinese Policy towards Indonesia, 1960-1965'. Working Paper no. 67. Woodrow Wilson International Center for Scholars. Retrieved 13June 2020 from https://www.wilsoncenter.org/publication/ ambivalent-alliance-chinese-policy-towards-indonesia-1960-1965.

\section{About the Authors}

Frans-Paul van Der Putten has a PhD in History from Leiden University and is a Senior Research Fellow at the Clingendael Institute. He is also the coordinator of the institute's China Centre. His research is focused on the geopolitical implications of China's increasing role in international affairs. Previously, he worked as a researcher at Nyenrode Business University. He is a former editor-in-chief of Itinerario:Journal of Imperial and Global Interactions. Together with Mamad Forough, he initiated the Clingendael Institute's Silk Road Headlines, a weekly news service providing updates on news articles related to China's Silk Road initiative.

Mirela PetKova has been a Junior Researcher at the Clingendael Institute's EU \& Global Affairs Unit. Her research focuses on China's foreign policy, in particular China's global trade, investment, and infrastructure practices, the BRI, and EU-China relations. Prior to working at Clingendael, she has worked at the European Institute for Asian Studies (Belgium) and in the administration of the President of the Republic of Bulgaria. 



\title{
9 Elite Legitimation and the Agency of the Host Country
}

\author{
Evidence from Laos, Malaysia, and Thailand's BRI \\ Engagement
}

Cheng-Chwee Kuik

\begin{abstract}
This chapter discusses Southeast Asian cases, turning to Laos, Malaysia, and Thailand. It asks why China's BRI projects progress relatively smoothly in communist Laos but slowly and selectively in military-ruled Thailand, and substantially, albeit with volatility, in quasi-democratic Malaysia. The chapter argues that differences in political systems are only part of the answer. Focusing on these three countries' BRI engagement, the study highlights the agency of host countries in shaping the patterns of foreign-funded infrastructure cooperation. China as a stronger partner will always 'push the envelope' in partnerships. Nevertheless, it is the host country (specifically the ruling elites) that engages China-backed projects, based on its need to optimize its respective pathways of legitimation, leading to varying responses.
\end{abstract}

Keywords: Belt and Road Initiative, China, Laos, Malaysia, Thailand, elite legitimation

As China's Belt and Road Initiative (BRI) gains ground globally, much has been written about the motivations, approaches, and impact of its economic statecraft (Goh 2016; Ferchen 2016; Rolland 2017; Li 2020; Ye 2020). Likewise, the number of scholarly works focusing on the responses of smaller states to the BRI has also increased (Liu \& Lim 2019; Ba 2019; Kuik 2020). While the vast majority of such studies, which are either single country or region-wide, provide useful insights into host countries' responses to the BRI, there is still

Schneider, Florian (ed.), Global Perspectives on China's Belt and Road Initiative: Asserting Agency through Regional Connectivity. Amsterdam, Amsterdam University Press 2021 DOI: $10.5117 / 9789463727853 \_$CHo9 
a dearth of comparative research that theorizes about this international phenomenon.

This chapter addresses this research gap by answering the question of why smaller states in the same region respond to big-power economic inducement differently. It focuses on Southeast Asia and compares the patterns of BRI engagement in Laos, Malaysia, and Thailand. Why focus on Southeast Asia and why these three countries? Southeast Asia is a region that is being prioritized in China's BRI statecraft. BRI-related projects have been making progress across the region, even during the COVID-19 pandemic. In March 2020, the Association of Southeast Asian Nations (ASEAN) as a whole replaced the EU as China's largest trading partner. The three ASEAN countries have been selected because they represent three different patterns of BRI engagement in Southeast Asia (and for that matter, other regions as well): enthusiastic embrace (Laos), partial participation (Thailand), and intense but occasional turbulent involvement (Malaysia). These differing patterns provide analytical space to consider why similarly situated smaller states have responded to the People's Republic of China (PRC)'s BRI-related inducements differently. Methodologically, this study is based on first-hand interviews, fieldwork research in all three countries, and open-source data, including media, scholarly work, official statements, and policy reports.

Malaysia's involvement with the BRI, which includes an industrial park, port cooperation, rolling stock production, e-commerce, and rail projects, is widest in terms of scope. In comparison, Thailand's BRI partnership is limited to high-speed rail cooperation. Meanwhile Laos is involved with constructing a high-speed rail connection from its capital, Vientiane, to the northern town of Boten, close to the border with China. It is also cooperating on industrial parks, as well as hydropower and mining projects. In terms of scale of BRI partnerships and speed of project cycles (from initiation to negotiation and implementation), Malaysia, overall, also represents the highest and fastest of the three case studies (see table 9.1).

These variations in the patterns of these smaller states' BRI engagement are primarily a function of their domestic politics, specifically, their ruling elites' legitimation. In all three cases, development-based performance legitimation is the primary pathway that drives the smaller Southeast Asian states to participate in the BRI and leverage China's infrastructure-based economic statecraft. However, this impetus has been supplemented, softened, or balanced by other pathways of justification (socialist authoritarianism in Laos, Thai identity discourse in Thailand, as well as ethnic balancing and democratic legitimation in Malaysia). Such optimization of legitimation pathways has shaped and limited the respective states' receptivity to 
foreign-funded partnerships. As the extent of these partnerships has been further filtered by the varying degrees of domestic power diffusion in these states, differing patterns of BRI engagement have emerged.

By focusing on elite legitimation as the key explanatory variable, this chapter thus unpacks the agency of the host country in shaping the progress and prospects of such foreign-funded infrastructure projects as the Chinabacked BRI. This approach challenges the prevailing view in the existing literature, which appears to over-emphasize - explicitly or otherwise - the power of China as the provider of capital and technology in infrastructure connectivity partnerships in smaller states. The research fieldwork and findings of this study indicate that the situation is much more complex. Despite their strengths, China's state-linked investors and entities do not always have the upper hand. Indeed, the varying patterns and pace of the three selected Southeast Asian countries' BRI engagement - from enthusiastic and smooth to selective, partial, and protracted - evidently highlight the agency of host countries, particularly their respective ruling elites. Whether, to what extent, and in what ways a foreign-backed infrastructure connectivity project progresses in a desired direction depends largely on the elites that are in power in the host country. These elites seek to advance their authority and interests by optimizing their legitimation pathways vis-à-vis contending elites and sociopolitical actors at home.

This chapter proceeds in four sections. The first presents a theoretical discussion of elite legitimation as a shaper of agency in the host country in managing foreign-funded infrastructure connectivity cooperation. The remaining sections identify and explain the different patterns of BRI engagement in Laos, Malaysia, and Thailand, respectively. These sections analyse the impact of elite legitimation-optimization on the scope, scale, and speed of these countries' engagements with China's BRI-related projects, as illustrated in table 9.1.

\section{Analytical Framework: Legitimation and the Agency of the Host Country in Infrastructure Cooperation}

This section develops a theoretical framework to explicate elite legitimation as a shaper of the agency of the host country in determining smaller states' responses to foreign-backed infrastructure connectivity cooperation such as the BRI-related projects. By 'agency', I refer to the capacity of unit-level actors to translate their own preferences into a desired outcome despite asymmetric power structure. They exercise this agency either by active 
Table 9.1 Laos, Malaysia, and Thailand's BRI engagement with China

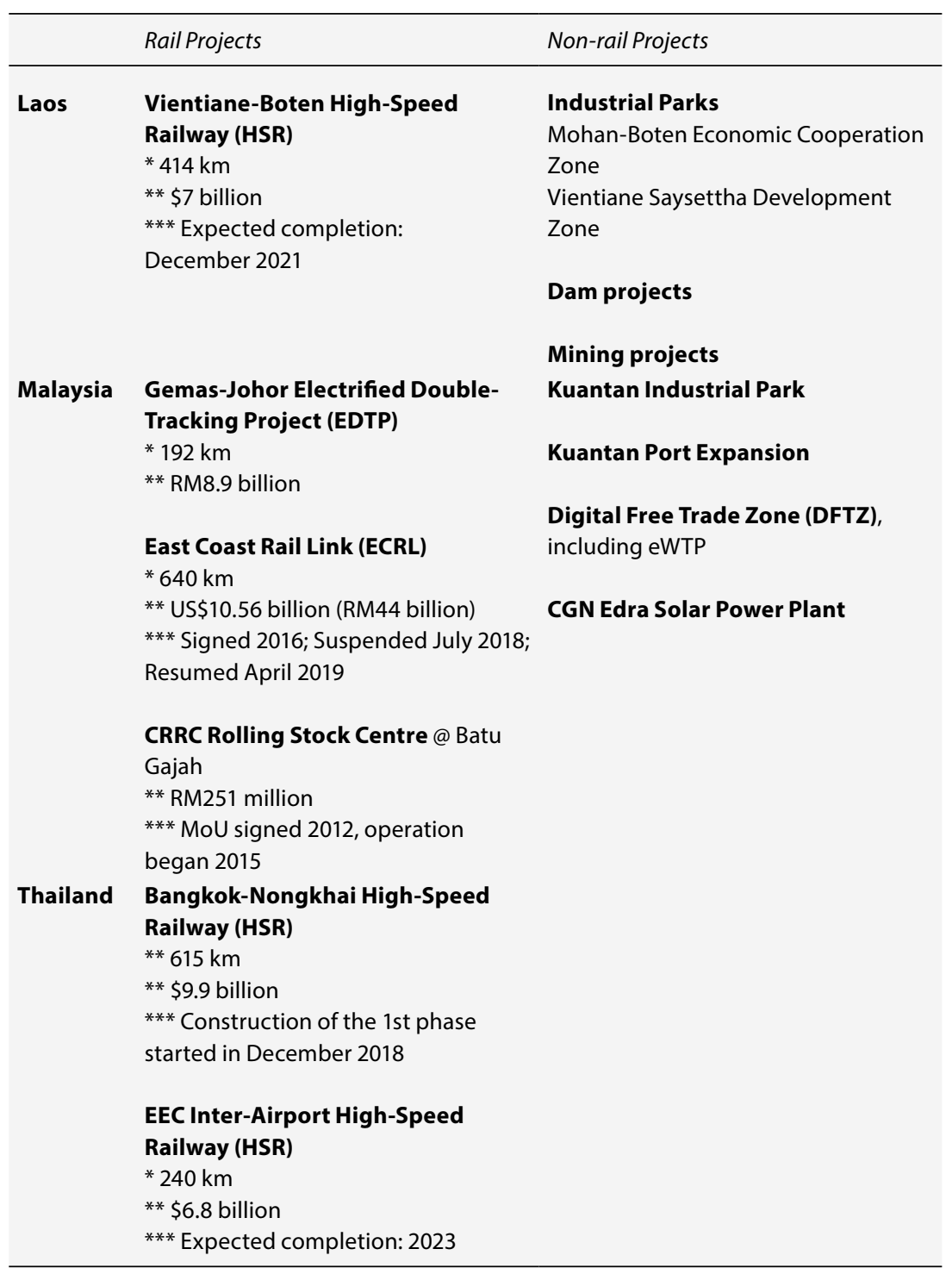

Source: Author's compilation

actions of initiating, influencing, and renegotiating, or by passive actions of denying, delaying, or distancing from a stronger power's initiative. Agency is thus conceived here as an intermediary between micro-processes and macro-structures (Parsons 1951; Giddens 1984; Sewell 1992; Wight 2006). By 'elite', I mean a small group of actors who exercise disproportionate 
power and influence over a given society on the grounds of governance authority, coercive capacity, wealth possession, and/or ideational excellence (Bottomore 1964; Lipset \& Solari 1967; Parry 2005; Axelrod 2015). This study focuses on governing elites or political class.

I hypothesize that it is elite legitimation - defined here as a process through which the ruling elites seek to justify and consolidate their authority before their targeted constituencies - that explains individual countries' differing patterns of BRI engagement and differing forms of agency. All elites claim their 'right' to rule by appealing to certain ideals, constructing substantial or substantiated narratives, and resorting to corresponding pathways. They do this in order to justify, enhance, and consolidate their domestic authority vis-à-vis other contesting elites and wider society (Kuik 2013; Lampton, Ho \& Kuik 2020). These legitimation pathways include multiple manifestations of development-based performance legitimation (e.g. ensuring growth and delivering development fruits, managing nationwide problems). The pathways also include identity-based, particularistic legitimation (including nationalist sentiments, ethnic and religious appeals, personal charisma), and ideology-based procedural legitimation (e.g. democratic values, social justice). No ruler relies on one single pathway to rule. In practice, all rulers resort to a combination of legitimation pathways - with different degrees of emphasis and mobilization - for their inner justification (Weber 1947; Weber 1978; Beetham 1991; Alagappa 1995; Gilley 2009). The combinations of pathways and degrees of emphasis matter because they determine the direction and prioritization of major state policies, both internal and external.

Given this chapter's focus on the responses to BRI-related projects in Laos, Malaysia, and Thailand, I concentrate on a state's relative emphasis on development-centred performance legitimation vis-à-vis other inner justifications (i.e. particularistic and/or procedural legitimation).

All things being equal, governing elites who emphasize performance legitimation more than other pathways of justification are more likely to embrace external investment, assistance, and partnerships that can boost their country's economic growth. Hence, the above-named Southeast Asian countries are relatively receptive because they see the BRI as an opportunity. Vietnam is a major contrast. While Vietnamese Communist Party elites attach importance to performance legitimacy, they also resort to nationalist legitimation much more than other state elites in the region. The centrality of nationalist legitimation colours the Vietnamese perceptions of Chinese power, driving them to view Beijing-backed projects more suspiciously than other countries in the same region. Hence, it can be inferred that the more 
the ruler emphasizes development performance over other pathways of legitimation, the more receptive they will be towards external partnerships, and the reverse is also true (in the case of Vietnam).

Nevertheless, this receptivity is also subject to the degree of power diffusion. In the one-party states of Laos and Vietnam (and to some extent, polities with one dominant political actor, namely, Cambodia, Singapore, Brunei), the ruling elites' authority and decisions are rarely openly contested, challenged, or criticized. Because the state is strong (in cooption and coercion) and society is weak (in mobilization and opposition), elite contestation usually takes place within rather than outside the establishment, with few instances of policy changes that are attributable to bottom-up constraints or societal pressure. This is in contrast to other Southeast Asian countries, such as Indonesia, the Philippines, Malaysia, Thailand, and, to some extent, Myanmar. Power diffusion is the most dominant political feature in these countries, where the ruling elites' authority and decisions are not only contested and challenged publicly, but also constrained persistently.

The next three sections illuminate the complex political and developmental logics underlying the responses to the BRI from Laos, Malaysia, and Thailand, respectively.

\section{The Case of Laos: Legitimation in a Landlocked Communist Country}

Laos's engagement with the BRI is openly receptive, and it has gradually intensified, albeit also being quietly contentious. Laos had collaborated with China on infrastructure development well before the BRI. It enthusiastically embraced the BRI when Chinese President Xi Jinping launched it in 2013. In addition to the 414-kilometre Vientiane-Boten High-Speed Railway (HSR), which is considered China's signature BRI project in Laos, the bilateral connectivity cooperation has gradually extended to special economic zones and other sectors, with intense but unequal partnerships in hydropower, mining, and agricultural projects.

The Lao-China HSR project is unique and significant in numerous ways. Its origins had more to do with the agency of small-state pull than big-power push. Contrary to the widespread impression that China pushed the HSR idea to its small neighbour, it was Laos that took the initiative to partner with China for its most ambitious infrastructure development project. In the early 200os, Lao leaders proposed to their Chinese counterparts that they should collaborate in building a railway line in the land-locked country (personal 
communications with Bangkok-based and Vientiane-based researchers, June 2019 and January 2020). This coincided with Beijing's 'going-out strategy' (zouchuqu zhanlüe [走出去战略]), which included encouraging Chinese firms to invest overseas, promoting intra-regional links, and accessing natural resources. China subsequently undertook a feasibility study of the Laos rail project. Eventually, in 2009, Laos and China agreed to pursue the project. At the same time, Laos launched its very first railroad line (in collaboration with Thailand) - a 3.5-kilometre track from the Lao capital, Vientiane, to Nong Khai, a city in northeast Thailand.

Laos and China signed a Memorandum of Understanding (MoU) on 7 April 2010. The Laos-China Railway Company was formed, with 30\% owned by Lao state railway and $70 \%$ by Chinese state-owned firms. China agreed to provide Laos with a long-term loan of about US\$4 billion. Another MoU was signed later that year after the Chinese Railroad Minister Liu Zhijun visited Laos and held further talks with Lao authorities regarding the railway construction (Radio Free Asia 2010).

The Laos rail project is also significant because it is, thus far, the only China-related high-speed railway (HSR) venture in Southeast Asia that is undergoing construction with a specific date of completion for the entire project. In comparison, only a small stretch of the first phase of the ThailandChina HSR is under construction, with no firm date set for the second phase (from Nakhon Ratchasima to Nong Khai). In Malaysia, the planned Kuala Lumpur-Singapore HSR was delayed after the Mahathir-led Pakatan Harapan (PH) came to power in May 2018. In Indonesia, although the authorities had set 31 December 2021 as the completion date for the Jakarta-Bandung HSR (after years of delay), at the time of writing the ongoing coronavirus crisis was compelling the authorities to consider extending the completion date (Wahyudi 2020). In Laos, despite the coronavirus situation, the rail project is still scheduled to be completed and opened for service in December 2021. The Laos-China Railway Company has been carrying out epidemic prevention measures, while aiming to complete sub-rail civil engineering and start track engineering this year (The Star 2020).

Another unique aspect of the Laos-China rail project is that its importance extends beyond national development and bilateral ties. When completed, the 1.435-meter standard-gauge railway will be the first and only modern rail line directly linking Southeast Asia and China. It will connect Laos, and eventually also other Southeast Asian countries, to China's vast high-speed railway network via the Yuxi-Mohan railway, a project linking the city of Yuxi in the centre of China's Yunnan Province with the town of Mohan on the border with Laos (Lampton, Ho \& Kuik 2020). Once the Laos line 
extends southward, crossing the Laos-Thailand border and linking with the Beijing-backed Sino-Thai HSR from Vientiane to Bangkok, it will be the first cross-border railway running through the heart of Southeast Asia to Bangkok, a regional transportation hub (see figure 9.1). If, and when, this trans boundary HSR line extends further southward and crosses into Malaysia and Singapore, it will result in the actualization of the 'Central Route' of the planned Singapore-Kunming Rail Link (SKRL), which has been envisaged since the mid-199os.

Its significance notwithstanding, the US $\$ 7$ billion Laos-China rail project has attracted criticism from the beginning. For years, critics have pointed to the dual long-term risks of debt and dependency. Others have highlighted the problems associated with transparency, resource mobilization, labour management, displacement of people, compensation for land acquisition, environmental sustainability, etc. (interviews with Lao academics, Vientiane, January 2020). There are also fears about large-scale migration of Chinese workers into the tiny Southeast Asian country, which has a population of less than 7 million. A report by National Public Radio (NPR) in the United States cited a local from Luang Prabang, the ancient capital of Laos, about midway along the rail route from the Mohan-Boten border station in the north to Vientiane: 'I worry that when the trains are completed, there will be many, many Chinese [moving] in from China to live in Laos and they will take the job[s] from local people' (Westerman 2019).

Given these risks and challenges, it has puzzled many observers that Laos, which is a small and underdeveloped country, has proceeded with this fiscally and politically costly megaproject. Several signs indicate a difficult negotiation process with China and an arduous decision-making process within the ruling Lao People's Revolutionary Party (LPRP). One sign was the lengthy period from the inking of the MoU to the beginning of construction. Although the two MoUs were signed in 2010, it took the LPRP regime about two years to approve the project, and then another three years to have the ground-breaking ceremony in December 2015, only to have the ceremony postponed to December 2016. Some of the problems were disagreements with Chinese firms over the project arrangements, including workers, social and environmental impact, and loan details such as the interest rate (Doig 2018: 33; personal communications with Lao researchers, June 2019). These disagreements must have sparked internal debates among the ruling LPRP elites. According to scholar Vatthana Pholsena (2012: 62), there were 'hiccups in the decision-making process' that took place behind closed doors regarding a party decision in 2011 to delay the high-speed rail project. The project was suddenly postponed to a later date, supposedly 
because there were 'concerns at the highest levels' of the party 'over the terms of the contract, which included the hiring of a massive number of Chinese labourers'.

Nevertheless, the project was eventually given a firm go-ahead in 2016 and has been progressing without disruptions and delays since (unlike the cases of Malaysian and Thai BRI engagement). Its progress despite the aforementioned concerns, perceived risks, and internal debates, indicates there are strong political imperatives at play. I would argue that the two most paramount political imperatives are a robust performance justification and a low power diffusion in the one-party country.

The LPRP's performance legitimation has been tied to a national narrative that speaks of transforming Laos from a land-locked' to 'land-linked' nation in order to bring the Lao people out of their generations-long poverty. This political justification - and the associated discourse mobilization - is rooted in the geographical and socio-economic realities of Laos. Laos is one of the poorest countries in the region. As its neighbours have slowly opened and developed their economies, Laos - where subsistence agriculture constitutes half of its economic output - has remained on the list of least developed countries' (LDCs) according to the United Nations Conference on Trade and Development (UNCTAD). This is primarily because Laos is the only land-locked nation in Southeast Asia and also because of such structural problems as weak infrastructure, inadequate labour, lack of skilled workers, low technological capabilities, and a low ranking in the business-enabling environment (Vilavong 2016).

To overcome these problems, the Lao government has emulated the developmentalist strategy of fellow communist countries China and Vietnam, of striking 'a balance between economic and social development', while drawing inspiration from non-communist regional economic powerhouses, most notably Japan, South Korea, and Taiwan (Forbes \& Cutler 2005; Howe \& Park 2015). Laos has undertaken ambitious projects in hydroelectricity and mining, embraced regionalist policies, and perhaps, most importantly, endeavoured to build better international connectivity within its region (Forbes \& Cutler 2005).

Constructing a north-south railway, which can connect Laos with China and the developed ASEAN markets, is thus a central component of such a development strategy and the legitimation-driven land-linked' discourse. Lao leaders view the railway as an 'iron river' that can transform the economic future of Laos by improving transport connectivity, attracting investment, and stimulating growth in multiple sectors (interview with senior policy official, Vientiane, June 2017). The former Deputy Prime Minister of 
Laos, Somsavat Lengsavad, who reportedly played an instrumental role in negotiating hydropower dam deals on the Mekong, as well as promoting the high-speed railway deal and pushing through a special session of the Lao National Assembly in 2012 to approve the deal, has said that the rail project 'will boost the Lao economy because many investors are now looking for a production base [in Laos]'. He added that the railway would help 'reduce their transportation costs', thereby making Laos 'more attractive to investors' (Doig 2018: 30-33).

According to Laos's 8th Five-Year National Socio-Economic Development Plan (2016-2020), part of the national strategy to elevate Laos out of being a 'least developed country' (LDC) involves the construction of large-scale infrastructure projects, particularly railways, hydropower dams, and mines (Tappe 2018: 169). At the ground-breaking ceremony of the railway project, which took place in the city of Luang Prabang in December 2016, the Lao Minister of Public Works and Transport, Bounchanh Sinthavong, remarked: 'Once completed, the railway will benefit Lao people of all ethnic groups, facilitate and reduce costs of transportation, stimulate the development of agricultural and industrial sectors, tourism, investment and trade, as well as generate income for Lao people and the country' (Chengliang 2016). His Vice Minister and the Chairman of the Laos-China Railway Project Management Committee, Lattanamany Khounnivong, stressed that the railway 'will facilitate Laos's ability to transport goods around the region faster and "about three times cheaper" than today' (Reed \& Hille 2019). The train, which can travel at up to 160 kilometres per hour (100 miles per hour), is expected to cut travel time between the capital, Vientiane, and the northern border town of Boten from three days to three hours.

Beyond the high-speed railway, the Lao People's Revolutionary Party (LPRP) elites have also partnered with China on developing economic zones (namely, the Mohan-Boten Economic Cooperation Zone and the Vientiane Saysettha Development Zone). They have also cooperated on building hydropower dams, as part of the government's long-term vision to make Laos the 'battery of Southeast Asia'. Key dam projects include: the US\$1.3 billion Nam Ngum 3 hydropower projects in the mountainous central Xaisomboun Province and the US\$308 million Nam Khan 2 Dam project in Luang Prabang Province. Both of these projects are operated by Sinohydro of China (personal communications with Lao researchers, Vientiane and Bangkok, January 2020 and April 2020).

These development benefits are central to the party's legitimacy, as the 'Lao party-state (phak lat)' relies on continuous economic growth and growing prosperity for the 'Lao multi-ethnic people' (Tappe 2018: 172). Mega 
infrastructure projects such as the railway and the hydropower dams are viewed as key to bringing economic prosperity to Laos.

Low power diffusion explains why, once the top-down decision was made by the ruling elites, the high-speed rail project has progressed relatively smoothly without disruptions. As a communist-ruled country with no independent media and very limited civil society groups, the Lao oneparty political system is characterized by high power concentration and low authority diffusion. Under such a system, the party's authority and the government's key policy decisions are rarely challenged openly. This neither means that there is no policy disagreement among party elites and government officials, nor that there is no bottom-up resentment from the society. Rather, policy disagreements among party elites and officials are usually aired behind closed doors, as has already been noted. Bottom-up sentiments and misgivings are typically contained and at times suppressed, with individual interests often sacrificed for the sake of social stability. A Vientiane resident reportedly told a foreign reporter that, despite local misgivings, ordinary people 'cannot go against [the railway project] because it's already been decided by the top people and we just have to accept [it]' (Westerman 2019).

\section{The Case of Malaysia: Legitimation in a Multiethnic Quasi- democratic Country}

Among the Southeast Asian cases, Malaysia's engagement with China's BRI has been the most receptive and regionally transformative. However, it has also been repeatedly recalibrated according to changing political circumstances. Malaysia's case displays the agency of the host country in multiple manifestations: mostly in the forms of proactive initiation and active involvement (driven largely by elites' performance and particularistic legitimation), but periodically also in the forms of passive recalibration and active renegotiation. The latter recalibration and renegotiation occur especially when inter-elite contestation and bottom-up resentment combine to increase the imperative for democratic procedural legitimation, compelling the government of the day to recalibrate the country's BRI involvement while correcting the terms of cooperation.

Malaysia's receptivity towards the BRI is evidenced by the extensive presence of China-backed connectivity projects in the multi-ethnic Southeast Asian country. As shown in figure 9.1, Malaysia's BRI engagement covers a broad scope of infrastructure and connectivity projects, including rail 
Figure 9.1 BRI-related projects in Laos, Malaysia, and Thailand

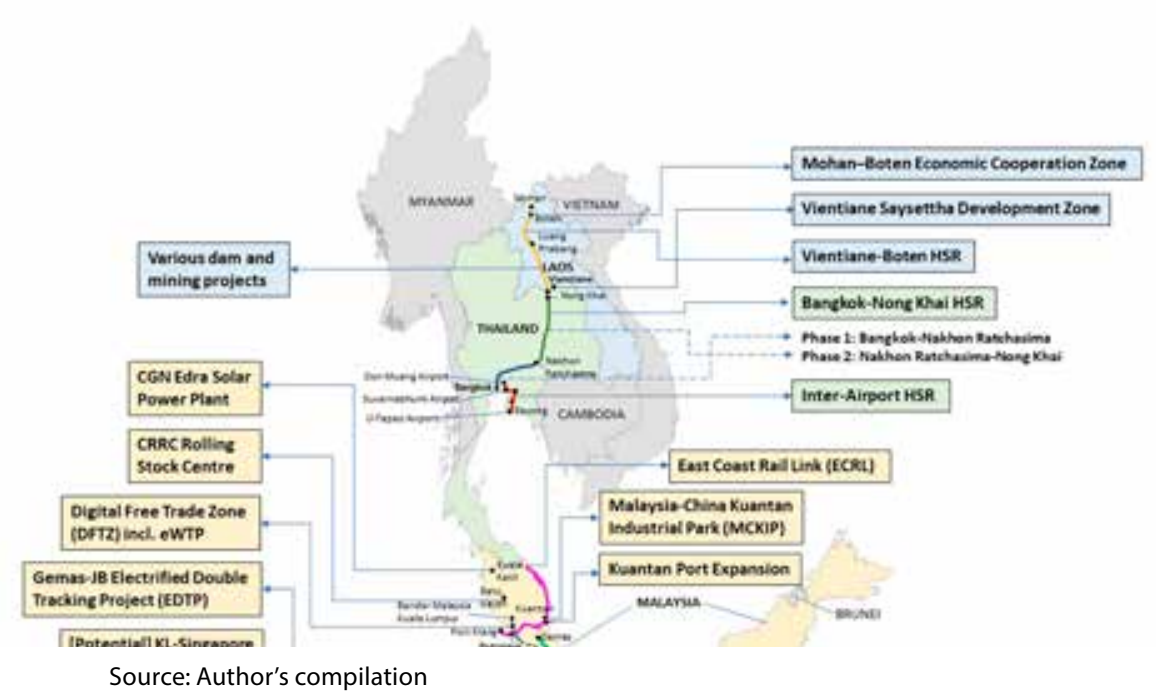

transport and port development, industrial park and manufacturing investment, and solar energy and digital connectivity cooperation. Most of these projects are of large financial and operational scale. Many were initiated and implemented at a speed faster than other regional cases.

Malaysia-China connectivity cooperation is not only the most extensive, it is also among the earliest, predating the BRI. Interestingly, the earlier projects were all initiated by the host country Malaysia, rather than China. These include the Second Penang Bridge project, which was proposed during the Abdullah Badawi premiership (2003-2009), and the Malaysia-China Kuantan Industrial Park (MCKIP), which was initiated under Najib Razak (2009-2018). In late 2006, during a closed-door meeting with his Chinese counterpart Wen Jiabao, Abdullah proposed securing a loan to build the 23-kilometre bridge in his home state Penang. In a matter of months, the two governments had signed a deal paving the way to their first bilateral infrastructure cooperation. In this deal, China provided a US $\$ 800$ million loan, reportedly the largest loan 'for any single project given to a foreign country by China' at that time (Wong 2007; Mazwin 2007). The interest rate was set at $3 \%$ for 20 years, and China waved the $7 \%$ insurance usually applied to developing countries and handled by Sinosure (China Export \& Credit Insurance Corporation, a state-funded and policy-oriented insurance company) (personal communication with Abdullah Badawi's senior aide, 
who was directly involved in Malaysia's dealing with China on the project, 30 April 2020).

The Malaysia-China Kuantan Industrial Park was also proposed by Malaysia. In April 2012, Najib mooted the idea when he was in China launching the Qinzhou Industrial Park (QIP) in Guangxi Zhuang autonomous region. He suggested to his counterpart Wen Jiabao establishing a 'sister industrial park' in Kuantan, the capital of his home state Pahang on the east coast of the Peninsular Malaysia. The proposal came to fruition in less than a year, when the two governments officiated it in February 2013. The Malaysia-China Kuantan Industrial Park and the Qinzhou Industrial Park, known as the 'twin industrial parks', are probably the only BRI-linked 'sister industrial parks' in the region.

The two countries have since forged more infrastructure and connectivity projects. Some of these projects - such as the China Railway Rolling Stock Corporation (CRRC) rolling stock centre, and the controversial East Coast Rail Link (ECRL) - will be regionally transformative. Because of Malaysia's geographical centrality in Southeast Asia (between the continental north and the maritime south, and between the Indian and the Pacific Ocean regions), many of the infrastructure connectivity projects in the country have cross-border regional implications, with planned or potential links extending into neighbouring countries. Besides the Malaysia-China Kuantan Industrial Park-Qinzhou Industrial Park port city links, several other Chinabacked projects in Malaysia also have a significance that extends beyond the bilateral. There are the rail links that will cross northward to link with Thailand and southward with Singapore. There is also a bilateral 'port alliance' that may evolve into a regional network. Then there are the rolling stock manufacturing centre and an Alibaba-backed e-commerce hub that are being established in Malaysia but eyeing ASEAN markets. A growing number of Chinese firms, such as Huawei, China Railway Group (CREC), China General Nuclear Power Group (CGN), and Alibaba, are opening their regional headquarters or hubs in Malaysia.

Despite Malaysian leaders' early embrace of China-backed infrastructure, the BRI has not always been smooth sailing in the country. Far from it, a number of the BRI-linked projects have been reviewed, revised, and even revoked by the Malaysian authorities in recent years, after the stunning return to power of Mahathir Mohamad (1981-2003, 2018-2020) following the May 2018 general election. In fact, as early as 2016, Mahathir, who fell out with Najib and formed the Parti Pribumi Bersatu Malaysia (PPBM), had already openly criticized Najib's various deals with China, warning that they 'may end up threatening Malaysia's sovereignty' (Malaysiakini 2016). 
His attacks intensified during the election campaign period. Once back to office, Mahathir displayed the agency of the host country by announcing his Pakatan Harapan (PH) coalition government's decision to review and eventually suspend three controversial, China-funded, big-ticket deals, namely the East Coast Rail Link (ECRL) and the two pipeline projects in Sabah and Malacca.

Many observers were quick to opine that Malaysia under Mahathir 2.0 was 'pushing back' against Beijing's BRI, 'confronting' China's assertiveness in the South China Sea, and 'resisting' Chinese hegemony in the region. These views are too simplistic. In reality, Mahathir's policy was more complex than widely perceived. Despite his decision to suspend the three projects, Mahathir allowed many other China-related projects, such as the Malaysia-China Kuantan Industrial Park and the Digital Free Trade Zone (DFTZ), to continue. He also repeatedly stressed Malaysia's support for both the BRI and Chinese investments. To underscore these points, he chose to make an early official visit to China in August 2018 (a few months after assuming office), and opted to visit the headquarters of the Chinese tech giants Alibaba and Zhejiang Geely (which owns a 49.9\% stake of Proton, the Malaysian national car maker) in Hangzhou before flying to Beijing. While in China's capital, Mahathir raised the 'unfair deals' and loan issues with Chinese leaders, but put all the blame on Najib's Barisan Nasional (BN) government for the country's debt (Jaipragas 2018; Teoh 2018).

Mahathir's moves were part and parcel of his active 'renegotiation' with China. This renegotiation was not only regarding the controversial contracts but also the two countries' bilateral relations. This exercising of agency is an extension of, and not a departure from, Malaysia's China policy during Mahathir's first tenure (Kuik 2013). It is less about a maverick leader rejecting Chinese power, but more about a smaller state's pragmatic posturing to renegotiate its asymmetric relations with the increasingly powerful neighbour at a time of growing uncertainty. In addition to seeking to reduce the costs and correct the terms of China-funded projects, as was expected by many voters who supported his coalition during the 2018 election, Mahathir was also leveraging Malaysia's decades-long diplomatic cordiality with China and also its geographical advantages for a more favourable, long-term relationship with Beijing.

Such a recalibration is part of the ruling elites' legitimation-optimization efforts, through which they seek to strike a balance between performance, particularistic, and procedural pathways of justification.

Since the early 1970s, performance and particularistic legitimation have motivated Malaysia's development and foreign policies, including its 
longstanding and multifaceted ties with China. Indeed, engaging China and ensuring a stable, productive, and balanced bilateral relationship has been a central component of the country's pragmatic external posture. This pragmatism is due in part to China's economic importance, in part to China's geopolitical clout, and in part to Malaysia's demographic structure: $69 \%$ of the Malaysian population are 'Bumiputera' ('sons of the soil', a term used to refer to Malay Muslims and indigenous peoples), $23 \%$ are Chinese, $7 \%$ Indians, and others. As most local ethnic Chinese are today much more conscious of their national identity as Malaysians (and have a shrinking identity attachment to their ancestral motherland), the growing economic and geopolitical significance of China has become the more important determinant driving Malaysia's policies towards China, rather than identity politics. Indeed, this has become the principal driver behind the successive ruling elites' deepening of Malaysia's pragmatic policy vis-à-vis China.

China has been Malaysia's largest trading partner since 2009. It has also emerged as one of Malaysia's top investors since 2014. This reverses the earlier pattern of bilateral investment ties, when Malaysia was one of the earliest investors in China after Deng Xiaoping launched the 'Reform and Opening-up' policy in 1978. Since the launch of the BRI in 2013 by Xi, Chinese foreign direct investment (FDI) in Malaysia has increased steadily and grew by over $1000 \%$ between 2012 and 2015, spreading over almost every state of the federal country (Ngeow forthcoming; Wan Saiful 2017; Gomez et al. 2020). Chinese investments cover diverse sectors, including manufacturing, real estate, infrastructure, transport, edible bird's nests, and e-commerce (Tham 2018).

A deepening and widening economic engagement with China-including a closer BRI partnership - is politically important to Malaysian ruling elites' development-based performance legitimation and patronage politics. Significantly, it is also a boost to the elites' identity-based particularistic legitimation. Although Malaysia's identity politics have long been constructed and contested along race-based grounds, this does not necessarily extend to external relations. Indeed, Malaysia's BRI engagement, and broader MalaysiaChina economic ties, are shaped less by a simple Malay-versus-Chinese equation and more by a complex political dynamic. That is, Malaysia-China infrastructure ventures are driven and dominated by politically connected forces surrounding leader-centred interest coalitions, e.g. Najib's BN coalition, the Mahathir-led PH bloc, and now (since the political coup in late February 2020) Muhyiddin Yassin's Perikatan Nasional (PN) government. Accordingly, Malay elites - and those politically connected to them - are the principal beneficiaries and key promoters of China-backed projects. 
The local ethnic Chinese are subordinates, partners, or executors of Malaydominated interests and ventures.

These Malay-dominated, identity-based power contestations and the successive ruling polities' patronage politics have combined to push Malaysia to lean towards, not distance itself from, China's economic inducements over the past few decades. Interestingly, the identity-based particularistic legitimation does not just converge with the BRI-related, development-based opportunities horizontally (across ethnic groups, at least at the elite level), but also vertically along federal-state relations. Because the key BRI projects (the Malaysia-China Kuantan Industrial Park, the Kuantan Port expansion, and the East Coast Rail Link) are located in or pass through the east coast states (populated predominantly by the Malays), and because these state governments are all supportive of the infrastructure development projects, the successive federal governments in Putrajaya have viewed these ventures as a platform to pursue both developmental and political purposes (some of these state governments are from the opposing coalition).

The convergence of performance and particularistic justifications aside, Malaysia's BRI engagement is also shaped by procedural legitimation. This distinguishes Malaysia's case from Laos and several other states that have embraced the BRI, where democratic, procedural ideals only play a marginal role. Of course, in semi-democratic Malaysia, procedural justification is not always at the forefront. However, if and when inter-elite struggle escalates and when the public mood swings against nationwide problems that transcend ethnic-based concerns, procedural legitimation would become the centre of political contestation.

This happened during the run-up to the 2018 general election, when the Mahathir-led opposition mobilized grassroots anger against Najib's 1Malaysia Development Berhad (1MDB) financial scandal and certain policies, including the China-backed East Coast Rail Link project, as has been noted above. Once Mahathir won the election and announced the suspension of the three China-funded projects, he made clear to China that renegotiation of those projects was necessary because of Malaysian people's resentments over the excessive debt, the lack of transparency, and other unfavourable terms. The renegotiated deals signed by the two governments in April 2019, which reduced the cost and altered the terms of the East Coast Rail Link while restoring Bandar Malaysia (a China-funded project suspended during Najib years), conferred some procedural legitimacy on the BRI ventures in Malaysia. Thus, democratic sentiments can provide leverage for small states to exercise agency in bargaining with a major power. 


\section{The Case of Thailand: Legitimation in a Military-Ruled Kingdom}

Thailand's partnership with China on BRI-related projects is highly selective, slow, and swiftly swayed by major domestic political vicissitudes such as regime change. Whenever there is a different government in Bangkok, key elements of previously agreed upon arrangements are amended.

Unlike Laos and Malaysia, which maintain BRI partnerships with China that cover several sectors, Thailand's BRI engagement is confined to only one area: high-speed railway (HSR) cooperation. This is manifested primarily in the Bangkok-Nong Khai HSR. Although some would consider the inter-airport HSR (linking Suvarnabhumi and Don Mueang international airports in the capital with U-Tapao airport in Rayong) as another BRIrelated project, most Thai officials and researchers would reject this label, insisting that this - a component of the Eastern Economic Corridor (EEC) - is Thailand's own national project (personal communications with Bangkokbased officials and researchers, January and March 2020). The inter-airport HSR is being developed by a consortium led by a Thai conglomerate, the Charoen Pokphand (CP) Group, which owns a 70\% stake. The China Railway Construction Corporation (CRCC) holds only a $10 \%$ stake in the consortium.

Thailand's BRI involvement is not only limited and selective in scope but also comparatively slow in implementation. Unlike the Laos-China high-speed railway that has been progressing as planned with a definite completion date of December 2021, the Thailand-China high-speed railway has been marked by a long and protracted process of on-again, off-again bargaining, renegotiations, and delayed implementations (Aiyara 2019; Sawasdipakdi forthcoming; Kuik forthcoming). Bilateral talks started under Abhisit Vejjajiva (2008-2011), progressed through Yingluck Shinawatra (20112014), and accelerated - but later dragged on - under the coup-installed Prayut Chan-o-cha government (2014-present). After dozens of rounds of negotiation over the past few years, the high-speed rail project has thus far resulted in the construction of a 3.5-kilometre section of phase one of the project, which is intended to cover the 253-kilometre route between Bangkok and Nakhon Ratchasima, the gateway to Isan, the country's northeast region. Negotiations are still ongoing for the second phase, the 350-kilometre route between Nakhon Ratchasima and Nong Khai on the Thai-Laos border (see figure 9.1), with no concrete date set for the completion of the overall project.

This protracted process is attributable to the third feature of Thailand's BRI engagement: its progress is directly affected by the country's periodic domestic political turmoil. The 2019 general elections did not change this pattern. Whenever there is a change of government, some core components of 
previously negotiated arrangements are altered or abandoned. For instance, the Abhisit administration's 2010 framework for Thailand-China high-speed rail cooperation called for three routes: the first connecting Nong Khai to Bangkok, the second going from Bangkok eastwards to the industrialized Thai Eastern Seaboard, and the third going from Bangkok southward to the Thai-Malaysian border at Padang Besar (AsiaNews 2010). Under the present military-led regime, the first route was retained, the second adapted, while the third was ignored. The regime similarly dismissed Yingluck's 'rice for high-speed rail' programme (Meyer 2014).

Thai patterns of BRI involvement can be puzzling if we consider the key contextual factors that underpin Sino-Thai relations. First, Thailand is a close partner of China, with longstanding bilateral political cordiality and broad cooperation. During the Cold War, the two countries were de facto allies against Vietnam's occupation of Cambodia. Their strategic partnership has extended into the post-Cold War era, with expanding areas of bilateral cooperation ranging from commerce and tourism to military and security domains. Thailand, despite its status as one of the two US treaty allies in Southeast Asia, is the first ASEAN country to have maintained security consultative mechanisms and bilateral military exercises with China. Second, Thailand has been active in promoting intra-regional integration and connectivity building in the ASEAN region and beyond, for example, through the Asia Cooperation Dialogue (ACD) and the Master Plan on ASEAN Connectivity (MPAC). Thailand has considered China as a key partner in nearly all of these endeavours (except perhaps in the Mekong, where China's Lancang-Mekong Cooperation [LMC] is regarded by Thai elites as a rival initiative to its own Ayeyawady-Chao Phraya-Mekong Economic Cooperation Strategy (ACMECS) (personal communications with Thai senior officials and researchers, Bangkok, March 2020). Given the centrality of Bangkok's geographical location, a railroad connecting Thailand with south China and various parts of Southeast Asia will further position it as an indispensable hub for the envisaged Kunming-Singapore rail route and the wider pan-Asian railway networks. Third, Thai elites have generally been receptive to forging rail partnerships with China and this political will converges with development logic on the ground. Given that Isan is one of the less developed areas in Thailand, constructing a rail line linking Isan with Bangkok and northwards to southern China makes long-term developmental sense.

Thai elites' receptivity towards rail cooperation with China can be traced back to the Abhisit years. In a 2017 interview, the former Prime Minister recalled that when his government began negotiations with China on the 
project, what China already had in mind was a regional rail network - a high-speed railway from Yunnan through Laos and Thailand and southward to the Thai-Malaysian border. Abhisit met with the Chairman of the China Railway Engineering Corporation (CREC) during his visit to China in November 2009. Abhisit found the idea of linking south China to Singapore 'an attractive one'. His government began negotiations with the Chinese government but they were not completed by the time he left office (interview with Abhisit Vejjajiva, 30 May 2017).

Considering these converging political and development reasons at various levels, why then is the high-speed rail project still undergoing prolonged negotiation with several rounds of postponed dates?

I would argue that the prolonged negotiations are a result of the Thai elites' continuous attempt to optimize two competing pathways of innerjustifications, namely performance legitimation and particularistic justification. The former necessitates that the Prayut regime forge closer ties with China for both developmental and diplomatic gains (showing that the regime is not isolated internationally, and offsetting Western pressure). Meanwhile, the latter demands that it projects an image of being independent and preserving national autonomy. The more the perceived dependence on China, the greater the need for the regime to project the kingdom's autonomy. As a result, Thailand exercises passive agency by delaying and limiting its BRI engagement.

Like Laos and Malaysia, performance legitimation has been a driver motivating Thailand's successive governments' decisions to engage with China in high-speed rail construction. Indeed, the fact that the military junta called off most of the Yingluck administration's key policies but decided to reinstate the Thai-Chinese rail project is indicative of strong development and political logic, where legitimation drives policy choices. Thai scholar Pavin Chachavalpongpun observes that the military junta is eager for the legitimacy that comes with large-scale infrastructure investment from China at a time when relations with traditional Western partners, especially the US, are strained' (World Politics Review 2017). Another analyst notes that because of the widespread impression that the junta has to look to China for diplomatic and strategic support in the face of the US and EU's criticisms over the military's suspension of democracy, the ruling elite had faced politicized criticism for not driving a harder bargain vis-à-vis Beijing, a not-so-subtle insinuation that the country has grown overly dependent on Chinese succour under his military rule' (Crispin 2016).

Elite legitimation is almost always pursued through multiple routes, particularly for General Prayut Chan-o-cha, the army head who launched a 
coup d'état and seized power in May 2014. As Prayut's military government lacks a democratic mandate, he has considered multiple ways to compensate for the deficit in procedural legitimacy. Projecting developmental aspirations and preserving national autonomy have been the principal pathways to providing inner justification for Prayut and his now defunct National Council for Peace and Order (NCPO). His government has sought to accomplish this through the ambitious 20-year National Strategy (2017-2036) and Thailand 4.0 policy, which involves, among other things, investing in quality infrastructure and leveraging Fourth Industrial Revolution technologies to transform the Thai economy. At the same time, however, the Prayut administration has also turned to identity-based particularistic legitimation. It has sought to resonate with and mobilize the unique 'Thainess' identity and its associated values of autonomy, which have been a salient source of the kingdom's external conduct (Kislenko 2002; Funston 1998), in order to use these as an additional basis of political authority and legitimacy before the domestic audience.

To optimize and balance between performance legitimation and autonomy-based particularistic justification, the military government has therefore been cautious. It has engaged China for developmental gains but without being too compliant vis-à-vis Beijing's preferences. Being too compliant would have further eroded the junta's domestic authority. As such, the Thai negotiators for the Thailand-China high-speed rail project have taken a cautious and firm stance on a number of politically sensitive issues, including financing arrangements, land use, and labour. According to Arkhom Termpittayapaisith, the Transport Minister who led the Thai negotiation team for the project, 'the Chinese wanted everything, just like in Laos'. He added: 'They wanted the right to use the land, the right to develop the station[s] and to import the labour[ers], but what we started with was - this is Thailand, so we will do our part' (Janssen 2018, emphasis added).

Thailand refused China the rights to develop land along the planned route. It rejected the management of the proposed line by Chinese firms. The two countries also disagreed on the interest rate of the loan and the total costs of the project. China put the total costs at 468 billion baht, but Thailand estimated these costs at only 369 billion baht (US\$10.31 billion) (Temphairojana \& Dhanananphorn 2015). As a sign of disagreement between the two sides on the financing plan, Prayut announced in March 2016 that Thailand alone would finance the 250-kilometre Bangkok to Nakhon Ratchashima section through domestic loans, but would use Chinese technology, equipment, and construction firms (Bangkok Post 2016). 
The long-drawn-out delay must have irritated China, leading to China's 'non-invitation' of Thai leaders to the BRI Summit in Beijing in May 2017. The move was described by a Thai scholar as China's 'shame offensive' (Busbarat 2017). Beijing's pressure seemed to have worked. The following month, Prayut exercised his executive power, invoking Article 44 to push through the rail project by waiving legal restrictions, allowing the employment of Chinese engineers for the project and bypassing normal procurement procedures to hire a Chinese state firm to do design work and construction consulting. In the language of legitimation, the government claimed that the special treatment was necessary to clear many legal obstacles faced by the project and in order 'to deepen the bilateral relationship and bring great benefit to people' (Tan 2017).

To strike a balance between the twin pathways of performance and particularistic justification, Thailand's responses to China-related ventures have been selective and uneven. This is discernible when one compares the junta's protracted approach to negotiating the Bangkok-Nong Khai line discussed above with the regime's more decisive push in advancing the inter-airport high-speed rail in the Eastern Economic Corridor (EEC). Although the Eastern Economic Corridor (EEC) mega-project was only launched in mid-2017, Prayut's cabinet and the parliament have fast-tracked the US\$2o billion worth of EEC-related infrastructure, pushing through the ambitious plan before the 2019 election (Janssen 2018). In November 2018, the Thai government awarded the contract to a Charoen Pokphand Group-led consortium. The China Railway Construction Corporation, which holds a minority stake in the consortium, is helping the Charoen Pokphand Group enter the rail business by filling the gap in critical rail technology (Kishimoto 2019). Since the consortium is led by a Thai conglomerate, the development- and autonomy-based pathways converge. Compared to the relatively swift and smooth process in advancing the Eastern Economic Corridor high-speed airport rail link, the junta's approach to the Sino-Thai high-speed rail project - particularly regarding the second phase, the Nakhon Ratchasima-to-Nong Khai portion of track - appear more cautious and selective.

The junta's more concerted and focused efforts in promoting the Eastern Economic Corridor as its 'flagship program to broaden the drivers of economic growth', for instance, may have to do with the fact that the military government views it as 'low-hanging fruit'. It is seen as a relatively easy and fast way for the junta to project its output legitimacy, by promising more tangible progress on the ground (interview with a Thai scholar, Bangkok, 2017). Indeed, the Eastern Economic Corridor - which covers the eastern 
provinces of Chachoengsao, Chonburi, and Rayong - is already among Thailand's best-developed areas, thanks to the successful implementation of the Eastern Seaboard project in the same region two decades ago (Janssen 2018.). It includes Thailand's largest port of Laem Chabang. Further upgrading key infrastructure in the area, especially through the high-speed airport rail link, will be crucial to the junta's goal as part of the Thailand 4.0 agenda of attracting advanced, added-value industries like aircraft, robotics, and nextgeneration automobiles to Rayong and its surroundings (Kishimoto 2019).

\section{Conclusion}

This chapter analyses the agency of the host country in foreign-funded infrastructure connectivity partnerships. Different forms and degrees of agency result in different manifestations of connectivity cooperation. It contends that the patterns of smaller states' BRI involvements are a function of their ruling elites' respective legitimation-optimization efforts. These elites pursue multiple narratives and approaches of inner justification, supplementing and optimizing them in ways that enable the elites to consolidate and broaden their authority at home. The primary pathway of legitimation is crucial because it sets the direction through which ruling elites pursue the corresponding prioritized 'national' goals. It determines the country's relative receptivity towards foreign-backed projects, as evidenced by how successive Lao, Malaysian, and Thai leaders have decided in favour of forging BRI connectivity cooperation with China. Nevertheless, this pathway alone does not explain: 1) why BRI-related projects proceed more smoothly in certain countries (e.g. Laos) than others; 2) why policy reviews or recalibrations might occur among originally enthusiastic countries (e.g. Malaysia under Mahathir 2.0); and 3) why some project negotiations are more protracted than others, and why some partnerships are more limited than anticipated, despite their developmental benefits and bilateral cordiality (e.g. Thailand).

The findings of this study indicate that it is legitimation-optimization processes amid power diffusion that explains the varying patterns and pace of the three countries' BRI engagement. While Lao, Malaysian, and Thai elites have all relied on development-based performance legitimation as their primary pathway of domestic justification, there are important distinctions as to how they pursue this pathway in tandem with differing supplementary, augmenting approaches. In Malaysia and Thailand, where power is more diffuse across the state and society, such legitimation pathway-optimizing processes are moulded and manipulated by inter-elite contestation and the associated grassroots 
mobilization. In Laos, where the power structure is highly centralized, the process is shaped almost exclusively by inter-elite dynamics behind the scenes.

Future studies may further examine to what extent and in what way inter-elite dynamics are a key determinant of host country agency in shaping the prospect and progress of foreign-backed connectivity partnerships. The preliminary observations from this study suggest that the variable can interrupt the functioning of governance and democratic processes (especially those which are inadequately or inappropriately institutionalized), either by strengthening or weakening the checks and balances on a given connectivity project. The greater the power diffusion, the greater the inter-elite narrative competitions and mobilizations, and the higher the likelihood of a project being reviewed, recalibrated, and even disrupted or terminated. More research should be conducted on examining power diffusion at multiple levels, i.e. how political power is distributed among the political elites, between the state and society, and within society, in order to further unpack the relations between elites' legitimation-optimization and the country's patterns of involvement in connectivity cooperation.

\section{Acknowledgments}

The author expresses gratitude to Florian Schneider, Matt Ferchen, and the anonymous reviewer for their useful feedback to improve earlier drafts of this essay. He thanks Lily Sprangers for thoughtful institutional support, as well as Intan Baizura and Atiqah Mokhter for superb research assistantship. Part of this essay is developed from the findings in Rivers of Iron: Railroads and Chinese Power in Southeast Asia (University of California Press, 2020) that the author co-wrote with David M. Lampton and Selina Ho. All shortcomings are the author's own.

\section{References}

Aiyara, Trin (2019). The Rise of China and High-Speed Politics in Southeast Asia: Thailand's Railway Development in Comparative Perspective. $\mathrm{PhD}$ dissertation, National Graduate Institute for Policy Studies.

Alagappa, Muthiah (ed.) (1995). Political Legitimacy in Southeast Asia: The Quest for Moral Authority. Stanford: Stanford University Press.

AsiaNews (2010, October 22). 'Beijing and Bangkok Agree to High-Speed Railway Linking the Two Countries'. AsiaNews. Retrieved 17 November 2020 from http:// 
www.asianews.it/news-en/Beijing-and-Bangkok-agree-to-high-speed-railwaylinking-the-two-countries-19797.html.

Axelrod, R. (ed.) (2015). Structure of Decision: The Cognitive Maps of Political Elites. Princeton: Princeton University Press.

Ba, Alice D. (2019). 'China's "Belt and Road" in Southeast Asia: Constructing the Strategic Narrative in Singapore'. Asian Perspective, 43(2), 249-272.

Bangkok Post (2016, March 24). 'Thailand to Go It Alone on Thai-Sino High-Speed Rail'. Bangkok Post. Retrieved 17 November 2020 from https://www.bangkokpost.com/thailand/general/9o8328/thailand-to-go-it-alone-on-thai-sinohigh-speed-rail.

Beetham, David (1991). The Legitimation of Power. London: Macmillan.

Bottomore, T.B. (1964). Elites and Society. Harmondsworth: Penguin Books.

Busbarat, Pongphisoot (2017). ‘China's “Shame Offensive”: The Omission of Thailand's Prime Minister from the Belt and Road Initiative Summit 2017'. ISEAS Perspective 54, 1-9.

Chengliang, Wu (2016, December 25). 'Construction of China-Laos Railway Officially Commences'. Xinhua. Retrieved 17 November 2020 from http://en.people.cn/ n3/2016/1225/c90000-9158981.html.

Crispin, Shawn W. (2016, April 1). 'China-Thailand Railway Project Gets Untracked'. The Diplomat. Retrieved 17 November 2020 from https://thediplomat. com/2016/04/china-thailand-railway-project-gets-untracked/.

Doig, Will (2018). High-Speed Empire: Chinese Expansion and the Future of Southeast Asia. New York: Columbia Global Reports.

Ferchen, Matt (2016). 'How New and Crafty Is China's "New Economic Statecraft”?' Carnegie-Tsinghua Center for Global Policy, Tsinghua University. Retrieved 29 October 2020 from https://carnegietsinghua.org/2016/03/o8/ how-new-and-crafty-is-china-s-new-economic-statecraft-pub-63002.

Forbes, Dean \& Cutler, Cecile (2005). 'Laos in 2004: Political Stability, Economic Opening'. Asian Survey, 45(1), 161-165.

Funston, John (1998). 'Thai Foreign Policy: Seeking Influence'. Southeast Asian Affairs, 25, 292-306.

Giddens, Anthony (1984). The Constitution of Society: Outline of the Theory of Structuration. Berkeley: University of California Press.

Gilley, Bruce (2009). The Right to Rule: How States Win and Lose Legitimacy. New York: Columbia University Press.

Goh, Evelyn (ed.) (2016). Rising China's Influence in Developing Asia. Oxford: Oxford University Press.

Gomez, Edmund Terence, Tham, Siew Yean, Li, Ran \& Cheong, Kee Cheok (2020). China in Malaysia: State-Business Relations and the New Order of Investment Flow. Singapore: Palgrave Macmillan. 
Howe, Brendan M. \& Park, Seo Hyun Rachelle (2015). 'Laos: The Dangers of Developmentalism?' Southeast Asian Affairs 2015, 165-185.

Jaipragas, Bhavan (2018, August 19). “It Is Not about the Chinese": Malaysia's Mahathir Blames Previous Government for Debt to Beijing and Project Woes'. South China Morning Post. Retrieved 17 November 2020 from https://www.scmp. com/news/china/article/216039o/it-not-about-chinese-malaysias-mahathirblames-previous-government-debt.

Janssen, Peter (2018, October 28). 'Thai Connectivity on Fast-Track under Junta'. Asia Times. Retrieved 17 November 2020 from https://asiatimes.com/2018/10/ thai-connectivity-on-fast-track-under-junta/.

Kishimoto, Marimi (2019, May 29). 'Thai CP Group Wins Government Approval on High-Speed Airport Rail: China Railway Construction to Provide Tech KnowHow for \$7bn Project'. Nikkei Asian Review. Retrieved 17 November 2020 from https://asia.nikkei.com/Business/Companies/Thai-CP-Group-wins-governmentapproval-on-high-speed-airport-rail.

Kislenko, Arne (2002). 'Bending with the Wind: The Continuity and Flexibility of Thai Foreign Policy'. International Journal, 57(4), 537-561.

Kuik, Cheng-Chwee (2013). 'Making Sense of Malaysia's China Policy: Asymmetry, Proximity, and Elite's Domestic Authority'. Chinese Journal of International Politics, 6(4), 429-467.

Kuik, Cheng-Chwee (2020). 'Connectivity and Gaps: The Bridging Links and Missed Links of China's BRI in Southeast Asia'. In Maria Adele Carrai, Jean-Christophe DeFraigne \& Jan Wouters (eds.), The Belt and Road Initiative and Global Governance (pp. 76-95). Cheltenham: Edward Elgar.

Kuik, Cheng-Chwee (forthcoming). 'The Politics of Thailand-China Railway Cooperation: Domestic Determinants of Smaller State BRI Engagement'. In Suthipand Chirathivat \& Anupama Devendrakumar (eds.), China's Rising Influence and Its Belt and Road Initiative: Its Significance, Progress and Challenges for ASEAN. Singapore: World Scientific.

Lampton, David M., Ho, Selina \& Kuik, Cheng-Chwee (2020). Rivers of Iron: Railroads and Chinese Power in Southeast Asia. Oakland: University of California Press.

Li, Mingjiang (2020). 'The Belt and Road Initiative: Geo-economics and Indo-Pacific Security Competition'. International Affairs, 96(1), 169-187.

Lipset, S.M. \& Solari, A. (1967). Elites in Latin America. New York: Oxford University Press. Liu, Hong \& Lim, Guanie (2019). 'The Political Economy of a Rising China in Southeast Asia: Malaysia's Response to the Belt and Road Initiative'. Journal of Contemporary China, 28(116), 216-231.

Malaysiakini (2016, November 2). 'Dr M: Najib's China Deals May Threaten Malaysia's Sovereignty'. Malaysiakini. Retrieved 17 November 2020 from https://www. malaysiakini.com/news/361440. 
Mazwin, Nik Anis (2007, July 14). 'Penang Bridge Loan Deal Signed'. The Star. Retrieved 17 November 2020 from https://www.thestar.com.my/news/nation/2007/07/14/penang-bridge-loan-deal-signed.

Meyer, Eric (2014, September 14). 'The End of the "Chinese Rice for Train Plan" in Thailand, Right?' Forbes. Retrieved 17 November 2020 from https://www.forbes. $\mathrm{com} /$ sites/ericrmeyer/2014/09/14/the-end-of-the-chinese-rice-for-train-plan-inthailand-right/\#32ae85149e1e.

Ngeow, Chow Bing (forthcoming). 'Malaysia and the Belt and Road Initiative: Maritime, Rail, and Digital Connectivity'. In Joseph Chinyong Liow, Hong Liu \& Xue Gong (eds.), Research Handbook of the Belt and Road Initiative. Cheltenham: Edward Elgar.

Parry, Geraint (2005). Political Elites. Colchester: ECPR Press.

Parsons, Talcott (1951). The Social System. New York: Free Press.

Pholsena, Vatthana (2012). 'Laos'. In Michael J. Montesano \& Lee Poh Onn (eds.), Regional Outlook: Southeast Asia 2012-2013 (p. 62). Singapore: Institute of Southeast Asian Studies.

Radio Free Asia (2010, October 21). 'Laos-China Railroad Set for Launch'. Radio Free Asia. Retrieved 17 November 2020 from https://www.rfa.org/english/news/laos/ railway-10202010150808.html.

Reed, John \& Hille, Kathrin (2019, October 30). 'Laos's Belt and Road Project Sparks Questions over China Ambitions'. Financial Times. Retrieved 4 August 2020 from https://www.ft.com/content/a8dobdae-e5bc-11e9-9743-db5a370481bc.

Rolland, Nadège (2017). China's Eurasian Century? Political and Strategic Implications of the Belt and Road Initiative. Washington, DC: National Bureau of Asian Research.

Sawasdipakdi, Pongkwan (forthcoming). 'Thailand and China's Belt and Road Initiative: Strong Will, Slow Implementation'. In Cheng-Chwee Kuik (ed.), Asymmetry and Authority: Southeast Asian Responses to China's BRI.

Sewell, W.H., Jr. (1992). 'A Theory of Structure: Duality, Agency, and Transformation'. American Journal of Sociology, 98(1), 1-29.

The Star (2020, February 15). 'Covid-19 or Not, China-Laos Railway Project Moves on as Planned'. The Star. Retrieved 17 November 2020 from https://www. thestar.com.my/news/regional/2020/02/15/covid-19-or-not-china-laos-railwayproject-moves-on-as-planned.

Tan, Hui Yee (2017, June 17). 'Prayut Fast-Tracks Sino-Thai Rail Project'. Straits Times. Retrieved 17 November 2020 from https://www.straitstimes.com/asia/se-asia/ prayut-fast-tracks-sino-thai-rail-project.

Tappe, Oliver (2018). 'On the Right Track? The Lao People's Democratic Republic in 2017'. Southeast Asian Affairs 2018, 169-183. 
Temphairojana, Pairat \& Dhanananphorn, Manunphattr (2015, December 2). 'Thailand to Sign Rail, Rice, Rubber Deal with China'. Reuters. https://www. reuters.com/article/idUSL3 $\mathrm{N}_{13} \mathrm{R}_{3} \mathrm{HB}_{20151202}$.

Teoh, Shannon (2018, August 16). 'Mahathir to Meet China's Top Leaders on Visit to "Recalibrate" Bilateral Ties, Review Mega Projects'. Straits Times. Retrieved 17 November 2020 from https://www.straitstimes.com/asia/east-asia/mahathirto-meet-chinas-top-leaders-on-visit-to-recalibrate-bilateral-ties-review.

Tham, Siew Yean (2018). 'Chinese Investment in Malaysia: Five Years into the BRI'. ISEAS Perspective, 11, 1-9.

Vilavong, Buavanh (2016). 'Laos in 2015: A Pivotal Year in Moving towards the AEC'. Southeast Asian Affairs 2016, 169-179.

Wahyudi, Eko (2020, March 21). 'Sempat Terhenti, Proyek Kereta Cepat Jakarta-Bandung Lanjut Lagi'. Tempo. Retrieved 17 November 2020 from https://bisnis.tempo.co/ $\mathrm{read} / \mathbf{1 3 2 2 2 1 1} / \mathrm{sempat}$-terhenti-proyek-kereta-cepat-jakarta-bandung-lanjut-lagi.

Wan Saiful, Wan Jan (2017). 'Malaysia's Priority Is to Manage, Not Stop, China's Investments'. ISEAS Perspective, 2017(46), 1-8.

Weber, Max (1947). Theory of Social and Economic Organization. A.M. Henderson \& Talcott Parsons (trans.). New York: Free Press.

Weber, Max (1978). Economy and Society: An Outline of Interpretive Sociology, Volume 1. Guenther Roth and Claus Wittich (eds.). Berkeley: University of California Press.

Westerman, Ashley (2019, April 26). 'In Laos, a Chinese-Funded Railway Sparks Hope for Growth - and Fears of Debt'. NPR. Retrieved 17 November 2020 from https://www.npr.org/2019/04/26/707091267/in-laos-a-chinese-funded-railwaysparks-hope-for-growth-and-fears-of-debt.

Wight, Colin (2006). Agents, Structures and International Relations: Politics and Ontology. Cambridge: Cambridge University Press.

Wong, Chun Wai (2007, July 11). 'RM1.7b Loan from China for Second Penang Bridge'. The Star. Retrieved 17 November 2020 from https://www.thestar.com.my/news/ nation/2007/07/11/rm17bil-loan-from-china-for-second-penang-bridge/.

World Politics Review (2017, May 18). 'Thailand's Junta Sees "One Belt, One Road" as Potential Source of Legitimacy'. World Politics Review. Retrieved 17 November 2020 from https://www.worldpoliticsreview.com/trend-lines/22198/ thailand-s-junta-sees-one-belt-one-road-as-potential-source-of-legitimacy.

Ye, Min (2020). The Belt Road and Beyond: State Mobilized Globalization in China: 1998-2018. Cambridge: Cambridge University Press. 


\section{About the Author}

Cheng-Chwee Kuik is Associate Professor and Head of the Centre for Asian Studies at the National University of Malaysia (UKM)'s Institute of Malaysian and International Studies (IKMAS). He is co-founder of the East Asian International Relations (EAIR) Caucus, a research platform for exchange, engagement, and empowerment among foreign affairs professionals in Malaysia. He served as Head of the Writing Team for the government of Malaysia's inaugural Defence White Paper (2020). Previously, he was a postdoctoral research associate at the Princeton-Harvard China and the World Program (CWP) and a Visiting Research Fellow at Oxford's Department of Politics and International Relations. 


\title{
10 The Two Faces of the China Model
}

\author{
The BRI in Southeast Asia
}

Matt Ferchen

\begin{abstract}
Chapter 10 argues that while analyses of the 'China model' of development have until recently mainly focused on China's domestic economic growth, as China's global role has expanded, especially under Xi Jinping and his signature BRI policy, there is growing interest in whether China seeks to export the China model abroad. Looking at Southeast Asia, the chapter shows that state-led forms of development, especially BRI-related infrastructure finance and construction, are only one aspect of the export of the China model. The chapter provides case studies from Cambodia, Myanmar, and Vietnam (with additional insights from the Philippines) to explore how informal and often illicit aspects of the China model are creating complications for the BRI in host countries and for China itself.
\end{abstract}

Keywords: Belt and Road Initiative, Southeast Asia, China model, Cambodia, Myanmar, Vietnam

This chapter aims to shed new analytical light on how governments, businesses, and civil society organizations in a select number of continental Southeast Asia countries understand and respond to the challenges and opportunities presented by China's Belt and Road Initiative (BRI). In particular, this chapter focuses on a set of Southeast Asian case studies that explore how the BRI is playing out against the broader background of China's economic and political relations with Cambodia, Myanmar, and Vietnam. For purposes of comparison, these cases were chosen because these three countries cover a range of ties to China, and responses to the BRI, that span from close embrace (Cambodia) to on-again, off-again patterns of engagement and antagonism (Myanmar), to frosty reception (Vietnam).

Schneider, Florian (ed.), Global Perspectives on China's Belt and Road Initiative: Asserting Agency through Regional Connectivity. Amsterdam, Amsterdam University Press 2021 DOI: 10.5117/9789463727853_CH10 
This chapter and its findings are meant as a complement to other chapters in this volume, in particular those by Frans-Paul van der Putten and Mirela Petkova (Chapter 8) as well as by Richard Ghiasy (Chapter 11), who analyse Indonesia and South Asia, respectively.

The fieldwork and background research for this chapter revealed two distinct faces of the 'China model' in these Southeast Asian countries. 'The first aspect of the China model is characterized by the prototypical and increasingly well understood, state-led components of the BRI, including Chinese policy bank lending for transport and energy projects that are often then built by Chinese state-owned enterprises (SOEs). ${ }^{2}$ This is the 'state capitalism' version of the China model that has come to dominate perceptions of large Chinese-led infrastructure projects in Southeast Asia and elsewhere, as well as being an important part of the reality of these projects. Yet the other, often far less recognized but nonetheless crucial, aspect of the China model is its 'informal' dimension. This is characterized by small-scale, often non-state, businesses, entrepreneurs, and sometimes outright criminals, who engage in a range of trade, investment, and other speculative commercial ventures that border between the legal and the illegal.

In the context of this volume's shared interest in questions of 'agency' involving different geographic and substantive aspects of the BRI, this chapter's analytical focus on these two 'faces' of the China model offers some key insights. In terms of agency, the basic distinction between the state-led version of the China model and the more informal version highlights a fundamental but still general distinction between different types of Chinese agency. ${ }^{3}$ Within each of these two categories, a variety of actors aim to use or appropriate the BRI for material gain or to signal their loyalty to their superiors. The BRI has therefore opened up multiple channels for

1 Fieldwork for the project consisted of four to seven days of interviews in Cambodia (Phnom Penh) and Myanmar (Yangon and Mandalay) in October of 2019 and in Vietnam (Ho Chi Minh City and Hanoi) in October 2019 and January 2020. The author wishes to thank Cheng-Chwee Kuik for insightful, early feedback on the author's initial musings for this chapter and for introductions in Hanoi. He also wishes to thank the Politikoffee group in Phnom Penh for inspiration for the 'two faces of the China model' theme, which came from a talk with that title that the author presented to the group in October 2019.

2 The focus here is on physical infrastructure in the form of transport and energy projects, but another important aspect is digital infrastructure.

3 For the purposes of this chapter, my focus on 'agency' distinguishes between different types of actors and different perceptions of who or what a 'Chinese' actor is. This conceptualization of agency also applies to the wide range of host country actors, although most of the focus here remains on Chinese actors. 
agency, including a wide range of behaviours that are not sanctioned by or in the interest of the Chinese central government and Communist Party authorities that are overseeing the BRI. In host countries, multiple actors, including government officials, businesses and civil society organizations, also interact with these two 'faces' of the China model. It is often a major challenge for these host country actors to understand, let alone regulate or change, the behaviour of their Chinese counterparts.

In order to more closely explore these issues, this chapter first offers an overview of the BRI and the 'China model'. This includes the domestic political economy background to both of these perspectives and the controversies attending them. The chapter then moves on to the specific case studies, analysing how the two faces of the China model matter for the BRI and broader ties between China and Myanmar, Cambodia, and Vietnam. The chapter then concludes by assessing how the two-faces framework, as it is applied in the main case studies, helps us understand broader questions of agency and development linked to the BRI and China's changing global role.

\section{The China Model and the BRI: Debates and Gaps}

Debates about a state-led versus more grassroots 'China model' of economic development go back nearly a decade before the BRI was introduced (Ferchen 2013). At least in the Anglosphere, the roots of such debates were Joshua Cooper Ramo's 2004 musings about a 'Beijing consensus' that had supposedly emerged to challenge 'Washington Consensus' ideas about economic development best practice and global leadership (Ramo 2004). Such discussions, which in some ways overlapped with ongoing Chinese debates about the proper role of the state in managing China's ongoing 'reform and opening-up' process, then morphed into broader discussions about whether there was an identifiable 'China model' of development. Such discussions picked up steam in the aftermath of the 2008/2009 financial crisis because they highlighted questions and controversies about the roots of China's own economic growth and whether China's experience was applicable to other (mostly developing) countries (Naughton 2010).

One of the key fault lines in such debates about the Beijing consensus or China model was whether or not China's own rapid economic development since the 1980 s was best explained by state-led policies or by non-state forces like markets and entrepreneurs (Huang 2008; Kennedy 2010). While most Chinese leaders were hesitant to publicly proclaim the merits or even existence of a 'Beijing consensus' or 'China model', they were keen to 
emphasize that Party and government leadership allowed for a pragmatic mix of market and state forces that led to 'stable' but dynamic growth. Such advocacy of 'pragmatic' leadership belied heated debates among Chinese scholars and policymakers about whether it was the more state-led or the more market-driven aspects of China's post-Mao development experience that should guide the way to future 'reform' policies (Ferchen 2013)

In the years prior to the announcement of the BRI in 2013, most discussions of the China model were focused on China's domestic economic development experience and its (still largely theoretical) contribution to other developing countries. However, in the decade before the rollout of the BRI, and in part building on the 'Go Out' policies announced in 1998, China was already becoming a major actor in trade, investment, and financial ties to developing country regions like Africa and Latin America, as well as with neighbouring regions like Southeast Asia (Eisenman \& Heginbotham 2018). Against this background, it was again the 2008/2009 financial crisis that spurred interest and controversies focused on China's commercial and political ties to developing countries. In particular, ideas such as 'state capitalism' and 'authoritarian capitalism' were coined to describe, and critique, China's growing role as a partner, and potential role model, for developing countries that at least since the end of the Cold War had often looked to the United States or Europe for policy guidance (McGregor 2012). Applying the concept of 'state capitalism' to China, analysts such as Ian Bremmer highlighted linkages with discussions about the China model by arguing that it was the state-led nature of China's own development path that explained China's continued economic growth and its broader appeal as a commercial and political actor on the global stage (Bremmer 2009).

Thus, by the time of the introduction of the BRI, there was already a wellestablished lineage of ideas, critiques, and debates about the strengths and weaknesses, benefits and threats, of China's state-led version of economic development. With the introduction of the BRI, such debates and concepts came to be grafted onto the BRI itself (Ferchen 2016). From the outset, the rhetoric and policies that Chinese officials have employed in support of the BRI have been state-led. Chinese President Xi Jinping has personally promoted the BRI and it is now widely seen as his signature foreign policy initiative. And whether the BRI is seen largely in symbolic terms through the signing of memoranda of understanding (MoUs) or primarily as an effort to finance and build infrastructure abroad, all such efforts include state-to-state dealmaking and involve a central role for Chinese policy banks and state-owned enterprises (SOEs). Whereas less than a decade ago Chinese officials were largely reticent to tout a statist, China model of 
development as part of China's foreign policy (Ferchen 2013), much of the public diplomacy behind the BRI rests on implicit or explicit claims that China's own state-led effort to build infrastructure at home offers a model for development promotion in BRI partner countries.

Even though Chinese authorities go to great efforts to portray the BRI in a positive light, emphasizing that it is sanctioned at the highest levels of the party-state and relying on project implementation by state banks and firms, the state-led nature of the BRI is also at the heart of many critiques levelled at it from outside of China (Rolland 2017). Such critiques often build on earlier concerns levelled at state capitalism, arguing that China's state-led BRI project is a vehicle for China's broader, mercantilist approach to economic development at home and abroad (Friedberg 2018). In this portrayal, the involvement of Chinese state banks and SOEs, not to mention the state-to-state nature of BRI-linked infrastructure dealmaking, leaves little room for non-Chinese firms to compete in project financing or construction. Moreover, it is often the state-led nature of Chinese-backed transport and energy projects (whether or not tied to the BRI) that is also linked to concerns about lax environmental and labour standards on such projects (Saha 2019). But at a broader, geopolitical level, one of the most important critiques of the BRI to gain traction in recent years is that it is a 'geoeconomic' project in which China, under the guise of 'development' and commerce, is seeking to build political and strategic leverage over its Southeast Asian neighbours and other BRI participants (Ferchen 2017).

The focus on a state-led China model, whether in its domestic guise or in its BRI instantiation, has always had its weaknesses and blind spots. As mentioned above, the original debates about the domestic version of the China model pitted those who argued for the virtues and necessity of state-led growth against critics who argued that it was the unleashing of non-state forces, including market forces, migration, and entrepreneurs, that explained much of China's economic growth and dynamism in the 1980s and 1990s (Huang 2008).

However, such 'state-versus-market' debates (which at the time were framed as New Left versus Neoliberal) always failed to account for the role of more 'informal' actors and behaviours. In fact, the willingness of many market and state actors to ignore, bend, or bargain over the rules and regulations created vast opportunities for behaviours and activities that have long been prevalent in China's domestic economy. From street vendors to knock-off clothing, pharmaceuticals to gambling and speculative real estate investment, a key but often overlooked part of the China model has 
always included behaviours that skirt the line between the legal and the illegal, the regulated and the unregulated, and the orderly and disorderly (Ferchen 2008).

While such debates about the China model were never fully resolved, the conventional wisdom today has coalesced around the overriding importance of the state in China's domestic and foreign political economy (Economist 2020). However, one key ingredient, which was both missing from the earlier China model debates and is almost completely absent from current discussion of the BRI or of China's broader global economic impact, is the role of these 'informal' actors beyond China's own borders. The fieldwork for this project has highlighted that it is in fact a combination of both state-led actors and the more informal actors also important to China's own domestic political economy that are crucial for understanding challenges faced by Southeast Asian countries as well as China. The state-led nature of the BRI and the critiques levelled against it almost completely overlook the importance of the challenges posed by these more informal actors.

\section{The Two Faces of the China Model in Southeast Asia: Evidence from Cambodia, Vietnam, and Myanmar}

Three case studies from Cambodia, Vietnam, and Myanmar will help to better illustrate how the two faces of the China model, the more state-led and the more informal, are shaping China's ties to a subset of countries in continental Southeast Asia. Although the research for this chapter and these case studies began with the explicit intent of analysing understandings and responses to China's BRI in the region, it is this important distinction between the more state-led and more informal aspects of China's role in each country that stood out. While most interviews for this project began with a focus on the BRI, discussions almost all led quickly into the more specific dimensions and challenges illustrated in the following case studies.

Ultimately, though, the BRI does provide a link between the two aspects of the China model. As the research for this chapter shows, Chinese state-led projects and government-to-government ties on the one hand, and more informal kinds of dealmaking on the other, are often linked in sometimes unexpected ways to the BRI. For example, if the symbolic heart of the BRI is largely focused on transport infrastructure projects, it is tempting to simply label any Chinese-backed railway, highway, or port project as a BRI project. Yet most smaller-scale projects, including many energy deals, cannot be 
found on any official BRI project list, but are sometimes nonetheless be portrayed as BRI projects by supporters or critics alike. Indeed, it is the broader policy and diplomatic framework created by many of the more state-led aspects of the BRI that sometimes creates the space and incentives for more informal, and even less well-regulated, types of dealmaking. In other words, the high-profile, state-led nature of the BRI can create opportunities for a wide range of Chinese and host country actors to use and manipulate the name and symbolism of the BRI for a wide range of more informal and illicit aims.

\section{Cambodia and China: Close Ties at the Top, Disruptive Speculation Below}

As with other countries in Southeast Asia, the forces that shape political, commercial and people-to-people ties between Cambodia and China far precede, and overshadow, the BRI (see Mertha 2014). Certainly Cambodia, more than any other country in the ten-member Association of Southeast Asian Nations (ASEAN), has embraced the BRI symbolically through the signing of MoUs and high-level attendance at China's BRI forums, among other obvious signals of approbation (Heng and Chheang 2019). If Chinesebacked infrastructure projects are also the symbolic heart of the BRI, then the Sihanoukville Special Economic Zone (SSEZ) in the Cambodian coastal city, and the planned expressway from the Cambodian capital Phnom Penh to Sihanoukville, certainly underscore the willingness of both countries to promote high visibility, BRI-type projects (Kha 2019). Indeed, on the Cambodian side at least, the SSEZ is clearly claimed as 'a landmark project on [the] "Belt and Road" Initiative' (SSEZ n.d.).

Yet symbolic and substantive cooperation on the BRI and BRI-like projects is just a part of a more comprehensive, state-to-state, and leader-to-leader relationship between Cambodia and China. Under the personalistic leadership of Hun Sen, who has been Cambodian Prime Minister since the 1980s, Cambodia has adopted a foreign policy position aligning itself closely with China. In doing so, Cambodia stands out from the majority of its ASEAN neighbours, most of which have adopted a more balanced approach to ties with China and the United States (Goh 2016). Cambodia, maybe only second to Pakistan, has adopted a diplomatic approach toward China meant to signal a deep and abiding camaraderie if not alliance. Assessments that Cambodia is a 'client state' of China certainly underestimate Cambodia's own strategic decisions while also underestimating China's 'geoeconomic' influencing prowess (West and 
Po 2019). Yet the reality of close, state-to-state, Cambodia-China ties, and personalistic links between Hun Sen and Xi Jinping, are nonetheless frequently touted by each side. ${ }^{4}$

Such close, high-level relations between Cambodia and China have facilitated a flood of dealmaking. Again, the most high-profile, 'official' BRI project is in Sihanoukville, which is a comprehensive 'special economic zone' that includes a port and hosts a wide range of businesses, including factories as well as casinos. However, high-level political ties have also facilitated a broad spectrum of China-financed and China-built projects, including both transport infrastructure (such as roads and bridges) as well as energy infrastructure (such as dams and power plants). In addition to larger scale and officially sponsored projects, the China Chamber of Commerce, with branches in different cities, including Phnom Penh and Sihanoukville, has played an active role as a go-between for Chinese business and projects around the country (interviews, Phnom Penh, March 2016).

Large-scale Chinese financed and built transport and energy infrastructure projects have elicited no shortage of concerns from Cambodian and international civil society organizations, especially those focused on environmental and local community impacts (Tower 2017). There are also broader concerns about the financial and debt sustainability of China-backed projects in Cambodia. Such concerns share much in common not just with those raised in other countries in the Mekong region and in Southeast Asia, but also in resource-rich parts of Latin America and Africa (see Ferchen on China and Latin America, Chapter 5 in this volume). Notably, high-profile infrastructure projects are generally the focus of both Chinese and host country efforts to highlight their support for the BRI, but they are also the subject of criticism and pushback by local citizens, international NGOs, and other countries. Yet in Cambodia it is not necessarily the state-led, high-profile elements of Chinese BRI and BRI-type activities that are turning out to be most disruptive or drawing the most ire and criticism.

In fact, more than any country in this research project, the more informal side of the China model is on full, and highly disruptive, display in Cambodia. Again, Sihanoukville stands out in this regard as by now the most wellknown and increasingly infamous example of the potentially destabilizing outcomes of 'Chinese' investment in Cambodia. For example, prior to a Cambodian government crackdown in August 2019, much of the Chinese

4 See the symbolism of Hun Sen's recent visit to China during the height of China's battle with the Coronavirus (Bong 2020). 
economic activity in Sihanoukville was focused on gambling - both online and in casinos - an activity that is illegal in China itself but that had been allowed in Cambodia (Murg 2019). Linked to the gambling activities, real estate speculation by Chinese citizens in Sihanoukville had also led to a real estate bubble, which burst in the aftermath of an August 2019 crackdown (Hutt 2020). While not as directly or obviously linked to semi-licit gambling activities, a great deal of real estate investment and construction in Phnom Penh has also been driven by the speculative activities of Chinese firms and individuals (interviews, Phnom Penh, 24-25 October 2019; Heijmans 2018). Ultimately, the August 2019 crackdowns on online gambling in places like Sihanoukville and border towns like Bavet, mandated by Hun Sen but supported by Beijing, were linked to a growing sense that such speculative, semi-licit or outright criminal behaviour was also a threat to Chinese citizens and China's reputation (Murg 2019). Yet such speculative, borderline illegal behaviour by Chinese citizens and firms in Cambodia has also had the effect of creating a rising sense of anti-China and anti-Chinese sentiment in Cambodia (Dunst 2019).

In order to understand the implications that derive from the impact of the two faces of the China model in Cambodia, both in terms of perceptions and responses, it is important to understand the linkages between them. Unlike the other two countries explored for this project, Myanmar and Vietnam, Cambodia does not share a border with China. Yet it is the high-level, close diplomatic and political relationship that has not just led to the promotion of BRI signature projects like the Sihanoukville Special Economic Zone, but has also paved the way for the wide range of more speculative and semi-legal behaviour that has flowed in its wake. In Cambodia, close, high-level, state-to-state relations have led to the branding of Sihanoukville as a BRI project and unleashed forces on both sides that have been highly disruptive in ways that an exclusive focus on just the state-led aspects of the BRI and China model would miss. Certainly, many other forces are at play in determining why Cambodia has promoted such an unregulated, open-door policy for a wide range of Chinese actors and why so many 'Wild West' and insalubrious Chinese speculative activities have found such fertile ground in Cambodia. Primary among the latter is Cambodia's dollarized economy, yet the outcome of such a confluence of interests and incentives is that both Cambodia and China find themselves confronting a situation that is potentially explosive and difficult to regulate. Only by understanding both faces of the China model, and in this case how the BRI is a bridge between the two, can we fully make sense of these challenges. 


\section{Vietnam: Giving the BRI the Cold Shoulder?}

If Cambodia is generally seen as the Southeast Asian country with the cosiest relationship with China, including the Cambodian government's official willingness to support the BRI rhetorically and in practice, then Vietnam is generally seen as the polar opposite. As with Cambodia, the underlying reality is far more complex, as the fieldwork for this chapter revealed. Like all of China's Southeast Asian neighbours, history, culture, and the structure of economic and political relations between Vietnam and China are crucial background to understanding how the BRI is playing out in Vietnam. Even though there is indeed a reluctance on the part of the Vietnamese government to voice anything like full support for the BRI, and even though Vietnam-China ties are often noted for their frostiness or even outright confrontational nature, Vietnam is not a vocal critic of the BRI per se. As in the case of Cambodia, the details of what is taking place below the surface of formal diplomatic ties as well as more complex on-the-ground outcomes reveal a range of dealmaking and related challenges.

As with the other countries explored in this chapter, the BRI is often but a marginal element in a more variegated set of political and economic issues that shape the Vietnam-China relationship. As fieldwork revealed, despite Vietnam's sceptical-but-not-confrontational approach to the BRI, aspects of the more informal side of the China model also play an important, and increasingly disruptive, role in the Vietnam-China relationship. In particular, Chinese-financed and/or built coal-fired power plants, which are associated with the BRI elsewhere (Saha 2019; Gallagher 2017), are filling a demand for energy to fuel Vietnam's dynamic economy (Wang 2020). Yet crucially, in Vietnam, these deals are part of more informal, unregulated dealmaking with various unintended and unwanted outcomes.

At the level of formal diplomatic and political ties, and despite being two of only a small handful of remaining countries ruled by communist parties, Vietnam-China relations have long been far from smooth. Such tensions have deep historical roots, both of the older and more recent varieties. Yet if Cambodia is seen (over-simplistically) as a client state of China, then Vietnam is often seen as China's primary Southeast Asian geopolitical antagonist. Undoubtedly tensions over the South China Sea have long played a central role in difficult Vietnam-China relations (Hayton 2015). Given this image of often-tense bilateral relations with China, it would be reasonable to expect Vietnam to be the leading Southeast Asian critic of the BRI and to reject outright any association with it. 
Yet the reality is more complex: Vietnam has not so much rejected or sought to directly set itself up as a critic of the BRI (in contrast with, say, India, for instance). Instead, it has chosen to 'slow-walk' its response. Interviews (Ho Chi Minh City, October 2019; Hanoi, January 2020) revealed that at least at the diplomatic level, Vietnamese foreign policy officials felt that choosing an assertively critical stance toward the BRI may exacerbate existing tensions in the relationship, including over the South China Sea. Interviews also highlighted that while certainly not embracing the BRI in rhetoric or practice, Vietnam has adopted a two-pronged approach to infrastructure cooperation with China. The first prong involves a willingness to highlight rail transport infrastructure networks connecting parts of Northern Vietnam with Guangxi and Yunnan Provinces in China. The other is green-lighting a few high-profile, China-linked infrastructure projects in Hanoi itself, including part of the Hanoi subway.

Yet neither the northern railway links nor the Hanoi subway project are explicitly listed as BRI projects. Moreover, especially the Hanoi subway project has turned into a bit of a debacle as it is late, over budget, and seen by many Vietnamese in the capital as unsafe (interview, Hanoi, 14January 2020; Duy 2019). And while these northern projects might at least give a sense of BRI-type cooperation on transport infrastructure projects, in Ho Chi Minh City in the south there is a clear and symbolic embrace of Japanese alternatives, including in city subway projects (interview, Ho Chi Minh City, 4 October 2019). Moreover, Chinese efforts to try to promote special economic zones (SEZs) designed to facilitate 'industrial capacity cooperation' in various parts of the border have triggered concerns that such projects may be threats to Vietnamese sovereignty (interviews, Hanoi, 13 January 2020).

Whilst at the more state-to-state level Vietnam has adopted a nonconfrontational approach to BRI engagement with China, even while dragging its feet in actual transport infrastructure dealmaking, there has been more active dealmaking in the area of energy infrastructure. Yet such dealmaking has not principally been of an official state-to-state nature, like much of China's energy financing elsewhere in BRI and non-BRI settings (Kong and Gallagher 2017). Instead, it has consisted of more small-scale, informal dealmaking in response to rapidly expanding Vietnamese energy demands. While certainly different from the scale and nature of gambling and speculative real estate deals in Cambodia, Chinese involvement in coal-fired power plant deals in Vietnam has also often been semi-licit. It has also frequently been in violation of Vietnamese environmental regulations or national strategies for capping fossil-fuel power generation while promoting more sustainable energy generation (Malczyk \& Robinson 2019). At the same 
time, interviews (Ho Chi Minh City, October 2019; Hanoi, January 2020) highlighted that some of this semi-licit or outright illegal dealmaking for coal-fired power plants has been facilitated by Party or government contacts at national and local levels. Interviews also revealed a growing sense of displeasure about such Chinese-linked dealmaking among a Vietnamese society already leery of its larger neighbour.

Thus, while clearly not part of the BRI in a formal sense, coal-fired power plant deals between Chinese and Vietnamese counterparts reveal the important, responsive (to demand and/or poor regulation), but potentially disruptive outcome of the more informal part of the China model. The same sort of entrepreneurial spirit that has long been at play in reform-era China and Vietnam (Abrami et al. 2013), which has included a willingness by some businesses as well as officials to skirt, bend, or bargain over the rules, is in many ways a more prominent part of the China-Vietnam infrastructure relationship than the more formal, state-to-state part. That said, it seems clear that the kind of unregulated free-for-all that defines important parts of the Cambodia-China relationship is not at play in the Vietnam-China relationship. This is despite the fact that China and Vietnam share a long border whereas China and Cambodia share none. In fact, when asked about this issue in particular, interviewees (Hanoi, January 2020) noted that, as a result of the generally sceptical attitude of the Vietnamese government and population toward China, the Vietnamese security services kept generally close tabs on the behaviour of Chinese citizens in Vietnam.

\section{Myanmar and China: Challenge of the Two Faces}

If Vietnam and Cambodia have adopted contrasting official reactions to China's BRI, yet both confront regulatory and political challenges tied to the more informal aspects of the China model, then Myanmar falls squarely in between. At the level of formal, diplomatic relations, Myanmar-China ties have been on a roller coaster since at least 2011, but certainly far before that as well (Steinberg 2009). Myanmar's official responses to the BRI have been conditioned by the vicissitudes of this often-rocky diplomatic relationship and by criticisms and controversies surrounding Chinese mining and energy infrastructure investments that predated the introduction of the BRI. Moreover, Myanmar's long and complicated experience with the more informal side of the China model also places it somewhere between the Cambodian and Vietnamese examples.

In 2011, and just prior to the introduction of the BRI in 2013, MyanmarChina relations came in for a course correction. It was around this time that 
momentous domestic changes in Myanmar's military junta-led government were taking place as the military gradually began to open up the political system as well as to move the country away from semi-autarky and international pariah status. Prior to 2011, China was a rare source of diplomatic support for the Myanmar military regime and Chinese government officials and businesses built on these ties with the Myanmar military to develop a range of mining and energy investment projects in Myanmar (Steinberg 2009). Yet as the domestic and foreign policy reforms picked up pace around 2011, China's previously privileged diplomatic and investment positions in Myanmar became a liability and source of friction. At least in geopolitical terms, there was a sense that Myanmar had become overly dependent on China economically and diplomatically. It was the Chinese-invested Myitsone Dam project, which the Myanmar government put on hold in 2011 (Fuller 2011), that symbolically kicked off Myanmar's foreign policy recalibration away from this perceived overdependence on China and toward more openness in general, including improved diplomatic and economic ties to the United States and Europe, in particular.

It is against this background that any symbolic or substantive cooperation on, or criticism of, the BRI and BRI-like projects has played out in Myanmar. Critics of Chinese claims that the BRI is merely a commercial or development project, and those who point to underlying strategic calculations, often cite evidence from Chinese-led projects in Myanmar. For example, both the oil and gas pipelines crossing Myanmar into China's bordering Yunnan Province and a project for a large port and special economic zone (SEZ) on Myanmar's Andaman coast are often cited as examples of China's geostrategic designs behind large infrastructure projects in the region (Marston 2020). The latest grand project, the China-Myanmar Economic Corridor (CMEC), is seen in a similar light and sometimes compared to the similarly named China-Pakistan Economic Corridor (CPEC). Yet for all the strategic calculations that might factor into the official support given by Myanmar and China to such projects, interviews (Yangon and Mandalay, October 2019) revealed that the perception that these projects are a clear sign of an unproblematic return to close political and geostrategic cooperation between China and Myanmar misses a far messier reality.

First, while the Myanmar government has recently signalled various forms of support for the BRI at a diplomatic and symbolic level (Reed 2020), actual BRI-branded deals are few and far between. None of the major projects listed above are officially BRI projects, at least not from the Myanmar government's official point of view. Moreover, previous or ongoing Chinesebacked gas and oil pipeline and port projects have run into a range of similar 
challenges to smaller-scale mining and dam projects. Namely, corporate social responsibility-type (CSR) issues, such as unsustainable environmental and local community impacts, have elicited civil society organizations' criticism and efforts to change or halt various deals (interviews, Yangon, March 2016 and October 2019). Concerns about environmental and local community impact in the still-unresolved conflict over the Myitsone Dam were directly tied to such CSR issues. Moreover, energy and transport projects that are designed to run from Myanmar into Yunnan confront the challenges of investing in, and building projects through, active conflict zones along Myanmar's border with China or in Rakhine State (Tower 2017). Recently, concerns about debt sustainability have come to play a role in discussions about the Kyaukpyu Port and special economic zone project in Rakhine State (interviews, Yangon, October 2019). So, from very bottom-up, civil society concerns to broader questions of project finance or even sovereign debt sustainability, it is not obvious that proposed Chinese infrastructure projects or other kinds of investments in natural resources will proceed smoothly or at all.

Many of the issues that have long troubled Chinese investments in Myanmar's infrastructure and natural resources are in some sense typical of the kinds of problems that similar Chinese state-led projects have run into in other developing countries in regions like Latin America and Africa. Concerns about unsustainable environmental, social, and debt impacts linked to Chinese projects are a frequent theme, especially among researchers and civil society organizations focused on Chinese BRI-type infrastructure investments and construction projects in these regions. Yet Myanmar has also long been a kind of ground zero for concerns about the more informal aspects of the China model.

Long before the inauguration of the BRI or the controversy about the Myitsone Dam, a key facet and trouble-spot in Myanmar-China relations was illicit border trade. Since the late 199os, researchers, journalists, and social activists from China and beyond have focused on the proliferation of the cross-border trade in jade, teak, heroin, and exotic animals, to name just some. Ruili, in China's Yunnan Province, which borders with Myanmar, has long been notorious as a trans-shipment point for such products and synonymous with lax border restrictions (Aspinwall 2019). To what extent such semi-licit or illicit trade was a product of 'Chinese' presence in Myanmar was always difficult to separate from the often-shadowy and historically complex connections between military leaders in Myanmar's 'cease-fire' zones along the border with China and the Chinese military or local government officials or traders. Adding to the infamous reputation 
of such 'Chinese' dealmaking in the border region is the reputation that Myanmar's second-largest city, Mandalay, has as a kind of Chinese outpost (Perlez 2016). Perceptions of Chinese 'domination' of Mandalay were around well before the emergence of the BRI. However, they have taken on a different dimension as plans for the China-Myanmar Economic Corridor envision Mandalay square along its path (to Kyaukpyu as the envisioned end point) (interviews, Mandalay, October 2019).

The realities and perceptions of the more informal aspects of Chinese commercial presence in Myanmar, either with respect to illicit border trade or Chinese control or domination of Mandalay, have always been linked to the complexities of identity, immigration, and politics in the region. The basic question of who is 'Chinese' in the more informal types of trade or investment relationships with Myanmar is often assumed rather than more closely explored by many in Myanmar as well as by outside observers (Gordon n.d.). Are border traders who have long gone back and forth between Yunnan and China just as 'Chinese' as the central or even provincial level state-owned enterprises making some of the bigger infrastructure deals (Scott 2010)? Are Mandalay traders and investors of Chinese background or ethnicity, going back potentially hundreds of years, to be understood in the same light as the Chinese citizens or speculators who are doing real estate and online gambling deals in Cambodia?

Despite the complexity of the answers to such questions, in Myanmar the public reaction to 'Chinese' commercial presence and political influence in the country has often involved a conflation of the more informal and more formal 'faces' of the China model. At the same time, some PRC citizens, as well as others with more tenuous connections to China or 'Chineseness', have found opportunities to leverage the ambiguity and popularity of the BRI to promote their more informal or outright illegal activities as part of the BRI. In fact, one of the key players in the online gambling activities in the Cambodian city of Sihanoukville, She Zhijiang, has already moved to Myanmar, and has often argued that his activities as the chairman of Yatai International Holding are part of the BRI (Nachemson 2020). ${ }^{5}$ Myanmar, as much as any country in Southeast Asia or the world, has long been on the front lines of the two faces of the China model. As such, it has been a kind of ongoing experiment in what forms 'agency' takes. In all three cases here, it is the official, state-led face of the China model and of the BRI that makes

5 The She Zhijiang case is ongoing as of the time of this writing and the Chinese government has issued a high-profile and rare rejection of She and Yatai's connection to the BRI. See Frontier Myanmar (2020) and Tang, et.al. (2020). 
it possible for a wide range of informal actors, be they Chinese citizens or not, to portray themselves or be perceived as 'Chinese'. In this context, the BRI underscores what a complex, shifting, and increasingly politicized concept 'agency' has become for all those attempting to understand China's global role and impact.

\section{Conclusion}

This chapter has proposed that there is analytical and practical value to the 'two faces of the China model' conceptual framework. The BRI is most often promoted (by China) and understood (by many outside of China) as a foreign policy initiative, or strategy, that has been formulated and implemented by a unitary Chinese state. In this sense, the BRI is a symbolic distillation of a kind of conventional wisdom about Chinese 'state capitalism' that predated the BRI itself. This wisdom held that China is a strategic, unitary actor. However, the case studies presented here highlight that whether or not the BRI per se is central to the kinds of commercial and diplomatic relations with China's continental Southeast Asia neighbours, the actors or agents associated with 'China' come in at least two, quite different forms. Those actors linked to the state, such as China's policy banks or state-owned enterprises (SOEs), have by now been quite well scrutinized if not always fully understood. However, the more informal actors and behaviours that have played such a key role in China's own political economy during the last 40 years have generally not been included in scholarship or policy analysis of the China model or the BRI, in particular.

This chapter has also highlighted that the two faces of the China model can come together in important and unexpected ways that impact how we understand questions of agency. Under the rubric of the BRI, for example, semi-legal Chinese online gambling operations in Cambodia can be promoted by unscrupulous entrepreneurs/criminals as part of the BRI. Prohibitions on the development of coal-fired power plants in Vietnam can be avoided through under-the-table arrangements between Chinese and Vietnamese government officials and business people. Or, in the case of Myanmar, the very question of who is and is not 'Chinese' can impact government and citizen responses to both major infrastructure projects as well as smaller-scale, illicit boarder trade. However, it is in Cambodia, where close political relations and state-to-state BRI infrastructure dealmaking seem to facilitate economically and socially disruptive and poorly regulated informal activities, where the regulatory challenges for all involved are 
most daunting. Ultimately, how the Chinese and host governments and societies understand these two distinct, but related, aspects of the China model will have a decisive impact on how they regulate those actors and on subsequent developmental outcomes.

\section{References}

Abrami, Regina M., Malesky, Edmund \& Yu, Zheng (2013). 'Vietnam through Chinese Eyes: Divergent Accountability in Single-Party Regimes'. In Martin Dimitrov (ed.), Why Communism Did Not Collapse: Understanding Authoritarian Regime Resilience in Asia and Europe (chap. 9). Cambridge: Cambridge University Press. Aspinwall, Nick (2019, September 11). 'On the Border of China and Myanmar, Commerce and Consternation'. SupChina. Retrieved 2 October 2019 from https:// supchina.com/2019/og/11/on-the-border-of-china-and-myanmar/.

Bong, Chansambath (2020, February 24). 'Hun Sen's Political Gamble: The COVID-19 Epidemic'. Japan Times. Retrieved 26 February 2020 from https:// www.japantimes.co.jp/opinion/2020/o2/24/commentary/world-commentary/ hun-sens-political-gamble-covid-19-epidemic/\#.XoTBMZP7Q6Y.

Bremmer, Ian (2009, May/June). 'State Capitalism Comes of Age: The End of the Free Market?' Foreign Affairs.

Dunst, Charles (2019, November 25). 'Where China Isn't Sending Its Best and Brightest'. Washington Monthly. Retrieved 3 December 2019 from https://washingtonmonthly.com/2019/11/25/where-china-isnt-sending-its-best-and-brightest/.

Duy, Anh (2019, October 3). 'Hanoi Metro Route Safety Check Far from Complete: Experts'. VNExpress International. Retrieved 8 June 2020 from https://e. vnexpress.net/news/business/economy/hanoi-metro-route-safety-check-farfrom-complete-experts-3991095.html.

Economist (2020, August 15). 'The New State Capitalism: Xi Jinping Is Trying to Remake the Chinese Economy'. The Economist. Retrieved 17 August 2020 from https://www.economist.com/briefing/2020/08/15/xi-jinping-is-trying-to-remakethe-chinese-economy.

Eisenman, Joshua \& Heginbotham, Eric (eds.) (2018). China Steps Out:Beijing's Major Power Engagement with the Developing World. New York: Routledge.

Ferchen, Matt (2008). Regulating Market Order in China: Economic Ideas, Marginal Markets and the State. $\mathrm{PhD}$ thesis, Cornell University.

Ferchen, Matt (2013). 'Whose China Model Is It Anyway? The Contentious Search for Consensus'. Review of International Political Economy, 20(2), 390-420.

Ferchen, Matt (2016). 'How New and Crafty Is China's "New Economic Statecraft"?' Carnegie-Tsinghua Center for Global Policy, Tsinghua University. Retrieved 
29 October 2020 from https://carnegietsinghua.org/2016/03/08/how-new-andcrafty-is-china-s-new-economic-statecraft-pub-63002.

Ferchen, Matt (2017, August 29). 'China, Geoeconomics, and the Problem of Leaderless Thought'. China-US Focus. Retrieved 29 August 2017 from https://www. chinausfocus.com/finance-economy/china-geoeconomics-and-the-problemof-leaderless-thought.

Friedberg, Aaron L. (2018). 'Competing with China'. Survival, 6o(3), 7-64.

Frontier Myanmar (2020, July 27). 'Shwe Kokko is 'Not Part of BRI' Says Developer Yatai'. Frontier Myanmar. Retrieved 29July 2020 from https://www.frontiermyanmar.net/en/shwe-kokko-is-not-part-of-bri-says-developer-yatai/.

Fuller, Thomas (2011, September 30). 'Myanmar Backs Down, Suspending Dam Project'. New York Times. Retrieved 16 April 2013 from https://www.nytimes. com/2011/10/o1/world/asia/myanmar-suspends-construction-of-controversialdam.html.

Gallagher, Kevin P. (2017, March). ‘China Global Energy Finance: A New Interactive Database'. Global Economic Governance Initiative Policy Brief 002.

Goh, Evelyn (2016, February 22). 'Southeast Asian Strategies toward the Great Powers: Still Hedging after All These Years?' The Asan Forum. Retrieved 25 September 2019 from http://www.theasanforum.org/southeast-asian-strategiestoward-the-great-powers-still-hedging-after-all-these-years/.

Gordon, Josh (n.d.). 'Myanmar and the Dream of the Golden Land'. Department of Anthropology, Yale University. Retrieved 20 July 2013 from https://www. academia.edu/2200899/Myanmar_and_the_Dream_of_the_Golden_Land.

Hayton, Bill (2015). The South China Sea: The Struggle for Power in Asia. New Haven, CT: Yale University Press.

Heijmans, Philip (2018, September 10). 'Chinese Money Is Driving One of Asia's Fastest Property Booms'. Bloomberg. Retrieved 8 January 2019 from https:// www.bloomberg.com/news/features/2018-o9-10/chinese-money-is-driving-aproperty-boom-in-cambodia.

Heng, Pheakdey \& Chheang, Vannarith (2019). 'The Political Economy of China's Maritime Silk Road Initiative in Cambodia'. In Jean-Marc F. Blanchard (ed.), China's Maritime Silk Road Initiative and Southeast Asia:Dilemmas, Doubts, and Determination (pp.163-19o). Singapore: Palgrave Macmillan.

Huang, Yasheng (2008). Capitalism with Chinese Characteristics: Entrepreneurship and the State. Cambridge: Cambridge University Press.

Hutt, David (2020, February 27). 'Chinese Exodus Pinpricks Cambodia Property Bubble'. AsiaTimes. Retrieved 3 March 2020 from https:/asiatimes.com/2020/02/ chinese-exodus-pinpricks-cambodia-property-bubble/.

Kennedy, Scott (2010). 'The Myth of the Beijing Consensus'.Journal ofContemporary China, 19(65), 461-477. 
Kha, Sok (2019, April 30). 'The Belt and Road in Cambodia: Successes and Challenges'. The Diplomat. Retrieved 12 September 2019 from https://thediplomat. com/2019/04/the-belt-and-road-in-cambodia-successes-and-challenges/.

Kong, Bo \& Gallagher, Kevin P. (2017). 'Globalizing Chinese Energy Finance: The Role of Policy Banks'. Journal of Contemporary China, 26(108), 834-851.

Malczyk, Brian \& Robinson, Tim (2019, July 10). 'Vietnam Needs to Break Its Addiction to Chinese Coal'. The Diplomat. Retrieved 18 November 2019 from https://thediplomat.com/2019/07/vietnam-needs-to-break-its-addiction-to-chinese-coal/.

Marston, Hunter (2020, January 20). 'Has the US Lost Myanmar to China? Xi's Visit Bolstered China-Myanmar Ties, but the West Can Still Compete'. The Diplomat. Retrieved 25 January 2020 from https://thediplomat.com/2020/o1/ has-the-us-lost-myanmar-to-china/.

McGregor, James (2012). No Ancient Wisdom, No Followers: The Challenges of Chinese Authoritarian Capitalism. Westport, CT: Prospecta Press.

Mertha, Andrew (2014). Brothers in Arms: Chinese Aid to the Khmer Rouge, 1975-1979. Ithaca: Cornell University Press.

Murg, Bradley J. (2019, September 5). 'How Cambodia's Online Gambling Ban Sparked the Great Chinese Exodus of 2019 - and Why Beijing Is Fine with It'. South China Morning Post. Retrieved 13 November 2019 from https://www. scmp.com/comment/opinion/article/3025687/how-cambodias-onlinegambling-ban-sparked-great-chinese-exodus-2019.

Nachemson, Andrew (2020, July 7). 'The Mystery Man behind the Shwe Kokko project'. Frontier Myanmar. Retrieved 20 July 2020 from https://www.frontiermyanmar.net/en/the-mystery-man-behind-the-shwe-kokko-project/.

Naughton, Barry (2010). 'China's Distinctive System: Can It Be a Model for Others?' Journal of Contemporary China, 19(65), 437-460.

Perlez, Jane (2016, November 27). 'Animosity in a Burmese Hub Deepens as Chinese Get Richer'. New York Times. Retrieved 28 November 2016 from https://www. nytimes.com/2016/11/27/world/asia/mandalay-china-myanmar-trade.html.

Ramo, Joshua Cooper (2004). The Beijing Consensus. London: Foreign Policy Centre. Reed, John (2020, January 18). 'China and Myanmar Sign off on Belt and Road Projects'. Financial Times. Retrieved 3 February 2020 from https://www.ft.com/ content/a5265114-39d1-11ea-ao1a-bae547046735.

Rolland, Nadège (2017). China's Eurasian Century? Political and Strategic Implications of the Belt and Road Initiative. Washington, DC: National Bureau of Asian Research.

Saha, Sagatom (2019, August 18). 'China's Belt and Road Plan Is Destroying the World'. National Interest. Retrieved 22 August 2019 from https://nationalinterest. org/feature/chinas-belt-and-road-plan-destroying-world-74166.

Scott, James (2010). The Art of Not Being Governed: An Anarchist History of Upland Southeast Asia. New Haven, CT: Yale University Press. 
SSEZ (n.d.). Cambodia Sihanoukville Special Economic Zone. Retrieved 22 March 2020 from http://www.ssez.com/en/.

Steinberg, David (2009). Burma/China: What Everyone Needs to Know. Oxford: Oxford University Press.

Tang, Ailin; Fan, Wenjun; Liang, Shuting \& Han, Wei (2020). 'A Fugitive Businessman's High-Profile Bet in Myanmar'. Caixin. Retrieved 27 October 2020 from https://www.caixinglobal.com/2020-10-26/cover-story-a-fugitive-businessmanshigh-profile-bet-in-myanmar-101618684.html.

Tower, Jason G. (2017, January). 'Belts, Roads, and Battlegrounds: Chinese Outbound Initiatives in Conflict and Post-Conflict Settings'. Stimson Center. Retrieved 20 June 2017 from https://www.stimson.org/wp-content/files/file-attachments/ Belts-Roads-Battlegrounds-Chinese-Outbound-Initiatives-Conflict-PostConflict-Settings_o.pdf.

Wang, Christoph Nedopil (2020, July 31). 'Investments in the Chinese Belt and Road Initiative (BRI) in 2020 during the Covid-19 Pandemic'. Green Belt and Road Initiative Center. Retrieved 5 August 2020 from https://green-bri.org/ investment-report-belt-and-road-initiative-bri-2020-covidig.

West, Lucy \& Po, Sovinda (2019, May 14). 'Hun Sen's Natural Bilateral “Bestie”.' The Interpreter. Retrieved 14 October 2019 from https://www.lowyinstitute.org/ the-interpreter/hun-sen-s-natural-bilateral-bestie.

\section{About the Author}

MATt FERCHEN's research focuses on the connections between China's foreign and domestic political economy. He has written extensively about China's economic statecraft, China's developing country diplomacy, and debates about the 'China model' of development. He is particularly interested in lessons researchers and policymakers can learn from comparisons of China's economic and political relations with different regions, from Southeast Asia to Latin America, Europe, and the United States. From 2008 to 2017 Ferchen was a faculty member in the Department of International Relations at Tsinghua University and from 2011 to 2019 he was a scholar with the Carnegie-Tsinghua Center for Global Policy. In 2020 he was appointed Head of Global China Research with the Mercator Institute for China Studies (MERICS). He has been engaged with LeidenAsiaCentre research since 2017. Ferchen holds an MA from Johns Hopkins School of Advanced International Studies and a PhD from Cornell. 


\title{
11 The Belt and Road Initiative in South Asia
}

\author{
Regional Impact and the Evolution of Perceptions and \\ Policy Responses
}

\author{
Richard Ghiasy
}

\begin{abstract}
Chapter 11 examines how the BRI has impacted South Asia. It investigates how academic perceptions and policies have evolved in India and Pakistan in response to the BRI since 2013. These two states provide a unique agency, defined as the ability to influence or resist influence, in the BRI context. The region's dominant power, India, is a staunch critic that refuses to sit at the BRI table. The region's other power, Pakistan, hosts the BRI's flagship project, the China-Pakistan Economic Corridor (CPEC), and is the single largest recipient of BRI investment. Through interviews with leading Indian and Pakistani academics, the chapter shows how they make sense of China in the region, providing understanding of the BRI's interplay with South Asia's various geopolitical fissures.
\end{abstract}

Keywords: Belt and Road Initiative, South Asia, China, India, Pakistan, agency

This chapter explores how the Belt and Road Initiative (BRI) has impacted connectivity and integration in South Asia. Following this, it investigates how academic perceptions and policies have evolved in the region in response to the BRI since its inception in 2013. ${ }^{1}$ Most countries in the

1 Academic perceptions tend to trickle down into policy advice and making. However, this chapter does not describe in which instances exactly this may have been the case.

Schneider, Florian (ed.), Global Perspectives on China's Belt and Road Initiative: Asserting Agency through Regional Connectivity. Amsterdam, Amsterdam University Press 2021 DOI: 10.5117/9789463727853_CH11 
region are discussed but the emphasis is on India and Pakistan. ${ }^{2}$ These two states provide a unique agency, in this chapter the ability to influence or resist influence, disparity in the BRI context. The region's dominant power, India, is a staunch critic that refuses to sit at the figurative BRI table. India is exemplary of the degree to which a non-partaking actor can counter, or supplement, the BRI in its region. The region's other power, Pakistan, hosts the BRI's flagship project, the China-Pakistan Economic Corridor (CPEC), and is the single largest recipient of BRI investment. Pakistan provides insight into how a deep-seated partaker's perceptions and policies on the BRI have evolved. Moreover, this chapter grants an understanding of the BRI's interplay with South Asia's various geopolitical fissures. To permit tailored data collection, the author conducted a series of interviews with leading Indian and Pakistani academics on a non-attributive basis. ${ }^{3}$ Reference to these interviews is made where due. The next section will explore three critical regional realities significant to the initiative.

\section{South Asia's Three Critical Realities}

Strategically South Asia, together with Southeast Asia, is the most important expanse to the BRI. For China, both regions are terrestrial gateways to the Indian Ocean. South Asia is also economically the world's fastest-growing region, growing at an average of $7 \%$ since 2014 (Song 2019). To understand the impact of the BRI on South Asia, and corresponding perceptions and policy responses, it is essential to first contemplate three critical regional realities significant to the initiative: 1) South Asia's distinct geography; 2) the region's deep-rooted geopolitical landscape; 3 ) the underpinnings of Indian-Chinese political ties. These realities are partially interrelated.

2 Myanmar is analysed by Matt Ferchen in his chapter on Southeast Asia (Chapter 10) in this volume. Neither is Bhutan part of the analysis, though there is a sporadic reference. Bhutan's foreign and defence policies are closely coordinated by India, as evidenced by the 2017 Doklam standoff between India and China. Bhutan has no diplomatic ties with China and is not part of the BRI. China tried to woo Bhutan to join the BRI in July 2018, to no avail.

3 Semi-structured non-attributive interviews with leading Indian academics from ten different institutes were conducted in New Delhi in September 2019. A series of non-attributive semi-structured interviews with leading Pakistani academics from five different institutes were conducted through Skype in September-October 2019. 


\section{Distinct Geography}

South Asia's distinct geography is a 'static reality'. Certainly, border conflicts characterize the region, but India's setting in the region is unlike any other in Asia. Like a monolith, India sits right at the centre of the region across four dimensions: geographic, political, economic, and historical/cultural. India borders four of the five regional, continental states: Bangladesh, landlocked Bhutan, landlocked Nepal, and Pakistan (see figure 11.1). The exception is Afghanistan. Meanwhile, the island states of the Maldives and Sri Lanka are situated closer to India than any other continental South Asian state.

Remarkably, none of the South Asian states border a regional state other than India. The region's states are therefore highly dependent on India for intra-regional (land) connectivity. Pakistan also borders Afghanistan, but landlocked Afghanistan is considered as the crossroads of South and Central Asia. Meanwhile, Bangladesh borders Myanmar, but Myanmar is an Association of Southeast Asian Nations (ASEAN) member and is more often classified as part of that region. ${ }^{4}$ The geographic centrality of India, the regional hegemon, limits smaller states' agency. It is something that makes South Asia stand out when compared to Southeast, Central and West Asia (the Middle East). Kaplan (2013: 228-254) and Marshall (2019: 189-216) elaborate on this in more detail. Besides India, the region's other common neighbour and geographic reality is China, the only country that is contiguous to every subregion of Asia. ${ }^{5}$ Except for Bangladesh, all of the continental states in South Asia border China. Therefore, both literally and figuratively, South Asian states sit between an emerging India, a more swiftly re-emerging China, and these two powers' diverging visions for connectivity.

\section{A Deep-Rooted Geopolitical Landscape}

The region's other reality, somewhat more fluid than its distinct geography, is that South Asia is rife with geopolitical tensions that intermingle with the BRI. These tensions and divisions have extended and continue to extend extra-regionally. China still sides with Pakistan, while the US has shifted away from Pakistan and towards India to counter China in the Indo-Pacific.

4 Afghanistan was considered part of the Greater Middle East (as is Pakistan in that classification) in US policies at the time of the George W. Bush administration. Regarding Myanmar, despite being an ASEAN member, major authorities (such as the World Bank in its Data series) exclude it from South Asia. Neither is the country geographically part of the Indian subcontinent. 5 If indeed Afghanistan is considered a part of the Greater Middle East, see also the previous footnote. 
Figure 11.1 India's unique geographic centrality in South Asia

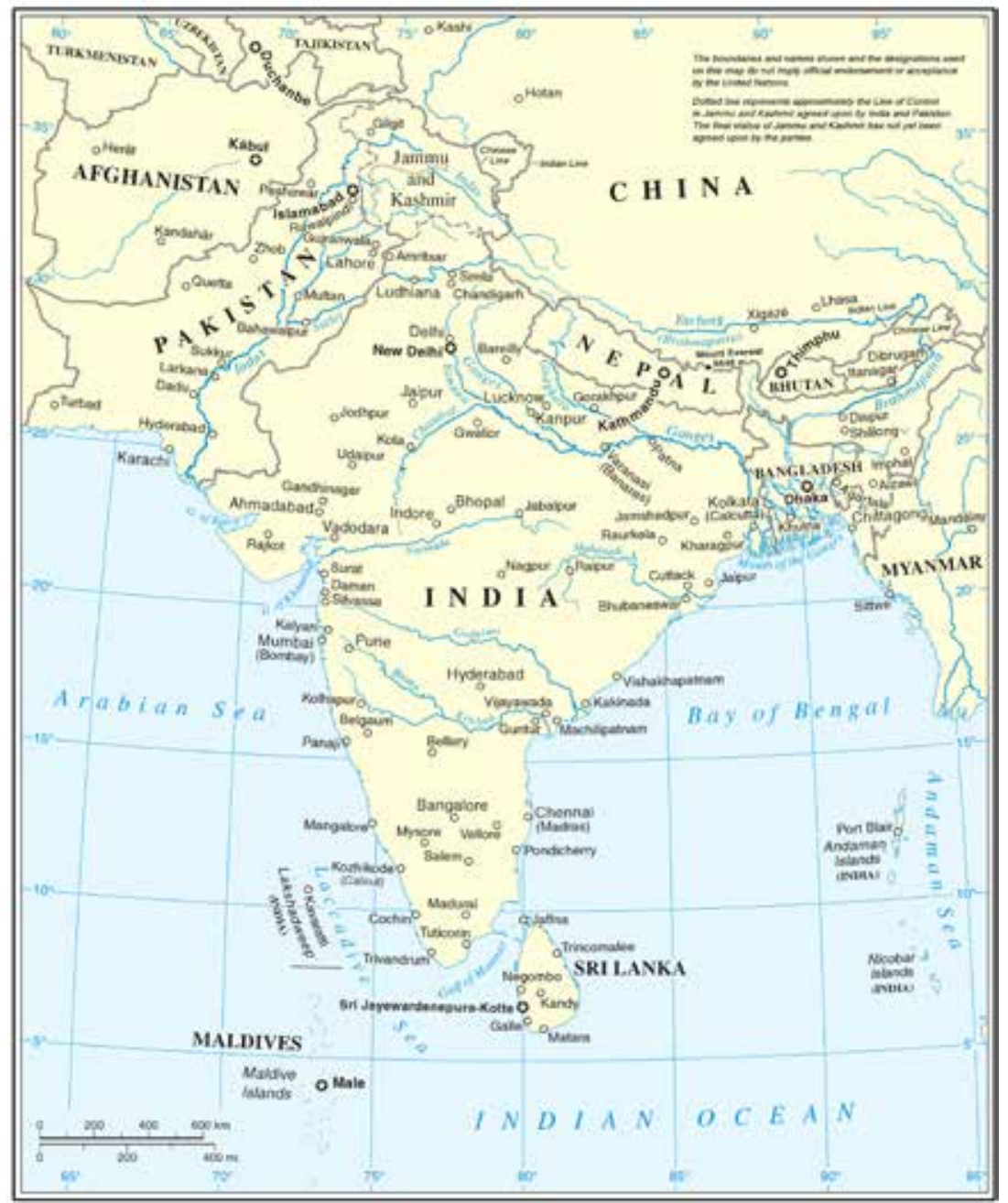

Source: Image in the public domain, via the United Nations ${ }^{6}$

The deep geopolitical acrimony between the nuclear-armed actors India and Pakistan continues to hold regional integration hostage. ${ }^{7}$ Low-intensity interstate (border) conflict frequently erupts between India and Pakistan,

6 Note that this map does not depict disputed areas comprehensively or in detail.

7 For a detailed record of the partition of India and the acrimony that has since characterized India-Pakistan relations, see Parts 1 and 2 of Ramachandra Guha's monumental work India after Gandhi (2017). 
as it did again in and over Kashmir in 2019. Pakistan also has very testing ties with its other neighbour, Afghanistan. ${ }^{8}$ The geographic centrality of India and these testing ties with Afghanistan result in Pakistan having no strategic depth to speak of. Moreover, ethnic and sectarian tensions are scattered through South Asia. As a result, this is where some of the world's most severe traditional and non-traditional security challenges congregate. These security challenges are ones with which the BRI needs to deal.

However, the largely impoverished region is also strikingly disconnected. This is partly because, between the 1950s and the start of the 1990s, India deliberately pursued disconnection policies to insulate itself from foreign influences. The trip to Sri Lanka in 2015 by the current Prime Minister of India, Narendra Modi, for example, was the first such official bilateral visit by an Indian Prime Minister since 1987 (Xavier 2020: 12). ${ }^{9}$ Naturally, smaller states' regional connectivity, which was overly dependent on Indian geographic centrality and policy, was affected by these disconnection policies. As such, intra-regional trade still remains relatively negligible. Xavier demonstrates this well by pointing out that India's land-based trade with neighbour Myanmar is about the same as India's total trade with distant and tiny Nicaragua (2020: 7 ).

Since it began implementing economic reforms in 1991, India has been pursuing greater connectivity with and beyond the region - albeit sluggishly. For comparison, intra-regional trade in East Asia is around $50 \%$ of the region's total trade, while in South Asia that figure is only $5 \%$ (World Bank 2018). Still, this pursuit has put India at the centre of regional connectivity initiatives and the pace has picked up under the current, more strategic, Modi administration. India, like any other state, requires a buffer of stability and prosperity in the region for its national security. The BRI's growing footprint is affecting Indian national security on the Indian subcontinent and in the Indian Ocean region.

\section{Underpinnings of Indian-Chinese Political Ties}

Third, and tied to the first two critical realities, perceptions of the BRI have to be understood in the broader context of India-China relations. India and China have had a complicated political relationship since the second half of the twentieth century. During India's partition, China sided with Pakistan.

8 Barfield 2010 grants a well-researched historic background to these testing ties.

9 Though it should be noted that there have been several bilateral state visits to other South Asian states during that time. 
Strategic distrust has persisted in Indian military, policy, and academic communities since a brief war with China in 1962. The war, which India lost, was over a border dispute between the two states. In addition, border disputes with China linger, and then there is China's all-weather friendship with India's arch-rival Pakistan. In 2010, Grant correctly concluded that 'Indians are much more nervous about the rise of China, New Delhi's foreign policy and defence establishments, in particular,' than the other way around (Grant 2010: 1). The BRI's expansion in South Asia, and a perceived encirclement by China, have amplified this Indian distrust of and nervousness about China (Sibal 2014). This plays a prominent role in the region's geopolitical landscape. For China on the other hand, India forms a massive geographic wedge in its terrestrial access to the Indian Ocean.

Irrespective, China is India's second-largest trading partner after the US. However, the balance is vastly tilted in China's favour, amounting to US\$87.07 billion on average in 2018-2019 (Times of India 2020). The two countries have rather similar stances on global issues such as climate change and they strive for a multi-polar global order. They frequently meet at fora such as the Shanghai Cooperation Organisation (SCO) and the Brazil, Russia, India, China, and South Africa (BRICS) summit. India is also the second-largest stakeholder in the China-initiated Asian Infrastructure Investment Bank (AIIB) and the largest beneficiary of its concessional loans (Sachdeva 2018: 289). Moreover, Chinese President Xi Jinping and Narendra Modi have already met eighteen times since Modi became the Indian Prime Minister in 2014. ${ }^{10}$ These examples demonstrate that the relationship is also characterized by high-level political consultation and economic cooperation, just not under the BRI banner. This is a paradox partially sustained by a hunger for foreign investment and lax Indian regulation on Chinese investment. It should be noted that at the moment of writing Indian policies on Chinese investment in sectors that are deemed vital to national security, particularly tech, are becoming more stringent.

The establishment of these three regional realities present in South Asia enables a more nuanced exploration of BRI impact on South Asia.

\section{BRI Regional Impact}

This section provides an analysis of how, since its inception, the BRI has impacted connectivity and integration in South Asia. First, it briefly examines

10 This number includes visits to each other's countries and meetings on the sidelines of international summits. 
Chinese strategic interests in South Asia. Following this, it explores the BRI's impact on connectivity and integration.

\section{Chinese Interests}

Why is China so interested in South Asia at large and Pakistan, in particular? China's push in South Asia, carried out through the BRI, pursues greater autonomy. It seeks to diversify and secure China's supply chains in the Indian Ocean, including energy imports from Africa and the Middle East. From a BRI perspective, South Asia's geography is of considerable strategic value. The two components of the BRI, the land-based 'Silk Road Economic Belt' (hereafter the 'Belt') and the maritime-based '21st-Century Maritime Silk Road' (hereafter the 'Road'), connect in South Asia. It is important to remember that the Belt and Road should not be seen as two distinct components, but as a mutually synergizing whole that helps China achieve strategic goals through conflict-evasive means (Ghiasy 2018). Also, the size and potential of investment and consumer markets in South Asia, in contrast to Central and Northeast Asia for example, is tremendous.

Furthermore, by means of the BRI, China's west, specifically the landlocked Xinjiang Uygur Autonomous Region, can connect with the Indian Ocean via Pakistan. Meanwhile, the equally landlocked Yunnan Province in China's south-west, and Tibet Autonomous Region in the south, can connect with that same ocean through Myanmar. In turn, Pakistan is the only country in South Asia through which China can bypass the US Navy-patrolled straits in and around Malacca. That grants China supply lines to and from the Indian Ocean directly overland without needing to trespass a third country. Indeed, China's strategic interests in the region are undeniable. China's interest in the region is shown by the way it has made investments in ports across South Asia, for instance in Gwadar (Pakistan), Hambantota (Sri Lanka), and Chittagong (Bangladesh). From an Indian defence perspective such investments in its sphere of influence, and the prospect of the dual-use of these ports, is deeply worrisome (interview, Delhi, September 2019). However, China is not the only actor to become more active in the security affairs of the Indian Ocean region: this region is gradually becoming a multipolar security space (Brewster 2016).

\section{A Connectivity Catalyst in a Disconnected Region}

BRI regional impact on South Asia can be viewed along two strands: cooperation on connectivity, and competition for connectivity. The BRI has provided 
an impetus to connect ${ }^{11}$ in a fragmented and disconnected region that is home to 1.8 billion citizens or $24 \%$ of humanity (World Bank Data 2020). ${ }^{12}$ In the region, the concept of connectivity has now taken on a new importance, and a spirit of development coordination has gradually emerged (Ghiasy et al. 2018). On balance, the region, bar India, has benefitted from better national and extra-national connectivity owing to the BRI (Samaranayake 2019). Examples of projects that have directly or indirectly contributed to this include rails and roads in Pakistan, ports such as Chittagong and an industrial zone and international exhibition centre in Bangladesh, cities such as Colombo Port City in Sri Lanka, airport upgrades and a prominent bridge in the Maldives, and hydropower projects in Nepal. However, it should be noted that infrastructure on its own does not lead to better connectivity per se. Equally important are the design and enforcement of policies that stimulate closer regional integration, or so-called 'soft connectivity'. This, however, is not in China's hands, but a matter of local leadership and enterprise.

To India, the BRI has acted as a trigger for a blossoming of regional and extra-regional connectivity initiatives. Since the launch of the BRI, India has initiated five major connectivity initiatives (which will be elaborated on in the specific subsection on India). Indirectly, the BRI has also pushed Japan, the US, and the EU, through its Connectivity Strategy, to allocate more infrastructure investment to South Asia and the Indian Ocean region. Although none of these alternative connectivity initiatives carry the BRI's financial and diplomatic clout, the BRI has acted as a game-changing pushand-pull factor. This role can be labelled a positive side effect.

At the same time, however, the BRI has also intensified historic geopolitical competition over influence and security between China and Pakistan on the one hand, and India on the other. Smaller states in the region are caught in the middle. They now need to attempt to balance Chinese and Indian interests. India is a closer geographic reality and power than China. However, substantial factions in many of these states (with the exception of Afghanistan and Bhutan) have been or are still wary of India's dominance and so welcome China's re-emergence in the region (Pakistani interviewees based in Islamabad, September 2019, via Skype). With China more active in the region, these states can better

11 Moreover, BRI gains should not merely be judged in their hard infrastructure manifestation. Benefits are also derived from adjustments to institutional, legal, and market frameworks that increase overall trade (Fengler \& Vallely 2019).

12 Statistics exclude Myanmar. 
balance India's dominant role, attract investment, and can gain bargaining power vis-à-vis India. In this regard, smaller states have gained agency in South Asia.

An example of how this increased competition in the region between China and India might benefit smaller states was seen in 2016. The People's Republic of China (PRC) central government committed a US\$38 billion economic package to Bangladesh. Then, barely half a year later, the Indian government sought to counter Chinese efforts by providing a US $\$ 5$ billion line of credit and other economic assistance to Bangladesh. This was the biggest single line of credit that India had ever extended to any country (Chakma 2019: 228). On another occasion, in 2018, India similarly sought to counter China by offering US\$1.4 billion in financial aid to the Maldives for infrastructure development (Ganapathy 2018).

\section{Integration of the Region or Integration with China?}

Even though Indian observers acknowledge that China has a legitimate interest in the Indian Ocean to protect its supply lines, many of these observers believe that the Road is a proxy for China's strategic ambitions and part of its 'String of Pearls' strategy ${ }^{13}$ (Singh 2019: 206). According to Singh (2019: 208) and Borah (2018), many Indian analysts believe that as part of this strategy China's People's Liberation Army Navy (PLAN) wants to dominate trans-continental littorals. These analysts see this ambition from China as something that significantly impacts India's security interests. According to one interviewee (Delhi, September 2019), China is using micro-steps to encroach on and make advancements in South Asia's security realm: first through diplomacy, then through the economy, and then into security. Over time, in the aggregate, these micro-steps become major strides. Another Indian interviewee (Delhi, September 2019) made a similar argument: 'China is trying to organically create a need for PLAN as if it is rendered necessary by supply chain protection, or circumstances such as a humanitarian disaster. That way, they will obtain incremental control.' Whereas these statements have a speculative nature, they are indicative of prevailing views of encirclement by China and are bound to feed into Indian policy-making processes.

The (perceived) encirclement is terrestrial as well. China has been insensitive to Indian territorial integrity and one of India's core interests:

13 A geopolitical theory introduced by the US and highly popular in Indian policy and academic circles claims that China premeditates a network of commercial and military facilities and relationships from its mainland through the Indian Ocean to the Horn of Africa. 
India-claimed and Pakistan-occupied Kashmir. Part of Kashmir is known in Pakistan as Gilgit-Baltistan, ${ }^{14}$ which the China-Pakistan Economic Corridor (CPEC) crosses. One interviewee (Delhi, September 2019) asked how China would feel if India were to go against China's core interests in, for example, Hong Kong, Taiwan, or the South China Sea. The interlocutor went further and stated that the rift between India and Pakistan is being sustained and hardened by the BRI. They said that, instead of closer integration, there is now an East South Asia and a West South Asia. This schism is perhaps somewhat overstated, as there was a(n) (in) visible rift in South Asia long before the BRI surfaced. However, it is true that the BRI has bolstered Pakistan's position and further complicated the Kashmir dispute. On the other hand, there is growing awareness in Pakistan and China that the CPEC makes limited economic sense if India and Afghanistan are not part of it (two interviewees based in Islamabad, October 2019, via Skype). Currently, BRI connectivity in continental South Asia courses vertically, i.e. it runs from China to Pakistan and then down through Pakistan to the Arabian Sea. There is no CPEC horizontal integration with either of Pakistan's regional neighbours, India or Afghanistan. However, this is a conscious choice that has been made by India, while Afghanistan has an uneasy relationship with Pakistan and is embroiled in an ongoing civil war.

The next section will discuss how the three South Asian regional realities are linked with the BRI's regional impact and the evolution of the perceptions and policies of individual regional states.

\section{The Evolution of Perceptions and Policy Responses in South Asia}

In line with the evolution of BRI impact since 2013, academic perceptions of the initiative in South Asia have also evolved. Academic perceptions and policy responses can be characterized by drawing the analogy of who is seated at the figurative BRI table. The perceptions and policy responses of different states are reflected by who cooperates with China under the BRI banner and how they have acted. Proximity to the table indicates greater interest. The role of the region's three critical realities are interwoven in the argumentation.

14 Gilgit-Baltistan, despite being part of the larger occupied Jammu and Kashmir issue has always had a slightly different status, as it gained and announced independence from the British, and then surrendered to Pakistan, which merged it into the larger Jammu and Kashmir territory. 


\section{Not at the Table but Keeping a Very Close Eye - India}

As elaborated on above, the political relations between India and China are complex. A number of Indian scholars define that relationship through the 4 C's of conflict, cooperation, competition, and containment (Sachdeva 2018: 286). India's position regarding the BRI best fits in the latter two categories of competition and containment. India has been both competing with, and containing, the BRI since 2014. It does this not only because the BRI infringes on Indian regional influence, but also because it is convinced that the Communist Party of China (CPC) wants a unipolar Asia (Katoch 2019: 104). India perceives that more connectivity brought about by the BRI aids this CPC objective. This connectivity translates into greater strategic space and mobility for China in South Asia and the Indian Ocean, at the expense of India's operational space (interview, Delhi, September 2019). This is, of course, a correct observation.

Keeping this in mind, India's official policy on the BRI has been consistent. The Indian government has always been outspoken about CPEC. ${ }^{15}$ However, formally India has mostly remained silent about the BRI and has neither really accepted nor rejected the initiative. Perceptions of the BRI in India can be divided into two phases:

Phase I. In this phase, between 2014 and 2017, the debate centred on geopolitical and developmental implications. China officially invited India to join the BRI in February 2014. However, the Indian government did not express much enthusiasm due to 1) a lack of clarity on the initiative's economic objectives, 2) a lack of consultation by China with India and others on BRI specifics, and 3) hesitation among many Indian observers about its strategic implications (Singh 2014: 135). This complied with a constant in India's rich and long history of foreign policy: independence of action alongside a level of realism and idealism. ${ }^{16}$ The BRI mostly hit the realism string. However, India did make more cooperative moves in the broader context of the Indian-Chinese relationship. In 2014, India became a founding member of the AIIB and the New Development Bank (formerly the BRICS Development Bank). It then became a full member of the Shanghai Cooperation Organisation in 2017. Chhibber (2017) refers to the phase of relations between India and China that stretched from 2014 to 2017 as one of 'competitive cooperation'.

15 After the 2018 Wuhan summit official rhetoric has toned down, perhaps as a result of a plea by President Xi Jinping.

16 Pande 2018 offers a useful overview of ancient to contemporary Indian foreign policy. 
In the early years of this period, 2014 to 2015, Indian analysts saw the BRI both as an opportunity to boost regional connectivity and a threat to India's prominence in South Asia and the Indian Ocean region (see, for instance, Singh 2014:143; Mohan 2014a and 2014b; Nataraj \& Sekhani 2015). These same analysts suggested that India come up with its own connectivity initiatives to hedge the BRI. Simultaneously, they expressed the rationale for joining the BRI. Some academics, to no avail, recommended a partial engagement (e.g. Singh 2014; Nataraj \& Sekhani 2015: 71). Recommendations to join the BRI were based on the fact that it would give India an ability to shape the agenda and to tap an unfolding geoeconomic reality. Mohan (2014a and 2014b) defined India's official stance at the time as rigid and detrimental.

The Indian government was, however, receptive to the China-led Bangladesh-China-India-Myanmar Economic Corridor (BCIM), which predated the BRI by fourteen years. India saw the BCIM as having the potential to open up India's tribal, landlocked Northeast region. Some analysts, such as Uberoi (2016), questioned this official stance, which produced the dichotomy of the $\mathrm{BRI}$ versus the BCIM. Yet, when the Chinese state subsumed the BCIM into the BRI in 2015, Indian official interest tumbled. In that year, the Indian government continued its silent official stance on the BRI, though it publicly rejected CPEC. By and large, in this first phase, geopolitics dominated over developmental implications because of a fixation on CPEC (Sachdeva 2018: 286). This fixation is increasingly visible from 2017 onwards. In 2017, the Indian government visibly protested by not sending a single delegate to the first Belt and Road Forum in Beijing. Publicly, a day before the forum, a key Indian policy shift took off. The Indian government started to oppose the BRI as a whole rather than just CPEC by pointing to lack of compliance with international norms on transparency, economic sustainability, and debt sustainability (Ministry of External Affairs 2017). Even the fact that it gained membership of the Shanghai Cooperation Organisation in that same year did not change India's stance towards the BRI.

Five prominent initiatives. Delhi used the years between the introduction of the BRI and the first forum to up its agency. To foster its ambitions and geographic centrality, India launched five prominent initiatives: the Neighbourhood First policy (2014), the Act East policy (2014), Project Mausam (2014), Security and Growth for All in the Region (SAGAR) (2015), and, coinitiated with Japan, the Asia-Africa Growth Corridor (AAGC) (2017). ${ }^{17}$ These initiatives are important policy responses and merit elaboration.

17 A year later it was renamed 'Platform for Japan-India Business Cooperation in Asia-Africa Region'. 
The Neighbourhood First policy firmly prioritized connectivity with South Asia, not merely restricted to commerce. The Act East policy is a follow-up on the somewhat inert Look East policy from 1991. The Act East policy, combined with the Modi administration's Neighbourhood First policy - a major foreign policy - tactically rebalanced India's geostrategic orientation. India's foreign policy had long been oriented towards the West but had now become more neighbourhood- and Indian Ocean-centric (Katoch 2019: 23).

To support this shift in orientation, the Indian government introduced Project Mausam. Mausam aims to revive 'lost' maritime, cultural, and economic connections in the Indian Ocean region. It can be interpreted as India's answer to the Road. Interestingly, cultural ties are utilized as a key cohesive driver in Project Mausam. Strategically, particularly administratively, financially, and diplomatically, India simply cannot compete with China and its BRI. It has therefore had to come up with alternative ways to compete. One interviewee (Delhi, September 2019) reflected on the rationale behind Project Mausam and articulated that 'Chinese money and investment are not the only currency: cultural, lingual, historical, and religious similarities are currencies, too. Economic incentives are shortterm, while cultural relations are long term' (my emphasis). Following after Project Mausam, Prime Minister Modi announced SAGAR, a vision at the conceptual level for economic growth and security in the Indian Ocean. The partnership with Japan lacks Indian investment, and progress has been slower than Japan foresaw (interview, Delhi, September 2019).

Phase II. In this phase, which began in late 2017 or early 2018 and continues to the present, geopolitics has remained a central element. In addition, the political economy, sustainability, and practical mishaps of the BRI have increasingly come to the fore. How can this be explained? In 2018, Chinese trade in the region was five times more than India's trade with its neighbours (Xavier 2020: 10). Suspicions of the BRI on the part of the Indian government and Indian analysts continued to grow in 2018-2019. The reasons for these suspicions became more fine-grained than mere geopolitics, they were 1) geoeconomic, 2) geostrategic, and 3) of a security nature.

Geoeconomically, the (perceived) mishaps of the BRI in South Asia made Indian commentators further doubt the BRI's vision and its intentions. An example of the type of events that increased Indian doubts about BRI is the case of Sri Lanka's Hambantota Port, which a Chinese company ${ }^{18}$ obtained through a so-called debt-for-equity swap. Describing the kind of misgivings felt in India about the BRI, Khurana (2019: 28) writes that 'the BRI is seen 
as a Chinese project which capitalizes on other nation's vulnerabilities, desires and insecurities'. The same author describes the BRI as a Chinese attempt to move low-end sunset industries elsewhere (ibid.: 29). On the same subject, a Pakistani interviewee stated that India, backed by the US, had deliberately been marketing the BRI in the region as a debt trap solely serving China (interviewee based in Islamabad, September 2019, via Skype). There is also growing belief among Indian analysts that the initiative has limited economic rationale in South Asia, particularly as it relates to CPEC, and is rather aimed to constrain the rise of India (Katoch 2019:33). This sentiment is also reflective of the underpinnings of strategic distrust in Indian-Chinese ties. One Indian interlocutor even questioned the benefit the BRI could provide India (Delhi, September 2019). They remarked: 'We are not anti-China, but what do we actually gain if we sign onto the BRI? The initiative is not transparent at all, so what is the use?' It may help that Chinese foreign direct investment (FDI) in India has been growing consistently, so India is not necessarily losing out on the BRI (Basrur 2019).

Geostrategically, in this phase Indian policy and academic observers have cemented their view of the BRI as being primarily a unilateral Chinese project. One analyst, for example, stated that 'the more we thought about the economic rationale of Gwadar, Hambantota, and Chittagong Ports the less sense it made' (interview, Delhi, September 2019). As a result, India has slightly shifted away from its long-term non-alignment policy and taken a harder position on the strategic grid. Trust, or rather the deficit of it in the context of China's BRI, was also a key message of Prime Minister Modi's address on connectivity and cooperation at the 2018 Shangri-La Dialogue (Modi 2018). India sought closer security coordination with, e.g., the US, Japan, and Australia through the nascent 'quad', and by endorsing the Japan-US initiative to 'marry' the Indian Ocean space with the Pacific, the 'Indo-Pacific'.

Security concerns, logically, have also mounted. The Indian Navy spotted fourteen Chinese People's Liberation Army Navy warships in the Indian Ocean in 2017 (Singh 2019: 203). India's sovereignty and development depend - profoundly - on maritime security, and China's swift naval expansion through the Road is challenging this. To emphasize the gravity of the situation, an interviewee (Delhi, September 2019) said: 'We feel that we may succeed, or we may fail as a state in the coming 100 to 150 years. Much of this will depend on our naval power in the IOR. Delhi perceives the BRI not as a threat but as a major risk factor, as are the US and the EU, in this regard'. India's interest in the maritime domain is therefore not induced by the BRI, but it has highlighted a fundamental national security interest. 
Another analyst (interview, Delhi, September 2019), interestingly, and accurately, concluded that the BRI, thus far, has mostly been examined by India through a geopolitical and regional lens. India only looks at the BRI in South Asia and does not look too much beyond the region for its impact. Therefore, perceptions are biased and there is no full-picture analysis. Irrespective of this, as of the middle of 2020 India is still not at the BRI table. Indian agency, or its ability to influence or resist influence in South Asia, has simultaneously been limited and boosted by the BRI. India has set up a few small connectivity tables of its own and watches very closely what neighbours do, particularly Pakistan.

\section{Deep Seated - Afghanistan and Pakistan}

Of all the different connectivity visions that include Afghanistan, the BRI is by any measure the grandest and most ambitious. The Afghan government has consistently been very receptive to the BRI and signed a Memorandum of Understanding in 2016. The president, Ashraf Ghani, and his administration want to transform the landlocked and war-torn country into a logistical hub between Central and South Asia and welcome infrastructure investment. However, BRI progress in Afghanistan has been limited. In 2016, the Sino-Afghanistan Special Railway Transportation Project resulted in freight being delivered by train from Nantong, in China's eastern Jiangsu province, to Hairatan, in Afghanistan's northern Balkh province. In 2017, cargo moved two ways, but the exchange, by and large, can be considered symbolic. A fibre-optic cable was laid through the sliver of land that connects Afghanistan with China, the Wakhan Corridor (Jahanmal 2017), and a road is being built to connect the two countries through this rugged province (Foster 2019). However, Afghanistan simply is not a very attractive investment destination for the BRI as long as armed conflict and political instability linger. India is, nevertheless, working to connect with Afghanistan through Iran's Chabahar Port (Pakistan does not permit India to use its territory for transit). This is part of the International North-South Transport Corridor (INSTC) that aims to improve connectivity between India, Russia, Central Asia, Afghanistan, and Iran. ${ }^{19}$ In 2017, India even managed to ship wheat through Chabahar to Afghanistan.

Like Afghanistan, Pakistan is very much seated at the BRI table, though it has a much more prominent seat. As mentioned previously, Pakistan is

19 An agreement was signed by the initiative's founders, India, Russia, and Iran, in September 2000 . 
host to the China-Pakistan Economic Corridor (CPEC), which is the flagship corridor of the entire BRI. It is also the single largest recipient of BRI financial allocations, having received some US $\$ 60$ billion by April 2018 (Hillman 2018), an amount close to $7 \%$ of Pakistan's external loans (Hussain 2019: 4). Financing has taken place through investment projects, concessional loans, interest-free loans, and government grants (Chattha \& Hyder 2019: 106). China and Pakistan have had a very close relationship since $195^{\circ}$ when Pakistan was one of the first countries to cut diplomatic ties with the Republic of China on Taiwan. An aspiration to have a corridor between the two countries runs back to that same period and motivated construction of the Karakoram highway. Pakistan has always had a strategic need to have China on its side as a counterweight to Indian dominance and centrality in the region. However, China is not just a strategic balancer; it is also a 'replacement'. When the US grew increasingly disillusioned with Pakistan, following growing evidence of its support of the Taliban in Afghanistan, China was the most logical go-to actor for Pakistan's leaders. It is also not just the policy community that holds these views: China is seen as a more reliable and constructive strategic partner than the US according to popular sentiment (Pakistani interviewees based in Islamabad, September and October 2019, via Skype). Pakistan also desperately needs Chinese investment and is very welcoming of it, like Cambodia in Southeast Asia (see Ferchen on China and Southeast Asia, Chapter 10 in this volume). Chinese investment is anticipated to give a boost to the economy and help fight unemployment and terrorism. It is also seen as a solution to Pakistan's endemic energy crisis, which has long crippled the economy.

Nonetheless, the interdependence between China and Pakistan is not straightforward, and agency is rather complex and asymmetric. While financially China has the upper hand, Pakistan is at an advantage geographically and strategically (Afridi \& Khalid 2016: 669). Gwadar Port, located in Pakistan's southern Baluchistan Province, offers China virtually direct access to the Strait of Hormuz, through which some $40 \%$ of global daily oil transit fares. CPEC will also shorten the route for China's energy imports from the Middle East by about 12,00o kilometres (Bhattacharjee 2015: 2). Moreover, it gives China a strategically advantageous position in South Asia.

Although there has been near-unanimous support for the game-changing CPEC since the inception of the BRI, the corridor has been a topic of hot contestation in the Pakistani policy community. Once China and Pakistan started to plan, quarrels flared up within Pakistan over dividends, routes, and specific projects (interviewee based in Islamabad, September 2019, via 
Skype). This was particularly the case when the Nawaz Sharif administration shifted the initial short(er) route from Pakistan's west, running through Khyber-Pakhtunkhwa Province, to a route which would also run through Punjab Province in the east. This altered route significantly lengthened the distance down to Gwadar Port in Baluchistan Province. However, it connected the various urban centres in the country, including Lahore and Faisalabad, which are, respectively, Pakistan's second- and third-largest cities. The Sharif administration controlled tensions relatively well by holding broad consultations with political parties and social leaders, thereby mitigating a more negative perception and impact of CPEC (Hussain 2019: 10). At the Pakistani subnational level, sidelined stakeholders of CPEC, most notably the Balochis and the business community, have frequently expressed dissatisfaction about transparency and the distribution of spoils. Insurgents in both Khyber-Pakhtunkhwa and Baluchistan have blown up pipelines and on occasion even attacked Chinese engineers. The Pakistani military has stepped up in response and CPEC's construction has continued on pace.

CPEC is being built in phases that are under continuous review. It has just passed the 2015-2018 phase of so-called early harvest projects. Many of these projects focused on power plants (mostly fossil, but also renewable and nuclear) and on critical infrastructure. The second phase, which will focus on additional connectivity projects and gradual industrialization, coincides with a new administration. While he was in opposition, the incumbent Prime Minister Imran Khan strongly opposed CPEC modalities, but not the corridor itself. He said the initiative needed to be more transparent and fairer in regard to economic burden and debt sustainability, mostly pointing the finger at his predecessor (Hussain 2018). At that time, Khan did not hold political office so he could afford to take this position. However, when he came to power in 2018, he adopted a much softer stance towards CPEC, even on the renegotiations that he had previously demanded. Most of the project timelines had already been met by the time he took office. Nonetheless, the Khan administration is more careful when chalking out new projects. As a result, there is slightly more transparency now (Hussain 2019: 13-14). Some projects have been revised. For example, Pakistan has insisted that a larger airport be constructed in Gwadar. China has also learned from how the CPEC project has unfolded in Pakistan. For instance, because the Chinese state needs a secure investment climate it is now engaging frequently with Baloch leaders and giving more attention to local communities too (Abrar 2019). As a result the agency of these local actors has grown, after it had diminished in the initial years of the CPEC project. 


\section{Moved the Seat - Bangladesh, the Maldives, and Sri Lanka}

Bangladesh, the world's eighth most populous country, has fairly consistently and skilfully balanced policy between pursuing the benefits of the BRI and showing sensitivity to India's core concerns (Chakma 2019; Titumir \& Rahman 2019). India edges virtually the entire stretch of Bangladesh's borders. But, if anything, because of its investment needs Bangladesh has moved its seat closer to the BRI table since 2016. In the process, Bangladesh has achieved remarkable economic growth. It has enjoyed a GDP growth rate of no less than $7 \%$ since 2016 (World Bank Data 2020). ${ }^{20}$ To Bangladesh, the Road and the BCIM corridor appeal in particular as means to increase export-import capacity (Karim \& Islam 2018). Bangladesh is the only other country in South Asia, besides Pakistan, where the Belt and the Road components of the BRI connect. Not coincidentally, Bangladesh is the second-largest recipient of BRI loans in the region after Pakistan. By early 2018, China had implemented US\$10 billion worth of infrastructure projects (China Daily 2018). A notable example is cooperation on capacity development of Bangladesh's largest port, Chittagong. Nevertheless, Bangladesh is a very selective borrower and coordinates the BRI well with its own development priorities without bending to pressure from either China or India (Ramachandran 2019). Still, Bangladesh is more important to India than to China, for security, economic, political, geographic, and foreign-policy reasons (Chakma 2019: 228; Islam 2016). Demonstrative of this is the fact that India had been Bangladesh's top trading partner for 40 years until China took over in 2015 (Anwar 2019).

The Maldives is a clear-cut case of a state that has distanced its seat from the BRI table due to fear of overdependence on China and a political leadership swing. The nearly 1200 islands that comprise the Maldives sit right in the middle of the Indian Ocean. This is a highly strategic setting among key international shipping lanes and has long been under India's political influence. Chinese diplomatic overtures, such as Chinese President Xi Jinping's visit to the archipelago in 2014, and BRI-related financial injections, helped to turn the tide during the five years that President Abdullah Yameen was in office, with his administration engaging in extensive borrowing. The Maldives even signed a Free Trade Agreement with China in 2017. Based on 2017 figures, the Maldives's debt to China accounted for $27 \%$ of external debt, though only $8.6 \%$ of total debt (Samaranayake 2019: 12). Yameen's successor, 
Ibrahim Mohamed Solih, who ousted him in a landslide victory in the 2018 elections, rectified the marginalization of India and overdependence on China under Yameen. After all, India is the central actor in the Maldives's greater geography. President Solih also tried to rescind BRI projects that were perceived as having inflated prices, but many had already been completed (Elmer 2019).

Like the Maldives, Sri Lanka is also strategically located along the EuropeAsia trade route as a low-cost transit point. It also lends itself well for foreign offshore supply to security and naval activities in the Indian Ocean. Shifts in the political landscape and growing debt concerns, even though China only holds an estimated $12 \%$ of Sri Lanka's external debt (Samaranayake 2019: 6), ${ }^{21}$ have also altered policy stances on the BRI. However, more than the Maldives, Sri Lanka is entangled in a power play that, besides China and India, also includes Japan and the US (the country's top export destination). Both China and India have attempted to influence Sri Lankan domestic politics. In turn, Sri Lanka has tried to play them against each other. Initially there was a pro-China tilt that translated into numerous BRI projects. In 2017, China accounted for $35 \%$ of foreign direct investment, more than twice India's 16\% share (Xavier 2020). The 99-year Hambantota Port lease sent shockwaves through global media, but the debt-for-equity swap was incompletely portrayed in Indian and Western media (Elmer 2019; Sautman and Yan 2019). Since 2019, the new Sri Lankan government led by President Gotabaya Rajapaksa has pursued agency that seeks to better balance foreign influence and maximize benefits to Sri Lanka. Chinese-Indian strategic distrust is a useful reality in that regard. President Rajapaksa has clearly warned, though, that unless powers other than China invest in the country, the BRI will prevail (Elmer 2019).

\section{To Sit or Not to Sit - Nepal}

While Sri Lanka's geographic setting means it can draw from a diverse pool of international interest, Nepal's setting is much less exploitable. Rugged Nepal is exemplary of a politically divided country that is (over)dependent for transit and investment on both India and China and accordingly needs to balance between the two. Nepal was an early BRI signatory in 2014, the same year that Chinese investment in the country surpassed that of India. Not long after this, Nepali authorities accused India of blockading the transit of (mostly) fuel and vital goods to Nepal (BBC 2015). As a result, Nepal has 
veered a little closer to China, but the country does not have a very coherent foreign policy due to political fragmentation. India wants to maintain Nepal within its sphere of influence, while China is actively working to pull it away. The Modi administration worries that the Belt will grant China (further) direct access to its territory (Sapkota 2017). It is important to realize that Nepal is landlocked and is enclosed by India on three sides and China on the other. As a result, India has had a de facto monopoly on Nepali exports. The BRI could change this. Nonetheless, perceptions of the BRI amongst academics and politicians range from lukewarm to positive (Sapkota 2017: 115). In the policy community this old division mostly runs along the fault lines between the single largest party, the pro-India Nepal Congress, and the pro-China Nepal Communist Party that currently rules. There are a number of reasons that specifically drive Nepali interest in the BRI. The most significant is that it could increase international trade and transform Nepal from a landlocked to a land-linked country (Shrestha 2017: 36; Panda 2019). Much of this revolves around the Trans-Himalayan Economic Corridor, part of the BRI. ${ }^{22}$ Nepal is a demonstrative of the weight and complex interplay of South Asia's three critical realities. It also indicates how this complex interplay can, potentially, be turned to an agency advantage by a small regional actor.

\section{Conclusion}

BRI impact on connectivity and integration in South Asia is dissimilar to any other region where the initiative is active. Three interrelated elements help produce this dissimilarity. The first is the region's distinct geographic reality. Emerging India is literally and allegorically the centre. Meanwhile, the more-swiftly re-emerging China is an immediate neighbour to all but one continental South Asian state. The second element is the way the region has a congregation of various, deep-rooted geopolitical fissures, most notably deep antagonism between its two largest actors, India and Pakistan. The third element is the severe strategic distrust of China in the Indian policy and military community, as well as in much of the Indian academic community. BRI connectivity in South Asia has consequently had to work its

22 This corridor could act as a land bridge between China and India and improve transit with and reduce transit costs to the Tibet Autonomous Region, Sichuan, and Yunnan (Adhikari 2018: 47-49). Together with CPEC, BCIM, and the Road, it is one of four main BRI subprojects in South Asia. 
way around India. Therefore, despite select improvements of national and select extra-national connectivity in Pakistan and smaller states, the BRI has not been able to genuinely integrate the region more closely - at least so far. However, the initiative has triggered a host of connectivity initiatives in South Asia, led mostly by India as well as by extra-regional powers. As a result of this and greater diversity of investors, the agency of South Asian states other than India has, on balance, improved - as has China's. Scholars should take note of this. The BRI has also given a highly fragmented region stronger impetus to connect, which is a remarkable accomplishment. Nonetheless, the BRI has intensified historical tensions between China-Pakistan versus India. It has also helped sustain the India-Pakistan rift. Moreover, the BRI has led to a further internationalization and complication of the region's geopolitics - including the geopolitics of the Indian Ocean.

The evolution of perceptions of the BRI, as well as policy responses to it, in South Asia differs from the evolution seen in other parts of the world. The changing perceptions of BRI and policy responses in the region can be characterized by drawing an analogy with who is seated at the figurative BRI table. India has been very consistent: it never took a seat. Since the BRI's inception, India has been suspicious of the economic rationale, and lack of transparency and multilateralism of the initiative. Of India's traditional foreign policy attributes of independence of action alongside a level of realism and idealism, the BRI has mostly hit the realism string. This string has continued to vibrate as the BRI has unfolded rapidly in India's sphere of influence. India has been actively seeking to compensate for the deliberate disconnection policies that it pursued for most of the second half of the twentieth century. That said, India does not have the diplomatic, financial, and administrative clout of the BRI. Therefore, Indian agency has simultaneously been limited and boosted by the BRI. War-torn Afghanistan, and Pakistan, both thirsty for investment, have also been very consistent in their BRI policies. However, contrary to India they both have very much taken a seat at the BRI table. In Pakistan, the policy community under the incumbent Prime Minister Imran Khan has become more involved and slightly more cautious in CPEC planning. The Maldives, Nepal, Sri Lanka, and Bangladesh have all become frontlines for Indian-Chinese competition over influence and investment. Sri Lanka and the Maldives have readjusted their interest in BRI following political leadership swings, concerns over the sustainability of external debt, and wariness over long-term strategic costs. They have distanced their seats a little from the BRI table. On the contrary, the selective-borrower Bangladesh has continuously been able to smartly 
negotiate BRI investments while tending to Indian core interests. Politically divided Nepal, landlocked between China and India, has taken a seat to lessen a long-term overdependence on India.

These responses indicate that countering the BRI by a regional power, in this case, India, is of limited effect in a geopolitically fragmented region that yearns for investment, improved connectivity, and a power balance. Despite having grown slightly less enthusiastic and cautious, South Asia, bar India, still welcomes BRI investments. Nevertheless, if India and China do not sit at the same regional connectivity table, the initiative will not truly integrate the region, and will sustain regional divisions.

\section{References}

Abrar, Mian (2019, September 11). 'Baloch Leaders Extend Support to CPEC during China Visit'. Pakistan Today. Retrieved 13 March 2020 from https://www.pakistantoday. com.pk/2019/og/11/baloch-leaders-extend-support-to-cpec-during-china-visit/.

Adhikari, Ashish (2018). 'Belt and Road Initiative and Nepal's Economic Perspective: Regionality and Specificity'. Kathmandu School of Law Review, 6(1), 41-52.

Afridi, Manzoor Khan \& Khalid, Imram (2016). 'The Politics of Interdependence: A Case of China-Pakistan Economic Corridor'. South Asian Studies, 31(2), 659-671. Anwar, Anu (2019, July 15). 'How Bangladesh Is Benefiting from the China-India Rivalry'. South Asia Journal. Retrieved 22 March 2020 from http://southasiajournal.net/how-bangladesh-is-benefiting-from-the-china-india-rivalry/.

Barfield, Thomas (2010). Afghanistan: A Cultural and Political History. Princeton: Princeton University Press.

Basrur, Ajesh (2019). 'The BRI and India's Grand Strategy'. Strategic Analysis, 43(3), 187-192.

BBC (2015, December 15). 'Nepal Blockade: Six Ways It Affects the Country'. BBC. Retrieved 3 March 2020 from https://www.bbc.com/news/world-asia-35041366. Bhattacharjee, Dhrubajyoti (2015, May 12). 'China Pakistan Economic Corridor (CPEC)'. Issue Brief. Indian Council of World Affairs. Retrieved 20 March 2020 from https://papers.ssrn.com/sol3/papers.cfm?abstract_id=2608927.

Bhattarai, Kamal Dev (2017, January 6). 'India and China's Tug of War over Nepal'. The Diplomat. Retrieved 4 March 2020 from https://thediplomat.com/2017/01/ india-and-chinas-tug-of-war-over-nepal/.

Borah, Rupakjyoti (2018). 'The Maritime Silk Road in China's OBOR (One Belt One Road) Initiative: How Should India Respond?' Asian Studies, 64(3), 10-17.

Brewster, David (2016). 'Silk Roads and Strings of Pearls: The Strategic Geography of China's New Pathways in the Indian Ocean'. Geopolitics, 22(2). 271-72. 
Chakma, Bhumitra (2019). 'The BRI and Sino-Indian Geo-economic Competition in Bangladesh: Coping Strategy of a Small State'. Strategic Analysis, 43(3), 227-239. Chattha, Muhammad Khudadad \& Hyder, Mustafa (2019). 'China-Pakistan Economic Corridor: Where Is the Money Going?' Journal of Infrastructure, Policy and Development, 3(1), 100-114.

Chhibber, Ajay (2017). 'China's Belt and Road Initiative and India's Options: Competitive Cooperation'. Journal of Infrastructure, Policy and Development, 1(2), 1-12.

China Daily (2018, March 22). 'China Implements \$1ob Worth of Infrastructure Projects in Bangladesh, Says Ambassador'. China Daily. Retrieved 19 March 2020 from http://www.chinadaily.com.cn/a/201803/22/WS5ab36aoaa3105cdcf65139df. html.

Elmer, Keegan (2019, December 1). 'Sri Lankan President Gotabhaya Rajapaksa Plays Down Links with China on Trip to India'. South China Morning Post. Retrieved 21 March 2020 from https://www.scmp.com/news/china/diplomacy/ article/3040119/sri-lankan-president-gotabhaya-rajapaksa-plays-downs-links.

Fengler, Wolfgang \& Vallely, Paul (2019, September 9). 'Connecting Central Asia to the World'. Brookings, Future Development Blog. Retrieved 16 February 2020 from https://www.brookings.edu/blog/future-development/2019/og/og/ connecting-central-asia-to-the-world/.

Foster, Kendrick (2019, December 5). 'The New Road to Conflict: Geopolitics of the Wakhan Corridor'. Harvard International Review. Retrieved 14 March 2020 from https://hir.harvard.edu/wakhancorridor/.

Ganapathy, Nirmala (2018, December 17). 'India Offers \$1.9 Billion Financial Aid to Maldives to Counter China's Influence'. Straits Times. Retrieved 19 April 2020 from https://www.straitstimes.com/asia/south-asia/india-offers-19-billionfinancial-aid-to-maldives-to-counter-chinas-influence.

Ghiasy, Richard (2018). China's Belt and Road Initiative: Security Implications and Ways Forward for the European Union. Policy Brief. Stockholm International Peace Research Institute (SIPRI). Retrieved 26 January 2020 from https://sipri.org/ publications/2018/other-publications/chinas-belt-and-road-initiative-securityimplications-and-ways-forward-european-union.

Ghiasy, Richard, Su, Fei \& Saalman, Lora (2018). The 21st Century Maritime Silk Road: Security Implications and Ways Forward for the European Union. Stockholm International Peace Research Institute (SIPRI). Retrieved 26 January 2020 from https://www.sipri.org/publications/2018/other-publications/21st-centurymaritime-silk-road-security-implications-and-ways-forward-european-union.

Grant, Charles (2010). India's Response to China's Rise. Policy Brief. Center for European Reform. Retrieved 6 February 2020 from https://www.cer.eu/sites/default/ files/publications/attachments/pdf/2011/pb_india_china_grant_aug10-206.pdf. Guha, Ramachandra (2017). India after Gandhi. London: MacMillan. 
Hillman, Jonathan E. (2018, April 3). 'How Big Is China's Belt and Road?' Center for Strategic \& International Studies (CSIS). Retrieved 21 February 2020 from https://www.csis.org/analysis/how-big-chinas-belt-and-road.

Hussain, Ejaz (2019). 'Will Change in Government Affect China-Pakistan Economic Corridor? The BRI, CPEC and the Khan Government: An Analysis'. Chinese Journal of International Review, 1(2).

Hussain, Tom (2018, August 12). 'Where Does Imran Khan's Government Stand on China's Belt and Road?' South China Morning Post. Retrieved 4 March 2020 from https://www.scmp.com/week-asia/geopolitics/article/2159245/ where-does-imran-khans-government-stand-chinas-belt-and-road.

Islam, Muinul (2016). Regional Connectivity: Current Challenges for Bangladesh. Paper prepared for presentation in the regional seminar of the Bangladesh Economic Association-Chittagong Chapter. Retrieved 20 March 2020 from https://www.bea-bd.org/site/images/pdf/mui.pdf.

Jahanmal, Zabihullah (2017, April 22). 'Afghanistan, China to Connect through Fiber Optic Network'. Tolo News. Retrieved 10 March 2020 from https://tolonews.com/ business/afghanistan-china-connect-through-fiber-optic-network.

Kaplan, Robert D. (2013). The Revenge of Geography. New York: Random House.

Karim, Mohd Aminul \& Islam, Faria (2018). 'Bangladesh-China-India-Myanmar (BCIM) Economic Corridor: Challenges and Prospects'. Korean Journal ofDefense Analysis, 30(2), 283-302.

Katoch, Dhruv (ed.) (2019). India's Foreign Policy: Towards Resurgence. New Delhi: Pentagon Press.

Khurana, Gurpreet S. (2019). 'India as a Challenge to China's Belt and Road Initiative'. Asia Policy, 14(2), 27-33.

Marshall, Tim (2019). Prisoners of Geography. London: Elliott and Thompson.

Ministry of External Affairs (2017, May 13). 'Official Spokesperson's Response to a Query on Participation of India in OBOR/BRI Forum'. Government of India. Retrieved 6 July 2020 from https://mea.gov.in/media-briefings.htm?dtl/28463/Official+Spoke spersons+response+to+a+query+on+participation+of+India+in+OBORBRI+Forum.

Modi, Narendra (2018). 'Prime Minister's Keynote Address at Shangri La Dialogue (June 01, 2018)'. Ministry of External Affairs, Government of India. Retrieved 10 December 2019 from https:/www.mea.gov.in/Speeches-Statements.htm?dtl/29943/ Prime+Ministers+Keynote+Address+at+Shangri+La+Dialogue+June+01+2018.

Mohan, C. Raja (2014a, August 13). 'Chinese Takeaway: One Belt One Road'. Indian Express. Retrieved 23 February 2020 from https://indianexpress.com/article/ opinion/columns/chinese-takeaway-one-belt-one-road/.

Mohan, C. Raja (2014b, September 15). 'Silk Route to Beijing'. Indian Express. Retrieved 23 February 2020 from https://indianexpress.com/article/opinion/ columns/silk-route-to-beijing/. 
Murton, Galen, Lord, Austin \& Beazley, Robert (2016). 'A Handshake across the Himalayas: Chinese Investment, Hydropower Development, and State Formation in Nepal'. Eurasian Geography and Economics, 57(3), 403-432.

Nataraj, Geethanjali \& Sekhani, Richa (2015). China's One Belt One Road - An Indian Perspective. Economic and Political Weekly, L(49), 67-71.

Onmanorama (2020, June 17). 'Despite Modi's 5 China Trips \& 18 Meetings with Xi, Sino-Indian Border Dispute Escalates'. Retrieved 6 July 2020 from https:// www.onmanorama.com/news/nation/2020/06/17/narendra-modi-china-sinoindia-border-dispute.html.

Panda, Jagannath P. (2019, November 4). 'Xi's Nepal Visit Reveals a Grander Chinese Himalayan Approach'. Institute for Defence Studies and Analyses. Comment. Retrieved 17 March 2020 from https://idsa.in/idsacomments/ xi-nepal-visit-jpanda-mrittika-041119.

Pande, Aparna (2018). From Chanakya to Modi: Evolution of India's Foreign Policy. Noida: HarperCollins.

Ramachandran, Sudha (2019, July 22). 'How Bangladesh Learned to Love the Belt and Road'. The Diplomat. Retrieved 13 March 2020 from https://thediplomat. com/2019/o7/how-bangladesh-learned-to-love-the-belt-and-road/.

Sachdeva, Gulshan (2018). 'Indian Perceptions of the Chinese Belt and Road Initiative'. International Studies, 55(4), 285-296.

Samaranayake, Nilanthi (2019, April). 'China's Engagement with Smaller South Asian Countries'. Special Report no. 446. United States Institute of Peace (USIP). Retrieved 4 March 2020 from https://www.usip.org/publications/2019/o4/ chinas-engagement-smaller-south-asian-countries.

Sapkota, Rupak (2017). 'Nepal in the Belt and Road: New Vista on Building a ChinaIndia-Nepal Economic Corridor'. China International Studies, Nov.-Dec., 105-121.

Sautman, Barry \& Hairong, Yan (2019, May 6). 'The Truth about Sri Lanka's Hambantota Port, Chinese "Debt Traps" and "Asset Seizures"'. South China Morning Post. Retrieved 12 March 2020 from https://www.scmp.com/comment/ insight-opinion/article/3008799/truth-about-sri-lankas-hambantota-portchinese-debt-traps.

Shrestha, Min B. (2017). 'Cooperation on Finance Between China and Nepal: Belt and Road Initiatives and Investment Opportunities in Nepal'.Journal of Finance and Data Science, 3, 31-37.

Sibal, Kanwal (2014, February 25). 'Silk Route to Tie India in Knots'. Ministry of External Affairs, Government of India. Retrieved 10 December 2019 from https://mea.gov.in/articles-in-indian-media.htm?dtl/22999/Silk+route+to+tie +India+in+knots.

Singh, Abhijit (2019). 'Sino-Indian Dynamics in Littoral Asia: The View from New Delhi'. Strategic Analysis, 43(3), 199-121. 
Singh, Zorawar Daulet (2014). 'Indian Perceptions of China's Maritime Silk Road Idea.' Journal of Defence Studies, 8(4), 133-148.

Song, Lei Lei (2019, August 2). 'How South Asia Can Continue as World's Fastest Growing Subregion'. Asian Development Bank. Retrieved 19 February 2020 from https://www.adb.org/news/op-ed/how-south-asia-can-continueworld-s-fastest-growing-subregion-lei-lei-song.

Times of India (2020, February 23). 'US Surpasses China to Become India's Top Trading Partner'. Times of India. Retrieved 23 February 2020 from http://timesofindia. indiatimes.com/articleshow/74264798.cms?utm_source=contentofinterest\& utm_medium=text\&utm_campaign=cppst.

Titumir, Rashed Al Mahmud \& Rahman, Zahidur (2019). 'Strategic Implications of China's Belt and Road Initiative (BRI): The Case of Bangladesh'. China and the World 2(3), 1-59.

Uberoi, Patricia (2016). 'Problems and Prospects of the BCIM Economic Corridor'. China Report, 52(1), 19-44.

World Bank (2018). 'Realizing the Promise of Regional Trade in South Asia'. Retrieved ${ }_{17}$ February 2020 from https://www.worldbank.org/en/news/feature/2018/10/og/ realizing-the-promise-of-regional-trade-in-south-asia.

World Bank Data (2020). Retrieved 17 February 2020 from https://data.worldbank. org/region/south-asia.

Xavier, Constantino (2020, January). 'Sambandh as Strategy: India's New Approach to Regional Connectivity'. Brookings India Policy Brief 012020-01. Brookings Institution India Center. Retrieved 31 January 2020 from https://www.brookings.edu/wp-content/uploads/2020/o1/India's-New-Approach-to-RegionalConnectivity-V/_M.pdf.

\section{About the Author}

RiCHARD GHIASY is a Senior Fellow at LeidenAsiaCentre and a Subject Matter Expert at The Hague Centre for Strategic Studies (HCSS). His main interests lie in Asian geopolitics and geoeconomics, EU-Asia relations, China's foreign and security policy, and conflict prevention. As a former Associate Researcher at Stockholm International Peace Research Institute (SIPRI), he has provided policy advice to inter alia the EEAS, European Commission, government ministries, the Organization for Security and Co-operation in Europe (OSCE), and the Organisation for Economic Cooperation and Development (OECD). Richard is a member of the Belt and Road Research Platform and the Stockholm Observatory for Global China at the Swedish Institute of International Affairs (UI). 


\title{
12 Geographic Agency
}

\author{
Iran as a 'Civilizational Crossroads' in the Belt and Road \\ Geography
}

Mohammadbagher Forough

\begin{abstract}
Chapter 12 focuses on Iran and tackles two issues. First, it seeks to demarcate the conceptual boundaries of 'geographic agency'. Second, it attempts to apply this concept to the case of Iran. Adopting a critical geography approach, the chapter unpacks how Iran is reinventing itself geographically through certain 'space-making processes' and 'space-framing assumptions'. The chapter argues that Iran is showing agency at three geographical levels: 1) as a nation state, it is systematically representing the 'idea of Iran' as a 'civilizational crossroads'; it does so 2) in a region that the Iranian government chooses to call 'West Asia' (and not 'the Middle East'), and 3) in an emergent world whose organizing trope is a 'New Silk Roads' imaginary and which has a geoeconomic rather than geopolitical logic.
\end{abstract}

Keywords: Belt and Road Initiative, Iran, geographic agency, Silk Roads, China, civilizational crossroads

If the twentieth century was defined mostly by geopolitics and mostly by Western actors, this century is being defined increasingly by geoeconomic processes mostly instigated through the agency of Asian actors such as China, India, and others. ${ }^{1}$ If the previous century was about establishing Westphalian political borders to separate nation states, this century is increasingly about how infrastructure can create further 'connectivity' among economies, cultures, and peoples. This connectivity brings both

1 This is not to say that the former century lacked geoeconomics or the current one lacks geopolitics.

Schneider, Florian (ed.), Global Perspectives on China's Belt and Road Initiative: Asserting Agency through Regional Connectivity. Amsterdam, Amsterdam University Press 2021 DOI: 10.5117/9789463727853_CH12 
opportunities and risks (such as the current pandemic, COVID-19). The Chinese Belt and Road Initiative (BRI) is currently the most forceful and the only truly global initiative in the world in terms of the economic, diplomatic, and discursive momentum that it has created. However, the BRI is not the only initiative and China is not the only actor showing such agency. The International North-South Transport Corridor (INSTC) aims to link India via Iranian land to Russia, Central Asia, and Europe. The Russian initiative, the Eurasian Economic Union (EAEU), aspires to geoeconomically (re) connect the former geography of the Soviet Union. Finally, the Ashgabat Agreement aims to connect Central Asia to international waters via Iran and the Persian Gulf.

A new geographic imaginary and global centre of gravity is emerging. This new centre has been described as 'Asia', 'new continentalism in Eurasia' (Calder 2012), 'Afro-Eurasia' (Frankopan 2015), or the 'East' leading to the 'Easternization' (Rachman 2017) of global geography. No matter which trope one adopts, West Asia or the Middle East plays a significant role in it. Its role is considerable for a host of important reasons and processes, which include global energy (production, transit, pricing, and conflicts), refugees, Persian Gulf security, nuclear non-proliferation, political Islam, non-state actors (such as Hezbollah and Hamas), the Israeli-Palestinian conflict, civil wars (such as that in Syria), regional tensions (such as the Saudi-Iranian rivalry), the Chinese BRI, the International North-South Transport Corridor, the Ashgabat Agreement, the Russian Eurasian Economic Union, as well as others.

Iran, which is centrally located at the heart of West Asia, is in one way or another deeply enmeshed in all these geoeconomic and geopolitical processes in the region and beyond. More often than not, the academic literature focuses on Iran only geopolitically. This chapter aims to address this gap in the literature by focusing on Iran's role in Eurasian geoeconomics. The questions that this chapter aims to address are 1) How is Iran adapting to the geoeconomic shifts unfolding in Eurasia, especially the rise of actors such as China and the advent of the BRI? and 2) How is Iran reimagining its 'place' and the place of its region in global geography? Adopting a critical geography perspective, which views geography as simultaneously both material and ideational, this chapter aims to address these questions by doing an analysis of both the ideational developments (the discursive developments) and the material developments (the policies and infrastructure processes) in which Iran is engaging.

The overall argument of this chapter is that in the context of contemporary geoeconomic processes, Iran is showing geographic agency by actively 
engaging in geoeconomic processes that are transforming not only global and regional geography but also Iranian national self-perceptions. Under contemporary conditions, Iran is geographically reimagining itself at three levels: Globally, Iran views the contemporary world in terms of the rise of 'the East', rise of Asia, and particularly in terms of the rise of the (New) Silk Roads, hence its 'turn to the East'. Regionally, it is articulating its preference for the concept of 'West Asia' to replace 'the Middle East', which it views as Eurocentric. Nationally, Iran is reimagining itself as a 'civilizational crossroads' between various economies, peoples, and civilizations. The three geographic reimaginings are deeply interlinked with each other and deeply rooted in Iranian history. In terms of the BRI, Iran is increasingly becoming integral (if not indispensable) to the China-Central Asia-West Asia (CAWA) Corridor.

The argument laid out above will unfolded in this chapter as follows: Section 2 will introduce the concept of geographic agency. Section 3 will briefly review the literature on the changing 'idea of Iran'. Section 4 will examine Iranian geographic assumptions about the rise of the New Silk Roads, the Iranian policy of 'turning to the East', and its preference for 'West Asia' as the name of the region. Then Section 5 will unpack Iran's new geoeconomic self-perception, what I call 'Iran as a civilizational crossroads' with its concomitant policies of port modernization and railway upgrade. This will be followed by a conclusion.

\section{Geographic Agency}

This section demarcates the conceptual boundaries of what I call geographic agency. First, geography. Traditionally, in the humanities, geography has been understood in terms of 'absolute space' that is rooted in Newtonian physics. In this conception, absolute space is understood, according to Harvey (2006: 121), as an absolute 'pre-existing and immovable grid amenable to standardized measurement and open to calculation'. The field of international relations (IR) has not been an exception to this rule. It has also suffered from such problematic 'geographical assumptions', including the 'territorial trap' of sovereignty (Agnew 1994), or what Larkins (2010) calls the 'territorial apriori [sic]'. These are assumptions that render IR state-centric (Guzzini \& Leander 2006), Eurocentric and ahistorical (Van der Pijl 2007), and West-centric (Bilgin 2010).

Critical geography aims to avoid such problematic assumptions by conceiving of geography as both ideational and material. Like many other 
critical schools of thought, it was a brainchild of the late 1960s and early 1970 on and was a response to the major issues of the time. These were issues such as the rise of civil rights and student movements, environmental movements, and the Vietnam War (Peet 200o). Traditional geography, according to Peet (ibid.), was part of a conservative shift in Enlightenment thinking in the late nineteenth century. Spatial science could be progressive only in the sense of 'social engineering rather than the organic sense of social transformation' (ibid.: 951). Critical or radical geography became critical of positivist schools of thought and methodologies. It went through several transformations that brought under its umbrella various critical schools of geography, such as Marxism, feminism, poststructuralism, postmodernism, and discourse analysis. Critical geography aims to approach the question of space as a dynamic process that both constructs and constrains social, political, and economic processes and is simultaneously constructed and constrained by them. It aims to remain socially and politically relevant, to uncover hegemonic arrangements, geographies of resistance, fears and hopes, and unpack (in)justices and power relations that are often hidden in geographic representations.

More specifically, this chapter will draw on the theoretical work of Matthew Sparke. He focuses on the hidden hyphen in the word 'geo-graphy', calling for a 'persistent examination in terms of acknowledging how the 'geo' of any particular geography is 'graphed', that is to say, produced, by multiple, often unnoticed, space-making processes and space-framing assumptions (Sparke 2007:338). The main objective of this chapter is to investigate these 'processes' (material geography) and 'assumptions' (ideational geography) that are at work in Iranian geographic agency.

What of agency? And how does it play into geography? Critical geography argued that traditional notions of geography and spatial thinking were themselves instruments of hegemonic power and oppression. These notions took agency away from oppressed actors and populations and represented them in a reductionist or negative manner, or simply did not represent them. Critical geography is more interested, as mentioned above, in doing justice to local representations and 'organic social transformations'. Part of such organic social transformations, I would argue, is the ability of actors to have agency over geographic matters and to define their own place in the various spaces of global geography. For the purposes of this chapter, geographic agency can be defined in a twofold fashion. Ideationally, it is the discursive ability of an actor (such as a group of people, an individual, or an organization) to define, articulate, and (rep)present themselves and their place (their identities, fears, and aspirations) in the world geographically; 
practically, geographic agency can be defined as the ability of the said actor to act in the world (through actions and implementing policies) to materialize their geographic discourse and self-representations. The two dimensions are inextricably interlinked.

Regarding methodology, the following approaches have been taken. To examine the ideational aspect (or 'space-framing assumptions'), the discourses of Iranian official outlets have been analysed to examine how Iran is geographically reimagining itself. Such outlets include announcements, policy documents, and policy speeches by the Iranian leader, Ayatollah Khamenei, the Iranian President (Hassan Rouhani), the Iranian Foreign Ministry, the Ministry of Transportation, and the Iranian Railways (RAI). They also include some (semi)official news outlets. For the material aspect (or space-making processes and policies), the chapter draws on the knowledge gained by the author during years of attending global academic workshops and conferences related to the topic (in both China and Iran), and attending think tank events about the topic in several countries. It also draws on eight field trips that the author has made to Iran in the last five years in order to investigate its role in the BRI and other initiatives. These include three recent trips that were made in late 2019 and 2020 specifically to gain the latest updates and carry out interviews to be included in this chapter. The recent field research included visits to the Iranian capital of Tehran to conduct semi-structured interviews with academics and policymakers in institutions including the Eurasia Center at Tehran University, the Chamber of Commerce, the Foreign Ministry, Boushehr (to investigate China's interests in Iranian energy resources), and Chabahar Port (to investigate Chinese and Indian interests in the International North-South Transport Corridor).

\section{'The Idea of Iran'}

This section offers a brief review of the literature about what Gnoli (1989) called 'the idea of Iran' and some of the momentous changes in the Iranian self-perception throughout history. Since their conception, terms such as 'Iran' and 'Iranians' have been contested concepts. Their meaning has been debated throughout the civilization's long history, a history of dominating, occupying, and traumatizing the region as well as being dominated, occupied, and traumatized by the forces of the region and beyond. The ebbs and flows of Iranian history show 'the remarkable resilience of the idea of Iran' (Axworthy 2008: xi). What is this idea? 
The agricultural settlements or villages in what is today Iran have been traced back to at least the sixth millennium BCE' (see Berkowitz 1996; Axworthy 2008). However, most of the Iranian popular and official discourse starts the historical narrative with the Achaemenid Empire (c. 550-330 BCE), the so-called First Persian Empire, founded by Cyrus. Since its advent, a foundational question has been what to name its geography and the rich diversity of its multinational state. The Achaemenid inscriptions did not define their kingdom in a geographic or ethnic sense (Gnoli 1989: 6). This was natural as the idea of the empire meant the whole globe (ibid.). Cyrus defined himself as 'the King of Kings'. Later emperors referred to themselves as 'the king of lands', 'king of the peoples', or the 'king of this (far-reaching) earth' (Gnoli 1989: 6-7). This empire, Gnoli argues, can be best known as the 'earth-empire' (ibid.: 7). Alexander put a brutal end to it, but the idea of this empire survived through absorbing Hellenistic culture and administration.

The idea of Iran returned with the Sassanian Empire (224-651 CE), this time with a more formulated agenda for territorial and political demarcation. This empire tried to create a systematic history and a definition of the medieval Iran. The word Iran is derived from èrān, the first existing record of which dates back to the investiture reliefs of Ardashir, the founder of Sassanian Empire. The geographic space that these people occupied came to be called 'Iranshahr' or the land or 'empire of the Iranians'. Anērān meant those subjects, peoples, and provinces that were part of the Iranian empire (such as present day Cappadocia, Syria, and Egypt) but whose peoples were not considered to be of Iranian identity. Little by little, èrān took on a geographic dimension and meant the land of Iranians. This obviously came into effect through imperially 'overwhelming the indigenous populations politically, linguistically, and culturally' (Malandra 2005: 116).

The Iranian narrative or myth of origin, and the sense of Iranian nationalism for many Iranians today, is rooted in these two pre-Islamic empires. In terms of physical geography, these two empires occupied and spread Iranian influence in the area between the Mediterranean Sea and the Indus River. They built major infrastructure projects that connected various parts of the empire. The most famous of these projects was the Royal Road built by Darius in the fifth century BCE, which was one of the first transcontinental highways, so to speak, built in global history, spanning from the south of Iran to present day Turkey (back then part of Achaemenid Empire). These infrastructure projects together with the state security provided by these two empires contributed immensely to the advent and operation of what we call the ancient Silk Roads geography. The Sassanians controlled much of Western Asia until it fell to the emergent Islamic Empire that began the Islamization of the country. 
Iran survived this invasion and absorbed the new ideas of Islam. Arab conquerors became Persianized (Canfield 2002: 4). Zoroastrianism did not survive as the state religion and Iran was Islamicized. Islam was partly Iranicized as well. After the Arab rule of Iran, the Samanid Empire (819 to 999) came to power, the first Iranian empire to rise after the invasion. The empire's religion was Sunni Islam, but it was tolerant of Shia Islam (Daniel 2012). It became independent of Arab rule and revived the Farsi language and culture, and with that the idea of Iran as an empire. This empire is regarded in today's scholarship as part and parcel of the 'Turko-Persian Islamicate culture', which is defined as an 'ecumenical mix of Arabic, Persian, and Turkic elements that melded in the ninth and tenth centuries in eastern Iran' and was carried 'to neighbouring areas, so that it eventually became the predominant culture of the ruling elite classes of West, Central and South Asia' (Canfield 2002: 1). Canfield goes on to write that the 'underlying stratum from which Turko-Persian Islamicate culture sprang was Persian'. This Persian stratum was rooted in the Achaemenid and Sassanian Empires (ibid.) and the material and ideational infrastructure they had built in the region.

Later dynasties further redefined Iran. The Safavids (1501-1736) converted the country to Twelver Shia Islam, which is the foundation of the contemporary official religious identity of the country. Other changes include the conquest of Iran by the Mongols between 1219-1221 (who also became Persianized), the invasion by Tamburlaine in 1383 (whose empire was also Persianized), and the conquest of India by the Iranian Nader Shah (1736-1747). Then there is also the idea of constitutional monarchy, which Iranians got from Europeans during the Qajar dynasty (1789-1925), the turn back between 1925 and 1935 to the absolutist dictatorship of the Pahlavi dynasty (a close ally of the West), and once again the return to political Islam with the 1979 revolution. To sum up, Iranian geography has always been a malleable heterogeneous repertoire of identities. As I will show in the next sections, the current Iranian ruling elites resort to both Islamic and pre-Islamic parts of Iranian history in order to make geographic and historical sense of the position of the country in the world today. The idea of Iran has always been creatively and conveniently (mis)read, (re)made, and revised by Iranians at moments of great strength or great weakness, as well as at moments of change such as our contemporary era. Selden (2013: 143) argues that 'creative mythmaking [...] has always served progressively to consolidate the identity of Iran'. Along the same lines, Axworthy (2008:12) rhetorically asks:

If [...] the centre of Iranian culture had moved at different times from Fars in southern Iran to Mesopotamia, to Khorasan in the north-east and 
Central Asia, and to what is now called Azerbaijan in the north-west; and given its strong influence far beyond the land of Iran itself, into Abbasid Baghdad and Ottoman Turkey for example on the one side and into Central Asia and Moghul India on the other, and beyond; then perhaps we should set aside our usual categories of nationhood and imperial culture and think instead of Iran as an Empire of the Mind?

In the following sections, I will unpack the ways in which the emergence of new Asian geoeconomic initiatives in general and the BRI in particular have impacted the idea of Iran.

\section{Iran Reimagining Global and Regional Geography}

Iranian geographic agency manifests itself most broadly at the global or continental level in actively promoting the revival of 'Silk Roads geographic imaginary', as well as presenting the rise of Asia or 'the East' (as a spaceframing assumption) and the 'turn to the East' strategy (as a space-making process or official policy). This section will argue that both the 'imaginary' and the 'turn' had already been at the heart of the Iranian official geographic discourse before the advent of the BRI. However, these have found clear unmistakable discursive, material, infrastructural, and policy expressions with the emergence of the BRI and other initiatives. At the regional level, Iranian officials are articulating their unmistakable preference for the geographic concept of 'West Asia' over 'the Middle East'.

\section{Iran Promoting the Revival of Silk Roads}

First, a caveat. There is a tendency in global mass media and even among some experts to associate the ancient Silk Roads with China (as if they were a highway between Rome and Beijing) and also to associate the new Silk Roads with China's BRI. Both accounts are simplistic and false. The ancient Silk Roads were 'not an actual road, but a stretch of shifting unmarked paths across massive' geographies of Afro-Eurasia (Hansen 2012: 5), hence the plural concept of 'Roads' used in this chapter. Nor is the idea of New Silk Roads a Chinese concept. The discourse has been alive and well in Iran, and in other countries in Asia, especially Central Asia, since at least the 1990 s.

Khamenei, who has been the Iranian leader since 1989, has been promoting this idea for a long time. In his 2009 meeting with Abdullah Gul, then Turkish president, Khamenei talked about how 'Iran and Turkey are capable 
of reviving the Silk Road' (Khamenei 2009). Khamenei's 2009 remarks about reviving the Silk Road is evidence of how the discourse of Silk Roads existed long before the BRI. It is not far-fetched to trace this idea back to TurkoPersian Islamic civilization discussed in the previous section. An even earlier attempt by Iran to revive this particular moment and geography of ancient Silk Roads is the very idea of the Economic Cooperation Organization (ECO), which is a regional integration organization (similar to the idea of ASEAN) that was set up in 1985 by Iran, Turkey, and Pakistan. When put together, the geographies of these three countries resonate with the geography of the Turko-Persian Islamicate cultures of the ninth and tenth centuries. The Economic Cooperation Organization's secretariat is based in Iran. De Cordier (1996) described the logic of this organization as 'New Silk Road', a 'road' intended to create 'a common destiny' (ibid.) for the three countries involved, thus eerily foreseeing the concept of the 'community of common destiny' adopted by the current Chinese President Xi Jinping in recent years.

The rise of the BRI gave a major boost to Iran (among others) in its promotion of the (New) Silk Roads discourse. There are several interesting reasons why Iranian elites have opted to refer to the BRI as the 'New Silk Roads'. First and foremost, it is easier for the audience of this discourse to understand the concept of the 'New Silk Roads' than to understand the new concept of the BRI. When described as the 'New Silk Roads', the Iranian and regional audiences can more readily understand the idea and its global implications. It resonates with both the elite and the general population in Iran. This is because various Iranian empires (such as the Achaemenid, Sassanian, and Sassanid dynasties) had a foundational or instrumental rule in the ancient Silk Roads. The idea of the Silk Roads is part of the collective historical and geographical consciousness of the nation. The role of the country in that world (and the myths therein) is invoked to suggest the promise of the future role of the country in the New Silk Roads, especially in the BRI.

This discourse also provides Iran and its regional or global partners with a common cultural, historical, and geographical language to speak with each other about their (desired) place in this brave new world. Chinese President Xi Jinping's visit to Iran in 2016 included paying a visit to the Iranian leader, Khamenei. During this visit, Xi pointed to the relations and interactions between the two civilizations along the ancient Silk Roads as the basis upon which future cooperation along the New Silk Roads could be built (Office of the Supreme Leader 2016). Iran's spatial assumption, one can infer, is that the Silk Roads constitute the next iteration of human globalization, a world in which Iran could not be sidelined due to the 'the centrality of Iranian geography'. This geographic centrality is a theme that 
comes up in every part of Iranian official geographical discourse and the interviews conducted.

It should be noted that the use of the term 'Silk Roads' by both the Iranian elites and ordinary citizens brings forth an often overly romanticized myth of the ancient Silk Roads. In this myth, it is assumed that Iran reigned supreme, although in reality it did so only at certain times and only over certain parts of that geography. At other moments, Iran was brutally victimized. There is a subconscious selectiveness at work in sidestepping the traumatic moments of history and focusing on the successful empires only. Along the same lines, there is also a selectiveness in the way that Iran has defined 'the East'.

\section{The 'Turn to the East'}

The rise of the New Silk Roads in Iranian official discourse is coterminous with the rise of Asia or 'the East'. Iranian leaders have opted for what has been named the 'turn to the East' or the 'look to the East' strategy as a policy that encompasses Iranian political, economic, and infrastructural involvement in the BRI, as well as in other initiatives such as the International North-South Transport Corridor (INSTC), the Eurasian Economic Union (EAEU), and the Ashgabat Agreement. For Iran, 'the East' was formerly synonymous with the Soviet Empire. However, in more contemporary official discourse, and due in part to the Soviet collapse and the geopolitical realities of Iran (such as the Western sanctions), 'the East' as a geographic discourse has undergone a transformation and taken on positive connotations. It now stands for Asia and represents economic and scientific progress. This progress is especially associated with actors such as China, India, Russia, and Turkey. Iran has pragmatic relations with all of these 'Eastern' actors.

The 'turn' to the East involves relying on foreign relations (both geoeconomically and geopolitically) with these 'Eastern' actors. This is done partly to evade the negative effects of the American sanctions regime, and to develop what has come to be known as the 'resistance economy'. It is also done partly out of cultural familiarity and mutual interests. According to Khamenei, who determines or at least officially greenlights all of Iran's strategic policies, this approach can be described as follows: '[R]egarding the realm of foreign policy, we should prefer the East to the West and neighbours to distant countries. We should choose nations and countries that share common interests with us' (Khamenei 2018b).

China and Iran do not currently lack common interests. This 'turn to the East' is being solidified in the backdrop of a Sino-Iranian 'comprehensive strategic partnership'. This partnership involves the BRI in more ways than 
one. Since Xi Jinping's 2016 visit to Iran, the two countries were rumoured to have been negotiating a comprehensive '25-year deal' or 'roadmap' (see New York Times 2020). This deal is supposed to cover all major areas of cooperation, including the energy sector (oil, gas, and petrochemicals), infrastructure, (multi-modal) transport, sizable investments in Iranian manufacturing, free economic zones (such as the Island of Qeshm), banking, industrial parks, and closer defence and intelligence cooperation in West Asia. The deal is estimated to be worth around US $\$ 400$ billion. The investments are from China to Iran. In return, China gets discounted Iranian energy. The general outline of the deal was confirmed by Javad Zarif, the Iranian Foreign Minister, in July 2020. The full details are yet to be made public. The deal, when finalized, will wed Iran to the BRI. It has divided the country. Some view it as an economic lifeline for Iran (whose economy and currency are at the moment under heavy pressure). Meanwhile, others (especially in popular Iranian social media circles) are very suspicious of the deal, suspicions that in too many cases are articulated through Sinophobic sentiments.

The same division exists with regards to the 'turn to the East' strategy. There are some factions within the ruling elites and the general population that prefer more cultural and economic ties with 'the West'. The ill-fated nuclear deal was carried out by this camp. However, with America reneging on the deal, and the Europeans being unwilling or unable to make a meaningful move independent of the US that would compensate for the damage that the US has introduced to the deal's dynamics, the 'turn to the East' strategy is witnessing increasing momentum. With the 25-year deal between China and Iran in the process of being finalized, this Iranian 'turn to the East' looks almost inevitable. The more pro-'Western' camp has been reduced to silence and compliance. In terms of relations with India and Turkey, there is agreement between all factions (conservative and moderate) that deeper relations with these two actors are positive for the country. Feelings about Russia show the same kind of ambivalence and division as those about China. However, the direction is clear. Iran is both choosing, and being forced by 'the West', to 'turn to the East'. All this is evidence of how relational, malleable, and contingent geoeconomics is.

\section{Iran Reimagining the Region as 'West Asia'}

If the new 'East' is synonymous with 'Asia', what kind of 'middle' does the 'Middle East' occupy as a region? One way in which Iran shows geographic agency has been through reconceiving the region in its official discourse 
as 'West(ern) Asia'. This is one of the most explicitly articulated examples of Iranian geographic agency that has been implemented in a top-down fashion, starting from the highest political-religious power in the country, the Iranian leader himself. From his office, this regional renaming discourse has percolated down to other political, economic, and media organizations. Khamenei never refers to the region as the Middle East in his speeches. The same is true for online archives, websites, and social media accounts associated with him or representing him or his office. In a 2012 speech to an academic audience, he made his geographic reasoning clear:

I insist on calling this region 'West Asia', not 'Middle East'. The terms 'Far East', 'Near East' and 'Middle East' are not correct. Far from where? From Europe. Near to where? To Europe. This implies that Europe is the centre of the world. [...] This is a definition that was presented by Europeans themselves, but this is not acceptable to us. Asia is a continent. It has an eastern part, a western part and a middle part. We are in the western part. Therefore, our region should be called 'West Asia', not 'Middle East'. (Khamenei 2012)

There are several aspects of this quote that are interesting. First it provides an accurate historical narrative of the origins of the term 'Middle East'. According to Beaumont et al. (1976: 1), the term Middle East was developed out of a 'strategic preference' in a 'Eurocentered world just as the older terms "The East”, "Far East”, and "Near East" had been' (ibid.). 'The Middle East' seems to have originated in the 1850 s in the British imperial office. It became 'current in the English-speaking world around 1900' (ibid.). Second, this is a surprisingly progressive view of geography from a conservative religious leader. In today's academic circles, especially the critical strands of the social sciences, Eurocentric or Orientalist views of global history and geography are being radically questioned (see Van der Pijl 2007 and Said 1979, respectively). For Iran, one can infer from the discourse that part of the logic of jettisoning the term 'the Middle East' is to do away with all the negative Orientalist connotations associated with the term and (re-)associate the region with Asia. Getting rid of the term aims to remove the vestiges of the imperialistic geographic imagination that named this geography 'the Middle East' and to rebrand the region in a new light. This is a clear sign that Iranian elites consciously and explicitly are aware of the constructed nature of geography and are actively engaged in the making of both the discursive and material geography of the country and the region. This is an instance of Iranian elites exercising their geographic agency. Apart from 
the push to call the region 'West Asia', other examples of this kind of agency are the creation and promotion of geopolitical terms such as the 'axis of resistance', a term used by Iranian elites to refer to Iran and its (state and proxy) allies in resisting American hegemony in the region.

It is therefore no surprise that the term 'West Asia' is being increasingly used by Iran and several other actors in the region and the rest of Asia. Among others, Chinese, Indian, Iranian, Turkish, and some Arab official discourses also refer to the region as 'West Asia', especially in their interaction with each other. In the official United Nations demarcations of regions in the world, 'Western Asia' is the official designation for this region. What is more, one of the six official economic corridors of the BRI that passes through the region is China-Central Asia-West Asia (CAWA) Corridor. In official discussions across Asia, the 'West Asia' discourse has gained increasing momentum since the advent of the BRI and the emergence of a Silk Roads geographic imaginary, especially when the interlocutors in these discussions are all from Asia.

One can argue that the rise of this 'West Asia' discourse shows the geographic agency of a whole region, or even a continent, that aims to rename and reclaim this region as part of Asia and the Asian heritage. It should however be noted that just as the choice of 'the Middle East' was a Western strategic and military choice, the choice of 'West Asia' made by Iran and other Asian actors is also a strategic choice. As the former Western discourse negatively (geo)politicized the region for (neo)colonial purposes, the new 'West Asia' discourse is also aiming to (geo)politicize the region (albeit in a way that is beneficial to Asian actors). This latter naming discourse is yet another political project that does not aim to separate geography from power relations. It aims to reclaim power.

\section{Iran Reimagining Itself as a 'Civilizational Crossroads'}

If contemporary Iranian geographic agency contends that the emerging global geography is a (New) Silk Roads geography, in which 'the East' or Asia is rising, and if the region is not 'the Middle East' but 'West Asia', then what is Iran? What kind of space-making assumptions and space-making processes or policies is Iran in the business of promoting or implementing about its role in the emerging regional or global geography? Such assumptions include, first, the idea of 'greater Iran' as a 'civilizational state' and, second, the idea of Iranian geography as a 'civilizational crossroads'. Three processes or policies that are being carried out in order to make the crossroads dream 
a reality are 'port connectivity policies', 'the railway revolution', and the international 'geoeconomic connectivity push'. These policies all result in international pacts, agreements, and initiatives. In what follows, I will briefly elaborate on the two assumptions about the identity of Iran and the three processes to which they lead.

\section{Space-Framing Assumptions: 'Greater Iran' as the 'Civilizational Crossroads'}

One common theme that appears in official Iranian discourse (politically and academically) is the idea of 'greater Iran', sometimes also called 'greater cultural Iran'. The expression is common among Western classicists and means 'that which was within the political boundaries of states ruled by Iran, including Mesopotamia and usually Armenia and Transcaucasia' (Frye 1962: 241). The term is clearly an academic one, but it seems that Iranian political elites have picked up on this academic discourse and are using it as a cultural and economic category. One of the strategic edicts that Khamenei has given the Iranian elites is to conduct what he calls 'public diplomacy'. This involves activities such as gathering the (academic and cultural) elites of 'West Asia' together for dialogue in Iran. He places special emphasis on the elites of the 'greater cultural Iran, that is the vast cultural geography of Iran in previous centuries' (Khamenei 2018a). This is therefore a demarcation of Iranian boundaries that goes beyond the Westphalian notions of Iran and views the Iranian geography as culturally, historically, linguistically, and religiously rooted in the pre-Islamic and Islamic imperial geographies of the country. The hegemonic ambitions beyond the idea of 'greater Iran' is hard to miss here. This idea is not very different from Axworthy's (2008) description of Iran as an 'empire of the mind'.

One can see that Iran is once more delving deep in its ancient preWestphalian history in order to dream of a future for itself in what it calls the 'post-Western world' (Zarif 2016) of Silk Roads. Along the same lines, in a 2018 UN speech Iranian President Hassan Rouhani rejected accusations that Iran is after geopolitical domination of the region by describing his country in the following terms: 'Iran does not need an empire. Iran is an empire, in terms of its civilization and culture. Not through political domination. Iran has served as the link between East and West and will continue to do so' (Rouhani 2018). The two themes or assumptions that frame Iran are evident: Iran as a 'link' or 'crossroads', and Iran as a 'civilization'. The discourse has not been hierarchically produced. It is part of what, in the theory section of this chapter, was called an 'organic social transformation'. Most Iranians 
of all walks of life understand their country in terms that go beyond the Westphalian geographic imaginary of nation states. For some the frame of reference is the Islamic traditions of the past, while for others it is the pre-Islamic imperial traditions of Iran, and then for a third group it is a combination of both. An example of the latter is former President of Iran Mahmoud Ahmadinejad, who tried, in vain, to push both banners of the Islamic and pre-Islamic Iran. These two discourses are not limited to any specific faction within Iran. They usually co-exist in the official discourses and are employed on an as-needed basis.

In the meetings between Iranian and Chinese leaders, the civilizational discourse is abundant. At the very beginning of the negotiation documents for the '25-year deal', for instance, there are references both to the 'greatness' of the Iranian and Chinese civilizations in the past and also to how their contemporary cooperation, including in the BRI context, is 'natural'. I would argue that the numerous references to the 'Iranian civilization' and 'Persian cultural heritage' in documents amounts to calling Iran a 'civilizational state'. The idea of such civilizational states is gaining increasing discursive momentum in Asia. Zhang (2012), for example, calls China a 'civilizational state' (his eponymous book became a bestseller in China). Meanwhile, Kumar (2002) calls India a 'civilization-state'. One can only infer that this is the discursive tool these actors choose to use in order to make sense of their long and complex history and geography in a Westphalian system of 'nation states' that is less than 500 years old. Without using this term explicitly, the Iranian discourse of 'greater Iran' is making a very similar geographical-historical-political move. Not only does Iran see itself as a 'civilization', but it sees itself as one whose identity is that of a 'link' or 'crossroads' between various other civilizations, economies, and cultures.

\section{Space-Making Processes: Connectivity Policy Drive, Port Modernization, and Railway Revolution}

In what follows, I will examine some of the policies and processes that Iran is actively pursuing in order to make its dream of being a 'civilizational crossroads' dreams become a reality. The first process discussed here is what can be called Iran's international 'geoeconomic connectivity drive'. It dates back to the early years of the Iranian Revolution of 1979 and aims to geoeconomically connect the country with the region and beyond. Immediately after the revolution, Iran initiated talks concerning founding the Organization for Economic Cooperation (ECO), which was discussed above. Turkey and Iran are particularly interested in the prospect of signing a free 
trade agreement under the auspices of this organization or in the form of a free trade agreement.

Iran has also enthusiastically welcomed the BRI and is considered an integral part of the CAWA Corridor. This is the least developed corridor of those in the BRI. Its lack of development is due in large part to the geopolitical complexities of the region and the conflicting geoeconomic and policy interests of regional actors, which are too numerous to unpack here. After the Joint Comprehensive Plan of Action (the Iran Nuclear Deal) came into effect in 2015, the Chinese President Xi Jinping was the first foreign leader of a major country to visit Iran, rushing to the country and signing seventeen economic and security agreements and MoUs, covering the various dimensions of the BRI. During the trip, Xi emphasized the 'geographic, human, and energy' potential of Iran. It is not an accident that Iranian geography plays such a central role in the discussions between the two countries' leaders. This geographic awareness exists among both Chinese and Iranian political and economic elites. According to the Iranian President, China and Iran signed the preliminary version of a 'comprehensive 25-year document' (discussed briefly in the previous section). This document indicates how seriously China takes the question of Iran in the three areas that Xi pointed to. This close partnership between China and Iran has been referred to by American observers as China's 'Great Game' in Iran'. Such a description, however, assigns too much agency to China and too little to Iran. The former is portrayed as an all-powerful evil actor and the latter as a victim in this kind of analysis.

However, dealing with the BRI and China is not the only game in town for Iran. Iran was a founding member of the International North-South Transport Corridor in May 2002. India is currently the main drive behind this initiative. Effectively, one might call this the Indian Silk Roads. India has given this initiative serious attention since the BRI was introduced. The role of Iran and the Chabahar Port (discussed below) is indispensable in this initiative. Iran is also a major trade partner of the Russian geoeconomic initiative, the Eurasian Economic Union (EEU). Iran and the EEU signed a free trade agreement in 2018, to be operationalized from 2021. The two countries have also signed a preferential trade agreement, which has already boosted trade between them to some extent. All these geoeconomic initiatives also connect to the Ashgabat Agreement, in which Iran has a pivotal role due to the centrality of its physical geography. Geopolitics (for instance, American sanctions) has very negatively affected and slowed down these processes. However, Iran's geoeconomic foundations have been solidified enough to ensure that its role in these processes and initiatives cannot be denied. 
The second space-making process that Iran is involved in is 'port modernization'. Ports across Asia are gaining significant attention in the context of the BRI, of the International North-South Transport Corridor, and other initiatives. Iran, given its well-connected geography in the region, is no exception. This dimension of Iranian geography involves several ports, such as Bandar Anzali and Astara in the north and Bandar Imam Khomeini, Bandar Abbas, Bushehr, and Chabahar in the south. Due to the limited scope of this chapter, I will briefly focus on Chabahar and its role as the only deep water port in Iran that is officially associated with all the major initiatives mentioned in this chapter, especially the BRI and the International North-South Transport Corridor.

In 2016, after years of negotiations, Iran, Afghanistan, and India signed a trilateral connectivity pact, the centrepiece of which is Chabahar Port in south-eastern Iran. This pact shows the geographic agency of all these three countries. All three countries are trying to overcome specific geographic challenges (for example, the issue of being landlocked for Afghanistan) and produce new geographic opportunities for themselves. At the signing ceremony in Tehran, Ashraf Ghani, Afghanistan's President, said the following words in the presence of Rouhani and Narendra Modi: 'We wanted to prove that geography is not our destiny. With our will, we can change geography' (Financial Times 2016). If there were to be one definition of 'geographic agency', this could be it. Changing geography is part of a dominant global trend that Khanna (2016) calls 'connectography'. This can be defined, to use the Ghani quote, as the will to change one's geography, and therefore to change one's destiny, by creating new types of geographic, cultural, economic, energy, and political connectivity.

Chabahar Port is supposed to connect India via Iran to Afghanistan, so that Indian exports do not have to go through Pakistan. In terms of land access to the rest of Asia, the Caucuses, Russia, and Europe, Chabahar is now and for the foreseeable future the only reliable option that India has. This fact makes the Iranian geography indispensable for India. Chabahar is, in the words of the Indian Prime Minister Narendra Modi, a 'golden gateway' for India (Bhattacharjee 2018). Indian officials feel that the Chinese BRI has geopolitical and containment elements against India. They want to create India's own geoeconomic Silk Roads, if you will. This Indian dream, however, is completely dependent on passing through Iran. Other options would be going through either Pakistan or China, which Indian officials do not find ideal for obvious geopolitical reasons. Here, geopolitics is producing unique geoeconomic realities. This is something that Iranian elites are taking advantage of by further deepening their ties with India and bringing Indian investment to Chabahar 
Port to further develop it. As the only Iranian deep water port, Chabahar can potentially rival the Pakistani port of Gwadar (the two ports are close to each other). Gwadar is the centrepiece of the China-Pakistan Economic Corridor.

Ports are nothing if not connected to other major cities. India is therefore investing in the Chabahar-Zahedan Railway. Zahedan is the closest major Iranian city to Chabahar. This brings us to Iran's third space-making process or national policy intended to materialize the idea of Iran as a geographical and civilizational 'crossroads'. This involves building new railway lines and upgrading old ones, a process described by some as the 'Iranian railway revolution' (Alterman \& Hillman 2017). The role of this railway upgrade is first and foremost to adapt and prepare the country for the BRI, which is heavily focused on railway transport technology. China is leading a 'high-speed railway revolution' in the world that is positively impacting its economic development (Chen et al. 2016). Iran is trying to catch up with the railway trend and is thus heavily dependent on China for this upgrade. For the BRI corridor to West Asia, China and Iran have already made operational a direct train connection. A train arrived in Iran from China for the first time in 2016. In 2018, another connection was established. The documents setting out the '25-year deal' between Iran and China emphasize and promise large investments in the transportation field, especially in railways.

China is not the only destination for Iranian railway. The Iranian railway network is connected to almost all neighbouring railway networks. According to a report provided by Abbas Nazari, ${ }^{2}$ networks that the Iranian rail system is connected to include those in Azerbaijan, Turkey, Pakistan, and the Indian subcontinent. The network also has Imam Khomeini Port's railway connection to international waters for multimodal transport, as well as the Bandar Abbas connection to international waters (it is also part of Bandar Abbas-Almaty Corridor). Then there is Amir Abad's railway connection to the Caspian Sea, Turkmenistan, and the Commonwealth of Independent States (CIS), which practically connects Iran to Central Asia, Russia, and Eastern European networks. In 2018, Rouhani also officially opened the rail connection to Iraq. There are currently two routes between Iran and China. The first passes through Kazakhstan, Uzbekistan, and Turkmenistan. The second takes a similar route that bypasses Uzbekistan. It is therefore not a surprise that the International Union of Railways (UIC) has its Middle East Office in Tehran, of which Abbas Nazari of Iranian Railways (RAI) is

2 Abbas Nazari is at the time of writing the Director General of the International Affairs Bureau of Iranian Railways and Director of the UIC Middle-East Regional Office, which is based in Tehran. 
currently the head. In 2019, Iran held the UIC's 7 th Nextstation Conference, which was described as 'the global reference for leaders and decision makers to share the latest experiences and best practices regarding the design, financing and operation of railway stations' (UIC 2019). Such proactive events and moves by Iranian Railways has increased familiarity, interest, and investment in Iran's railway network.

Iranian Railways (RAI) as an institution has been very proactive and shown systematic geographic agency by holding such conferences as well as bilateral or multilateral meetings as part of the country's railway revolution and connectivity drive. It is also in the process of developing seven new railway projects inside the country. The high-speed rail between TehranQom-Isfahan is the showpiece of the whole network, financed and under construction by China and officially associated with the BRI. Construction started in 2015 but is facing delays due to sanctions and other issues. Interestingly, RAI's maps of Iran's current and planned railway network on its official website refers to Iranian connectivity to Europe and China in terms of the 'Silk Road' (see, for instance, Alterman \& Hillman 2017). It can therefore be argued that institutions such as Iranian Railways are involved in the making of geography both in the material sense (the physical railway) and the ideational sense (the Silk Roads vocabulary). Such activities, policies, and institutional undertakings speak of the fact that discourses constitute and make realities and are not merely figments of imagination.

\section{Conclusion: Iran between Geopolitics and Geoeconomics}

As an international actor, Iran is viewed in both the global mass media and academic literature in political science and international relations as an almost exclusively geopoliticized country. In such literature, the geoeconomic processes and policies of the country are, more often than not, ignored. The Iranian geographic imagination has also not been critically assessed either. This chapter was an attempt to compensate for this dual gap in the literature.

Since the 1979 revolution, Iranian elites have been trying to geoeconomize the country by coming up with the plans and initiatives that were discussed above. The geoeconomic drive has been boosted considerably since the advent of the BRI. Iran is increasingly aligning its destiny with the geoeconomics of Asia, and especially with the Chinese BRI. The recent official acknowledgements of the Sino-Iranian '25-year deal' point to one conclusion: Iran, with its vast and central geography and its steady partnership with China, has become 
the centrepiece of China's West Asian policy and the most important piece, one could argue, of the BRI's CAWA Corridor. A question remains, however, about how lopsided Iranian reliance on China and the BRI will be. To avoid this lopsidedness, Iran has made itself an indispensable part of the International North-South Transport Corridor and the Ashgabat Agreement, as well as an important partner for the Eurasian Economic Union. Such geoeconomic processes can potentially help geoeconomize certain regions such as West Asia, Central Asia, or certain actors such as Iran or Pakistan, which have been geopoliticized in the dynamics of the last century (see Forough 2019).

Currently, geopolitical processes (mainly American unilateralism) are making this transformation slow and complicated. However, the trend in the past three decades has been one in which Iran has made itself integral to Eurasian geoeconomics. In this emerging world, functional infrastructure can say much more about how the world operates than Westphalian political borders. Contemporary maps should show highways, railways, ports, airports, pipelines, communications lines, as well as paths of contagion and other risks, instead of merely showing political borders (Khanna 2016). Iranian geographic discourse, in a major multi-pronged effort to plug the country into this dynamic geoeconomic world, selectively picks and chooses elements, events, or processes from its long history (both Islamic and pre-Islamic) and geography in order to create a coherent narrative about the country's role in the world. Thanks to the BRI and other initiatives discussed above, the idea of Iran, for now at least, is turning into one of a 'civilizational crossroads', in a region it chooses to call 'West Asia', in a world in which the principal organizing trope, geographically and historically speaking, is that of the (New) Silk Roads. As opposed to the 'neither West nor East' narrative of the 1979 Iranian Revolution, Iran is currently shooting off in all directions, 'East' and 'West' as well as 'North' and 'South', in the hope of someday becoming a fully fledged crossroads.

\section{References}

Agnew, John (1994). 'The Territorial Trap: The Geographical Assumptions of International Relations Theory'. Review of International Political Economy, 1(1), 53-80. Alterman, Jon B. \& Hillman, Jonathan E. (2017, May 10). 'Iran's Railway Revolution'. Reconnecting Asia/Center for Strategic \& International Studies (CSIS). Retrieved 28 September 2020 from https://reconnectingasia.csis.org/analysis/entries/ irans-railway-revolution/.

Axworthy, Michael (2008). Iran: Empire of the Mind: A History from Zoroaster to the Present Day. London: Penguin. 
Berkowitz, Mark. (1996). World's earliest wine. Archaeology, 49(5), 26-26.

Beaumont, Peter, Gerald H. Blake, and J. Malcolm Wagstaff (1976). The Middle East: A Geograghical Study. London: John Wiley and Sons

Bhattacharjee, Kallol (2018, February 18). 'Chabahar Will Be a Golden Gateway, Says Narendra Modi'. Retrieved 28 September 2020 from: https://www.thehindu. com/news/national/chabahar-will-be-a-golden-gateway-says-narendra-modi/ article22786234.ece.

Bilgin, Pinar (2010). 'The "Western-Centrism" of Security Studies: "Blind Spot" or Constitutive Practice?' Security Dialogue, 41(6), 615-622.

Calder, Kent E. (2012). The New Continentalism: Energy and Twenty-First-Century Eurasian Geopolitics. New Haven, CT: Yale University Press.

Canfield, Robert Leroy (ed.) (2002). Turko-Persia in Historical Perspective. Cambridge: Cambridge University Press.

Chen, Zhenhua, Junbo Xue, Adam Z. Rose, and Kingsley E. Haynes (2016). "The impact of high-speed rail investment on economic and environmental change in China: A dynamic CGE analysis." Transportation Research Part A: Policy and Practice 92: 232-245.

Daniel, Elton L. (2012). The History of Iran. Santa Barbara, CA: Greenwood.

De Cordier, Bruno (1996). 'The Economic Cooperation Organization: Towards a New Silk Road on the Ruins of the Cold War?' Central Asian Survey, 15(1), 47-57. Forough, Mohammadbagher (2019). 'Intervention with Chinese Characteristics: The Belt and Road Initiative Reconfiguring (Afro-) Eurasian Geo-economics'. Conflict, Security \& Development, 19(3), 275-281.

Frankopan, Peter (2015). The Silk Roads: A New History of the World. London: Bloomsbury. Frye, Richard Nelson (1962). 'Reitzenstein and Qumrân Revisited by an Iranian'. Harvard Theological Review, 55(4), 261-268.

Financial Times (2016, May 24). 'India to Bypass Pakistan on the Road to Central Asia'. Financial Times. Retrieved 28 September 2020 from https://www.ft.com/ content/8510176c-2188-11e6-9d4d-c11776a5124d.

Gnoli, Gherardo (1989). The Idea of Iran: An Essay on Its Origin. Roma: Istituto Italiano per il Medio ed Estremo Oriente.

Guzzini, Stefano \& Leander, Anna (2006). 'Wendt's Constructivism: A Relentless Quest for Synthesis'. In Stefano Guzzini \& Anna Leander (eds.), Constructivism and International Relations: Alexander Wendt and His Critics (pp. 73-92). London: Routledge.

Hansen, Valerie (2012). The SilkRoad: A New History. Oxford: Oxford University Press. Harvey, David (2006). Spaces of Global Capitalism. London: Verso.

Khamenei, Ali (2009, March 10). 'Leader Meets with Turkish President'. Khamenei. ir. Retrieved 28 September 2020 from http://english.khamenei.ir/news/106o/ Leader-Meets-with-Turkish-President. 
Khamenei, Ali (2012, August 12). 'Leader's Speech to Professors'. Khamenei.ir. Retrieved 28 September 2020 from http://english.khamenei.ir/news/1661/ Leader-s-Speech-to-Professors.

Khamenei, Ali (2018a). 'Bayaanaat dar Didaare Nokhbegan va Estedaad-haaye Elmi' [Speech to academic and scientific elites]. Khamenei.ir. Retrieved 28 September 2020 from http://farsi.khamenei.ir/speech-content?id=43719.

Khamenei, Ali (2018b, February 12). 'Preference of East over West Is a Priority for Iran'. Khamenei.ir. Retrieved 28 September 2020 from http://english.khamenei.ir/ news/5487/Preference-of-East-over-West-is-a-priority-for-Iran-Imam-Khamenei.

Khanna, Parag (2016). Connectography: Mapping the Future of Global Civilization. New York: Random House.

Kumar, Ravinder (2002). 'India: A “Nation-State” or “Civilisation-State”?' South Asia:Journal of South Asian Studies, 25(2), 13-32.

Larkins, Jeremy (2010). From Hierarchy to Anarchy: Territory and Politics before Westphalia. New York: Palgrave Macmillan.

Malandra, William W. (2005). 'Zoroastrianism i. Historical Review up to the Arab Conquest'. In Encyclopedia Iranica. Retrieved 28 September 2020 from https:// iranicaonline.org/articles/zoroastrianism-i-historical-review.

New York Times (2020). 'Defying US, China and Iran Near Trade and Military Partnership'. New York Times. Retrieved 28 September 2020 from https://www. nytimes.com/2020/07/11/world/asia/china-iran-trade-military-deal.html.

Office of the Supreme Leader (2016). 'Ayatollah Khamenei: Iran-China 25-Year Strategic Agreement a Wise Move'. Retrieved 28 September 2020 from https:// www.leader.ir/en/content/14066/www.leader.ir.

Peet, Richard (2000). 'Celebrating Thirty Years of Radical Geography'. Environment and Planning $A$, 32(6), 951-953.

Rachman, Gideon (2017). Easternization: Asia's Rise and America's Decline from Obama to Trump and Beyond. New York: Other Press.

Rouhani, Hassan (2018). 'Full text of Iran's President Rouhani Speech at UNGA 73'. The Iran Project. Retrieved 28 September 2020 from https://theiranproject. $\mathrm{com} / \mathrm{blog} / 2018 /$ og/25/full-text-of-irans-president-rouhani-speech-at-unga-73/.

Said, Edward (1979). Orientalism. New York: Vintage Books.

Selden, Daniel (2013). 'Iskander and the Idea of Iran'. In Tim Whitmarsh \& Stuart Thomson (eds.), The Romance between Greece and the East (pp. 142-161). Cambridge: Cambridge University Press.

Sparke, Matthew (2007). 'Geopolitical Fears, Geoeconomic Hopes, and the Responsibilities of Geography'. Annals of the Association of American Geographers, 97(2), 338-349.

UIC (2019). 'UIC and Iranian Railways (RAI) Have Successfully Organised the 7 th UIC Nextstation Conference in Tehran under the Theme Railway Stations Boosting 
the City'. International Union of Railways (UIC). Retrieved 28 September 2020 from https://uic.org/com/uic-e-news/668/article/uic-and-iranian-railways-raihave-successfully-organised-the-7th-uic?page=modal_enews.

Van der Pijl, Kees (2007). Nomads, Empires, States. London: Pluto Press.

Zarif, Javad (2016). Doraan-e Gozaar dar Ravaabete Beinolmelal dar Donyaaye Pasaagharbi [The transition in international relations of the post-Western world]. Tehran: Center for International Research and Education.

Zhang, Wei-Wei (2012). The China Wave: Rise of a Civilizational State. Singapore: World Scientific.

\section{About the Author}

Mohammadbagher (MAmad) Forough is University Lecturer in the International Relations of Modern Iran at Leiden University and a LeidenAsiaCentre fellow. His research is, broadly speaking, focused on geoeconomic and geopolitical shifts at the global level (i.e. the retreat of the West and the rise of the rest, especially China and India, at the global level and Iran at the regional level). Theoretically focused on critical geography, he investigates how the elements of 'geo' (namely, geographical factors, connectivity, infrastructure projects, and geographic discourse) and 'politics' and 'economics' mutually affect and are affected by each other when it comes to theories of geopolitics and geoeconomics. Together with Frans-Paul van der Putten, he initiated the Clingendael Institute's Silk Road Headlines, a weekly news service providing updates on news articles related to China's Silk Road initiative. 



\title{
13 Exploring the Political, Economic, and Social Implications of the Digital Silk Road into East Africa
}

\author{
The Case of Ethiopia
}

Sanne van der Lugt

\begin{abstract}
Chapter 13 analyses various causal relations through which Ethiopian and Chinese actors interact in the context of the Digital Silk Road initiative. What is playing out in Africa is part of a larger contest between the West and China for dominance over technology and global influence. From a Chinese perspective, the Digital Silk Road is an attempt to narrow the gap between underdeveloped and developed countries through capacity building. From a Western perspective (Freedom House, Human Rights Watch, etc.), Chinese investments in the Digital Silk Road provide unethical support to authoritarian leaders. The chapter moves beyond this simple dichotomy of good and bad Chinese investments in the digitalization of Africa, instead identifying the actors involved and investigating their motives and levels of influence.
\end{abstract}

Keywords: Belt and Road Initiative, Digital Silk Road, East Africa, Ethiopia, China, agency

In March 2015, the Chinese government announced plans for a third component of the Belt and Road Initiative (BRI): the Digital Silk Road. The plans for the Digital Silk Road included the construction of cross-border optical cables, transcontinental submarine optical cables, and spatial and satellite information passageways. These would be created to expand information exchanges and cooperation (NDRC 2015). The decision of the

Schneider, Florian (ed.), Global Perspectives on China's Belt and Road Initiative: Asserting Agency through Regional Connectivity. Amsterdam, Amsterdam University Press 2021 DOI: 10.5117/9789463727853_CH13 
Chinese government to develop the Digital Silk Road could be seen as its reaction to the news that Western spy agencies were tapping submarine cables (see, for example, Goetz et al. 2013). Shen (2018: 2691) suggests that through the Digital Silk Road, the Chinese government aims to create its own 'transnational network infrastructure through submarine, terrestrial, and satellite links, primarily alongside the Belt and Road Initiative countries'.

Ethiopia is one of these Belt and Road Initiative (BRI) countries. The Ethiopian Ministry of Innovation and Technology (MIT) ${ }^{1}$ aspires to lead the Ethiopian economy toward tech-led growth. As a result, MIT revised its fifteen-year-old national science, technology, and innovation policy as part of a series of reforms currently taking place in Ethiopia (Ayele 2019).

The aim of the Ethiopian government to become Africa's next tech hub and the plan of the Chinese government to promote the Digital Silk Road seem to go hand in hand. From an Ethiopian perspective, the transnational network infrastructure that the Chinese government plans to build in the BRI countries is an opportunity to be better connected. Meanwhile, from a Chinese perspective, the Digital Silk Road is an attempt to 'narrow the gap between underdeveloped and developed countries, to remove bottleneck problems holding up the development of relevant countries, and to greatly improve their own production capacity [of these relevant countries]' (Lu 2017). However, the question is whether the cooperation between countries such as Ethiopia and Chinese firms will lead to more or less independence. And who will have control over these technologies?

From a Western perspective (as expressed by organizations such as Freedom House and Human Rights Watch), Chinese investments in the Digital Silk Road are often depicted as the unethical support of authoritarian leaders. This is especially the case when these investments take place in countries with authoritarian regimes. For example, the 'Freedom on the Net 2018' report, an annual country-by-country assessment of Internet freedom published by Freedom House, stated that 'Beijing' took steps to propagate its model abroad by conducting large-scale training of foreign officials and providing technology to authoritarian governments (Freedom House 2018). Perhaps this means that support from the Chinese government leads to more independence for the Ethiopian government, but less independence for the ordinary citizens in Ethiopia.

Western NGOs and the Chinese government use different discourses to convince their audiences that the support of Chinese firms for the digitalization 
of African countries is either good or bad; that it is either about development or exploitation. With this study, I aim to go beyond the simple dichotomy of good and bad. I will identify the different actors that, with the help of Chinese firms, are involved in the digitalization of East Africa and investigate their motives and levels of influence. Then I will test the dominant propositions that have been made about the social, economic, and political impacts of support from Chinese firms for the digitalization of East African countries. The main question addressed is: In the context of the Digital Silk Road, to what extent does Chinese information and communications technology (ICT) contribute to the Ethiopian government's control over its citizens?

\section{Digital Developments within Ethiopia}

Ethiopia is underestimated as a source of digital talent. The country is usually connected with either coffee or drought and drought-related hunger. It might surprise many Western readers, for example, that the Ethiopian software developers of iCog Labs in Addis Ababa developed part of the software for Sophia, a social humanoid robot created by the Hong Kong-based Hanson Robotics (and the only robot in the world with citizenship).

iCog Labs is a research-and-development company that collaborates with international artificial intelligence (AI) research groups and serves customers around the world. It was established by Getnet Aseffa with the help of American researcher Ben Goertzel (Wuilbercq 2015). The company's core specialty is AI, including machine-learning-based data analysis, computational linguistics, computer vision, mobile robots and cognitive robotics, cognitive architectures, and artificial general intelligence. One of the employees of iCog Labs, Betelhem Dessie, is a good example of the kind of digital talent that exists in Ethiopia. Only 20 years old, she is the founder and CEO of Anyone Can Code, a coding school at iCog Labs that teaches children the skills that are needed for the future job market. Dessie started coding when she was just nine years old (Mella TV 2019). At the age of twelve, she started working as a developer for the Ethiopian Information Network Security Agency (INSA). Aseffa argues that Ethiopian programmers have the same skills as those from China, from the US, and Europe. The only difference is the economic gap and the daily challenges that they face. These challenges include: lack of infrastructure, erratic Internet access, and frequent power cuts (Wuilbercq 2015).

MIT aims to establish Ethiopia as the premier IT hub in Africa. In June 2019, the government approved legislation that would open the telecom market 
to competition and provide much needed foreign investment. In September 2019, the process to part-privatize Ethio Telecom, the only provider of telecommunications services in Ethiopia, moved forwards when the company was audited. Meanwhile, it is expected that two licenses will be offered to international operators by the end of 2020 (Lancaster \& Lange 2020).

In January 2020, the French company ArianeGroup started to build a satellite manufacturing, assembly, integration, and testing (MAIT) facility in Addis Ababa. The company is using funding from the European Union's European Investment Bank (EIB) (Space in Africa 2019b). After completion, the MAIT facility will be managed by the Ethiopian Space Science and Technology Institute. It is expected to be the centrepiece for Ethiopian satellite technology development and manufacturing. There are currently only two functioning assembly, integration, and testing facilities on the African continent, in Algeria and South Africa. However, Egypt and Nigeria are also building facilities (Ibeh 2019; Ibeh 2020).

\section{State of Research}

This section discusses the three main debates examined in this study. These are: 1) the debate about the impact of high technology on development and repression; 2) the debate about the extent to which China-Africa relations pose a threat; and 3) the discussion about the need to include African agency in studies on China-Africa relations.

\section{High-Tech and Development versus Repression}

Shen (2018) argues that the Chinese leadership has assigned its Internet companies a central position in the BRI to achieve five major policy objectives: cutting industrial overcapacity, enabling corporate China's global expansion, supporting the internationalization of China's currency, the renminbi $(\mathrm{RMB})$, constructing a China-centred transnational network infrastructure, and promoting an Internet-enabled 'inclusive globalization'. Meanwhile, according to Wang Yiwei, a professor in the School of International Studies at Renmin University, the Digital Silk Road will also offer benefits for participants by efficiently connecting landlocked and developing countries to the global economy through a more inclusive international trade and investment system (Wang in Shen 2018: 2693).

In contrast to the self-interested high-tech discourse's promises about the inherently democratic nature of new information and telecommunication 
technologies, Walton (2001) argues that these technologies are embedded in a social context. It is not the technology itself but the way people will use it that leads to either development or repression. However, this does not mean that technology is inherently neutral. Rather, the context in which a new technology is used influences whether the impact of this new technology is perceived as positive or negative.

European development cooperation institutes, such as the German Society for International Cooperation (GIZ), are enthusiastic about the potential of 'digital solutions for sustainable development' (GIZ 2017). However, Western institutes are more critical about the digitalization of African countries when Chinese firms are involved. For example, the 'Freedom on the Net 2018' report by the US-based non-governmental organization Freedom House (2018: 2) states that:

[Chinese] companies have supplied telecommunications hardware, advanced facial-recognition technology, and data-analytics tools to a variety of governments with poor human rights records, which could benefit Chinese intelligence services as well as repressive local authorities.

\section{China-Africa Relations}

In the literature on relations between China and African nations, the main debate has been about whether or not China's growing presence in Africa is a threat to Western or African interests. The blog 'China in Africa: The Real Story' and the associated book The Dragon's Gift, both produced by the scholar Deborah Brautigam (2009), have contributed to shifting this debate more in favour of China. Hirono and Suzuki (2014) have suggested that the conclusion that the behaviour of Chinese actors on the African continent is not uniquely immoral is not so surprising. They argue that the idea of a China threat is the result of the heavy influence of Western states' policy interests on the literature on Chinese foreign policy.

Another recurring debate in the literature on Sino-African relations, linked to the idea of a China threat, is the debate about the motives behind Chinese overseas direct investment (ODI) in Africa and the role of the Chinese government in this. Chinese economic cooperation in Africa is seen by some as a 'charm offensive' through which it seeks to win political and economic clout. Buckley et al. (2007) argue that the Chinese government has used ODI to ensure the supply of those natural resources that are scarce in China. This leads to Chinese ODI that is primarily resource seeking. Others have argued that Chinese telecom companies' investments in large 
infrastructure networks in Africa are used by the Chinese government for both traditional and economic espionage (Reed 2013).

These theories about the motives behind Chinese ODI all share the assumption that Chinese policymakers have an all-encompassing strategy for Africa. However, as Taylor and Xiao (2009) have rightly pointed out, China is not a centrally controlled, monolithic, unitary actor. There is a multiplicity of Chinese actors operating in Africa. As such, there is a need to go beyond broad studies that look at the motives and practices of Chinese investors in general. Instead, it is necessary to conduct more detailed studies of specific Chinese actors to get a better understanding of the motives of various Chinese players in Africa, as well as their specific practices and the challenges related to these.

\section{Agency}

In most analyses of China's engagement with Africa, little consideration is given to the role of African agency (Mohan \& Lampert 2012). Brown and Harman (2013) argue that the study of Africa's international relations has for a long time been preoccupied with explaining how the continent has been governed, shaped, and marginalized by external actors. In their book, they ask how far, and in what ways, African political actors are impacting on, and operating within, the international system, instead of looking at how the international system impacts on Africa. Their book attempts to focus on interaction rather than one-way domination.

As a philosophical concept 'agency' refers to the capacity of individuals to act independently and to make their own free choices. The idea of the individual as a 'free agent' - able to make rational choices - was born with the emergence of philosophical individualism in the early Enlightenment. Later, the English philosopher John Locke (1978) rejected the binding power of tradition, affirming the capacity of human beings to shape the circumstances in which they live. According to Emirbayer and Mische, this way of thinking 'embedded agency in an individualistic and calculative conception of action that still underlies many Western accounts of freedom and progress' (1998: 965). Ethiopia is often considered to be a more collectivistic society (Hofstede-insights 2020). It, therefore, makes sense to look at a more relational aspect of agency in this study.

In her research on poverty and citizenship, Lister (2003, 2004) distinguishes between four dimensions of agency and argues that these dimensions interrelate. For example, to act politically, one first requires a sense of personal agency and then acting as a citizen further strengthens that sense 
of personal agency. Coulthard (2012) had pointed to how Lister's connection of personal agency with political agency relates to debates from Giddens, Long, and Van der Ploeg about the socially embedded nature of agency. These scholars argue that the capability a person has to act and make a difference to a pre-existing state of affairs or events necessarily involves social relations and can only function through them (Coulthard 2012).

This chapter, therefore, uses a definition of agency that emphasizes the ability to make free choices - either as a group or an individual. How free is the choice made by the Ethiopian government about whether or not to use Chinese ICT? How free are the choices made by groups in Ethiopian society about whether or not to make use of Chinese ICT? Are these actors capable of exercising agency and changing a pre-existing state of affairs?

\section{Methodology}

The research question in this chapter is: In the context of the Digital Silk Road, to what extent does Chinese ICT contribute to the control of the Ethiopian government over its citizens? This is a question about both agency and motivation. Currently, most studies of the motives behind Chinese outward direct investment (ODI) are based upon statistical correlation (see, for example, Buckley et al. 2007; Kolstad \& Wiig 2012; Ramasamy et al. 2012). However, while such regression analysis can point out the strength of a certain correlation, it cannot prove a causal relationship. For this reason, in the research for this chapter, I have adopted a case study method to answer the research question.

\section{Design}

Case studies can make inferences about which causal mechanisms may have been at work by examining intervening variables in individual cases using a method called process tracing. In this way, 'process tracing is a fundamental tool of qualitative analysis' that can contribute decisively to evaluating causal claims (Collier 2011: 823). Process tracing involves a mechanistic understanding of causality. It is the search for intervening variables that link an independent variable with a dependent variable in a process that is commonly referred to as a causal mechanism. When it is possible to theorize a mechanism linking a cause, or several causes, with an outcome, process tracing can be used to test this theory. 
To study the impact that the use of Chinese ICT in Africa has on the control that governments have over citizens, a case study is selected which looks at Ethiopia. For this case study, there are various theories which hypothesize causal mechanisms and which we can test. Beach and Pedersen (2016) suggest five steps when using process tracing for theory testing: 1) select typical cases, 2) conceptualize and operationalize the causal mechanism, 3) collect empirical material and evaluate whether there is evidence of the predicted causal mechanism and if we can trust this evidence. When evidence is not found for the whole mechanism, it then becomes necessary to 4) investigate whether the chosen case was idiosyncratic, or when evidence is not found for even a part of the mechanism, it is necessary to 5) engage in theory building to revise the theory.

The following sections will describe how these steps have been carried out in this study of the use of Chinese ICT in Ethiopia. The next section discusses the sampling of data that was performed for this study.

\section{Sample}

Ethiopia is an East African country with strong economic relations with China. It is linked to China's BRI via the small neighbouring nation of Djibouti, where Chinese firms have invested heavily in port infrastructure and Africa's first fully electrified transnational railway from Djibouti Port to the Ethiopian capital Addis Ababa (Clemoes 2019). The Ethiopian authorities are focusing on digital economic transformation as part of their Second Growth and Transformation Plan (GTP II). They aim to improve the ICT infrastructure and services in Ethiopia and to enhance the role of the ICT sector in economic, social, and political activities for their country to become a 'low middle-income country by 2025' (National Planning Commission 2016: ix).

This digitization of the Ethiopian economy is being enabled with technology and support from China. The Chinese telecom vendors Huawei and ZTE have dominated the telecom infrastructure market in Ethiopia since 2008, supplying the sole telecom provider in the country, the state-owned Ethio Telecom. This Chinese dominance in the country's digital infrastructure was last year supplemented by the launch of the first Ethiopian remote sensing satellite, which was developed and largely paid for by China and then launched in China (Reuters 2019). It was also increased by recent agreements between China and Ethiopia regarding the joint development of a communication satellite (Space in Africa 2019a) and a new digital trade platform (Gebre 2019). 
Ethiopia has long been seen as an authoritarian regime and is still regarded as 'not free' in terms of Internet freedom, political rights, and civil liberties (Freedom House 2020a, 2020b). However, Ethiopia is changing for the better. In February 2018, Hailemariam Desalegn suddenly resigned as the Prime Minister to allow reforms in the country after mass protests led to the loss of life and displacement of thousands of Ethiopians (NTV Kenya 2018). Reports by Freedom House show the progress that is being made in Ethiopia. In 2018, Ethiopia received only 12 out of the maximum 100 points in the Freedom House awards. In 2020, this number increased to 24 .

After Hailemariam's resignation, the reform-minded Abiy Ahmed took the position of Prime Minister in a snap election. In the first few months after he came to power, Abiy lifted the state of emergency, ordered the release of political prisoners, allowed exiled dissidents to return home, and unblocked many websites and TV channels. He filled half of his cabinet with women. He also ended the state of war with Eritrea by agreeing to give up disputed border territory, for which he received the Nobel Peace Prize in 2019 (Nobel Prize 2019).

However, although Ethiopia is becoming freer it still has a long way to go to be classified as 'free' by Freedom House. A controversial hate speech law, which imposes jail terms for people whose Internet posts stir unrest, was passed in February (Al Jazeera 2020). The question of how the use of Chinese ICT in Ethiopia will impact the government's control over its citizens is therefore highly relevant.

\section{Conceptualization and Operationalization}

This study seeks to test whether, and in what ways, the use of Chinese ICT leads to strengthened control of the Ethiopian government over its citizens. To test this, it is necessary to identify the observable manifestations (the potential evidence or 'empirical fingerprints') of the causal mechanisms theorized in the literature. Testing a causal mechanism might be likened to the method of Sherlock Holmes, who looks for evidence that proves or disproves his theories. In the same regard, 'empirical fingerprints' are a kind of evidence that when present can help prove or disprove a causal relation. We, therefore, need to ask: If $\mathrm{X}$ causes $\mathrm{Y}$, what do we expect to observe?

Beach and Pedersen (2016) suggest that researchers should first identify as many potential observable manifestations of a causal mechanism as possible. Then they should evaluate the pros and cons of these different observable manifestations systematically, before selecting the most appropriate evidence (empirical fingerprints) of the causal relation to look for 
in their data. In this study, one hypothesized causal mechanism is that the use of Chinese ICT in Ethiopia leads to strengthened control of the Ethiopian government over its citizens. We might expect to see the following empirical fingerprints or evidence of this causal mechanism at work:

1 Chinese firms advise the Ethiopian government on a master plan for ICT.

2 Ethiopian firms initiate contact with Chinese firms to acquire hardware and software from them that could be used as surveillance tools.

3 The Ethiopian government requests surveillance tools from China.

4 The Chinese government invites Ethiopian officials for training in China on controlling cyberspace.

5 Chinese firms provide the Ethiopian government with hardware and software that could be used as surveillance tools.

6 Chinese firms provide the Ethiopian government with access to data collected via their technology.

7 Ethiopian officials attend the 2017 World Internet Conference in the Chinese city of Wuzhen.

8 Ethiopian officials attend a Seminar on Cyberspace Management for Officials of Countries along the BRI in China.

9 Ethiopia has an authoritarian regime.

10 The Ethiopian government can legally search and seize personal data at any time.

11 Western firms refuse to deliver surveillance technologies to Ethiopia because of moral objections.

12 The Ethiopian government adopts a cybersecurity law that mimics the Chinese cybersecurity law.

13 The Ethiopian government passes restrictive media laws that mimic Chinese media laws.

The resulting causal mechanism in figure 13.1 shows how these empirical fingerprints are expected to be linked to each other.

\section{Data Collection}

The data for this study consists of both primary and secondary data. ${ }^{2}$ I have collected media, academic, government, and company reports dealing with (and either confirming or disconfirming the presence of)

2 I had planned to collect both primary and secondary data. However, due to the COVID-19 pandemic it was not possible to make a field trip to Ethiopia. 
Figure 13.1 The causal mechanism

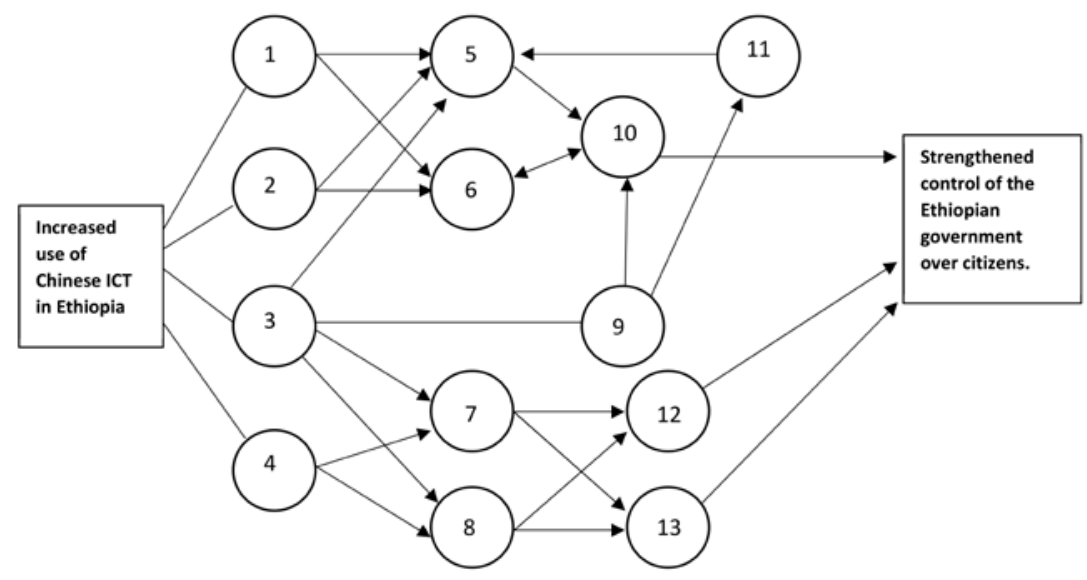

the potential observable manifestations that I identified. Primary data collection was performed using the search engine Google. When this did not yield sufficient, or sufficiently reliable, data about the topic under investigation, I then used my networks in China and on the African continent to supplement this with additional data. The data received from my network in China and on the African continent was always checked for reliability. For example, a Chinese colleague told me that the Ethiopian Minister of Information had attended the World Internet Conference in Wuzhen and sent a link to information about this in Mandarin. On checking the website, the picture of the 'minister' did not match with the actual minister at that time.

The following section will provide an analysis of whether there is evidence to prove the presence of the causal mechanism hypothesized by the literature. To reiterate, this causal mechanism is that the increased use of Chinese ICT in Ethiopia in the context of the BRI is strengthening the control of the Ethiopian government over its citizens.

\section{Analysis}

In this section, I test the popular assumption that the Digital Silk Road (and with that the use of Chinese ICT in countries along the Silk Road) benefits repressive local authorities. I do so by carefully studying the case of Chinese ICT support in Ethiopia under the label of BRI. 
The previous section discussed the need to identify the evidence of causal mechanisms which analyses should look for, or to ask: 'If X causes $\mathrm{Y}$, what do we expect to observe?' Before we can ask this, however, we need to find out whether $\mathrm{X}$ and $\mathrm{Y}$ themselves are true, or merely assumptions. Let us first look at X, which in this case is the use of Chinese ICT technology in Ethiopia. It should be asked whether Chinese ICT (surveillance) technology is being used in Ethiopia and whether its use has increased since the announcement of the Digital Silk Road.

From 2008 to 2013, the Chinese firm ZTE was the only telecom vendor building telecom infrastructure in Ethiopia. Since 2013, ZTE has shared this market with the large Chinese company Huawei. These two Chinese firms have each gained a $50 \%$ share in the carrying out of a US $\$ 1.6$ billion project to introduce $4 \mathrm{G}$ in Addis Ababa and expand ${ }_{3} \mathrm{G}$ services around the country (Maasho 2013). In 2014, the Swedish company Ericsson took over part of ZTE's share in this project because the Ethiopian government had disagreed with ZTE about the costs of upgrading an existing network (Reuters 2014). ${ }^{3}$ However, in 2016 Huawei took over a $3 \mathrm{G}$ project that was part of Ericsson's share (Fikade 2016). Huawei and ZTE, therefore, continue to dominate the telecom infrastructure market in Ethiopia.

The digital infrastructure over land in Ethiopia is supplemented with digital infrastructure in space. In December 2019, Ethiopia launched its first remote sensing satellite into space. This satellite was developed by Chinese and Ethiopian engineers, largely paid for by the Chinese government, and being launched in China (Reuters 2019). In July 2019, the Chinese and Ethiopian governments also agreed on jointly developing a communication and broadcast satellite (Space in Africa 2019a). In November 2019, another digital connection between China and Ethiopia was created when the Ethiopian government agreed with Jack Ma, the co-founder and former executive chairman of the Alibaba Group, to connect Ethiopia to Alibaba's electronic world trade platform (eWTP) (ENA 2019). Then 2020 started with talks between China and Ethiopia about jointly building a continental satellite data receiver station in Ethiopia (Ibeh 2020). To conclude, Chinese ICT use in Ethiopia has increased since the Digital Silk Road was announced.

Having established that X is true and that Chinese ICT is being used in Ethiopia, it is then also necessary to look at Y. Does the Ethiopian government

3 However, it is important to note that ZTE's strategy for entering into a new market is to initially make an underpriced offer to build a network with the aim of then earning money through the maintenance and upgrading of the project (interviews with ZTE employees in Africa, January 2016). 
use technology to exercise control over its citizens and in what ways? According to Freedom House the Ethiopian government still has strict control over its citizens:

Despite the recent improvements, Ethiopia still has a nationwide Internet blocking and filtering system that can be redeployed at any time for political reasons.

Anonymous communication is compromised by strict SIM card registration requirements. Upon purchase of a SIM card through Ethio Telecom or an authorized reseller, individuals must provide their full name, address, government-issued identification number, and a passport-sized photograph. Ethio Telecom's database of SIM registrants enables the government to terminate individuals' SIM cards and restrict them from registering for new ones. Internet subscribers are also required to register their personal details, including their home address, with the government. (Freedom House 2019)

It can therefore be concluded that the Ethiopian government has strict control over its citizens that is partly accomplished through technology.

Four players potentially have a key role in the increased use of Chinese ICT in Ethiopia. These are: the Ethiopian government, Ethiopian firms, the Chinese government, and Chinese firms. These are therefore the four potential starting points of the presented causal mechanism.

The remainder of this section tests whether we see the hypothesized causal mechanism at work in the case. To recap, this is a causal mechanism that shows how the use of Chinese ICT in Ethiopia (X) could contribute to the control of the Ethiopian government over its citizens $(\mathrm{Y})$. The section tests for this causal mechanism by looking to see whether those empirical fingerprints that I have previously identified as key indicators of this causal mechanism are present.

Empirical Fingerprint 1: Chinese firms advise the Ethiopian government on a master plan for ICT

The Shenzhen Outbound Alliance (SOA) set up its first African branch in Ethiopia in 2017. According to the SOA, it is responding to the aims of the BRI and is helping Chinese companies to go global. It represents Shenzhen-based companies abroad. According to Sun Tianlu, vice chairman and secretary of SOA, Shenzhen is well-placed to share best practice with other global cities as this is the city where global tech firms like Huawei and ZTE are based (Mamabolo 2017). On its website, SOA claims to have good relations with the Ethiopian government (SOA n.d.). 
From this information about SOA, we cannot conclude that Chinese firms necessarily have such a level of influence over the Ethiopian government that they can advise on a master plan for ICT. However, this information does show that Chinese firms often have the means, as well as the contacts, to carry out lobbying. Therefore, while Empirical Fingerprint 1 can be observed to some degree in the data, the evidence to suggest that Chinese firms advise the Ethiopian government on a master plan is less clear than expected.

\section{Empirical Fingerprint 2: Ethiopian firms initiate contact with Chinese} firms to acquire hardware and software from them that could be used as surveillance tools

Ethio Telecom issues the tenders for telecom infrastructure (HRW 2014; Maasho 2015). Ethio Telecom is a state-owned company (HRW 2014). This means that any choice to use Chinese technology is a choice made by the Ethiopian government and not by independent Ethiopian firms.

The project to build and launch Ethiopia's first remote sensing satellite is being run by the Ethiopian government. The Ethiopian Space Science and Technology Institute (ESSTI) is affiliated with the Ministry of Innovation and Technology. It was also ESSTI that signed the Framework Agreement with China for a communication satellite (Space in Africa 2019a).

In other words, the initiative for using Chinese ICT seems to mainly come from the Ethiopian government and not from private firms. Therefore, there is no evidence that Ethiopian firms initiated contact with Chinese firms and so Empirical Fingerprint 2 has not been observed.

\section{Empirical Fingerprint 3: The Ethiopian government requests surveillance tools from China}

As discussed above, when looking for Empirical Fingerprint 2, the evidence showed that Ethiopian government agencies have initiated most of the cooperation with Chinese agencies in the realm of digital technology. For example, the communication satellite that will be developed with support from the Chinese government will be fully owned by the government (Space in Africa 2019b). It is too early to judge whether the Ethiopian government will use this communication satellite as a surveillance tool. No public sources are showing that the Ethiopian government has made requests for Chinese technology to use it for surveillance. However, the communication satellite will increase the surveillance capabilities of the Ethiopian government.

Furthermore, the evidence looked at for Empirical Fingerprint 2 also showed that the Ethiopian government chose ZTE to build the national 
backbone. ZTE offers its customers the ability to make use of surveillance software, presenting this software as a tool to manage a customer database (see the discussion of Empirical Fingerprint 5 for more information about this software). The international non-governmental organization Human Rights Watch (HRW 2014) found that the Ethiopian government has been making use of this software for surveillance. However, this is not conclusive proof that the Ethiopian government requested the surveillance tools from China. Theoretically, it could be that the surveillance tools were an advantage that came with the Chinese technology. To conclude, there is some, limited evidence that the Ethiopian government might request surveillance technology from China and so Empirical Fingerprint 3 has been partly observed.

Empirical Fingerprint 4: The Chinese government invites Ethiopian officials for training in China on controlling cyberspace

There is information available online describing the training of Ethiopian engineers in China. However, this training seems to be focused on building and maintaining satellites (Space in Africa 2019b). It would be more interesting to know whether Ethiopian government officials have also been sent to China for training in controlling cyberspace. Such training would be more likely to involve the control of information. However, Freedom House (2018) does not mention Ethiopia specifically as one of the countries whose government officials have received Chinese training on controlling cyberspace.

It might be telling, however, that during his 2018 visit to Ethiopia the chairman of the Standing Committee of the National People's Congress of China (NPC), Li Zhanshu, said China will work with the Ethiopian parliament to improve the country's legal environment (Bo 2018). Muferiat Kamil (speaker of the Ethiopian House of People's Representatives) and Keria Ibrahim (speaker of the Ethiopian House of Federation) replied to say that Ethiopia valued cooperation with the NPC. They said that Ethiopia was ready to learn from China's development experience. During his stay, Li also visited the data centre of the Ethiopian Ministry of Science and Technology.

From this information, we cannot conclude that the Chinese government invited Ethiopian officials for training focused on controlling cyberspace. However, such training was likely included in the broader training that the Chinese government has offered to Ethiopian officials. Therefore, Empirical Fingerprint 4 has not been observed. No evidence has been found that the Chinese government invited Ethiopian officials for training in controlling cyberspace, but it has also not been shown that this definitely has not occurred. 
Empirical Fingerprint 5: Chinese firms provide the Ethiopian government with hardware and software that could be used as surveillance tools In 2008, the Chinese firm ZTE won a deal with Ethio Telecom to exclusively develop Ethiopia's nationwide network to cover fourteen major cities in Ethiopia. In 2009, ZTE's video surveillance solution won the bidding for a city security surveillance project in Ethiopia. This project involved placing more than 200 cameras on the roads of the Ethiopian capital, Addis Ababa (ZTE n.d.). In 2013, ZTE and Huawei together won a new deal to introduce $4 \mathrm{G}$ in Addis Ababa and expand $3 \mathrm{G}$ services around the country. As mentioned previously, the Swedish company Ericsson took over a part of ZTE's share in this project in 2014. However, in 2016 Huawei again took over part of Ericsson's share. As a result, the Chinese firms Huawei and ZTE are still the main providers of telecom infrastructure for Ethio Telecom, which is Ethiopia's sole telecom provider.

According to Human Rights Watch (HRW 2014), information on all phone calls and text messages in Ethiopia is stored and easily accessed through Ethio Telecom's customer management system, called ZSmart. The customer management software was developed by ZTE. It should be noted that this software is rather common and has not been specially developed for the Ethiopian government. It is also in use in the Netherlands and Germany (Dutch IT-channel 2014), for example. Human Rights Watch suggests that, unlike democratic countries, Ethiopia also makes use of the software's potential to record phone calls and text messages, as well as ZTE's centralized monitoring system, called ZXMT. Human Rights Watch quotes Eric King from Privacy International, one of the world's leading researchers on surveillance technology, who states that:

One of the things that sets ZTE apart is that when it enters a telecom market it often packages all of its products together as part of its contract, so you get the 'lawful' interception products unless you specifically request to opt out of it. Not too many governments that ZTE does business with are likely to do this. $\left(\right.$ HRW 2014) ${ }^{4}$

In March 2019, Ethio Telecom and ZTE agreed to establish a joint innovation centre. As part of this agreement, ZTE donated and deployed new technologies worth more than US $\$ 3$ million to help build the innovation

4 HRW emphasizes that the term 'lawful intercept' is used by equipment makers as an industry label for systems that enable surveillance and does not necessarily mean surveillance practices are legal under national or international law. 
centre (Ethio Telecom 2019). The agreement to establish the centre dates back to the middle of 2017 when the two institutions decided to further develop their cooperation and collaborative engagement. In 2017, Ericsson was close to bankruptcy. The timing of the initial agreement could therefore have been an attempt by ZTE to regain some of its market share in Ethiopia after losing business to Ericsson and Huawei.

From this information, we can conclude that Chinese firms have provided the Ethiopian government with hardware and software that could be used for surveillance. Therefore, Empirical Fingerprint 5 has been observed.

\section{Empirical Fingerprint 6: Chinese firms provide the Ethiopian government} with access to data collected via their technology

The Ethiopian government also has a Safe City agreement with Huawei. Safe City initiatives are Huawei's flagship public safety solution for providing local authorities with a wide range of modern products intended to improve policing efforts. When asked if Huawei implemented any safeguards to ensure the technology would not violate human rights, Adam Lane, senior director of public affairs for Huawei's Southern Africa division, said:

Huawei does not manage, use or have access to any of our systems - we only sell them to the customer and train them how to use it. It is up to individual countries to set their own policies, regulations and laws to govern how such systems are used, and for their legal systems to ensure implementation. (Lane in Woodhams 2020)

From this information, we can conclude that Chinese firms provide the Ethiopian government with access to data collected via their technology. To conclude: Empirical Fingerprint 6 has been observed.

Empirical Fingerprint 7: Ethiopian officials attend the 2017 World Internet Conference in the Chinese city of Wuzhen

On the official website for the 2017 World Internet Conference, a list of important guests with their photos indicates that the Ethiopian Minister of Information attended. However, the picture of the minister on the site does not match the description given. The man in the picture is not the former Ethiopian Minister of Communication and Information Technology Debretsion Michael.

From this information, we cannot conclude anything. No evidence could be found that Ethiopian government officials attended the conference and 
so Empirical Fingerprint 7 could not be observed. However, it could not be proven that such officials did not attend the conference either.

\section{Empirical Fingerprint 8: Ethiopian officials attend a Seminar on} Cyberspace Management for Officials of Countries along the BRI in China It was not possible to find any information on the attendance of this seminar. However, this does not necessarily mean that Ethiopian officials did not attend this seminar.

Again, from this limited information, we cannot conclude anything. Therefore, Empirical Fingerprint 8 could not be observed, however, it was also not possible to show that some Ethiopian officials did not attend the seminar.

\section{Empirical Fingerprint 9: Ethiopia has an authoritarian regime}

Although Ethiopia is reforming, it is still regarded as 'not free' (the lowest category) in terms of Internet freedom, political rights, and civil liberties (Freedom House 2020a, 2020b). In February 2020, a controversial hate speech law that imposes jail terms for people whose Internet posts stir unrest was passed (Al Jazeera 2020). Therefore, there is evidence that Ethiopia has an authoritarian regime and so Empirical Fingerprint 9 can be observed.

Empirical Fingerprint 10: The Ethiopian government can legally search and seize personal data at any time

The 1995 Ethiopian Constitution introduced a range of privacy safeguards, which were informed by the privacy provisions found in international human rights instruments to which Ethiopia is party. However, the right to privacy is not absolute in Ethiopia. It can be limited to protect other competing interests (such as national security or the public peace, the prevention of crimes or the protection of health, public morality, or the rights and freedoms of others) provided in subsidiary laws if the necessary conditions are met (Taye \& Teshome 2018). These limitations to privacy and data protection are actually similar to those that are found in the European Union (EDPS 2020). It is the way government officials use this space that determines how protected citizens feel.

The Ethiopian government collects personal data. For instance, the Registration of Vital Events and National Identity Card Proclamation allows the collection of personal data, as well as the transfer of this data to various institutions, including intelligence authorities, without consent (Federal Negarit Gazeta 2012). Again, the same applies to European Union countries. However, one main difference seems to be the lack of adequate legal, regulatory, and policy frameworks in Ethiopia (Taye \& Teshome 2018). 
Another important difference between Ethiopia and EU countries in this respect is the fact that Ethiopia has only one telecommunication service provider: the state-owned Ethio Telecom. Ethio Telecom requires a lot of personal information from users when they register SIM cards. It has access to all phone calls and text messages sent via its networks. It is more than likely that the 'not free' Ethiopian government collects and monitors this data. Ethiopian refugees interviewed by Human Rights Watch (HRW 2014) have stated that the Ethiopian government has access to their call histories and messages. However, the revelations made by Edward Snowden in 2013 have shown that this is not unique for so-called authoritarian states and that the US government also conducts mass surveillance of its citizens.

To conclude, evidence that the Ethiopian government collects data on its citizens has been found and so Empirical Fingerprint 10 has been observed. However, it may be noted that this finding is not unique for Ethiopia.

\section{Empirical Fingerprint 11: Western firms refuse to deliver surveillance technologies to Ethiopia because of moral objections}

A report by Human Rights Watch (HRW 2014) on telecom surveillance in Ethiopia stated that in 2012 a FinSpy command and control server had been discovered in Ethiopia. FinSpy is an example of a type of remote monitoring tool (often referred to as spyware or malware). In 2012, the FinSpy software was still owned by a UK-headquartered company called Gamma International, which said it sold this software exclusively to governments (the software is now owned by the German company FinFisher). The Human Rights Watch report argued that the presence of a command and control server in Ethiopia did not by itself mean that the Ethiopian government was deploying FinSpy. However, the report also said that 'given the high costs of these tools and the fact that Gamma states it only sells to governments, it is unlikely that a nongovernmental party would have purchased and used the tool in Ethiopia' (HRW 2014). The software has been found in the devices of Ethiopian citizens who are living overseas and who have links to Ethiopia's opposition party.

Human Rights Watch has also reported the use of spyware from the Italian company Hacking Team. It reported that this spyware was employed in an attempt to hack into the Ethiopian Satellite Television Service (ESAT) - a diaspora-run satellite television station. Hacking Team offers a product called 'Remote Control System', which allows the user to take control of infected computers or mobile phones. Like the FinSpy software, the Remote Control System is very expensive software and Hacking Team has stated that it only sells this software to governments, 
particularly to law enforcement or intelligence agencies. According to its publicly available customer policy, Hacking Team does not sell products to governments or countries blacklisted by the US, EU, UN, NATO, or ASEAN. However, Ethiopia is not on any of these sanctions lists. Human Rights Watch asked Hacking Team about whether it had discovered any 'red flags' during its review process in Ethiopia. In response, Hacking Team said that it 'expect[s its] clients to behave responsibly and within the law as it applies to them'.

From this information, we can conclude that not all Western firms have refused to deliver surveillance technologies to Ethiopia. Therefore, the evidence does not show that Western firms refuse to provide technologies to Ethiopia and so Empirical Fingerprint $n$ has not been observed.

Empirical Fingerprint 12: The Ethiopian government adopts a cybersecurity law that mimics the Chinese cybersecurity law

In this case, mimicking implies that the Ethiopian government actively and consciously followed the example given by China's laws. This seems to be the case. However, Fourie (2015) has argued that this mimicking is more likely to be the result of an Ethiopian tradition than the result of efforts made by the Chinese government to export its model. She has described how for decades Ethiopian elites have looked at 'frontrunner' countries to draw lessons. These elites not only looked to the models offered by European countries such as France and the UK but also looked to Japan and other nations for models. In the 1970 s and 1980 s, the repressive Derg government looked at the Soviet Union as a model.

Fourie (2015) explained that when the Ethiopian People's Revolutionary Democratic Front (EPRDF) ousted the Derg in 1991, it found itself at a critical juncture. The various rebel groups that comprised the EPRDF had all been founded and run on communist principles, yet the ideology had now become unpopular both globally and within the country. As a result, there was a period of relative ideological uncertainty in Ethiopia.

The desire shown by Prime Minister Meles Zenawi, as well as other members of the EPRDF, to learn from China is in line with these historical processes. In 2005, Ethiopia's most democratic elections to date ended in chaos and contestation. Some believed that the electoral violence was a result of Ethiopia having tried to liberalize too much and too soon. This belief led to arguments that Ethiopia should adopt a model that would allow it to reap the rewards of the global market while keeping control firmly in the hands of a strong and authoritarian ruling party. The model for this was found in China. 
Gagliardone (2014) has argued that the Chinese government has aided Ethiopia both indirectly, by offering legitimation for alternative models of media engagement, and also directly, through the provision of essential technical and financial support. The Chinese government's offer of a US\$1.9 billion loan in 2006 was a critical factor in the Ethiopian government's ability to expand mobile services and Internet connectivity while keeping the state-owned Ethio Telecom as the only player in the market.

However, we have to keep in mind the agency that the Ethiopian government has in choosing its own development path. As Fourie (2015) has also explained, the initiative to adopt elements of the China model came from the Ethiopian elite, who were looking for examples abroad of how to manage economic development while resisting neoliberalism. Political stability is one of the core aims of the governments in both Ethiopia and China. As Gagliardone (2014) has noted: 'Even the increasingly popular "Africa rising" narrative is placing greater emphasis on stability, as a precondition for investments, over rights.'

At the moment, the Chinese government is putting more effort into promoting its cybersecurity model abroad. In the International Strategy of Cooperation on Cyberspace (Ministry of Foreign Affairs of the PRC 2017), Chinese Internet firms were encouraged to go global and to help developing countries with such things as distance learning, remote health care, and e-business to contribute to their social development. The promotion of Chinese technology exports seems to still focus on serving the main goal of the Chinese government, namely maintaining political stability. China's 2017 International Cyberspace Cooperation Strategy emphasizes Internet sovereignty. With the export of Chinese technology, the Chinese government makes it possible for developing countries to claim Internet sovereignty and experience its benefits. This then means that these developing countries will likely support this Chinese concept in international institutions.

From this information, we can conclude that the Ethiopian government actively and consciously mimics the Chinese cybersecurity law. Therefore, evidence of Empirical Fingerprint 12 has been observed.

\section{Empirical Fingerprint 13: The Ethiopian government passes restrictive media laws that mimic Chinese media laws}

When Prime Minister Abiy Ahmed was awarded the Nobel Peace Prize in October 2019, the Nobel committee praised his 'discontinuing media censorship' among a series of achievements made during his first hundred days in power in 2018. Ethiopia jumped 40 places in the 2019 World Press 
Freedom Index compiled by Reporters Without Borders - from 150 to 110 out of 180 . This is the largest leap that has been made by any country.

At the same time, Freedom House has criticized the current Ethiopian government for repressing media and repeating the authoritarian ways of previous governments. In particular, it has criticized the ongoing implementation of a controversial Anti-Terrorism Proclamation to stifle dissent. One reason for the restrictions that is given by Prime Minister Abiy is that Ethiopian media are 'fomenting unrest'. In this respect, Abel Wabella, the managing editor of the Addis Ababa-based newspaper Addis Zebye, has said in an interview with the German news organization Deutsche Welle that:

The problem now is that so many individuals are mixing up the roles of activist and media when they shouldn't go together - media is meant to have its own ethics and rules. You have people running media who are calling for protests - it's totally absurd. (Jeffrey 2019)

Eskinder Nega, a prominent Ethiopian journalist and blogger who was released from prison under Abiy's reforms in early 2018, admits that journalists double as activists 'as a necessity':

We have found out as Ethiopian journalists that to be a journalist you have to have a liberal democratic order, but if you live in an authoritarian setting, it's not going to work. So, whether you like it or not, to be a journalist here, you have to struggle for democracy, you have to double as an activist. (Jeffrey 2019)

Kiya Tsegaye, an Addis Ababa-based lawyer, argues that Ethiopia is a fragile society and therefore that a Western, liberal-style, free media is not possible. He argues that Ethiopia is in a transitional time and that the government needs to intervene to keep the country stable.

Some Ethiopian journalists have noticed a trend that has occurred after every regime change since the fall of Haile Selassie in 1974. Initially, new media flourish with the lifting of restrictions, but within a few years, the new government once again begins cracking down and attempting to put the lid back on what it opened.

Abiy Ahmed may be following this trend, or he may be really working on long-term reforms for the media in Ethiopia and just being careful in doing so. Regardless of which of these is true, Ethiopian media law seems to reflect the national situation at different times. For example, in the middle of June 2020, Ethiopia's state-owned telecommunications monopoly, Ethio 
Telecom, suspended the country's Internet service for more than a week. It is suspected that they did this because the government was trying to block the leak of national exam answers (Mbah 2019). Then again, on June 22, there was another Internet shutdown enforced across Ethiopia, after a group of soldiers staged a failed coup in Amhara state.

In other words, Ethiopian media law does not appear to have been mimicking China's media law but instead following its own path. Therefore, Empirical Fingerprint 13 could not be observed.

\section{Conclusion}

This study found that the empirical evidence partly supports the hypothesis and popular belief that increased use of Chinese ICT in Ethiopia leads to strengthened control of the Ethiopian government over its citizens (see figure 13.2). The 'fingerprints' that are coloured green are the fingerprints where I found evidence to suggest that the causal mechanism was present. The 'fingerprints' that are coloured red are the fingerprints for which I found evidence that challenged the idea that this causal mechanism was present. The fingerprints that are coloured grey, are the fingerprints for which I did not find confirming or disconfirming evidence. The fingerprints with the green stripes are the fingerprints for which I found some, but limited, evidence to support the presence of this causal mechanism.

When we look at figure 13.2 we see that there are two most plausible routes:

Route 1:

$\mathrm{X}(3) 5+910 \mathrm{Y}$

Route 2:

$\mathrm{X}(1) 5+610 \mathrm{Y}$

To begin, let us follow the first set of causal links that can occur in this causal mechanism (Route 1), shown by the first green path in figure 13.2. One example of the increased use of Chinese ICT technology in Ethiopia $(X)$ that has been partially observed in this study is that the Ethiopian government requested surveillance tools (3) and has received Chinese technologies that could be used as surveillance tools (5). The findings show that the Ethiopian government initiated most of the cooperation with Chinese agencies in the realm of digital technology. The combination of the fact that the Ethiopian 
Figure 13.2 The resulting causal mechanism

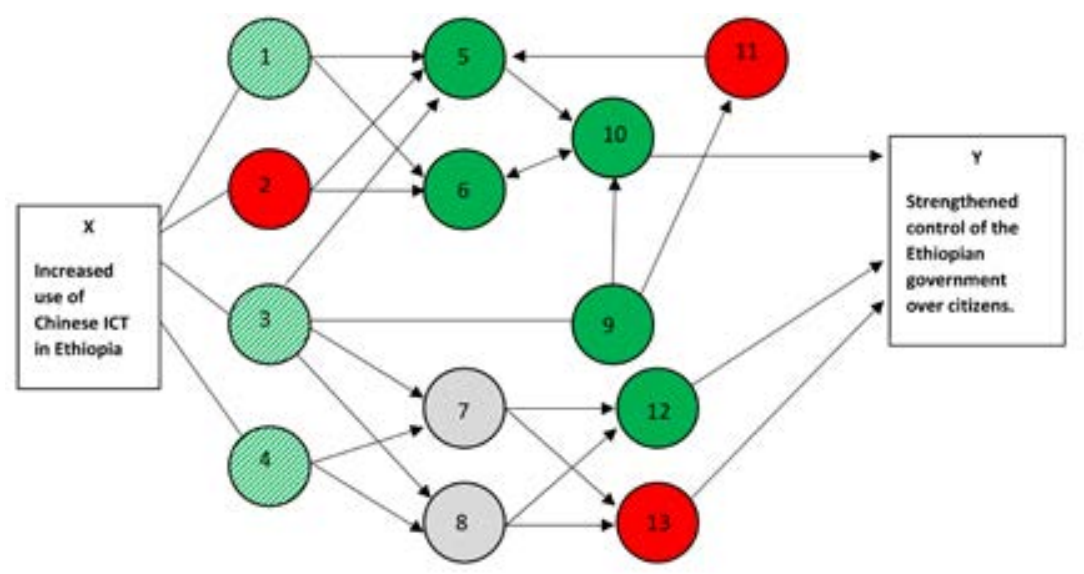

government classifies as an authoritarian regime (9), has access to surveillance tools (5) and can legally search and seize personal data at any time (10) leads to the fact that the Ethiopian government strengthened its control over its citizens $(\mathrm{Y})$.

However, the findings for Empirical Fingerprint 11, or the fact that Western companies did not appear to be refusing to supply the Ethiopian government with software on moral grounds, suggests that this causal process does not only occur for Chinese ICT support to Ethiopia. Despite the fact that many Western countries have criticized the export of Chinese surveillance tools to authoritarian states, Human Rights Watch has demonstrated that European companies also sell surveillance tools to the Ethiopian government. The Chinese company ZTE appears to offer more ways for the Ethiopian government to monitor the users of its network than either Huawei or the European companies Ericsson and Nokia. However, with the software provided by European companies such as FinTech and Hacking Team, the Ethiopian government can collect similar information to that which it collects with the ZTE software ZSmart. This means that the outcome would not be so different if the Ethiopian government did not use Chinese ICT and instead made use of other foreign ICT.

Now let us follow the second set of causal links that can occur in this causal mechanism (Route 2), also shown as a green path in figure 13.2. The fact that Chinese firms have the means and contacts to advise the Ethiopian government on a master plan for ICT (1) is another potential example of the increased use of Chinese ICT technology in Ethiopia (X) that has been partially observed in this study. It has then been found 
that Chinese firms provide the Ethiopian government with hardware and software that can be used as surveillance tools (5) and that they also provide the Ethiopian government with the data that these tools collect (6). Furthermore, this study has found that the Ethiopian government can legally search and seize personal data at any time (10). This means that Chinese ICT strengthens the control of the Ethiopian government over its citizens $(\mathrm{Y})$.

It appears that on the Chinese side it is the commercial interests of Chinese firms, rather than the geopolitical interests of the Chinese government, that is driving involvement in Ethiopia and the supply of technology to the Ethiopian government. On the Ethiopian side, the government's desire to enhance its control appears to be the reason why it has chosen to work with ZTE instead of with European companies such as Ericsson or Nokia, and also the reason why it has chosen to develop satellites together with China. The Ethiopian government has only been able to maintain its monopoly over the telecoms industry, held by the state-owned telecom provider Ethio Telecom because it has been able to borrow money from the Chinese government to build an advanced telecom network. The Ethiopian government also may have decided to develop its own satellites in cooperation with the Chinese government to break from its dependence on foreign satellites for which the costs were considered too high.

To answer the main research question: This study has found that in the context of the Digital Silk Road, the use of Chinese ICT does contribute to the control of the Ethiopian government over its citizens. However, it should be noted that the main Chinese actor involved in the digitization of Ethiopia does not seem to be the Chinese Communist Party (CCP) or the central state, but commercial and state-owned enterprises. This does not preclude 'Chinese influence' (i.e. state influence) but points to the complexity of the reality on the ground.

The main Ethiopian actor that is actively bringing in Chinese ICT is the Ethiopian government. However, this study has found that the Ethiopian government also acquires ICT from German, French, Italian, and British companies.

The focus in Western media on China's export of surveillance technology to Ethiopia attributes most of the agency to Chinese firms and the Chinese state. However, this study has found that the Ethiopian government has the agency to independently choose what technology it acquires and from where. By cooperating with China as well as Europe to develop its own space technology, the Ethiopian government safeguards its negotiation position and capacity to act independently. 
At the same time, this study has also found that non-state actors in Ethiopia (like iCog Labs) are putting much effort into developing homegrown and state-of-the-art technologies. With these efforts, they are perhaps helping to make their country more independent from foreign technologies.

From a European perspective, it would have been more desirable if Ethiopia had to open up its telecom market to improve its network and if the Ethiopian government remained dependent on Western-made satellites. However, the Chinese government has increasingly offered an alternative to these options and as a result, the tables have now turned. The Ethiopian government is increasingly leaning on Chinese ICT. This has made it of greater interest for Europe to promote the technological self-sufficiency of Ethiopia as a way of ensuring it does not become too dependent on China. The European funding for a satellite MAIT facility in Ethiopia is a step in that direction.

As Gagliardone (2014) rightly points out at the end of his article on new media and the developmental state of Ethiopia:

The Ethiopian government is unlikely to radically revise its media strategy in response to donor criticism. But it may evolve a more open and responsive system over time if it is encouraged to reform from within, in a way that is consistent with the principles on which the state has been founded.

Throughout history, the Ethiopian leadership has striven to leapfrog by learning from other states while keeping a focus on maintaining stability in the country. This is how the impact of the use of Chinese ICT on the control of the Ethiopian government over its citizens should be interpreted.

\section{References}

AlJazeera (2020, February 13). 'Ethiopia Passes Controversial Law Curbing "Hate Speech"'. AlJazeera. Retrieved 19 March 2020 from https://www.aljazeera.com/news/2020/02/ ethiopia-passes-controversial-law-curbing-hate-speech-200213132808083.html.

Ayele, Behailu (2019, January 21). 'Ethiopia: Ministry Manoeuvres toward Digital Economy'. Tralac. Retrieved 20 March 2020 from https://www.tralac.org/news/ article/13847-ethiopia-ministry-manoeuvres-toward-digital-economy.html.

Beach, Derek \& Pedersen, Rasmus B. (2016). Causal Case Study Methods: Foundations and Guidelines for Comparing, Matching, and Tracing. Ann Arbor: University of Michigan Press. 
Bo, Xiang (2018, May 12). 'China's Top Legislator Visits Ethiopia to Boost Bilateral Ties'. Xinhua. Retrieved 20 March 2020 from http://www.xinhuanet.com/ english/2018-05/12/c_137173731.htm.

Brautigam, Deborah (2009). The Dragon's Gift: The Real Story of China in Africa. Oxford: Oxford University Press.

Brown, William \& Harman, Sophie (2013). African Agency in International Politics. London: Routledge.

Buckley, Peter J., Clegg, Jeremy L., Cross, Adam R., Liu, Xin, Voss, Hinrich \& Zheng, Ping (2007). 'The Determinants of Chinese Outward Foreign Direct Investment'. Journal of International Business Studies, 38, 499-518.

Clemoes, Charlie (2019, March 6). 'Cities on the New Silk Road: Djibouti City'. Topos. Retrieved 20 March 2019 from https://www.toposmagazine.com/ cities-on-the-new-silk-road-djibouti/.

Collier, David (2011). 'Understanding Process Tracing'. Political Science and Politics, 44(4), 823-830.

Coulthard, Sarah (2012). 'Can We Be Both Resilient and Well, and What Choices Do People Have? Incorporating Agency into the Resilience Debate from a Fisheries Perspective'. Ecology and Society, 17(1), 4.

Dutch IT-channel (2014). 'ZTEsoft Introduceert ZSmart Application Programming Interface (API) Beheeroplossing' [ZTEsoft introduces ZSmart Application Programming Interface (API) management solution]. Retrieved 30 April 2020 from https://dutchitchannel.nl/516712/ztesoft-introduceert-zsmart-applicationprogramming-interface-api-beheeroplossing.html.

EDPS (2020). 'Data Protection'. European Data Protection Supervisor. Retrieved 20 March 2020 from https://edps.europa.eu/data-protection/data-protection_en.

Emirbayer, Mustafa \& Mische, Ann (1998). What Is Agency? American Journal of Sociology, 103(4), 962-1023.

ENA (2019, November 25). 'Ethiopia Launches Electronic World Trade Platform'. Ethiopian News Agency. Retrieved 20 March 2020 from https://www.ena.et/ en/?p=10924.

Ethio Telecom (2019). 'Ethio Telecom - ZTE Joint Innovation Center Inaugurated'. Retrieved 7 April 2020 from https:/www.ethiotelecom.et/ethio-zte-jointinnovation-center/.

Federal Negarit Gazeta (2012, August). 'Registration of Vital Events and National Identity Card Proclamation'. Federal Democratic Republic of Ethiopia. Retrieved 20 February 2020 from https://chilot.files.wordpress.com/2013/04/proclamation-no760-2012-registration-of-vital-events-and-national-identity-card-proclamation.pdf.

Fikade, Birhanu (2016, July 2). 'Huawei Takes over Ericsson's Portion of Network Project'. The Reporter. Retrieved 13 March 2020 from https://www.thereporterethiopia.com/ content/huawei-takes-over-ericsson $\% \mathrm{E} 2 \% 80 \% 99$ s-portion-network-project. 
Fourie, Elsje (2015). 'A New Map for Africa? Ethiopian and Kenyan Responses to the "Chinese Model" of Development'. Afrique contemporaine, 1(253), 87-103.

Freedom House (2016). 'Financial Statements'. Retrieved 20 March 2020 from https:// freedomhouse.org/sites/default/files/FINAL_Basic_Financial_Statements_2016. pdf.

Freedom House (2018). 'Freedom on the Net 2018: The Rise of Digital Authoritarianism'. Retrieved 20 February 2020 from https://freedomhouse.org/report/ freedom-net/2018/rise-digital-authoritarianism.

Freedom House (2020a). 'Countries'. Retrieved 20 March 2020 from https:// freedomhouse.org/countries/freedom-net/scores?sort=asc\&order=Total\%20 Score\%2oand\%2oStatus.

Freedom House (2020b). 'Freedom in the World: Ethiopia'. Retrieved 20 March 2020 from https://freedomhouse.org/country/ethiopia/freedom-world/2020.

Gagliardone, Iginio (2014). 'New Media and the Developmental State in Ethiopia'. African Affairs, 451, 279-299.

Gebre, Samuel (2019, November 27). 'Ethiopia's Digitization Drive Attracts Global Tech Giants'. Bloomberg. Retrieved 9 March 2020 from https://www.bloomberg. com/news/articles/2019-11-27/two-tech-giants-named-jack-are-in-ethiopiathis-week.

GIZ (2017). 'Digital Solutions for Sustainable Development (DSSD)'. Deutsche Gesellschaft für Internationale Zusammenarbeit (German Society for International Cooperation). Retrieved 15 April 2019 from https://www.giz.de/en/ worldwide/73176.html.

Goetz, John, Leyendecker, Hans \& Obermaier, Frederik (2013, August 28). 'Britischer Geheimdienst zapft Daten aus Deutschland ab' [British secret service taps data from Germany]. Süddeutsche Zeitung. Retrieved 3 June 2020 from https://www. sueddeutsche.de/politik/internet-ueberwachung-britischer-geheimdienst-zapftdaten-aus-deutschland-ab-1.1757068.

Hofstede-insights (2020). 'Country Comparison'. Retrieved 11 June 2020 from https:// www.hofstede-insights.com/country-comparison/ethiopia,the-netherlands/.

Hirono, Miwa \& Suzuki, Shogo (2014). 'Why Do We Need "Myth-Busting" in the Study of Sino-African Relations?' Journal of Contemporary China, 23(87), 443-461. HRW (2014). “They Know Everything We Do”: Telecom and Internet Surveillance in Ethiopia'. Human Rights Watch. Retrieved 20 March 2020 from https://www. hrw.org/report/2014/03/25/they-know-everything-we-do/telecom-and-internetsurveillance-ethiopia.

Ibeh, Joseph (2019, October 14). 'Ethiopia to Commence Construction of Satellite Manufacturing, AIT Centre'. Space in Africa. Retrieved 13 March 2020 from https://africanews.space/ethiopia-to-commence-construction-ofsatellite-manufacturing-ait-centre/. 
Ibeh, Joseph (2020, March 13). 'Egypt to Launch Two Experimental Satellites Ahead of a Planned NGEO Constellation'. Space in Africa. Retrieved 13 March 2020 from https://africanews.space/egypt-to-launch-two-experimental-satellites-aheadof-a-planned-ngeo-constellation/.

Jeffrey, James (2019, November 16). 'Press Freedom under Siege Again in the New Ethiopia'. Deutsche Welle. Retrieved 20 February 2020 from https://www.dw.com/ en/press-freedom-under-siege-again-in-the-new-ethiopia/a-51276791.

Kolstad, Ivar \& Wiig, Arne (2012). 'What Determines Chinese Outward FDI?' Journal of World Business, 47, 26-34.

Lancaster, Henry \& Lange, Peter (2020). 'Ethiopia - Telecoms, Mobile and Broadband - Statistics and Analyses'. BuddeComm. Retrieved 19 March 2020 from https:// www.budde.com.au/Research/Ethiopia-Telecoms-Mobile-and-BroadbandStatistics-and-Analyses.

Lister, Ruth (2003). Citizenship: Feminist Perspectives. 2nd ed. New York: New York University Press.

Lister, Ruth (2004). Poverty. Cambridge: Polity.

Locke, John (1978). Two Treatises of Government. New York: E.P. Dutton.

Lu, Youqing (2017, May 11). 'Tanzania - the Belt and Road Initiative and ChinaTanzania Relations'. All Africa. Retrieved 13 March 2020 from https://allafrica. com/stories/201705110195.html.

Maasho, Aaron (2013, August 18). 'Ethiopia Signs \$80o Million Mobile Network Deal with China's ZTE'. Reuters. Retrieved 9 March 2020 from https://www.reuters. com/article/us-ethiopia-china-telecom/ethiopia-signs-8oo-million-mobilenetwork-deal-with-chinas-zte-idUSBRE97HoAZ20130818.

Maasho, Aaron (2015, October 28). 'Ethiopia to Open Bids for Telecoms Expansion in Dec or Jan - CEO'. Reuters. Retrieved 19 March 2020 from https://www.reuters. com/article/ethiopia-telecoms/ethiopia-to-open-bids-for-telecoms-expansionin-dec-or-jan-ceo-idUSL8N12S3U620151028.

Mamabolo, Matshelane (2017, November 27). 'Ethiopia Links up with China's Shenzhen Province to Bolster ICT'. ITWeb Africa. Retrieved 20 February 2020 from https://itweb.africa/content/o1Jr5MxgrabqKdWL.

Mbah, Fidelis (2019, June 25). 'Outrage over Ethiopia's Continuing Internet Blackout'. AlJazeera. Retrieved 9 March 2020 from https://www.aljazeera.com/news/2019/o6/ outrage-ethiopia-continuing-internet-blackout-190625105401629.html.

Ministry of Foreign Affairs of the PRC (2017). International Strategy of Cooperation on Cyberspace. Retrieved 11 November 2020 from https://www.fmprc.gov.cn/mfa_eng/ wjb_663304/zzjg_663340/jks_665232/kjlc_665236/qtwt_665250/t144239o.shtml.

Mella TV (2019, May 25). 'Mella Monthly Episode 19: Betelhem Dessie, CEO of iCog - Anyone Can Code'. Retrieved 20 February 2020 from https://www.youtube. com/watch?v=hdg7EICnyoc. 
Mohan, Giles \& Lampert, Ben (2012). 'Negotiating China: Reinserting African Agency into China-Africa Relations'. African Affairs, 112(446), 92-110.

National Planning Commission (2016, May). 'Growth and Transformation Plan II (GTP II) (2015/16-2019/20): Vol. I: Main Text'. Federal Democratic Republic of Ethiopia. Retrieved 9 March 2020 from https://www.greengrowthknowledge.org/sites/default/files/downloads/policy-database/ETHIOPIA\%29\%20 Growth\%2oand\%2oTransformation\%2oPlan\%2oII\%2C\%2oVol\%2oI.\%20\%20 $\% 282015 \% 2 \mathrm{C} 16-2019 \% 2 \mathrm{C} 20 \% 29 . p d f$.

NDRC (2015, March). 'Vision and Actions on Jointly Building Silk Road Economic Belt and 21st-Century Maritime Silk Road'. National Development and Reform Commission, Ministry of Foreign Affairs and Ministry of Commerce, People's Republic of China. Retrieved 25 October 2020 from https://web.archive.org/web/20181127225143/ http://en.ndrc.gov.cn/newsrelease/201503/t20150330_669367.html.

Nobel Prize (2019). 'Abiy Ahmed Ali'. Retrieved 3 April 2019 from https://www. nobelprize.org/prizes/peace/2019/abiy/facts/.

NTV Kenya (2018). 'Ethiopia Prime Minister Hailemariam Desalegn Resigns: Says Move Is to Aid Reforms in the Country'. Retrieved 12 January 2020 from https:// www.youtube.com/watch?v=fCOuatOOjı.

Patrick, Stewart P. (2018, July 2). Belt and Router: China Aims for Tighter Internet Controls with Digital Silk Road. The Internationalist. Retrieved 9 March 2020 from https://www.cfr.org/blog/belt-and-router-china-aims-tighter-internetcontrols-digital-silk-road.

Ramasamy, Bala, Yeung, Matthew \& Laforet, Sylvie (2012). 'China's Outward Foreign Direct Investment: Location Choice and Firm Ownership'. Journal of World Business, 47(1), 17-25.

Reed, John (2013, August 4). 'Is Tech Firm a Front for China to Spy?' IOL. Retrieved 11 April 2019 from http://www.iol.co.za/scitech/technology/security/is-techfirm-a-front-for-china-to-spy1.1556887\#.UvQBwmJ5Pcw.

Reuters (2014, December 11). 'Ethiopia Says Ericsson to Take Part of Telecom Deal after ZTE Row'. Reuters. Retrieved 19 May 2020 from https://www.reuters.com/ article/ethiopia-telecomunications/ethiopia-says-ericsson-to-take-part-oftelecom-deal-after-zte-row-idUSL6NoTV2KO20141211.

Reuters (2019, December 20). 'Ethiopia Launches First Satellite into Space'. Reuters. Retrieved 9 March 2020 from https://www.reuters.com/article/us-ethiopia-satellite/ ethiopia-launches-first-satellite-into-space-idUSKBNiYOoIU.

Shen, Hong (2018). 'Building a Digital Silk Road? Situating the Internet in China's Belt and Road Initiative'. International Journal of Communication, 12, 2683-2701. SOA (n.d.). 'Africa Branch of Shenzhen Outbound Alliance'. Shenzhen Outbound Alliance. Retrieved 20 March 2020 from http://www.szsoa.org/html/1/156/168/ index.html. 
Space in Africa (2019a, May 28). 'Ethiopia Signs Communications Satellite Development Agreement with China'. Space in Africa. Retrieved 9 March 2020 from https://africanews.space/ethiopia-signs-communication-satellitedevelopment-agreement-with-china/.

Space in Africa (2019b, August 23). 'Ethiopian Space Science and Technology Institute Director General Sheds Light on Ethiopia's Direction In Space Strategy'. Space in Africa. Retrieved 20 March 2020 from https://africanews.space/ ethiopian-space-science-and-technology-institute-director-general-sheds-lighton-ethiopias-direction-in-space-strategy/.

Spacewatch Africa (2019, October). 'Ethiopia to Begin Work on Satellite MAIT Facility with European Funding'. Spacewatch Africa. Retrieved 20 March 2020 from https://spacewatch.global/2019/10/ethiopia-to-begin-work-on-satellitemait-facility-with-european-funding/.

Taye, Berhan \& Teshome, Roman (2018, September). 'Privacy and Personal Data Protection in Ethiopia'. Collaboration on International ICT Policy in East and Southern Africa (CIPESA). Retrieved 20 March 2020 from https://cipesa. org/?wpfb_dl=301.

Taylor, Ian \& Xiao, Yuhua (2009). 'A Case of Mistaken Identity: "China Inc." and Its "Imperialism" in Sub-Saharan Africa'. Asian Politics \& Policy, 1(4), 709-725.

Walton, Greg (2001). China's Golden Shield: Corporations and the Development of Surveillance Technology in the People's Republic of China. Montreal: International Centre for Human Rights and Democratic Development.

Woodhams, Samuel (2020, March 20). 'Huawei Says Its Surveillance Tech Will Keep African Cities Safe but Activists Worry It'll Be Misused'. Quartz Africa. Retrieved 20 March 2020 from https://qz.com/africa/1822312/huaweis-surveillance-techin-africa-worries-activists/.

Wuilbercq, Emeline (2015 November 19). 'Des geeks éthiopiens veulent fabriquer les robots de demain' [Ethiopian geeks want to build the robots of tomorrow]. Le Monde. Retrieved 19 May 2020 from https://www.lemonde.fr/afrique/ $\operatorname{article} / 2015 / 11 / 19 /$ des-geeks-ethiopiens-veulent-fabriquer-les-robots-dedemain_4813340_3212.html.

ZTE (n.d.). 'ZTE Build a High-Tech National Public Safety System for Ethiopia'. Retrieved 20 February 2020 from https://usa.ingrammicro.com/media/Documents/vendors/z/zte/docs/zte_build_a_high_tech_national_public_safety.pdf. 


\section{About the Author}

Dr. SANne VAN DER Lugt is an Associate Fellow with LeidenAsiaCentre and Clingendael Institute. Her research is aimed at the consequences of China's re-emergence as a global power for Europe, with a special focus on China's economic activities in Africa and China's position in the fourth industrial revolution. Prior to joining the LeidenAsiaCentre she worked for (among others) the Centre for Chinese Studies at Stellenbosch University and Profundo, a Dutch not-for-profit research centre on sustainability. She conducted fieldwork in various African countries for projects commissioned by Oxfam, the WWF, and the European Commission regarding the social and environmental impacts of Chinese investments. 


\section{Contributors}

Dr. INGRID D'HoogHE is sinologist and a researcher at the LeidenAsiaCentre, China lecturer at Leiden University, and senior associate fellow at the Clingendael Institute of International Relations. For the LeidenAsiaCentre she has studied cooperation in the field of research and higher education between China and the EU/Netherlands (LeidenAsiaCentre 2018, update September 2019, follow-up study to be published October 2020). Her fields of interest include China's foreign policy and diplomacy, China and global governance, and China's Belt and Road Initiative. Major publications include the monograph China's Public Diplomacy (Brill/Nijhoff, 2015) and the coauthored report 'Assessing China - EU Collaboration in HE and Research'.

MATT FERCHEN's research focuses on the connections between China's foreign and domestic political economy. He has written extensively about China's economic statecraft, China's developing country diplomacy, and debates about the 'China model' of development. He is particularly interested in lessons researchers and policymakers can learn from comparisons of China's economic and political relations with different regions, from Southeast Asia to Latin America, Europe, and the United States. From 2008 to 2017 Ferchen was a faculty member in the Department of International Relations at Tsinghua University and from 2011 to 2019 he was a scholar with the Carnegie-Tsinghua Center for Global Policy. In 2020 he was appointed Head of Global China Research with the Mercator Institute for China Studies (MERICS). He has been engaged with LeidenAsiaCentre research since 2017. Ferchen holds an MA from Johns Hopkins School of Advanced International Studies and a PhD from Cornell.

Mohammadbagher (MAMAD) Forough is University Lecturer in the International Relations of Modern Iran at Leiden University and a LeidenAsiaCentre fellow. His research is, broadly speaking, focused on geoeconomic and geopolitical shifts at the global level (i.e. the retreat of the West and the rise of the rest, especially China and India, at the global level and Iran at the regional level). Theoretically focused on critical geography, he investigates how the elements of 'geo' (namely, geographical factors, connectivity, infrastructure projects, and geographic discourse) and 'politics' and 'economics' mutually affect and are affected by each other when it comes to theories of geopolitics and geoeconomics. Together with Frans-Paul van der Putten, he initiated the Clingendael Institute's Silk Road Headlines, a weekly news service providing updates on news articles related to China's Silk Road initiative. 
RICHARD GHIASY is a Senior Fellow at LeidenAsiaCentre and a Subject Matter Expert at The Hague Centre for Strategic Studies (HCSS). His main interests lie in Asian geopolitics and geoeconomics, EU-Asia relations, China's foreign and security policy, and conflict prevention. As a former Associate Researcher at Stockholm International Peace Research Institute (SIPRI), he has provided policy advice to inter alia the EEAS, European Commission, government ministries, the Organization for Security and Co-operation in Europe (OSCE), and the Organisation for Economic Cooperation and Development (OECD). Richard is a member of the Belt and Road Research Platform and the Stockholm Observatory for Global China at the Swedish Institute of International Affairs (UI).

Ruben GONZALEZ-ViCENTE is a Lecturer at Leiden University. His research interests include 'South-South' development cooperation, China's international relations (with a specific interest on China's engagement in Latin America and the Caribbean), the role of natural resources in processes of development, and the transformation of politics and international relations under late capitalism. His work has been published in journals such as Review of International Political Economy, Political Geography, Globalizations, the China Quarterly, and Latin American Politics and Society. He received his $\mathrm{PhD}$ from Cambridge in 2012 and worked as an Assistant Professor in the City University of Hong Kong between 2012 and 2016 before moving to Leiden.

Cheng-Chwee Kuik is Associate Professor and Head of the Centre for Asian Studies at the National University of Malaysia (UKM)'s Institute of Malaysian and International Studies (IKMAS). He is co-founder of the East Asian International Relations (EAIR) Caucus, a research platform for exchange, engagement, and empowerment among foreign affairs professionals in Malaysia. He served as Head of the Writing Team for the government of Malaysia's inaugural Defence White Paper (2020). Previously, he was a postdoctoral research associate at the Princeton-Harvard China and the World Program (CWP) and a Visiting Research Fellow at Oxford's Department of Politics and International Relations.

Dr. StACEY Links is a South African national based in the Netherlands as a Research Fellow at the LeidenAsiaCentre. Having obtained her PhD from Utrecht University's Department of Law, Governance and Economics, she now holds the position of Lecturer at Leiden University's Institute of Area Studies (LIAS), where her teaching focuses on China-Africa relations, postcolonial and critical international relations theory, as well as regional 
integration in Sub-Saharan Africa. Her research interests are human rights in China-Africa relations and specifically the right to development. Her research is set against the backdrop of critical IR theory as well as critical approaches to development.

Irma Mosquera Valderrama is Associate Professor of Tax Law at Leiden University, the Netherlands. She obtained her $\mathrm{PhD}$ (cum laude) in 2007 at the University of Groningen, the Netherlands. Her areas of expertise are international tax law and comparative tax law in developed and developing countries and, more recently, exchange of information, including taxpayers' rights and safeguards in exchange of information and BEPS-related issues in developing countries. She has published several articles in peer-reviewed journals and non-peer-reviewed journals. She has been awarded an ERC Starting Grant by the European Research Council to carry out research from 2018 to 2022 on a New Model of Global Governance in International Tax Law Making (GLOBTAXGOV).

Mirela Petkova has been a Junior Researcher at the Clingendael Institute's EU \& Global Affairs Unit. Her research focuses on China's foreign policy, in particular China's global trade, investment, and infrastructure practices, the BRI, and EU-China relations. Prior to working at Clingendael, she has worked at the European Institute for Asian Studies (Belgium) and in the administration of the President of the Republic of Bulgaria.

Michael Sampson is Assistant Professor of International Relations at Leiden University's Institute of Political Science. His research focuses on international political economy and the strategic and distributional consequences of trade institutions.

FlORIAN SCHNEIDER, PhD, Sheffield University, is Senior University Lecturer in the Politics of Modern China at the Leiden University Institute for Area Studies. He is managing editor of Asiascape: Digital Asia, director of the Leiden Asia Centre, and the author of three books: Staging China: the Politics of Mass Spectacle (Leiden University Press, 2019), China's Digital Nationalism (Oxford University Press, 2018), and Visual Political Communication in Popular Chinese Television Series (Brill, 2013, recipient of the 2014 East AsiaNet book prize). In 2017, he was awarded the Leiden University teaching prize for his innovative work as an educator. His research interests include questions of governance, political communication, and digital media in China, as well as international relations in the East Asian region. 
Dr. SANnE VAN DER LugT is an Associate Fellow with LeidenAsiaCentre and Clingendael Institute. Her research is aimed at the consequences of China's re-emergence as a global power for Europe, with a special focus on China's economic activities in Africa and China's position in the fourth industrial revolution. Prior to joining the LeidenAsiaCentre she worked for (among others) the Centre for Chinese Studies at Stellenbosch University and Profundo, a Dutch not-for-profit research centre on sustainability. She conducted fieldwork in various African countries for projects commissioned by Oxfam, the WWF, and the European Commission regarding the social and environmental impacts of Chinese investments.

Frans-PAul VAn Der PutTen has a PhD in History from Leiden University and is a Senior Research Fellow at the Clingendael Institute. He is also the coordinator of the institute's China Centre. His research is focused on the geopolitical implications of China's increasing role in international affairs. Previously, he worked as a researcher at Nyenrode Business University. He is a former editor-in-chief of Itinerario:Journal of Imperial and Global Interactions. Together with Mamad Forough, he initiated the Clingendael Institute's Silk Road Headlines, a weekly news service providing updates on news articles related to China's Silk Road initiative.

JUE WANG is a Lecturer at the Leiden University Institute for Area Studies. She is a scholar of international political economy, with a focus on China, its external economic relationships, and its role in regional and global economic governance. She also has a wide range of research interests in international economic organizations, international cooperation, and the development of emerging economies. Her academic work has been published in, amongst others, International Affairs and the Chinese Political Science Review. She is also an Associate Fellow in the Asia-Pacific Programme at Chatham House. She regularly comments on Chinese and international affairs for media outlets, including the BBC, CGTN, Al Jazeera, the New York Times, and The Times. 